Carine de Godoi Rezende Costa

\title{
Dinâmica e interação oceano-atmosfera de ondas de instabilidade tropical e ondas de Rossby curtas
}

\author{
Dissertação apresentada ao Instituto \\ Oceanográfico da Universidade de São \\ Paulo, como parte dos requisitos para \\ obtenção do título de Mestre em Ciências, \\ Programa de Oceanografia, Área de \\ Oceanografia Física. \\ Orientador: Prof. Dr. Paulo Simionatto \\ Polito
}

São Paulo 
Universidade de São Paulo

Instituto Oceanográfico

Dinâmica e interação oceano-atmosfera de ondas de instabilidade tropical e ondas de Rossby curtas

Carine de Godoi Rezende Costa

Dissertação apresentada ao Instituto Oceanográfico da Universidade de São Paulo, como parte dos requisitos para obtenção do título de Mestre em Ciências, Programa de Oceanografia, Área de Oceanografia Física. Versão corrigida.

Julgada em __ l _ $/$

$\operatorname{Prof}(\mathrm{a}) . \operatorname{Dr}(\mathrm{a})$

Conceito

Prof(a). Dr(a).

Conceito

Prof(a). Dr(a).

Conceito 


\section{Sumário}

Resumo

\begin{tabular}{ll}
\hline Abstract & xvii
\end{tabular}

\begin{tabular}{lll}
\hline & Introdução & 1
\end{tabular}

1.1 Ondas de Instabilidade Tropical e Ondas de Rossby Curtas . . . . . . . . 1

1.2 Interação oceano-atmosfera sobre anomalias transientes de TSM . . . . . 6

1.2.1 O papel da Zona de Convergência Intertropical . . . . . . . . . . 11

1.3 Descrição do problema $\ldots \ldots$. . . . . . . . . . . . . . . . . . 12

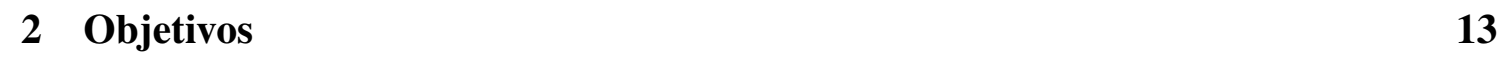

\begin{tabular}{lll}
\hline Área de estudo & 15
\end{tabular}

\begin{tabular}{lll}
\hline & Dados e métodos & 18
\end{tabular}

$4.1 \quad$ Conjuntos de dados $\ldots \ldots \ldots$. . . . . . . . . . . . . . . . . . 18

4.2 Metodologia . . . . . . . . . . . . . . . . . 23

$4.2 .1 \quad$ Filtros FIR 2D $\ldots \ldots \ldots \ldots \ldots \ldots$

4.2 .2 Transformada de Radon . . . . . . . . . . . . . . . . . . . . . 29

4.2 .3 Diagramas de dispersão . . . . . . . . . . . . . . 31

4.2 .4 Regressão e correlação . . . . . . . . . . . . . . . . . 35

\begin{tabular}{|lll}
\hline 5 & Resultados e discussão & 37
\end{tabular}

5.1 Determinação da posição e intensidade da ZCIT . . . . . . . . . . . . . . 37

5.2 Caracterização das OITs e ORCs no tempo e no espaço . . . . . . . . . . 42

5.3 Caracterização das OITs e ORCs com base na teoria . . . . . . . . . . . 52

5.4 Mapas de regressão . . . . . . . . . . . . . . . . . . 62

5.5 Correlações $\ldots \ldots \ldots \ldots$. . . . . . . . . . . . . . . . 69

5.5.1 Interação oceano-atmosfera sobre anomalias transientes de TSM . 69

5.5 .2 Relação entre TSM $\mathrm{e} \eta \ldots \ldots \ldots$. . . . . . . . . . 80

5.6 Salinidade . . . . . . . . . . . . . . . . . . . . . 82 
\begin{tabular}{|lll}
\hline 6 & Conclusões & 92
\end{tabular}

6.1 Sumário . . . . . . . . . . . . . . . . . . . . . . . 92

6.2 Considerações finais e sugestões de trabalhos futuros . . . . . . . . . . 95

\begin{tabular}{lr}
\hline Referências & 100
\end{tabular} 


\section{Lista de Figuras}

$1 \quad$ Ondas de Instabilidade Tropical são observadas entre $5^{\circ} \mathrm{N}$ e $5^{\circ} \mathrm{S}$ nos dados de TSM $\left(\mathrm{em}^{\circ} \mathrm{C}\right)$ obtidos pelo TRMM Microwave Imager (TMI) em 10 de julho de

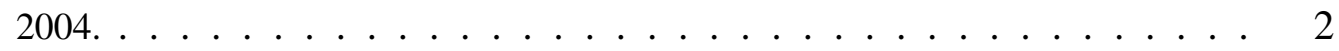

2 Representação esquemática das hipóteses de alteração do vento sobre anomalias de TSM positivas (círculos vermelhos) e negativas (círculos azuis) propostas por

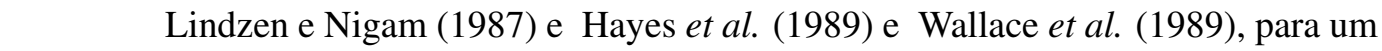
vento de leste. O vento está representado pelas flexas pretas. "DIV" e "CONV" indicam, respectivamente, as regiões de divergência e convergência do vento em

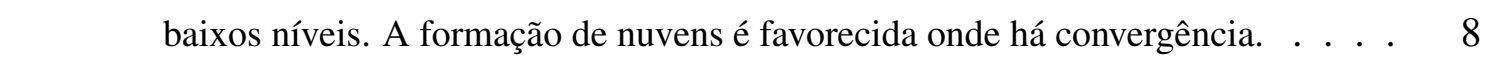

3 Distribuição horizontal das principais correntes tropicais para a Água Tropical \begin{tabular}{|c|c|}
\hline de Superfície, de 0 a $100 \mathrm{~m}$ de profundidade durante a primavera do hemisfério \\
\hline
\end{tabular} \begin{tabular}{|c|c|c|}
\hline Norte. Adaptado de & Stramma e Schott (1999). As siglas representam a Corrente \\
\hline
\end{tabular} Norte Equatorial (CNE), Contra Corrente Norte Equatorial (CCNE), Corrente \begin{tabular}{|c|c|c|}
\hline da Guiné (CG), ramos norte, equatorial, central e sul da Corrente Sul Equatorial \\
\hline
\end{tabular} (CSEn, CSEe, CSEc e CSEs, respectivamente), Subcorrente Equatorial (SE), Corrente Norte do Brasil (CNB), Subcorrente Sul Equatorial (SSE), Contra Corrente Sul Equatorial (CCSE), Corrente da Angola (CA), Corrente do Brasil (CB), Domo da Guiné (DG), Domo da Angola (DA) e regiões de ressurgência (r). . . . 16

4 Similar à Figura 3 durante o outono do hemisfério Norte. . . . . . . . . . . . . 16

5 Divergente da tensão de cisalhamento do vento, em $\mathrm{kg} \mathrm{m}^{-2} \mathrm{~s}^{-2}$, proveniente dos dados originais do NCDC (esquerda) e da componente de larga escala dos dados do NCDC (direita) no dia 14 de fevereiro de 2004. . . . . . . . . . . . . . . . 24

6 Anomalia da temperatura da superfície do mar (TSM') original (esquerda) e filtrada (direita) em 10 de julho de 2004. O sinal filtrado explica 73\% da variância do original. . . . . . . . . . . . . . . . . 26

7 Resultado da aplicação dos filtros FIR 2D em dados sintéticos. As curvas revelam a semelhança dos filtrados com 17 e 21 dias entre si e destes com o interpolado para 7 dias e filtrado com 21 dias. A unidade de amplitude é arbitrária. . . 27 
8 Resultado da aplicação dos filtros FIR 2D em dados sintéticos. As curvas reve-

lam a semelhança entre os sinais original, filtrado com 17 dias, filtrado com 21

dias e interpolado para 7 dias e filtrado com 21 dias. As unidade de tempo e amplitude são arbitrárias. . . . . . . . . . . . . . . . . . 2 28

9 Seção longitudinal em $2,5^{\circ} \mathrm{N}$ de densidade potencial referida na superfície do WOA09. . . . . . . . . . . . . . . . . 32

10 Relação de dispersão das ondas equatoriais para $n=-1$ (linha azul), $n=0$ (linha preta), $n=1$ (linha vermelha), $n=2$ (linha laranja) e $n=3$ (linha amarela). A unidade da frequência $\omega^{*}$ é $\sqrt{\beta c}$ e a unidade do número de onda zonal $k^{*}$ é o inverso do raio de deformação de Rossby $(\sqrt{c / \beta})$. [De Philander (1990)[Cane e Sarachik (1976)] . . . . . . . . . . . . . . . . . . 32

11 Perfil meridional da corrente zonal considerado no cálculo da frequência das ondas de Rossby modificada pelo efeito Doppler. . . . . . . . . . . . . . . . . 34

12 Média da componente zonal da velocidade geostrófica do SVP, em $\mathrm{m} / \mathrm{s}$. . . . . . 34

13 Vapor d'água integrado na atmosfera ( $V$, à esquerda), em mm, e divergente da tensão de cisalhamento do vento $\left(\vec{\nabla} \cdot \vec{\tau}\right.$, à direita), em $\mathrm{kg} \mathrm{m}^{-2} \mathrm{~s}^{-2}$, em $10 \mathrm{de}$ janeiro, 14 de fevereiro, 13 de março, 17 de abril, 22 de maio e 26 de junho de 2004. As linhas horizontais tracejadas e as linhas verticais pretas representam as médias e os desvios padrão mensais dos limites da ZCIT, respectivamente, definidos pelos máximos de $V$. . . . . . . . . . . . . . . . . . . . . . . 39

14 Similar à Figura 13 em 10 de julho, 7 de agosto, 11 de setembro, 9 de outubro, 13 de novembro e 18 de dezembro de 2004 . . . . . . . . . . . . . . . 40

15 Temperatura da superfície do mar $(\mathrm{a}, \mathrm{b}, \mathrm{c}, \mathrm{d}, \mathrm{e}, \mathrm{f}), \mathrm{em}{ }^{\circ} \mathrm{C}, \mathrm{e}$ anomalia da altura da superfície do mar (g, h, i, j , k, l), em mm, em 22 de maio, 26 de junho, 10 de julho, 7 de agosto, 11 de setembro e 9 de outubro de 2004, respectivamente. . . 43

16 Diagramas Hövmöller das ORCs (superior) e OITs (inferior) nos dados de TSM de 2003 a 2005. As linhas tracejadas cinzas representam o mês de maio e as pretas o mês de outubro. . . . . . . . . . . . . . . . . . . . . . . 46

17 Semelhante à Figura 16 nos dados de $V . \ldots \ldots$. . . . . . . . . . 47 
18 Semelhante à Figura 16 nos dados de $P . \ldots \ldots \ldots$. . . . . . . . . . 48

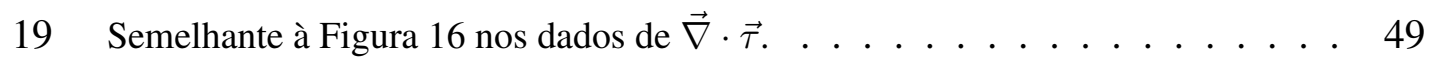

20 Semelhante à Figura $\mid 16$ nos dados de $\eta$. . . . . . . . . . . . . 50

21 OITs nos dados de TSM (esquerda) e $\eta$ (direita) em maio, junho, julho, agosto, setembro e outubro de 2004. . . . . . . . . . . . . . . . . . . . 51

22 Relação de dispersão das OITs (linha preta) e ORCs do primeiro, segundo e terceiro modos meridionais (linhas cinzas progressivamente menos espessas) nas latitudes $10^{\circ} \mathrm{S}, 8^{\circ} \mathrm{S}, 6^{\circ} \mathrm{S}, 5^{\circ} \mathrm{S}, 4^{\circ} \mathrm{S}, 3^{\circ} \mathrm{S}, 2^{\circ} \mathrm{S}$ e $1^{\circ} \mathrm{S}$. As soluções com efeito Doppler para os três modos estão representadas pelas linhas cinzas tracejadas em suas respectivas espessuras. O círculo vermelho (azul) representa as OITs (ORCs) na TSM e o quadrado vermelho (azul) representa as OITs (ORCs) de $\eta$. A cruz representa o erro associado a cada medida de $k$ e $\omega$ com intervalo de confiança de $95 \%$. . . . . . . . . . . . . . . 55

23 Similar à Figura $22 \mid$ em $0^{\circ} \mathrm{N}, 1^{\circ} \mathrm{N}, 2^{\circ} \mathrm{N}, 3^{\circ} \mathrm{N}, 4^{\circ} \mathrm{N}, 5^{\circ} \mathrm{N}, 6^{\circ} \mathrm{N}$ e $8^{\circ} \mathrm{N}$. O círculo \begin{tabular}{|c|}
\hline vermelho (azul) representa as OITs (ORCs) na TSM e o quadrado vermelho \\
\hline
\end{tabular} (azul) as OITs $(\mathrm{ORCs}) \mathrm{em} \eta$. . . . . . . . . . . . . . . . 56

24 Similar à Figura $22 \mid \mathrm{em} 10^{\circ} \mathrm{N}, 12^{\circ} \mathrm{N}, 16^{\circ} \mathrm{N}$ e $19^{\circ} \mathrm{N}$. O círculo vermelho (azul) representa as OITs (ORCs) na TSM e o quadrado vermelho (azul) as OITs (ORCs) em $\eta \ldots \ldots \ldots \ldots \ldots \ldots \ldots$

25 Variância de TSM $\left({ }^{\circ} \mathrm{C}^{2}\right), V\left(\mathrm{~mm}^{2}\right), P\left(\mathrm{~mm}^{2} \mathrm{~h}^{-2}\right), \vec{\nabla} \cdot \vec{\tau}\left(\mathrm{DIV} \mathrm{em} \mathrm{kg}^{2} \mathrm{~m}^{-4} \mathrm{~s}^{-4}\right)$ e $\eta\left(\mathrm{ASM} \mathrm{em} \mathrm{mm}^{2}\right.$ ) para ORCs (esquerda) e OITs (direita). O símbolo + indica o ponto de referência (de máxima variância) de TSM, centrado em $0,875^{\circ} \mathrm{N}$ $10,125^{\circ} \mathrm{W}$ nas ORCs e $0,875^{\circ} \mathrm{N} 15,875^{\circ} \mathrm{W}$ nas OITs. Os valores extremos de $\eta$ no Golfo do México foram desconsiderados para efeito de ilsutração. . . . . . . . 64

26 Mapas de regressão de $\operatorname{TSM}\left({ }^{\circ} \mathrm{C}^{\circ} \mathrm{C}^{-1}\right), V\left(\mathrm{~mm}^{\circ} \mathrm{C}^{-1}\right), P\left(\mathrm{~mm} \mathrm{~h}^{-1}{ }^{\circ} \mathrm{C}^{-1}\right), \vec{\nabla} \cdot \vec{\tau}$ (DIV em $\left.\mathrm{kg} \mathrm{m}^{-2} \mathrm{~s}^{-2}{ }^{\circ} \mathrm{C}^{-1}\right)$ e $\eta\left(\right.$ ASM em $\mathrm{mm}^{\circ} \mathrm{C}^{-1}$ ) para ORCs (esquerda) e OITs (direita). O símbolo + indica o ponto de referência (de máxima variância) de TSM, centrado em $0,875^{\circ} \mathrm{N} 10,125^{\circ} \mathrm{W}$ nas ORCs e $0,875^{\circ} \mathrm{N} 15,875^{\circ} \mathrm{W}$ nas

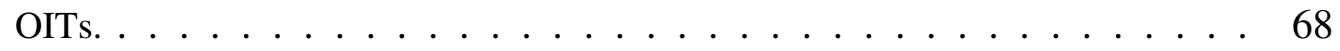


27 Superior: Correlação, com intervalo de confiança superior a 95\%, entre as séries temporais de $\vec{\nabla} \cdot \vec{\tau}$ e a série de TSM no ponto de referência indicado pelo símbolo + na banda das OITs. Inferior: Mapas de regressão de $\vec{\nabla} \cdot \vec{\tau}$ em relação à TSM no ponto $+\left(\mathrm{kg} \mathrm{m}^{-2} \mathrm{~s}^{-2}{ }^{\circ} \mathrm{C}^{-1}\right.$, escala de cores), onde a correlação é estatisticamente significativa, e de TSM em relação à TSM no ponto $+\left({ }^{\circ} \mathrm{C}^{\circ} \mathrm{C}^{-1}\right.$, contornos) na banda das OITs. Os contornos pretos contínuos (tracejados) representam regressão de TSM positiva (negativa) e estão plotados a cada 0,08 ${ }^{\circ} \mathrm{C}^{\circ} \mathrm{C}^{-1}$ entre -1 e $1{ }^{\circ} \mathrm{C}^{\circ} \mathrm{C}^{-1}$. A linha roxa é a seção latitudinal onde calculamos a correlação na Figura $28 \mid \ldots \ldots 71$

28 Esquerda: Regressões de $T_{s}\left({ }^{\circ} \mathrm{C}^{\circ} \mathrm{C}^{-1}\right)$ (linha azul) e $\vec{\nabla} \cdot \vec{\tau}\left(\mathrm{kg} \mathrm{m}^{-2} \mathrm{~s}^{-2}{ }^{\circ} \mathrm{C}^{-1}\right)$ (linha vermelha) para OITs na seção latitudinal a $0,875^{\circ} \mathrm{N}$ entre $23,625^{\circ} \mathrm{W}$ e $6,125^{\circ} \mathrm{W}$ representada pela linha roxa na Figura|27| Direita: Correlação com defasagem zonal entre as regressões de $T_{s}$ e $\vec{\nabla} \cdot \vec{\tau}$ na seção latitudinal. Diferença de fase positiva indica que $T_{s}$ lidera $\vec{\nabla} \cdot \vec{\tau}$. A máxima correlação está indicada pelo círculo vermelho. Correlações fora da região limitada pelas linhas tracejadas estão dentro do intervalo de $95 \%$ de confiança. . . . . . . . . . . . . . . . . 71

29 Similar à Figura 27 |para os mapas de correlação (superior) e de regressão de $V$ $\left(\mathrm{mm}^{\circ} \mathrm{C}^{-1}\right.$, inferior) em relação à TSM no ponto de referência para OITs. . . . . . 74

$30 \quad$ Similar à Figura $27 \mid$ para os mapas de correlação (superior) e de regressão de $P$

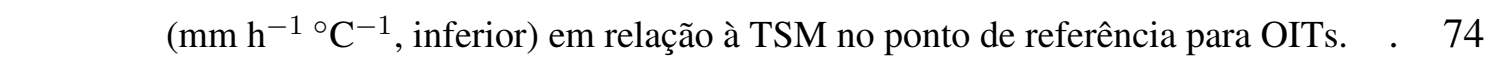

31 Mapas de regressão de $V\left(\mathrm{~mm}^{\circ} \mathrm{C}^{-1}\right.$, escala de cores) e de $P\left(\mathrm{~mm} \mathrm{~h}^{-1}{ }^{\circ} \mathrm{C}^{-1}\right.$, contornos) em relação à TSM no ponto de referência indicado pelo símbolo + na banda das OITs. Apenas as regiões onde a correlação entre as variáveis e a TSM é estatiscamente significativa estão representadas. Os contornos pretos contínuos (tracejados) representam regressões de $P$ positivas (negativas) e estão plotados a cada $0,01 \mathrm{~mm} \mathrm{~h}^{-1}{ }^{\circ} \mathrm{C}^{-1}$ entre $-0,1$ e $0,1 \mathrm{~mm} \mathrm{~h}^{-1}{ }^{\circ} \mathrm{C}^{-1}$. . . . . . . . 75 
32 Superior: Correlação, com intervalo de confiança superior a 95\%, entre as séries temporais de $\vec{\nabla} \cdot \vec{\tau}$ e a série de TSM no ponto de referência indicado pelo símbolo + na banda das ORCs. Inferior: Mapas de regressão de $\vec{\nabla} \cdot \vec{\tau}$ em relação à TSM no ponto $+\left(\mathrm{kg} \mathrm{m}^{-2} \mathrm{~s}^{-2}{ }^{\circ} \mathrm{C}^{-1}\right.$, escala de cores), onde a correlação é estatisticamente significativa, e de TSM em relação à TSM no ponto $+\left({ }^{\circ} \mathrm{C}^{\circ} \mathrm{C}^{-1}\right.$, contornos) na banda das ORCs. Os contornos pretos contínuos (tracejados) representam regressão de TSM positiva (negativa) e estão plotados a cada 0,08 ${ }^{\circ} \mathrm{C}^{\circ} \mathrm{C}^{-1}$ entre -1 e $1{ }^{\circ} \mathrm{C}^{\circ} \mathrm{C}^{-1}$. A linha roxa é a seção latitudinal onde calculamos a correlação na Figura $33 \mid \ldots \ldots$. . . . . . . . . . . . . . . . 78

33 Esquerda: Regressões de $T_{s}\left({ }^{\circ} \mathrm{C}^{\circ} \mathrm{C}^{-1}\right)$ (linha azul) e $\vec{\nabla} \cdot \vec{\tau}\left(\mathrm{kg} \mathrm{m}^{-2} \mathrm{~s}^{-2}{ }^{\circ} \mathrm{C}^{-1}\right)$ (linha vermelha) para ORCs na seção latitudinal a $3,125^{\circ} \mathrm{N}$ entre $20,625^{\circ} \mathrm{W}$ e $8,875^{\circ} \mathrm{W}$ representada pela linha roxa na Figura 32 | Direita: Correlação com defasagem zonal entre as regressões de $T_{s}$ e $\vec{\nabla} \cdot \vec{\tau}$ na seção latitudinal. Diferença de fase positiva indica que $T_{s}$ lidera $\vec{\nabla} \cdot \vec{\tau}$. A máxima correlação está indicada pelo círculo vermelho. Correlações fora da região limitada pelas linhas tracejadas estão dentro do intervalo de $95 \%$ de confiança. . . . . . . . . . . . . . . . . 78

34 Similar à Figura 32 para os mapas de correlação (superior) e de regressão de $V$ $\left(\mathrm{mm}{ }^{\circ} \mathrm{C}^{-1}\right.$, inferior) em relação à TSM no ponto de referência para ORCs. . . . 79

35 Similar à Figura $32 \mid$ para os mapas de correlação (superior) e de regressão de $P$

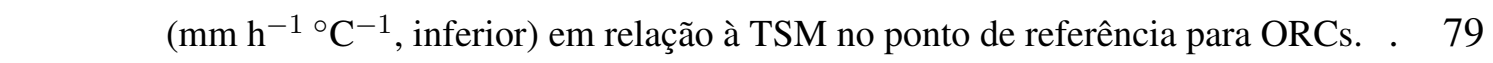

36 Mapas de regressão de $V\left(\mathrm{~mm}^{\circ} \mathrm{C}^{-1}\right.$, escala de cores) e de $P\left(\mathrm{~mm} \mathrm{~h}^{-1}{ }^{\circ} \mathrm{C}^{-1}\right.$, contornos) em relação à TSM no ponto de referência indicado pelo símbolo + na banda das ORCs. Apenas as regiões onde a correlação entre as variáveis e a TSM é estatiscamente significativa estão representadas. Os contornos pretos contínuos (tracejados) representam regressões de $P$ positivas (negativas) e estão plotados a cada $0,01 \mathrm{~mm} \mathrm{~h}^{-1}{ }^{\circ} \mathrm{C}^{-1}$ entre $-0,1 \mathrm{e} 0,1 \mathrm{~mm} \mathrm{~h}^{-1}{ }^{\circ} \mathrm{C}^{-1}$. . . . . . . . 80 
37 Mapas de regressão de $\eta\left(\mathrm{mm}{ }^{\circ} \mathrm{C}^{-1}\right.$, escala de cores) e de $\mathrm{TSM}\left({ }^{\circ} \mathrm{C}^{\circ} \mathrm{C}^{-1}\right.$, contornos) em relação à TSM no ponto de referência localizado a $0,875^{\circ} \mathrm{N} 10,125^{\circ} \mathrm{W}$ na banda das ORCs. Apenas as regiões onde a correlação entre $\eta$ e TSM no ponto de referência é estatiscamente significativa estão representadas. Os contornos pretos contínuos (tracejados) representam regressões de TSM positivas (negativas) e estão plotados a cada $0,08{ }^{\circ} \mathrm{C}^{\circ} \mathrm{C}^{-1}$ entre -1 e $1{ }^{\circ} \mathrm{C}^{\circ} \mathrm{C}^{-1}$. . . . . 81

38 Esquerda: $T_{s}\left({ }^{\circ} \mathrm{C}^{\circ} \mathrm{C}^{-1}\right)$ (linha azul) e $\eta\left(\mathrm{mm}^{\circ} \mathrm{C}^{-1}\right)$ (linha vermelha) na seção latitudinal a $0,875^{\circ} \mathrm{N}$ entre $-23,625^{\circ} \mathrm{W}$ e $6,125^{\circ} \mathrm{W}$ representada pela linha roxa na Figura $37 \mid$ Direita: Correlação com defasagem zonal entre $T_{s}$ e $\eta$ na seção latitudinal. Diferença de fase positiva indica que $T_{s}$ causa $\eta$. A máxima correlação está indicada pelo círculo vermelho. Correlações fora da região limitada pelas linhas tracejadas estão dentro do intervalo de $95 \%$ de confiança. . . . . . . 81

39 ORCs nos dados de $P$ (linha verde, em $\mathrm{mm} \mathrm{h}^{-1}$ ) e $S$ (linha vermelha) para cada boia PIRATA . . . . . . . . . . . . . . . . . . . . . 85

40 Semelhante à Figura 39 para as OITs $\ldots \ldots$. . . . . . . . . . . 86

41 Perfis verticais de salinidade provenientes das boias PIRATA e dos derivadores ARGO coletados no mesmo dia e perfis climatológicos mensais do World Ocean Atlas 2009 (WOA09) na mesma localização. Os erros das medidas de salinidade do ARGO é de 0,02 nos pontos $0^{\circ} 10^{\circ} \mathrm{W}$ e $6^{\circ} \mathrm{S} 10^{\circ} \mathrm{W}, 0,05$ em $10^{\circ} \mathrm{S} 10^{\circ} \mathrm{W}$ e 1,00 em $12^{\circ} \mathrm{N} 23^{\circ} \mathrm{W} . \ldots \ldots \ldots \ldots$. . . . . . . . . . . . . 87

42 Semelhante à Figura $41 \mid$ para os perfis de temperatura $\left({ }^{\circ} \mathrm{C}\right)$. Os erros das medidas de temperatura do ARGO é de $0,02{ }^{\circ} \mathrm{C}$ nos quatro pontos. . . . . . . . . . . 88

43 Média vertical da salinidade de $0 \mathrm{~m}$ a $5 \mathrm{~m}$ proveniente dos derivadores ARGO de março de 2000 a dezembro de 2010 . . . . . . . . . . . . . . . . . 89

44 Posição dos perfis ARGO de março de 2000 a dezembro de $2010 . \quad$. . . . . . . . 89

45 Médias da salinidade (esquerda) e temperatura (direita) superficiais dos derivadores ARGO de 2000 a 2010 (escalas de cores) onde a correlação significativa de TSM com a TSM no ponto de referência para OITs é positiva (linhas contínuas) e negativa (linhas tracejadas) $\ldots \ldots \ldots$. . . . . . . . . . . . . . . . 90 
46 Média e desvio padrão da salinidade e temperatura superficiais obtidas dos derivadores

ARGO na região onde a $T_{s}$ associada às OITs são negativas (azul) e positivas (vermelho). . . . . . . . . . . . . . . . . . 90

47 Média da salinidade superficial dos derivadores ARGO de 2000 a 2010 (escala de cor) onde a correlação significativa de $P$ com a TSM no ponto de referênia é positiva (linhas contínuas) e negativa (linhas tracejadas) para OITs (esquerda) e ORCs (direita) $\ldots \ldots \ldots \ldots$

48 Média e desvio padrão da salinidade superficial obtida dos derivadores ARGO na região onde a correlação de $P$ associada às OITs (esquerda) e ORCs (direita) são negativas (azul) e positivas (vermelho). ～. . . . . . . . . . . . . . . 991

49 OITs nos dados de TSM no meses em que as amplitudes são máximas em cada ano. . . . . . . . . . . . . . . . . . . 113

50 Diagramas Hövmöller das ORCs (superior) e OITs (inferior) nos dados de TSM.

As linhas tracejadas cinzas representam o mês de maio e as pretas o mês de outubro. 114

$51 \quad$ Semelhante à Figura $50 \mid \operatorname{nos}$ dados de $V . \ldots \ldots \ldots$

52 Semelhante à Figura $50 \mid$ nos dados de $P . \ldots \ldots$. . . . . . . 116

53 Semelhante à Figura $50 \mid$ nos dados de $\vec{\nabla} \cdot \vec{\tau} . \quad \ldots \ldots$. . . . . . . 117

54 Semelhante à Figura 50 nos dados de $\eta$. . . . . . . . . . . . . . . . . . 118

55 Mapas de regressão de $V\left(\mathrm{~mm}^{\circ} \mathrm{C}^{-1}\right)$ para ORCs de maio a outubro. O símbolo + indica o ponto de referência (de máxima variância) de TSM, centrado em $0,875^{\circ} \mathrm{N} 10,125^{\circ} \mathrm{W} . \ldots \ldots \ldots$

56 Semelhante à Figura 55 para as OITs. O símbolo + indica o ponto de referência (de máxima variância) de TSM, centrado em $0,875^{\circ} \mathrm{N} 15.875^{\circ} \mathrm{W}$.

57 Mapas de regressão de $V\left(\mathrm{~mm} \mathrm{~h}^{-1}{ }^{\circ} \mathrm{C}^{-1}\right)$ para ORCs de maio a outubro. $\mathrm{O}$ símbolo + indica o ponto de referência (de máxima variância) de TSM, centrado

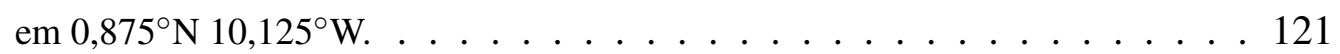

58 Semelhante à Figura $57 \mid$ para as OITs. O símbolo + indica o ponto de referência (de máxima variância) de TSM, centrado em $0,875^{\circ} \mathrm{N} 15.875^{\circ} \mathrm{W}$. . . . . . . . . 121 
59 Mapas de regressão de $\vec{\nabla} \cdot \vec{V}\left(\mathrm{~kg} \mathrm{~m}^{-2} \mathrm{~s}^{-2}{ }^{\circ} \mathrm{C}^{-1}\right)$ para ORCs de maio a outubro. $\mathrm{O}$ símbolo + indica o ponto de referência (de máxima variância) de TSM, centrado em $0,875^{\circ} \mathrm{N} 10,125^{\circ} \mathrm{W} . \ldots \ldots \ldots 12 \ldots \ldots \ldots$

60 Semelhante à Figura $59 \mid$ para as OITs. O símbolo + indica o ponto de referência (de máxima variância) de TSM, centrado em $0,875^{\circ} \mathrm{N} 15.875^{\circ} \mathrm{W}$. . . . . . . . . 122 


\section{Lista de Tabelas}

1 Médias e desvios padrão mensais das latitudes máximas e mínimas da ZCIT de 1998 a 2010 com base nos dados de $V$ e valores médios mensais de $V(\bar{V})$ e $\vec{\nabla} \cdot \vec{\tau}<0(\vec{\nabla} \cdot \vec{\tau}<0)$ na região da ZCIT. . . . . . . . . . . 41

2 Variâncias máximas $\left(\sigma_{\max }^{2}\right)$ e médias $\left(\sigma_{\text {med }}^{2}\right)$ das variáveis em estudo para ORCs e OITs. . . . . . . . . . . . . . . . . . . 63

3 Coeficientes de correlação $(c)$ entre $P$ e $S$ e valores de $p$ para ORCs e OITs nas latitudes das boias PIRATA. As correlações estatisticamente significativas estão representadas em negrito. O percentual de dias com ausência de dados em relação à duração da série temporal de cada boia estão indicados na última coluna. 83 


\section{Agradecimentos}

Ao Lucas, por tudo. Por existir. Pelo amor, companhia, compreensão, carinho e tudo que só você sabe fazer por mim! Por entender minha ausência nos fins de semana e me incentivar. Por me fazer buscar ser uma pessoa melhor. Por me acompanhar mais de perto que ninguém durante este trabalho. E durante todos os 8 anos. Você é o cara!

À minha família! Aos meus pais, Cláudio e Luzia, pelo amor incondicional. Por serem as pessoas em quem me espelho. Por me ensinarem valores. Por serem o que eu quero ser. Por me mostrarem a importância da união e do amor. Às minhas avós, Olga e Waldete e a todos os tios e primas infinitos dessa minha família. À Carol e ao João! Obrigada por espalharem a alegria na minha vida! Serei a eterna First Maid! E como a família sempre aumenta, obrigada também à Eliane, ao Edison, ao Daniel, à Letícia e à Jully. Obrigada pela força e por acreditarem em mim.

Ao Prof. Paulo Polito, pela orientação neste trabalho, nos anteriores e na vida profissional! Obrigada por mais uma oportunidade e por me encaminhar para mais uma conquista. Obrigada por estar sempre disponível para tirar as dúvidas, clarear as ideias, tomar um café e desabafar. Tudo fica mais produtivo e prazeroso quando o orientador reúne competência, vontade e disponibilidade. E você tem todos estes quesitos! Estendo meus agradecimentos também à Profa. Olga Sato, pela oportunidade na monitoria da disciplina de Ondas e Marés. Pude aprender muito mais quando tive que ensinar. Obrigada por ser um exemplo profissional e por todo o suporte e companheirismo nestes quase 6 anos no LOS.

Aos professores do IOUSP, Belmiro Castro, Edmo Campos, Ilson da Silveira, Marcelo Dottori e Paulo Polito. Obrigada pelas aulas excelentes e por nos permitir estar em contato com os maiores pesquisadores em Oceanografia Física do mundo! As listas intermináveis e as provas foram de fundamental importância na consolidação do aprendizado em sala de aula. Estendo minha gratidão a todos os docentes do Instituto, que me acompanham e me ensinam desde 2006, e que também contribuíram para minha formação como oceanógrafa. 
Ao Danilo por todos os motivos do mundo: amizade, chocolate, almoços, viagens e, obviamente, por sempre me ensinar GMT, LaTeX e Matlab. A oceanografia não seria nada sem você! Você vai longe!

Às Dads! Companheiras incríveis e amigas para todos os momentos! O que seriam das teses, dissertações e monografias sem nossas divertidas festas, baladas, viagens e emails sem fim? Amoooo!!!! Obrigada Carlinha, Ju, Mare, Nati, Pati e Thati! Sou eternamente grata por ter amigas como vocês!

À turma de 2011 da pós-graduação, aos já mestres e aos temporariamente mestrandos e doutorandos! Alexandre, Ana Paula, César, Fábio, Felipe, Gabriel, Gilberto, Jéssica, Juliana, Luciana, Mariana, Natália, Paulo e Roberto. Estudar é muito bom! Mas estudar com uma turma unida nos motiva e nos ensina muito mais! Obrigada a todos vocês pela amizade e pela companhia durante as intermináveis listas, listões, provas e barzinhos também, porque ninguém é de ferro.

À todo o pessoal que já passou pelos LOS nos últimos 6 anos: Ana Beatriz, Guilherme, Fábio, Fabrício, Lucas, Márcio Borges, Márcio Yamashita, Nancy, Patrícia, Piero, Roberto, Sebastian, Thalles, Tito e Wandrey. Obrigada pela amizade, companhia, pelos "pitacos", pelos cafés, papos furados e por serem ótimos patinhos de borracha! Me sinto orgulhosa por ter feito parte deste time.

Também não posso deixar de agradecer ao pessoal do LHiCo que acaba de me acolher, professores e alunos, e em especial ao Zero. Desculpa pelo stress agora no final, e muito obrigada pelos conselhos e pela amizade! Obrigada pelos momentos de "maior descontração" nos trabalhos de campo. Estendo meus agradecimentos também a todos os integrantes do LIO. Apesar do trabalho intenso, sair um pouco do ar condicionado dos laboratórios e ir para o mar faz bem a todo oceanógrafo e a toda dissertação!

A todos os funcionários do IO, em especial ao Wagner da biblioteca por esclarecer dúvidas que só você sabe com a maior precisão possível. Às meninas da secretaria de pós, Ana Paula, Silvana e Letícia. Obrigada pela compreensão e esclarecimentos nos vários momentos de euforia devido à tensão pré-depósito, mesmo quando este prédepósito se torna um pouco mais comprido que o de costume. 
Ao Coral do IO, por me fornecer momentos de paz e felicidade. Obrigada a todos, em especial a Ângela e ao Leo, vocês espalham alegria por onde passam! Agradeço também à Angélica e à Eliete, por me fazerem rir, principalmente no coral, e por sempre destrancar a porta quando eu me trancava do LOS com a chave do LHiCo.

À Didi, ao Betão e a todos os funcionários da lanchonete, pelos cafés, "chocotinos", chocolates, bolos, pães de queijo e "mãos de vaca". Mas, mais do que a todas estas gostosuras, obrigada pela amizade e por trazerem calma aos alunos em desespero.

Às amigas de antes, durante e com certeza após a dissertação, Carol, Renata e Vivian. Vocês fazem parte disso também! Obrigada por estarem presente durante mais uma etapa e pela amizade verdadeira e sincera.

Agradeço ao Conselho Nacional de Desenvolvimento Científico e Tecnológico (CNPq) e à Fundação de Amparo à Pesquisa do Estado de São Paulo (FAPESP) pela concessão de bolsas sob processos 135017/2011-4 e 2011/03720-9. 
But more wonderful than the lore of old men and the lore of books is the secret lore of ocean. 


\section{Resumo}

A hipótese principal deste trabalho é que as anomalias de precipitação na ZCIT com períodos de 20 a 50 dias e dimensão zonal de 1000 a 1500 km, causadas remotamente por Ondas de Instabilidade Tropical (OITs) e/ou Ondas de Rossby Curtas (ORCs) podem causar anomalias de salinidade da superfície do mar. Para responder à hipótese, o presente trabalho quantifica a influência dos padrões propagantes da temperatura da superfície do mar sobre variáveis atmosféricas na escala das ORCs e OITs. Os coeficientes de regressão do vapor d'água integrado verticalmente e da precipitação revelam que a influência da temperatura superficial na atmosfera se dá remotamente à região de domínio das ondas, alcançando a ZCIT. A distribuição das anomalias do divergente do vento corroboram a ideia de aceleração dos ventos sobre águas quentes e desaceleração sobre águas frias. A carência de correlações estatisticamente significativas entre a precipitação e a salinidade superficial, devido à baixa qualidade dos dados, não permitiu que a hipótese principal fosse avaliada. Entretanto, fica evidente a influência destas ondas em variáveis atmosféricas que alteram o balanço de evaporação e precipitação que tem influência direta na salinidade superficial. Denominamos ORCs as oscilações com período de $\sim 49$ dias e comprimento de onda de $\sim 1500 \mathrm{~km}$ e OITs os padrões com $\sim 21$ dias e $\sim 1000 \mathrm{~km}$. A identificação dinâmica destas ondas foi feita através da teoria linear de ondas equatoriais no modelo de águas rasas quase-geostrófico para um oceano invíscido de 1,5 camadas. Os dados de anomalia da altura da superfície do mar revelaram apenas a existência de ORCs, enquanto que a temperatura da superfície do mar apresentou o sinal de ambas as ondas, sendo as OITs dominantes até $6^{\circ}$ do Equador. A principal contribuição deste trabalho é a confirmação da hipótese de que OITs e ORCs coexistem, são distinguíveis e geram alterações no vento por mecanismos similares. Até o presente momento, desconhecemos outro estudo que alie a separação teórica dos padrões oceânicos propagantes obtidos por satélites à quantificação da variabilidade atmosférica associada às anomalias de TSM em bandas do espectro zonal-temporal características de ondas dinamicamente distintas.

Palavras-chave: dinâmica equatorial, interação oceano-atmosfera, ondas de instabilidade tropical, ondas de Rossby curtas, Atlântico tropical. 


\begin{abstract}
We hypothesize that rainfall anomalies with 20-50 days and 1000-1500 km on the Intertropical Convergence Zone (ITCZ) can induce sea surface salinity anomalies. We argue that these precipitation anomalies are remotely caused by Tropical Instability Waves (TIWs) and Short Rossby Waves (SRWs). We have quantified the sea surface temperature influence on atmospheric fields at the TIWs and SRWs spectral bands through regression analysis. In that, wind anomalies are larger over temperature anomalies. Winds tend to accelerate over positive temperature anomalies and slow down over negative anomalies. Changes on water vapor and rainfall occur predominantly on the ITCZ, far from the strongest temperature anomalies near the equator. However, we couldn't address the main hypothesis due to the lack of significant correlation between rainfall and sea surface salinity anomalies. We speculate that this is a consequence of the low quality of the salinity data used in this study. We have identified TIWs as the waves with $\sim 21$ days and $\sim 1000 \mathrm{~km}$ and SRWs as the oscillations with $\sim 49$ days and $\sim 1500 \mathrm{~km}$. The identification of the dynamics was made according to equatorial long waves theory based on a linear, quasi-geostrophic, 1.5 layers, inviscid ocean model. Sea surface height anomalies could only reveal SRWs. Sea surface temperature anomalies show both type of waves, with TIWs dominating within $6^{\circ}$ from the equator. Our main contribution was to show that TIWs and SRWs coexist, can be isolated and change wind field through similar mechanisms. We do not know any other study that linked theoretical identification of dinamically different oceanic waves to the atmospheric variability in a quantitative fashion.
\end{abstract}

Keywords: equatorial dynamics, ocean-atmosphere interaction, Tropical Instability Waves, Short Rossby Waves, tropical Atlantic. 


\section{Introdução}

A particularidade dos movimentos oceânicos na região equatorial sempre atraiu a atenção da comunidade científica. A singularidade da dinâmica equatorial está associada ao complexo sistema de correntes zonais, ao fenômeno de ressurgência e à esfericidade da Terra. O cisalhamento entre as correntes que fluem em sentidos alternados gera instabilidades barotrópicas que propiciam o surgimento de ondas (PHILANDER, 1978). A ressurgência promove a inclinação das isopicnais e estimula o desenvolvimento de feições ondulatórias por instabilidades baroclínicas (YU et al., 1995). Estas oscilações podem interagir com o fluxo básico e tornar o estudo da dinâmica das ondas bastante complexo.

Diferentemente dos movimentos de larga escala em latitudes médias, no Equador a anulação da componente vertical da vorticidade planetária no efeito de rotação estabelece que a curvatura da Terra deve ser considerada. Como resultado, a região equatorial atua como um guia de ondas (O’BRIEN, 1979; GILL, 1982). Apesar das ondas serem zonalmente confinadas, a influência destas sobre parâmetros atmosféricos pode propagar a resposta das oscilações para outras latitudes. Dentre as diversas escalas espaciais e temporais das oscilações equatorialmente aprisionadas, estão as Ondas de Instabilidade Tropical (OITs) e as Ondas de Rossby Curtas (ORCs).

\subsection{Ondas de Instabilidade Tropical e Ondas de Rossby Curtas}

OITs, também chamadas de Ondas de Rossby-gravidade ou Ondas de Yanai, foram observadas por sensoriamento remoto no Pacífico equatorial sob a forma de meandros na temperatura da superfície do mar (TSM) (LEGECKIS, 1977) e na concentração de clorofila entre $2^{\circ} \mathrm{N}$ e $6^{\circ} \mathrm{N}$ (FLAMENT et al., 1996). O desenvolvimento das ondas está associado à geração de instabilidades pelo intenso cisalhamento das correntes zonais que fluem em sentidos alternados (PHILANDER, 1978; COX, 1980) e aos fortes gradientes de temperatura da superfície do mar induzidos pela ressurgência equatorial (YU et al., 1995). Assim, as OITs podem ser observadas na região da língua fria, que limita as águas frias da ressurgência das águas quentes ao norte (LEGECKIS, 1977; DÜING et al., 1975). 
De acordo com Polito et al. (2001), as OITs no Pacífico se propagam para oeste, possuem aproximadamente período de 30 dias, comprimento de onda de $1000 \mathrm{~km}$ e velocidade de fase de $35 \mathrm{~km} /$ dia. Entretanto, os valores de período, comprimento de onda e velocidade podem variar de 20 a 40 dias, de 1000 a $2000 \mathrm{~km}$ e de 26 a $52 \mathrm{~km} / \mathrm{dia}$, respectivamente (QIAO e WEISBERG, 1995). Segundo Polito et al. (2001), os meandros observados nos dados de TSM obtidos por satélites (Figura 11) resultam da advecção do gradiente meridional de temperatura pelas correntes geostróficas induzidas pelas anomalias da altura da superfície do mar associadas às ondas.

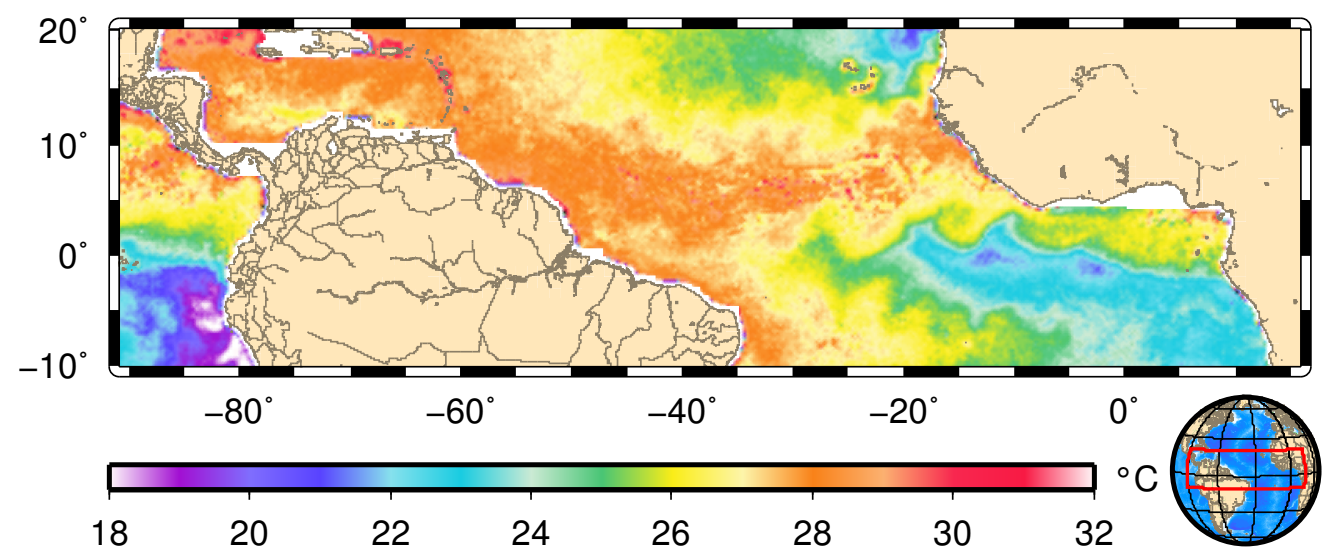

Figura 1: Ondas de Instabilidade Tropical são observadas entre $5^{\circ} \mathrm{N}$ e $5^{\circ} \mathrm{S}$ nos dados de TSM (em $\left.{ }^{\circ} \mathrm{C}\right)$ obtidos pelo TRMM Microwave Imager (TMI) em 10 de julho de 2004.

A observação das OITs em dados de TSM ocorre no período em que há intrusão da língua fria. Segundo Liu et al. (2000), no oceano Pacífico, estas ondas possuem um sinal mais acentuado de junho a novembro e durante condições de La Niña. Hashizume et al. (2001) estudaram as OITs no Atlântico no ano de 1999 e definiram o período das OITs entre junho e setembro. Caltabiano et al. (2005) publicaram o primeiro trabalho no Atlântico utilizando dados de satélites de diversos anos e verificaram que o período de ocorrência das ondas, assim como a latitude de domínio do sinal, são interanualmente variáveis e dependem da intensidade da ressurgência equatorial. Mais recentemente, $\mathrm{Wu}$ e Bowman (2007a) observaram que no Atlântico as OITs estão mais ativas nos meses de junho, julho e agosto, quando as ondas atingem amplitudes máximas, e então começam a enfraquecer. De acordo com Mitchell e Wallace (1992), o rápido desenvolvimento e decaimento da língua fria no Atlântico em comparação ao desenvolvimento gradual 
do Pacífico deve-se ao fato do Atlântico ser fortemente influenciado pela presença dos continentes. No Atlântico a língua fria atinge sua máxima intensidade no início de agosto e então passa a enfraquecer. O mesmo ocorre com as OITs.

Uma vez que as OITs ocorrem como ondulações na frente de TSM promovida pela ressurgência, variações interanuais da TSM na região equatorial causam variações de mesma escala nas ondas (WU e BOWMAN, 2007b). Na região equatorial, esta variabilidade está associada ao fenômeno El Niño Oscilação Sul (ENOS). Contreras (2002) verificaram que as OITs no Pacífico são mais intensas durante a fase negativa do ENOS (La Niña) e quase inexistentes durante a fase positiva (El Niño). Wu e Bowman (2007b) estudaram a variabilidade interanual das OITs no Pacífico e Atlântico associada ao ENOS utilizando 8 anos de dados de TSM do TMI (TRMM Microwave Imager). Os autores observaram que a correlação negativa entre a atividade das OITs na temperatura e o índice do ENOS também ocorre no Atlântico.

Perez et al. (2012) caracterizaram a variabilidade interanual das OITs no Atlântico considerando não apenas a TSM obtida por satélite como também a anomalia da altura da superfície do $\operatorname{mar}(\eta)$. Ambos conjuntos de dados sugerem que a $5^{\circ}$ de latitude do Equador, a instabilidade barotrópica entre o ramo norte da Corrente Sul Equatorial (CSEn) e a Contra Corrente Norte Equatorial (CCNE) domina em relação à ressurgência na determinação da variabilidade interanual das ondas. Próximo ao Equador, os processos que controlam e associam a variabilidade TSM e $\eta$ não puderam ser determinados.

Os mecanismos de geração das OITs por processos de instabilidade ainda não são detalhadamente conhecidos (SCHUCKMANN et al., 2008). Trabalhos mais antigos defendem que a instabilidade barotrópica é a principal fonte de energia para a produção das ondas no Pacífico (e.g.: $\quad$ Philander (1978); Weisberg e Weingartner (1988); Kelly et al. (1995)). De acordo com Philander (1978), a instabilidade barotrópica devida ao cisalhamento entre a Corrente Sul Equatorial (CSE) e a CCNE promove ondas instáveis com período de $\sim 1$ mês e comprimento de onda de $\sim 1100 \mathrm{~km}$. Yu et al. (1995) verificaram que, apesar da instabilidade barotrópica devido ao cisalhamento da CSE contribuir no crescimento das OITs, a principal fonte de energia é a instabilidade baroclínica associada 
à frente de TSM. Trabalhos mais recentes baseados em dados de correntes no Atlântico equatorial em $23^{\circ} \mathrm{W}$ constataram que ambas instabilidades são importantes na geração das ondas (GRODSKY et al., 2005; SCHUCKMANN et al., 2008).

Masina et al. (1999) e Pezzi e Richards (2003) analisaram a geração de OITs no Pacífico por instabilidades através de simulações numéricas usando um modelo de circulação geral. Os autores observararam que o desenvolvimento das ondas ocorre da conversão de instabilidades barotrópicas e baroclínicas. Segundo Masina et al. (1999), no Equador há domínio da instabilidade barotrópica e a baroclínica prevalece ao norte. As ondas são influenciadas pelo termo de mistura lateral, parametrizado nas simulações. Pezzi e Richards (2003) concluíram que a contribuição de cada instabilidade na produção das ondas depende da forma e da intensidade dos coeficientes da parametrização da mistura lateral. Quando a mistura lateral é baixa, há domínio da instabilidade barotrópica.

As OITs somente se desenvolvem na região equatorial. No espectro de frequência e número de onda que nitidamente separa as ondas de Rossby das ondas de gravidade, as OITs são como um elo de ligação entre elas (MATSUNO, 1966). Por isso, também são chamadas de ondas de Rossby-gravidade.

As ondas de Rossby devem sua existência à variação latitudinal da vorticidade planetária. Via de regra, podem ocorrer em qualquer latitude. O mecanismo restaurador destas ondas é a conservação de vorticidade potencial. Quando uma parcela de água em movimento perde (ganha) vorticidade planetária ao se deslocar em direção ao Equador (aos pólos), ela deve ganhar (perder) vorticidade relativa para que a vorticidade potencial seja conservada. Assim, no hemisfério Norte, ao se aproximar (afastar) do Equador, a parcela de água ganha rotação ciclônica (anticiclônica). O movimento assim induzido resulta na propagação de uma onda com velocidade de fase para oeste e grupo para leste. No caso das ondas de Rossby baroclínicas longas, o deslocamento vertical da termoclina desempenha o papel equivalente ao da vorticidade relativa, de forma que se a profundidade da termoclina aumenta (diminui), a vorticidade planetária aumenta (diminui).

O mecanismo restaurador das OITs depende de sua frequência e número de onda, podendo ser a gravidade ou a conservação de vorticidade potencial. A velocidade de grupo 
é sempre para leste, mas podem propagar fase para leste ou para oeste. As ondas com os menores comprimentos de onda cuja velocidade de fase é para leste possuem frequências semelhantes às ondas de gravidade curtas. Já a solução da relação de dispersão das OITs de baixa frequência com propagação de fase para oeste se aproxima à das ORCs.

As ORCs são facilmente observadas nos dados de $\eta$ e possuem comprimento de onda de aproximadamente $1500 \mathrm{~km}$ e período de aproximadamente 50 dias (POLITO e SATO, 2003). Segundo Polito et al. (2001), as variações de $\eta$ ocorrem principalmente devido às variações da temperatura da camada superior, por expansão/contração térmica.

Na região equatorial, OITs e ORCs ocorrem simultaneamente. Apesar de dinamicamente diferentes, a assinatura de ambas nos dados de TSM e $\eta$ com períodos e comprimentos de onda muito similares, torna-as semelhantes sob o ponto de vista observacional. Por este motivo, ondas de Rossby e ondas de Rossby-gravidade são diversas vezes genericamente denominadas de OITs, o que torna a definição dos parâmetros destas ondas em dados observacionais tão controverso.

Atualmente, acredita-se que ondas diferentes coexistem e que são geradas por processos distintos, porém todos associados à instabilidades das correntes e à ressurgência equatorial. Lyman et al. (2007) observaram ondas de Rossby-gravidade no Pacífico equatorial com período de 17 dias e ondas de Rossby em $5^{\circ} \mathrm{N}$ com 33 dias. Bunge et al. (2007) sugeriram a existência de dois tipos de OITs geradas por mecanismos independentes nos hemisférios Norte e Sul. Han et al. (2008) também defendem a existência de tipos diferentes de OITs em função da latitude. Os autores observaram anomalias de $\eta$ associadas às ondas mais intensas a $2^{\circ}-5^{\circ}$ do Equador. No Atlântico, Schuckmann et al. (2008) observaram ondas de Rossby-gravidade próximo ao Equador com períodos de 14 a 40 dias e ondas de Rossby entre $2^{\circ} \mathrm{N}$ e $5^{\circ} \mathrm{N}$ com períodos de 20 a 50 dias.

A semelhança entre OITs e ORCs também ocorre sob o ponto de vista termodinâmico. A passagem das ondas desloca verticalmente a picnoclina e, portanto, altera o conteúdo de calor armazenado. Consequentemente, a energia disponível para ser trocada com a atmosfera pela interface através de fluxos de calor latente e sensível também é alterada (POLITO e SATO, 2003). 


\subsection{Interação oceano-atmosfera sobre anomalias transientes de TSM}

A principal forçante da circulação oceânica em grande escala é a tensão de cisalhamento exercida pelos ventos que sopram sobre a superfície do mar (CUSHMANROISIN e BECKERS, 2006). Estes ventos também promovem liberação de vapor d'água na camada limite atmosférica, que se estende pelos primeiros 1-2 km a partir da superfície. Ao ser transportado para a troposfera, este vapor d'água condensa e forma nuvens e chuva, liberando calor latente que é uma importante fonte de energia para a circulação atmosférica. Dessa forma, os processos de interação oceano-atmosfera são a chave para a compreensão das circulações tanto oceânica como atmosférica e extremamente importantes no entendimento dos papéis dos dois reservatórios na variabilidade climática (CHELTON e XIE, 2010).

A evaporação causada pelo vento promove o resfriamento da superfície do mar. Dessa forma, em escala global, a correlação entre TSM e velocidade do vento próximo à superfície é negativa (LIU et al., 1994; MANTUA et al., 1997; OKUMURA et al., 2001; XIE, 2004). Esta correlação representa a resposta passiva do oceano aos fluxos de calor latente e, em menor grau, calor sensível induzidos pelo vento. Quanto mais intenso o vento, maior a evaporação e menor a TSM (CHELTON e XIE, 2010).

O advento dos satélites permitiu que a interação entre a TSM e o vento pudesse ser observada em escalas espaciais menores. Diversos autores verificaram que em regiões de frentes oceânicas e vórtices a correlação entre a TSM e o vento é positiva (LIU et al., 2000; CHELTON et al., 2001; HASHIZUME et al., 2001; CORNILLON e PARK, 2001; PARK e CORNILLON, 2002; SMALL et al., 2008). Isso mostra que os processos de interação oceano-atmosfera na escala de 10-1000 km e 10-100 dias são fisicamente diferentes dos que ocorrem em escala global e, mais ainda, que a atmosfera responde às variações espaciais de TSM através de fluxos de calor (CHELTON e XIE, 2010; SMALL et al., 2008). Nesta escala, os processos de interação ar-mar associados às OITs e às ORCs revelam a dominância de certos fenômenos oceânicos sobre os atmosféricos.

Estudos observacionais mostraram que as variações da TSM associadas às OITs e/ou ORCs podem acarretar em alterações de ventos superficiais, vapor d'água e precipita- 
ção (HAYES et al., 1989; WALLACE et al., 1989; DESER et al., 1993; XIE et al., 1998; HASHIZUME et al., 2001; SMALL et al., 2003). Existem duas hipóteses principais que atribuem a variabilidade do vento na região tropical às variações de TSM. Na primeira delas, a alteração do vento é induzida por flutuações da pressão atmosférica ao nível do mar por balanço hidrostático, e foi proposta por Lindzen e Nigam (1987). Neste caso, assume-se que as massas de ar são bem misturadas próximo à superfície e, consequentemente, a temperatura do ar e a pressão hidrostática estão diretamente relacionadas à TSM. Dessa forma, baixas pressões se desenvolvem sobre águas quentes e altas pressões sobre águas frias. Isto induz gradientes de pressão e resulta em convergência e divergência do vento em baixos níveis sobre anomalias positivas e negativas de TSM, respectivamente.

De acordo com a segunda hipótese, sugerida por Hayes et al. (1989) e Wallace et al. (1989), a variabilidade do vento deve-se à mistura vertical. Conforme o vento passa sobre águas quentes, este aquece, a camada limite atmosférica se torna instável, a mistura vertical aumenta, o cisalhamento do vento com a superfície diminui e a velocidade do vento aumenta. Sobre águas frias, a estratificação da atmosfera é mais estável, o vento na superfície se dissocia do vento em altitude e, assim, a mistura vertical e a velocidade do vento são menores. Dessa forma, a aceleração dos ventos sobre águas quentes gera centros de convergência e divergência sobre os máximos gradientes de TSM. As duas hipóteses se diferenciam pela importância que cada uma confere aos termos de gradiente de pressão e de mistura vertical no balanço de momentum. No mecanismo de gradiente de pressão proposto por Lindzen e Nigam (1987), as anomalias de TSM e do divergente do vento estão $180^{\circ}$ fora de fase, enquanto que no mecanismo proposto por Hayes et al. (1989) e Wallace et al. (1989), estas anomalias estão defasadas em $90^{\circ}$, como esquematizado na Figura 2.

Xie et al. (1998) estudaram a interação ar-mar em frentes oceânicas usando dados de satélites e observaram que os ventos superficiais e a TSM estão praticamente em fase, de forma que os alíseos de sudeste são acelerados (enfraquecidos) sobre águas quentes (frias). Hashizume et al. (2001) verificaram que tanto o gradiente de pressão quanto a mistura vertical são igualmente importantes na determinação da variabilidade do 
vento relacionada às anomalias de TSM. Outros trabalhos baseados em dados de satélites verificaram que o mecanismo de mistura vertical é o processo dominante (LIU et al., 2000; CHELTON et al., 2001; CALTABIANO et al., 2005; PEZZI et al., 2005; WU e BOWMAN, 2007a). Segundo Liu et al. (2000), a variação da velocidade do vento devido às OITs atinge $2 \mathrm{~m} \mathrm{~s}^{-1}$. Entretanto, a diferença de fase entre o vento e a TSM utilizada por Liu et al. (2000); Caltabiano et al. (2005); Wu e Bowman (2007a) pode gerar conclusões irreais se a advecção horizontal não for considerada (SMALL et al., 2003).

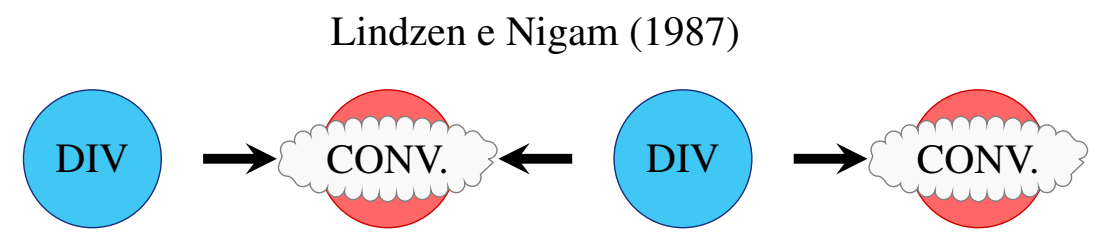

Hayes et al. (1989) e Wallace et al. (1989)

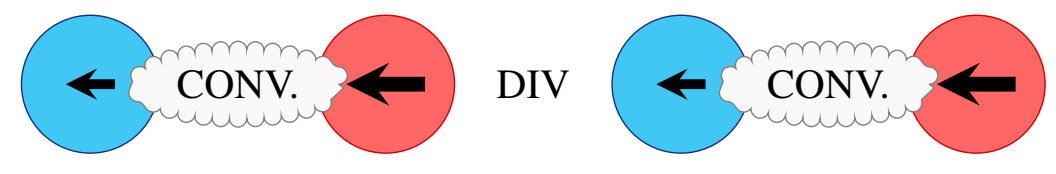

Figura 2: Representação esquemática das hipóteses de alteração do vento sobre anomalias de TSM positivas (círculos vermelhos) e negativas (círculos azuis) propostas por Lindzen e Nigam (1987) e Hayes et al. (1989) e Wallace et al. (1989), para um vento de leste. O vento está representado pelas flexas pretas. "DIV" e "CONV" indicam, respectivamente, as regiões de divergência e convergência do vento em baixos níveis. A formação de nuvens é favorecida onde há convergência.

Small et al. (2003) estudaram a importância relativa de cada um dos termos do balanço de momentum em resultados de simulações numéricas e verificaram que a distribuição do campo de vento associada às anomalias de TSM deve-se não apenas ao gradiente de pressão e à mistura vertical, mas também à advecção horizontal. Segundo Small et al. (2003), em baixos níveis, as contribuições da mistura vertical e do gradiente de pressão no balanço de momentum são praticamente iguais e opostas e, portanto, a advecção horizontal, apesar de menor em magnitude, é importante para determinar a tendência total. De acordo com os mesmos autores, o deslocamento das anomalias de temperatura do ar e pressão para oeste em relação às anomalias de TSM, causado pelo 
vento médio, gera um padrão de vento grosseiramente em fase com as anomalias de TSM. Essa relação de fase é tradicionalmente atribuída ao mecanismo de mistura vertical, mas, de fato, é consistente com o mecanismo do gradiente de pressão.

A importância da advecção horizontal das anomalias de pressão pelos ventos zonais médios, sugerida por Small et al. (2003) através de estudos numéricos, foi corroborada por estudos observacionais posteriores. Cronin et al. (2003) utilizaram dados de pressão barométrica do projeto Tropical Atmosphere-Ocean e verificaram que o mecanismo do gradiente de pressão é o processo dominante no ajuste da atmosfera ao forçamento pela TSM associada às OITs. Os autores observaram que a advecção pelo fluxo médio faz com que os ventos devido ao gradiente de pressão convirjam a jusante das anomalias de TSM quando as anomalias de pressão estão a jusante das anomalias de TSM. Wu et al. (2008) analisaram dados de vento e TSM provenientes de satélites e verificaram que há convergência do vento superficial associada a águas quentes e divergência associada a águas frias, apesar dos máximos de convergência e divergência estarem localizados a noroeste (a jusante) das anomalias de TSM. Segundo estes autores, a localização dos centros de convergência em relação às anomalias de TSM não permite a determinação exata do mecanismo pelo qual a atmosfera responde às OITs sem que a advecção horizontal seja considerada.

A distribuição do padrão de nuvens associado à temperatura depende do mecanismo dominante na relação entre as anomalias de TSM e vento. Deser et al. (1993) observaram uma forte associação entre nuvens e TSM e propuseram que a formação de nuvens é promovida por convecção térmica. Neste caso, a nebulosidade é intensificada sobre as anomalias quentes de TSM, onde ocorre convergência do vento, e condições de céu claro são encontradas sobre as anomalias frias, onde há divergência do vento superficial, conforme esquema da hipótese de Lindzen e Nigam (1987) na Figura 2, Já Xie et al. (1998) isolaram o sinal das OITs nos dados de vento proveninentes de satélite e mostraram que os alíseos de sudeste são intensificados sobre anomalias positivas de TSM e enfraquecidos sobre anomalias negativas. Dessa forma, os autores observaram convergência do vento a oeste das anomalias positivas de TSM e aumento de vapor d'água 
integrado verticalmente a noroeste das anomalias quentes de $\mathrm{TSM}, 90^{\circ}$ fora de fase em relação às anomalias de cobertura de nuvens obtidas por Deser et al. (1993), conforme esquematizado na hipótese de Hayes et al. (1989) e Wallace et al. (1989) na Figura 2.

Hashizume et al. (2001) observaram que no Pacífico central o aumento da atividade convectiva está flanqueado pela crista da frente de TSM a oeste e pelo cavado a leste, o que corrobora a hipótese de Xie et al. (1998). Wu e Bowman (2007a) observaram anomalias positivas de vapor d'água integrado verticalmente provenientes de satélite sobre anomalias positivas de TSM e também a norte e a oeste destas. Small et al. (2003) verificaram tanto em dados de satélites quanto em resultados de modelo que os extremos de vapor d'água localizam-se ligeiramente a norte e a oeste dos extremos de TSM e que os máximos e mínimos do vapor correspondem com regiões de convergência e divergência do vento, respectivamente. Entretanto, os perfis verticais de vapor d'água derivados de modelo mostram que o vapor d'água e a TSM encontram-se praticamente em fase e que a inclinação para oeste do perfil de vapor com a altitude pode explicar a defasagem observada entre vapor integrado e TSM. Dessa forma, a hipótese de que a mistura vertical favorece aceleração dos ventos sobre águas quentes e formação de nuvens a oeste das anomalias quentes pode estar equivocada. Portanto, os processos de mistura vertical, gradiente de pressão e advecção horizontal atuam conjuntamente na associação entre TSM, vento e vapor d'água (SMALL et al., 2003; WU e BOWMAN, 2007a).

Os feedbacks da alteração do stress vento superficial pelas ondas nas propriedades das OITs do Pacífico foram estudados por Pezzi et al. (2004) utilizando um modelo de circulação geral dos oceanos. Segundo os autores, o vento desfavorece o crescimento das ondas, reduzindo a variabilidade das correntes meridionais e, consequentemente, da temperatura, tanto em superfície como em subsuperfície. Isto resulta num maior resfriamento da língua fria e em correntes equatoriais mais intensas, devido à diminuição dos transportes meridionais de calor e momentum. Seo et al. (2007) estudaram os mesmos feedbacks no oceano Atlântico utilizando um modelo climático acoplado regional de alta resolução. Os autores observaram que as perturbações do vento superficial causadas pelas ondas estão em direção oposta às correntes superficiais associadas às ondas, o que reduz 
o crescimento das mesmas, corroborando os resultados de Pezzi et al. (2004).

\subsubsection{O papel da Zona de Convergência Intertropical}

Na região de ocorrência das OITs e ORCs encontra-se também a Zona de Convergência Intertropical (ZCIT). A ZCIT é uma região de baixa pressão atmosférica onde o movimento vertical ascendente das parcelas de ar gera, por continuidade, convergência dos ventos em baixos níveis e promove a formação de nuvens e chuva. A ZCIT sofre alterações de sua posição ao longo do ano, ocupando latitudes mais ao norte entre junho e dezembro e mais ao sul entre janeiro e maio (XAVIER et al., 2000). O que controla a migração da ZCIT é a distribuição das anomalias de TSM na região Equatorial conhecida como padrão de dipolo (NOBRE e SHUKLA, 1996). O padrão de dipolo gera gradientes meridionais de anomalias de TSM que definem a posição da ZCIT e, consequentemente, a distribuição das chuvas (HASTENRATH e GREISCHAR, 1993). O padrão de dipolo positivo (águas quentes no hemisfério Norte e frias no hemisfério Sul) ocorre durante o período de máxima intensidade das OITs entre junho e agosto (WU e BOWMAN, 2007a), e desloca a ZCIT para norte, fora da região de domínio das ondas.

Embora restritas a latitudes próximas ao Equador, a influência das OITs no oceano Atlântico atinge latitudes mais ao norte, alcançando a ZCIT (HASHIZUME et al., 2001; WU e BOWMAN, 2007a). Hashizume et al. (2001) verificaram alteração da precipitação na ZCIT no ano de 1999, quando esta encontrava-se anomalamente mais ao sul, tornando-a suscetível à influência das ondas. Os mesmos autores observaram essa influência apenas sobre o Atlântico, pois neste oceano a ZCIT ocupa posições mais ao sul que no Pacífico, apesar de que Xie et al. (1998) verificaram anomalias de precipitação na ZCIT associadas às OITs no oceano Pacífico. Embora 1999 tenha sido um ano anômalo, Wu e Bowman (2007a) puderam observar alterações do vento, do vapor d'água, do conteúdo de água líquida nas nuvens e da precipitação na ZCIT associadas às OITs durante os anos de 1998 a 2005. Apesar das anomalias de TSM associadas às OITs estarem restritas a $5^{\circ} \mathrm{N}$, as anomalias do campo de ventos alcançam $8^{\circ} \mathrm{N}$, onde são mais intensas do que na própria região de desenvolvimento das ondas (WU e BOWMAN, 2007a). Estes autores 
encontraram anomalias positivas (negativas) do vapor d'água associadas a anomalias positivas (negativas) de TSM e sobre os centros de convergência (divergência) do vento. Além disso, as anomalias positivas (negativas) de precipitação associadas a anomalias positivas (negativas) de vapor sugerem uma possível influência indireta das OITs sobre a precipitação no Atlântico.

\subsection{Descrição do problema}

A dinâmica pertinente à região equatorial do planeta possui particularidades associadas à rotação da Terra, à ressurgência e ao sistema de correntes. Estes fatores permitem o desenvolvimento das OITs, intrínsecas à região equatorial. Estas ondas podem ser facilmente estudadas por dados provenientes de satélites. Entretanto, a similaridade e a grande variedade dos valores de frequência e número de onda das OITs as fazem semelhantes às ORCs sob o ponto de vista observacional. Isto torna a definição de OITs bastante genérica, cuja denominação pode fazer referência a ondas de Rossby-gravidade ou ondas de Rossby. Apenas uma caracterização com base na teoria de ondas equatoriais permite a identificação correta dos padrões propagantes observados. Portanto, a partir da classificação dinâmica das oscilações que a literatura denomina OITs e ORCs é possível verificar se os padrões observados são ondas dinamicamente distintas e se podem produzir respostas atmosféricas diferentes.

Assumindo que as anomalias de TSM das OITs e/ou ORCs podem causar anomalias de precipitação na ZCIT, a salinidade nos primeiros metros de coluna d'água pode sofrer variações indiretamente associadas às ondas. Assim, anomalias negativas (positivas) de salinidade podem estar relacionadas a anomalias positivas (negativas) de precipitação. Sob este ponto de vista, o presente trabalho propõe estudar a interação entre as OITs e/ou ORCs com a atmosfera e a influência destas sobre o oceano na região de ocorrência da ZCIT no Atlântico Equatorial, seguindo a hipótese de que as anomalias de precipitação na ZCIT com períodos de 20 a 50 dias e dimensão zonal de 1000 a 1500 km, causadas remotamente pelas OITs e/ou ORCs podem causar anomalias de salinidade da superfície do mar. 


\section{Objetivos}

A hipótese principal deste trabalho é que as anomalias de precipitação na ZCIT com períodos de 20 a 50 dias e dimensão zonal de 1000 a 1500 km, causadas remotamente pelas OITs e/ou ORCs podem gerar anomalias de salinidade da superfície do mar. As dificuldades encontradas a posteriori na análise dos dados de salinidade dificultaram o teste dessa hipótese principal. Isto nos levou a trabalhar com hipóteses ad hoc menos abrangentes que, na lógica do problema, intermediam a ligação entre as ondas e a salinidade:

1. O modelo linear de águas rasas quase-geostrófico para um oceano invíscido de 1,5 camadas no plano $\beta$ equatorial é capaz de descrever a dinâmica de ORCs e OITs;

2. OITs e ORCs tem sinais distinguíveis e coexistem no Atlântico equatorial;

3. OITs e ORCs produzem alterações nas variáveis atmosféricas através de mecanismos similares.

Neste contexto, o presente estudo tem como objetivo geral detectar anomalias de salinidade superficial na banda espectral das OITs e ORCs na região da ZCIT. Pretendemos, de forma mais específica:

- determinar a posição e a intensidade da ZCIT, durante o período de ocorrência das ondas, através do máximo vapor d'água integrado na atmosfera e da máxima convergência do vento;

- caracterizar as OITs e/ou ORCs no tempo e no espaço através de dados de TSM e $\eta$ com base na teoria linear para ondas equatoriais no modelo de águas rasas quasegeostrófico para um oceano de 1,5 camadas;

- detectar anomalias de vapor d'água, precipitação e vento na banda espectral das ondas na região da ZCIT, considerando-se o espectro 2D zonal-temporal;

- correlacionar as anomalias de vapor d'água, precipitação e vento com as anomalias de TSM associadas às OITs e/ou ORCs; 
- identificar anomalias de salinidade na faixa espectral das ondas e correlacioná-las às anomalias de precipitação;

- sugerir, dentre os possíveis mecanismos físicos responsáveis por tais correlações, qual é o dominante. 


\section{3 Área de estudo}

Na região tropical, os ventos alíseos são a principal forçante para a circulação oceânica em larga escala, caracterizada por diversas correntes e contra correntes zonais com extensões meridionais e verticais muito reduzidas (STRAMMA e SCHOTT, 1999). As Figuras 3 e 4 mostram o padrão de circulação superficial oceânica no Atlântico tropical de Stramma e Schott (1999) para a primavera e o outono do hemisfério Norte. As correntes superficiais que fluem para oeste são as Corrente Norte Equatorial (CNE) e Corrente Sul Equatorial (CSE). Os fluxos para leste ocorrem em superfície através das Contra Corrente Norte Equatorial (CNE) e Contra Corrente Sul Equatorial (CCSE), e em subsuperfície pelas Subcorrente Equatorial (SE) e Subcorrente Sul Equatorial (SSE). Baseado nas denominações de Molinari (1982), Stramma e Schott (1999) dividem a CSE em 4 ramos: sul (CSEs), central (CSEc), equatorial (CSEe) e norte (CSEn). Estes ramos são separados pelos fluxos para leste das CCSE, SSE e SE. A SSE é um fluxo abaixo da termoclina e é geralmente observada entre $3^{\circ} \mathrm{S}$ e $5^{\circ} \mathrm{S}$ (STRAMMA e SCHOTT, 1999).

A camada de mistura do Atlântico tropical é formada pela Água Tropical de Superfície (ATS) e possui temperaturas em torno de $27^{\circ} \mathrm{C}$. A isoterma de $20^{\circ} \mathrm{C}$ representa o limite inferior da ATS, próximo a $50 \mathrm{~m}$ de profundidade. Abaixo desta, encontra-se a Água Central (AC), composta predominantemente pela Água Central do Atlântico Sul (ACAS), proveniente do giro subtropical. A ACAS é transportada pela CSE em direção à costa do Brasil e em seguida em direção ao Equador pela Corrente Norte do Brasil (CNB) e pela Subcorrente Norte do Brasil (SNE) (STRAMMA e SCHOTT, 1999).

O Atlântico equatorial exibe versões mais fracas da piscina quente e da língua fria do Pacífico (TALLEY et al., 2011). Estas regiões estão associadas aos ventos alíseos de leste que causam empilhamento de água superficial na porção oeste da bacia. Este empilhamento gera uma força de gradiente de pressão para leste que conduz a SE para leste logo abaixo da superfície, entre 60 e 120 m no Atlântico. Próximo ao contorno oeste, o núcleo da SE encontra-se abaixo de $100 \mathrm{~m}$ e, na porção leste da bacia, localiza-se a 30 $\mathrm{m}$ (TALLEY et al., 2011). A velocidade da SE pode exceder $80 \mathrm{~cm} \mathrm{~s}^{-1}$, ainda assim mais fraca que a sua análoga no Pacífico, que chega a $100 \mathrm{~cm} \mathrm{~s}^{-1}$ (WACONGNE, 1990). 


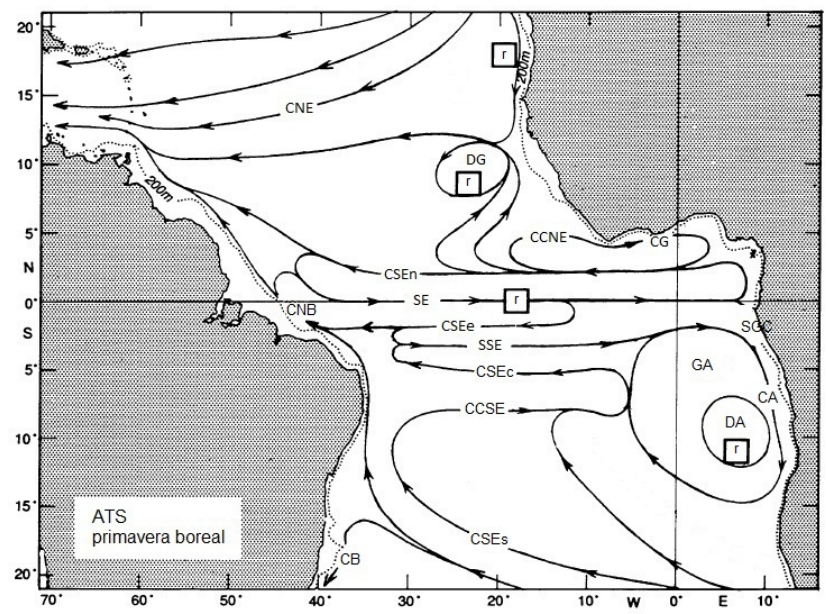

Figura 3: Distribuição horizontal das principais correntes tropicais para a Água Tropical de Superfície, de 0 a $100 \mathrm{~m}$ de profundidade durante a primavera do hemisfério Norte. Adaptado de Stramma e Schott (1999), As siglas representam a Corrente Norte Equatorial (CNE), Contra Corrente Norte Equatorial (CCNE), Corrente da Guiné (CG), ramos norte, equatorial, central e sul da Corrente Sul Equatorial (CSEn, CSEe, CSEc e CSEs, respectivamente), Subcorrente Equatorial (SE), Corrente Norte do Brasil (CNB), Subcorrente Sul Equatorial (SSE), Contra Corrente Sul Equatorial (CCSE), Corrente da Angola (CA), Corrente do Brasil (CB), Domo da Guiné (DG), Domo da Angola (DA) e regiões de ressurgência (r).

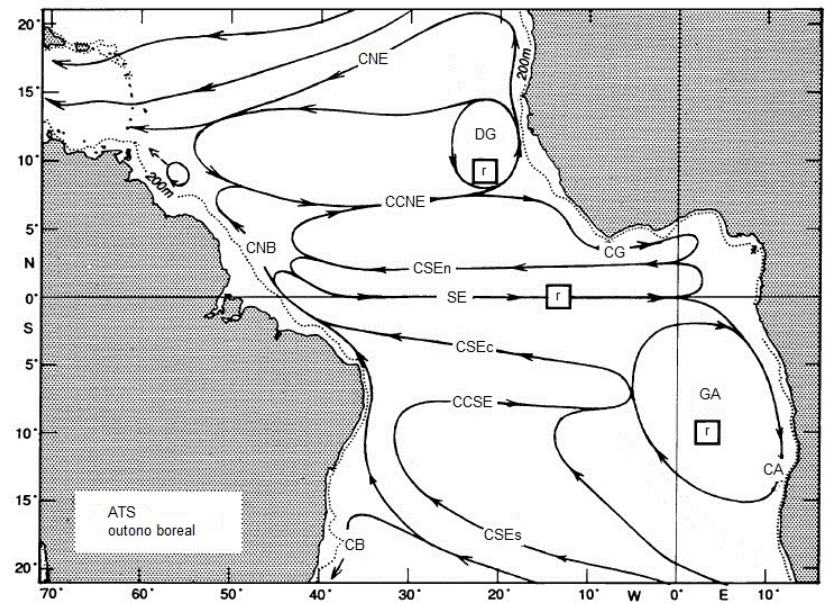

Figura 4: Similar à Figura 3 durante o outono do hemisfério Norte.

A CCNE limita a circulação tropical e a separa do giro subtropical do Atlântico Norte, cujo ramo sul é composto pela CNE (TALLEY et al., 2011). Quando a CCNE atinge a costa do continente africano, ela se divide em Corrente da Guiné (CG), que acompanha a costa e retroflete para oeste alimentando a CSEn, e num fluxo para norte, que alimenta a CNE para oeste. A região a leste, entre a CNE e a CCNE, forma o ciclone 
denominado Domo da Guiné e é uma região de ressurgência (SIEDLER et al., 1992).

Por volta de $7-8^{\circ} \mathrm{S}$ encontra-se a CCSE, que é sazonal e está associada à ZCIT (TALLEY et al., 2011). Ao se aproximar da costa da África, a CCSE é alimentada pelo fluxo de ressurgência oriundo da SE e flui para sul formando a Corrente da Angola (CA). Eventualmente, a CA flui para oeste contribuindo para a CSEs e forma uma região ciclônica de ressurgência denominada de Domo da Angola (WACONGNE e PITON, 1992).

A CSEs representa a porção norte do giro subtropical do Atlântico Sul. Quando a corrente atinge a costa do continente sul-americano, ela se bifurca formando a Corrente do Brasil (CB), que flui para sul, e a CNB para norte. (TALLEY et al., 2011) A CSEs também alimenta a CCSE, que por sua vez, alimenta parcialmente a CSEc. A CSEc alimenta a $\mathrm{CNB}$ a oeste de $35^{\circ} \mathrm{W}$ e atravessa o Equador em direção noroeste.

As Figuras 3 e 4 revelam a sazonalidade das CNE, CCNE, CSEe e SSE. O ciclo sazonal presente na circulação superficial é reflexo da variação dos ventos e da migração da ZCIT (STRAMMA e SCHOTT, 1999). Segundo os autores, quando a ZCIT se move para norte no início do verão boreal, as CNE e CSE também se movem para norte. A sazonalidade da CCNE está associada à retroflexão da CNB. No fim do verão, os ventos alíseos de sudeste cruzam o Equador e a CNB retroflete e alimenta a CCNE. Durante a primavera, a CCNE na porção oeste se torna fraca e pode até mesmo reverter o fluxo para oeste. Em junho de 1991 a $27^{\circ} \mathrm{W}$, a CCNE alcançou valores de $60 \mathrm{~cm} \mathrm{~s}^{-1}$ (STRAMMA e SCHOTT, 1999). Na primavera, parte da ATS da CNB retroflete e alimenta a SE e parte continua para noroeste acompanhando a costa sul-americana (Figura 4). Já no outono, a porção da CNB que flui ao longo da costa retroflete e, juntamente com a CNE, alimenta a CCNE (STRAMMA e SCHOTT, 1999). Apesar da CCNE ter um ciclo sazonal marcado, grande parte da região tropical que compõe a ATS não apresenta um ciclo sazonal significativo (STRAMMA e SCHOTT, 1999). Devido à pequena variação na inclinação quase perpendicular dos raios solares incidentes na região tropical, a TSM não apresenta um ciclo sazonal marcado como nas regiões subtropicais. Entretanto, próximo ao Equador nas porções central e leste dos oceanos, a TSM apresenta uma sazonalidade bem marcada devido à ressurgência equatorial que promove ascenção de águas mais frias na superfície. 


\section{Dados e métodos}

\subsection{Conjuntos de dados}

Para o estudo dos fenômenos de interesse neste trabalho, foram utilizados dados in-situ e provenientes de sensoriamento remoto. Os dados in-situ compreendem os perfis de temperatura, salinidade e pressão coletados pelos projetos PIRATA (Pilot Research Moored Array in the Tropical Atlantic) e ARGO.

O PIRATA é um programa de cooperação entre Brasil, França e Estados Unidos iniciado em 1997 que consiste numa rede de monitoramento de dados meteoceanográficos. Atualmente é composto por 21 boias distribuídas sobre o Atlântico tropical que coletam a cada 10 minutos dados meteorológicos de temperatura do ar, umidade relativa, radiação de ondas curtas, precipitação e vento superficial e perfis verticais oceânicos de temperatura, salinidade e pressão até $500 \mathrm{~m}$ de profundidade.

O projeto ARGO consiste numa rede de 3000 de derivadores que coletam e transmitem em tempo quase-real perfis de temperatura, salinidade e pressão até $2000 \mathrm{~m}$ de profundidade. Está contido em diversas iniciativas de observação global, o CLIVAR ( $\mathrm{Cli}$ mate Variability and Predictability Experiment), GODAE (Global Ocean Data Assimilation Experiment) e o GCOS/GOOS (Global Climate Observing System/Global Ocean Observing System). O programa foi iniciado em 2000 e é considerado o maior sistema de observação oceânica global.

Os dados de sensoriamento remoto foram obtidos por satélites. A grande vantagem do uso destes dados em relação aos in-situ é a obtenção de medidas sinóticas da superfície do mar com a maior cobertura geográfica em altas resoluções temporal e espacial. Dentre os sensores a bordo de satélites existentes, os dados utilizados neste trabalho provém de altímetros, radiômetros de micro-ondas e escaterômetros.

Os satélites altimétricos medem a distância entre um alvo na superfície da Terra e a antena pelo tempo de retorno e distorção do pulso eletromagnético emitido e refletido pela superfície. Superfícies não homogêneas, que contém descontinuidades ou grandes inclinações, como gelo, rios e os continentes, não fornecem estimativas confiáveis. Os 
melhores resultados são obtidos sobre os oceanos. A medida da altura da superfície do mar é a distância entre a superfície e o geóide, que é um campo onde o potencial gravitacional é constante. Assim, subtraindo a distância medida pelo sensor da distância do satélite ao geóide, obtém-se a altura da superfície do mar, que é relevante para a dinâmica. No caso dos satélites com órbita de repetição exata, este geóide é a média temporal da distância entre o sensor e a superfície medida em cada ponto. Assim, os sensores altimétricos fornecem a denominada anomalia da altura da superfície do mar, em relação ao geóide marinho. Estas anomalias implicam em movimento geostrófico no oceano, uma vez que se a altura estivesse paralela ao geóide, a parcela de água estaria em repouso.

Os sensores altimétricos operam na banda Ku de radar e emitem mais de 1700 pulsos por segundo. A cada $1 \mathrm{~s}$ são feitas médias da distância para fornecer medidas acuradas. Os satélites com órbita de repetição exata coletam os dados no Nadir, ao longo da trajetória. No caso do TOPEX/Poseidon, a trajetória é determinada com acurácia através do sistema Doris, que consiste de 50 estações em superfície que emitem um sinal captado pelo satélite. Este satélite amostra a superfície da Terra entre $66^{\circ} \mathrm{N}$ e $66^{\circ} \mathrm{S}$, passando no mesmo ponto a cada 9,9156 dias com uma resolução espacial de 315 km no Equador. Já o ERS-2 passa pelo mesmo ponto somente depois de 35 dias, mas a distância máxima entre os trajetos é de apenas 80 km no Equador. Assim, uma combinação de diferentes satélites altimétricos possibilita equilibrar o dilema entre resoluções espacial e temporal.

Devido à influência da atmosfera e ao deslocamento da superfície em relação à antena, são necessárias uma série de correções, detalhadas em Benada (1997). Levando em conta estas correções, o erro nominal dos dados obtidos é de $2 \mathrm{~cm}$. As principais limitações dos dados altimétricos são a dificuldade de medição do nível do mar em regiões costeiras, devido à influência da maré modificada pela topografia local, e a suavização das correntes médias devido à pouca resolução do geóide. Em contrapartida, os altímetros são capazes de realizar medições sinóticas de fenômenos em subsuperfície com cobertura global, permitindo, portanto, a observação de ondas de Rossby.

Os radiômetros de micro-ondas são instrumentos passivos que medem a radiação eletromagnética emitida pela superfície da Terra. Se por um lado a radiação medida atra- 
vessa a atmosfera apenas uma vez e, portanto, sofre menor espalhamento e absorção por ela, por outro a baixa potência recebida implica em perda de precisão pelos sensores passivos. Estes sensores podem operar em vários canais de frequência, de 7 a 90 GHz. Esta diversidade permite a medição de múltiplos parâmetros geofísicos, como temperatura da superfície do mar, intensidade do vento superficial, vapor d'água integrado na atmosfera, conteúdo de água líquida nas nuvens, precipitação e temperatura do ar. O radiômetro TMI (TRMM Microwave Imager) a bordo do TRMM (Tropical Rainfall Measuring Mission), cujos dados são utilizados neste trabalho, está em órbita tropical e fornece medidas diárias entre $40^{\circ} \mathrm{N}$ e $40^{\circ} \mathrm{S}$ com resolução de $0,25^{\circ}$.

Os radiômetros de micro-ondas medem a temperatura da superfície do mar mesmo em condições nubladas, o que é uma grande vantagem em relação a sensores de infravermelho, que obtém a temperatura apenas sob condições de céu limpo. Além disso, a presença de aerossois e vapor d'água não afeta as medições realizadas pelos radiômetros. Por outro lado, as medidas dos radiômetros são influenciadas pela rugosidade da superfície, o que não afeta os sensores de infravermelho. Por isso, o TMI possui uma rotina para remoção deste efeito. A limitação dos radiômetros está nas baixas resoluções temporal e espacial em comparação aos sensores que operam na banda do infravermelho. Dependendo da órbita do satélite, as resoluções dos sensores de infravermelho podem alcançar $12 \mathrm{~h}$ e $1 \mathrm{~km}$ para os de órbita polar e 30 min e $2 \mathrm{~km}$ para os geoestacionários. Isto deve-se ao fato do espectro de emissão eletromagnética da Terra conter muito mais energia na faixa do infravermelho do que na de micro-ondas. Entretanto, neste trabalho, a órbita tropical dos radiômetros de micro-ondas possibilita a aquisição de dados na região equatorial com resolução suficiente para o estudo dos fenômenos de interesse.

Os escaterômetros são instrumentos ativos que também operam na banda de radar e estimam o vento através de medidas da radiação eletromagnética retro-espalhada na superfície do mar. Da razão entre a potência retro-espalhada captada pelo sensor e a potência emitida é obtida a medida básica do escaterômetro que é a seção reta normalizada de $\operatorname{Radar}\left(\sigma_{0}\right) . \sigma_{0}$ depende da intensidade do vento e também da direção deste em relação à direção da antena projetada no solo (azimute). São tiradas várias medidas do mesmo 
ponto da superfície com azimutes diferentes e dessa forma os vários valores de $\sigma_{0}$ são convertidos no vetor vento equivalente neutro a $10 \mathrm{~m}$ da superfície pela Geophysical Model Function (GMF) (EBUCHI et al., 2002). O espalhamento na superfície se dá devido à similaridade entre o comprimento da onda de radar e das ondas capilar-gravidade, da ordem de 1 a $5 \mathrm{~cm}$. Estas ondas são diretamente influenciadas por mudanças no vento próximo à superfície e permitem que os escaterômetros infiram estas variações através do espalhamento Bragg do sinal emitido pelo sensor (ROBINSON, 2004). A desvantagem dos escaterômetros é a baixa resolução temporal, pois a atmosfera se modifica rapidamente em relação ao oceano. O escaterômetro SeaWinds a bordo do satélite QuikSCAT opera desde 1999 e amostra diariamente $90 \%$ da superfície dos oceanos livre de gelo com resolução de $25 \mathrm{~km}$ sob qualquer condição de tempo. Os erros sistemáticos são relativamente baixos: $1 \mathrm{~m} \mathrm{~s}^{-1}$ na magnitude e $20^{\circ}$ na direção (EBUCHI et al., 2002). As estimativas são confiáveis se o estado do mar permite a observação de ondas capilar-gravidade, quando a velocidade do vento está entre $4 \mathrm{~m} \mathrm{~s}^{-1}$ e $20 \mathrm{~m} \mathrm{~s}^{-1}$. Como essa situação ocorre na maior parte do tempo, praticamente todo o oceano pode ser monitorado continuamente.

Dentre as diversas variáveis físicas obtidas por instrumentos de medição in-situ e remota, para a elaboração do trabalho foram utilizados os seguintes dados, para os anos de 1998 a 2010, resumidamente:

- Anomalia da altura da superfície do $\operatorname{mar}(\eta)$ fornecidos pelo Archiving, Validation and Interpretation of Satellite Oceanographic data (AVISO) e processados pelo SSALTO/DUACS (Ssalto multimission ground segment/Data Unification and Altimeter Combination System), com resolução de $0,25^{\circ} \times 0,25^{\circ} \times 7$ dias.

- Temperatura da superfície do mar (TSM), vapor d'água integrado na atmosfera $(V)$ e precipitação $(P)$, obtidos diariamente pelo satélite TRMM (Tropical Rainfall Measuring Mission) através do sensor TMI (TRMM Microwave Imager), com resolução espacial de $0,25^{\circ}$;

- Tensões de cisalhamento zonal $\left(\tau_{x}\right)$ e meridional $\left(\tau_{y}\right)$ do vento, fornecidas pelo National Climatic Data Center (NCDC) com resoluções de $0,25^{\circ}$ e 1 dia. 
- Perfis verticais de salinidade $(S)$ e temperatura $(T)$, obtidos a cada 10 minutos pelas boias do programa PIRATA localizadas a $0^{\circ} 10^{\circ} \mathrm{W}, 6^{\circ} \mathrm{S} 10^{\circ} \mathrm{W}, 8^{\circ} \mathrm{S} 30^{\circ} \mathrm{W}$, $10^{\circ} \mathrm{S} 10^{\circ} \mathrm{W}, 12^{\circ} \mathrm{N} 23^{\circ} \mathrm{W}, 12^{\circ} \mathrm{N} 38^{\circ} \mathrm{W}, 15^{\circ} \mathrm{N} 38^{\circ} \mathrm{W}$ e $20^{\circ} \mathrm{N} 38^{\circ} \mathrm{W}$.

- Perfis verticais de $S$ e $T$ medidos pelos derivadores ARGO.

No caso dos dados altimétricos, usamos o AVISO reference data set que é composto, sempre que possível, de dados de 2 altímetros, um da série ERS1/2/Envisat e um da série TOPEX/Jason1/2. A opção por usar este conjunto de dados em vez de outro que inclui todos os satélites disponíveis visa a homogeneidade estatística no tempo, uma vez que no caso do reference há aproximadamente o mesmo número de amostras por mapa.

Para calcular a tensão de cisalhamento do vento com resolução de $0,25^{\circ}$, o NCDC combina dados de intensidade do vento provenientes de diversos satélites (QuikSCAT, SSMIs, TMI e AMSR-E) com dados observacionais. As vantagens desta combinação são o aumento das resoluções espacial e temporal dos dados e as reduções dos erros por subamostragem (aliasing) e dos erros randômicos. Somente a intensidade do vento é obtida a partir de observações. A velocidade é decomposta nas direções $u$ e $v$ a partir dos resultados da reanálise do NCEP (NRA-2). Isto é feito para que haja consistência na determinação das direções. Dos dados de sensoriamento remoto, somente as séries temporais de vento obtidas por escaterômetros, mais recentes, possuem medidas de direção. A validação desta combinação de dados encontra-se em Zhang et al. (2006), Os dados diários utilizados neste trabalho são calculados a partir da média dos dados de resolução de 6 h. As componentes zonal e meridional da tensão de cisalhamento do vento são respectivamente calculadas da seguinte forma:

$$
\begin{aligned}
\tau_{x_{s}} & =-\left(\frac{w_{s}}{w_{m}}\right)^{2} \cdot \tau_{x_{m}} \\
\tau_{y_{s}} & =-\left(\frac{w_{s}}{w_{m}}\right)^{2} \cdot \tau_{y_{m}}
\end{aligned}
$$

onde $w$ é a velocidade do vento e os índices $s$ e $m$ estão associados às variáveis obtidas por satélites e às variáveis provenientes do modelo, respectivamente. 


\subsection{Metodologia}

A partir das componentes zonal e meridional, calculamos o divergente da tensão de cisalhamento do vento $(\vec{\nabla} \cdot \vec{\tau})$. Considerando a razão de aspecto para movimentos de larga escala $(\delta<<1)$, podemos assumir que a atmosfera é um fluido incompressível cujo movimento se dá no plano horizontal. Dessa forma, o divergente da tensão de cisalhamento pode ser definido como:

$$
\vec{\nabla} \cdot \vec{\tau}=\frac{\partial \tau_{x}}{\partial x}+\frac{\partial \tau_{y}}{\partial y}
$$

onde $\tau_{x}, \tau_{y}$ são as componentes da tensão de cisalhamento do vento nas direções zonal e meridional, respectivamente. Desta forma, um divergente não nulo é interpretado como estiramento vertical. Apesar da medida do vento ser referente a $10 \mathrm{~m}$ da superfície do mar e considerarmos apenas o movimento no plano horizontal, convergência e divergência horizontal do vento podem ser associados a movimentos verticais na atmosfera que induzem formação de vapor d'água e precipitação.

Como a resolução temporal dos dados de $\eta$ é semanal, interpolamos cubicamente os dados diários de TSM, $V, P, \vec{\nabla} \cdot \vec{\tau}$ e $S$ para a resolução de 7 dias. Mesmo após a interpolação temporal, como a cobertura espacial dos dados provenientes do TMI é prejudicada pela presença de tempestades fortes, a região que ainda apresentou ausência de dados foi interpolada linearmente no espaço.

A ZCIT é uma região de convergência do vento em baixos níveis, também caracterizada pela presença de grande quantidade de vapor d'água devido à geração de movimento ascendente, cuja intensidade foi quantificada pelos máximos de $V$ e $\vec{\nabla} \cdot \vec{\tau}$. Como o campo de $\vec{\nabla} \cdot \vec{\tau}$ calculado a partir da tensão de cisalhamento proveniente dos dados do NCDC apresentou grande quantidade de ruído, calculamos o $\vec{\nabla} \cdot \vec{\tau}$ utilizando como $\tau_{x}$ e $\tau_{y}$ as respectivas componentes de larga escala provenientes do processo de filtragem com filtro de resposta impulsiva finita (finite impulsive response - FIR) de Polito e Liu (2003). Este filtro opera no espaço zonal-temporal e decompõe a série filtrada em padrões propagantes e não propagantes. A componente não propagante com escala espacial do tamanho 
da bacia oceânica contém sinais sazonais e interanuais como o ENOS (no oceano Pacífico) e, portanto, é capaz de revelar a variação sazonal da localização da ZCIT. A Figura 5 mostra os mapas de $\vec{\nabla} \cdot \vec{\tau}$ calculados a partir dos dados do NCDC e a partir da componente de larga escala. Os dois mapas são consistentes, mas a grande quantidade de ruído existente no primeiro campo em relação ao segundo revela que a componente de larga escala permite uma identificação mais precisa da posição latitudinal média da ZCIT.

Apesar do campo filtrado de $\vec{\nabla} \cdot \vec{\tau}$ ser extremamente suave, em algumas épocas do ano este ainda apresenta variabilidade relativamente alta, que dificulta a determinação exata da região de máxima convergência. Dessa forma, a posição da ZCIT foi definida pelos máximos de $V$. Para cada instante de tempo, calculamos a média de $V$ na latitude onde o máximo valor de $V$ foi encontrado. As latitudes máximas e mínimas foram definidas onde os valores médios de $V$ não diferissem por mais de $10 \%$ em relação ao valor médio de $V$ na latitude onde $V$ é máximo. Por fim, obtivemos a posição média da ZCIT para cada mês do ano calculando a média mensal das latitudes extremas da ZCIT.

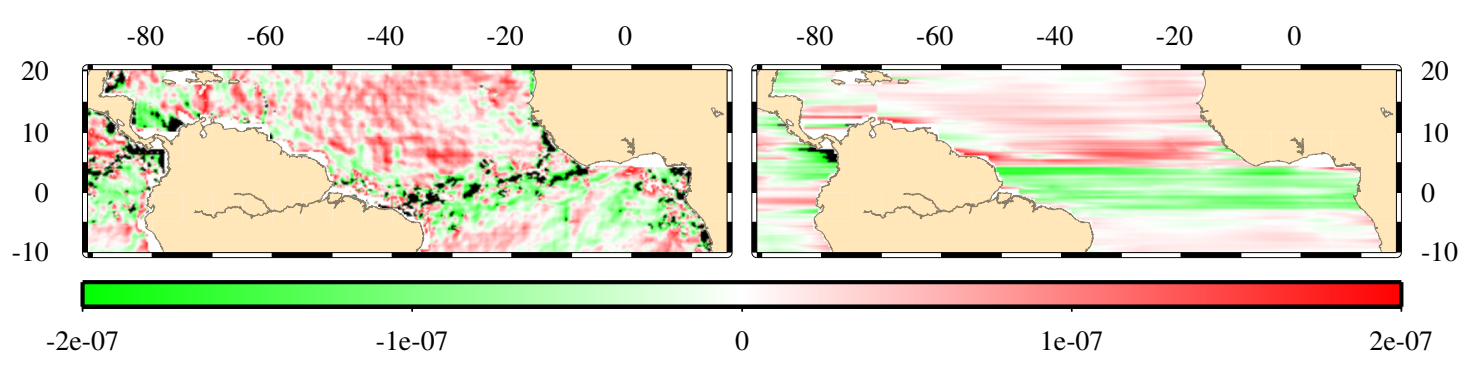

Figura 5: Divergente da tensão de cisalhamento do vento, em $\mathrm{kg} \mathrm{m}^{-2} \mathrm{~s}^{-2}$, proveniente dos dados originais do NCDC (esquerda) e da componente de larga escala dos dados do NCDC (direita) no dia 14 de fevereiro de 2004.

Os dados de $S$ e $T$ provenientes das boias PIRATA possuem dois parâmetros denominados $q$ e $s$. O primeiro deles está associado à qualidade do dados e varia de $1 \mathrm{a}$ 4. O $s$ está associado ao viés do sensor e varia de 1 a 5 . Quanto maior o flag, menor é a qualidade. Entretanto, os dados dificilmente alcançam o nível de alta qualidade definido pelo programa TAO (Tropical Atmosphere Ocean project). Dessa forma, utilizamos os dados onde $q=2$ e $s=1$. Para calcular um sinal anual razoavelmente representativo, para cada uma das boias, selecionamos o período onde há dados por pelo menos 2 anos. 
Mesmo selecionando este período, as séries que ainda apresentavam ausência de dados, que em alguns casos foi superior a 2 meses, foram interpoladas durante a obtenção da resolução temporal de 7 dias.

Os perfis de $S$ e $T$ medidos pelos derivadores ARGO foram utilizados para comparação com os perfis obtidos pelas boias PIRATA. Apenas os dados de boa qualidade definido pelo Global Data Assembly Center (GDAC) foram considerados. Devido à natureza Lagrangiana dos parâmetros medidos pelo ARGO, estes dados não foram submetidos às etapas de processamento descritas na sequência.

Os sinais anuais, as médias e as tendências temporais de $\eta$, TSM, $V, P, \vec{\nabla} \cdot \vec{\tau}$ e $S$ foram obtidos para cada ponto de grade através de ajuste linear senoidal de mínimos quadrados com período anual. A descrição deste método encontra-se no apêndice A. A partir da subtração dos respectivos sinais anuais, médias e tendências, calculamos as anomalias $\eta^{\prime}$, TSM', $V^{\prime}, P^{\prime}, \vec{\nabla} \cdot \vec{\tau}$ ' e $S^{\prime}$. De posse destas anomalias, iniciamos o processo de filtragem, descrito na seção a seguir.

\subsubsection{Filtros FIR 2D}

As remoções de oscilações de alta frequência e do sinal semianual e a obtenção dos sinais das ORCs e/ou OITs deram-se a partir da aplicação de filtros FIR 2D, segundo um método simplificado, baseado naquele descrito por Polito e Sato (2003). Estes filtros baseiam-se na convolução 2D entre a variável a ser filtrada, no caso as anomalias das 5 variáveis em estudo obtidas por sensoriamento remoto ( $\eta^{\prime}$, TSM', $V^{\prime}, P^{\prime}$ e $\vec{\nabla} \cdot \vec{\tau}{ }^{\prime}$ ), e o filtro. Para eliminar as oscilações espaciais de alta frequência dos mapas de anomalia, aplicamos um filtro gaussiano $2 \mathrm{D}$ com dimensões meridional de $1,25^{\circ}$ e zonal de $3,75^{\circ}$, correspondente à metade do comprimento de onda típico das OITs nos dados de TSM. A Figura 6 revela que a filtragem diminuiu o ruído dos dados e preservou o sinal das ondas.

Em seguida, organizamos os dados em diagramas Hovmöllers (zonais-temporais). Para cada latitude, a remoção do sinal semianual e a obtenção dos sinais das ondas deram-se por filtragens no domínio espaço-tempo. Para remover o sinal semianual nãopropagante, utilizamos um filtro gaussiano 2D com dimensões temporal de 6 meses e 
zonal do tamanho da bacia oceânica em cada latitude. Os filtros utilizados para isolar as ondas possuem a forma de um cosseno amortecido e são função do comprimento de onda e do período do sinal de interesse. O espectro de interesse neste trabalho compreende as frequências e números de onda associados às ORCs e/ou OITs. A literatura apresenta valores bastante amplos para comprimento de onda e período, principalmente para OITs. Devido à baixa resolução temporal dos dados, a escolha do período do filtro influencia muito mais o sinal resultante que a escolha do seu comprimento de onda, e, por isso, merece mais atenção.

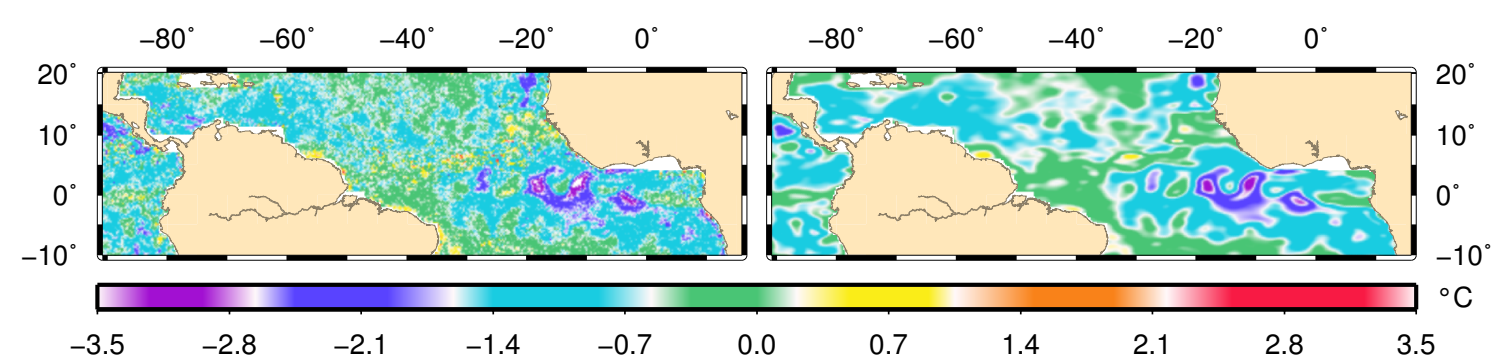

Figura 6: Anomalia da temperatura da superfície do mar (TSM') original (esquerda) e filtrada (direita) em 10 de julho de 2004. O sinal filtrado explica 73\% da variância do original.

Recentemente, Lyman et al. (2007) mostrou que oscilações da temperatura de subsuperfície no Pacífico equatorial com períodos de 17 e 33 dias se assemelham, respectivamente, a ondas de Rossby-gravidade e ondas de Rossby. Consistentemente a estes resultados, as análises espectrais dos diagramas de número de onda-frequência de Shinoda et al. (2009) nos dados de $\eta$ e TSM revelaram picos espectrais correspondentes a ondas de Rossby do primeiro modo meridional com período de 33 dias e comprimento de onda de $1500 \mathrm{~km}$. Tomando estes trabalhos como base, mas levando em conta a resolução temporal dos dados, definimos o que neste trabalho denomina-se ORCs e OITs.

Com uma resolução temporal de 7 dias, o filtro mais próximo do que Lyman $e t$ al. (2007) definiu como OITs é o de 21 dias. Para verificar se este filtro é capaz de isolar o sinal de 17 dias, criamos dados diários representativos da banda de 17 dias de Lyman et al. (2007). Para isso, somamos ondas sintéticas com períodos de 15, 16, 17, 18, 19, 20, 21, 22 e 23 dias, onde a variância de cada componente foi $4,8 \cdot 10^{-3}$ (unidade arbitrária). A estas ondas somamos também um ruído branco com variância igual a 1,0 $10^{-2}$. A linha 
cinza na Figura 7 mostra a série sintética. Sinais regulares ocorrem entre os dias 50 e 100, representando a intermitência realística das ondas nos dados de TSM. Como o desvio padrão da série varia no tempo, o uso de métodos baseados na transformada de Fourier não seria ideal. Já os filtros FIR permitem obter a assinatura de fenômenos intermitentes.

A estes dados sintéticos foram aplicados dois filtros: um com período de 17 dias e outro de 21 dias, cujos resultados são mostrados na Figura 7. O desempenho semelhante dos filtros revela que o sinal de 17 dias está presente em ambos sinais resultantes. Mas, como os dados sintéticos eram diários, para verificar se a resolução temporal dos dados reais poderia conter o sinal de 17 dias e este poder ser isolado pelo filtro de 21 dias, interpolamos os dados sintéticos para uma resolução semanal e, em seguida, aplicamos o filtro de 21 dias. A comparação do filtrado da série sintética interpolada (linha magenta na Figura 7) com os filtrados da série sintética original (linhas laranja e azul na Figura 7) mostra que o filtro de 21 dias é capaz de isolar o sinal de 17 dias em dados semanais. O sinal proveniente desta filtragem explica aproximadamente $90 \%$ da variância do sinal original e possui uma correlação de $99 \%$ com o sinal de 17 dias nos dados diários. Portanto, torna-se possível fazer comparações entre as OITs definidas neste trabalho com 21 dias $1000 \mathrm{~km}$ e as OITs de Lyman et al. (2007).

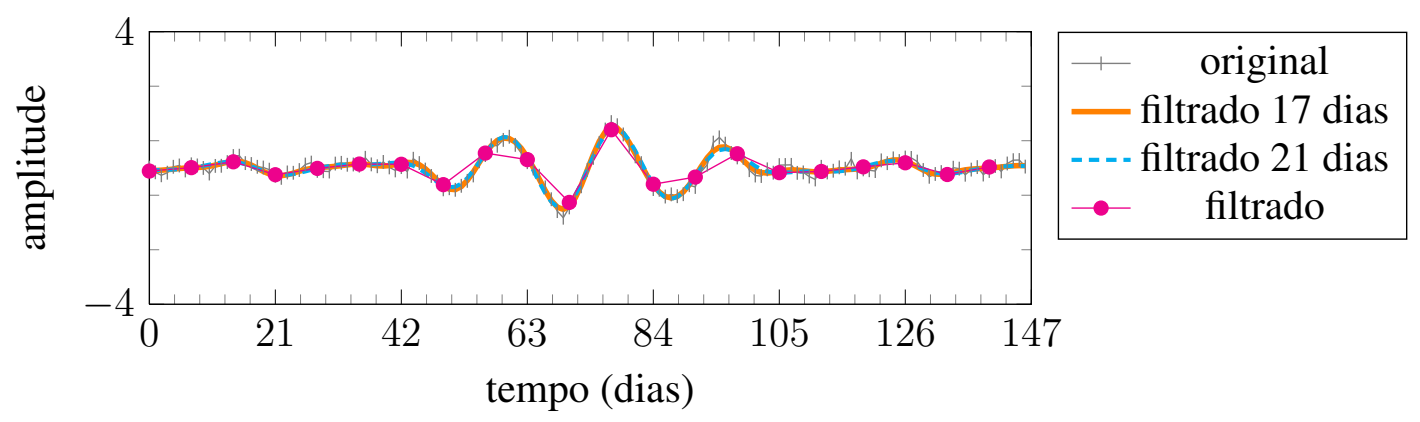

Figura 7: Resultado da aplicação dos filtros FIR 2D em dados sintéticos. As curvas revelam a semelhança dos filtrados com 17 e 21 dias entre si e destes com o interpolado para 7 dias e filtrado com 21 dias. A unidade de amplitude é arbitrária.

Um filtro de 33 dias para ORCs, possibilitaria a comparação dos resultados com as oscilações identificadas como ondas de Rossby por Lyman et al. (2007); Shinoda et al. (2009). Mas, neste caso, a simulação da filtragem para ORCs e OITs em dados sintéticos, revelou perda de semelhança em relação às respectivas séries originais. Dessa forma, com 
base no trabalho de Polito e Sato (2003), o filtro para ORCs foi definido com 49 dias e 1500 km. Assim, numa simulação, somamos ondas sintéticas representativas das ORCs e OITs, com variância de $2,2 \cdot 10^{-10}$ unidades arbitrárias, e um ruído branco de $1,2 \cdot 10^{-9}$ de variância. A Figura 8 mostra que os resultados gerados pelos filtros para ORCs e OITs em dados sintéticos são muito semelhantes às respectivas ondas originais. Os sinais filtrados representativos às ORCs (linha magenta) e às OITs (linha azul) preservaram aproximadamente $96 \%$ e $87 \%$ da variância dos respectivos sinais originais.

A ortogonalidade entre os sinais das ondas filtradas no domínio espaço zonal $(x)$ e tempo $(t)$ foi testada através do produto escalar. Para dar uma estimativa de quão pequeno deve ser o produto escalar entre os sinais $\nu_{O R C}$ e $\nu_{O I T}$ para considerá-los ortogonais, utilizamos como critério o produto entre os desvios padrão das duas ondas $\left(\sigma_{O R C}\right.$ e $\left.\sigma_{O I T}\right)$. Em todos os casos,

$$
\iint \nu_{O R C} \cdot \nu_{O I T} \mathrm{~d} x \mathrm{~d} t<<\sigma_{O R C} \cdot \sigma_{O I T} \cdot x \cdot t
$$

ou seja, as ORCs e OITs isoladas neste trabalho são ortogonais, pois o produto escalar entre elas é praticamente nulo. Isto demonstra que, uma vez que a parte correlacionada entre os sinais é removida, os filtros FIR garantem a ortogonalidade das componentes filtradas.

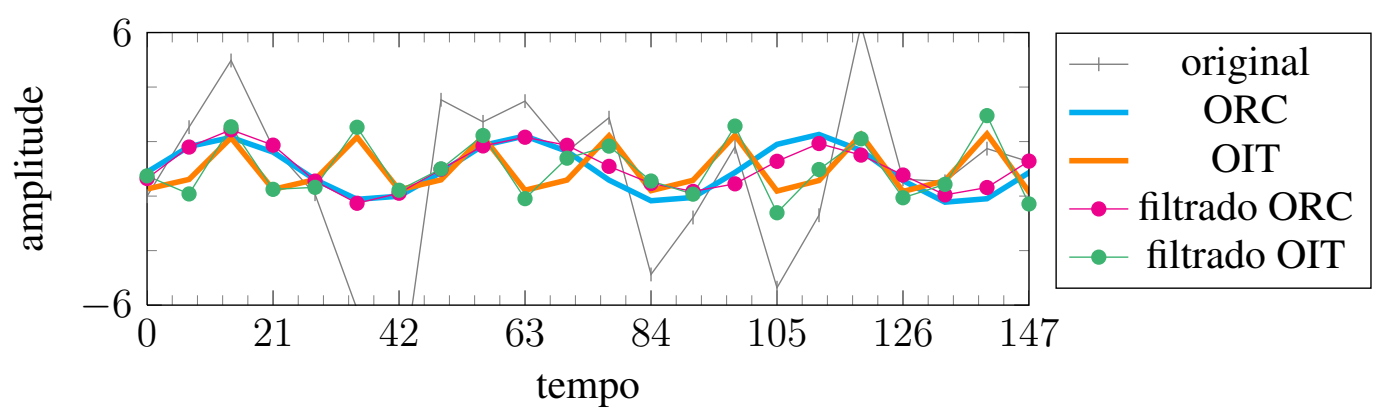

Figura 8: Resultado da aplicação dos filtros FIR 2D em dados sintéticos. As curvas revelam a semelhança entre os sinais original, filtrado com 17 dias, filtrado com 21 dias e interpolado para 7 dias e filtrado com 21 dias. As unidade de tempo e amplitude são arbitrárias.

É importante destacar que a resolução temporal de 7 dias é suficiente para resolver fenômenos de 21 e 49 dias. As Figuras 7 e 8 revelam que erros do tipo aliasing 
não ocorrem devido à proximidade da frequência de amostragem dos dados à frequência de Nyquist, especialmente no caso das OITs.

Por fim, os filtros foram aplicados nos dados de $\eta$, TSM, $V, P$ e $\vec{\nabla} \cdot \vec{\tau}$. Primeiramente, isolamos o sinal correspondentes às ORCs. Em seguida, o sinal destas ondas foi subtraído das anomalias originais e aos dados resultantes selecionamos as OITs. Para garantir a ortogonalidade entre as ondas, a parte correlacionada entre os sinais foi removida por mínimos quadrados.

Por serem medidas pontuais, os dados de $S$ medidos pelo projeto PIRATA foram submetidos apenas à filtragem no domínio do tempo. Para isolar os sinais das ondas, filtramos a série temporal de cada boia com 2 filtros do tipo gaussiano, um com 49 dias e outro com 21 dias. O filtrado para ORCs foi subtraído da série original antes da obtenção do sinal das OITs, semelhantemente ao procedimento adotado aos dados obtidos por satélites. Porém, os mapas sinóticos provenientes de sensoriamento remoto permitem obtenção de sinais propagantes, no caso para oeste, o que não é possível com as medidas pontuais das boias PIRATA. O sinal que se obtém neste caso pode ou não ter propagação, em qualquer direção e o comprimento de onda não pode ser especificado.

\subsubsection{Transformada de Radon}

Neste trabalho, os padrões propagantes para oeste com período de 21 dias e comprimento de onda de $1000 \mathrm{~km}$ denominam-se OITs e os padrões com período de 49 dias e comprimento de onda de $1500 \mathrm{~km}$ são referidos como ORCs. Tendo em vista a grande variabilidade encontrada na literatura a respeito dos parâmetros do que é genericamente identificado como OITs, o presente trabalho identificou estas oscilações com base na teoria de ondas equatoriais para possivelmente distinguir observacionalmente o que são OITs e ORCs. Para isso, foi necessário calcular as frequências e números de onda de cada diagrama Hovmöller. Isto foi feito através da transformada de Radon modificada.

A transformada de Radon estima a velocidade de fase $\left(c_{p}\right)$ pela inclinação dos padrões propagantes nos diagramas Hovmöller e o comprimento de onda $(L)$ e o período (T) por mínimos quadrados. Para isso, cada diagrama é dividido em blocos de tamanho 
$2 L \times 2 T$. O método então rotaciona o sistema de coordenadas da matriz de autocorrelação de cada bloco até que os padrões se alinhem com o eixo vertical. A matriz de autocorrelação é utilizada em substituição ao dado original porque contém a mesma informação espectral e erros randômicos consideravelmente menores. $\mathrm{O}$ alinhamento é ótimo quando a variabilidade projetada no eixo horizontal é maximizada. Uma vez que $c_{p}=L / T$, a velocidade de fase é a tangente do ângulo de rotação $(\theta)$. A estimativa do erro de $c_{p}$ é baseada no erro de $\theta$, que quantifica quão bem definido é o máximo da variabilidade. Como o cálculo de $c_{p}$ é mais acurado que o de $L$ e $T$, por usar mais pontos, e a estimativa de $T$ é mais confiável que a de $L$, por observação empírica, substitui-se o comprimento de onda por $L=T c_{p}$. A descrição completa do método encontra-se no trabalho de Polito e Cornillon (1997).

O método modificado da transformada de Radon calcula também o erro associado ao ajuste de mínimos quadrados, que resulta em $L$ e $T$, num intervalo de $95 \%$ de confiança. O cálculo do erro baseia-se no erro do instrumento de medida de cada variável. De acordo com as especificações do radiômetro de temperatura, o erro na medida da TSM é de $0,58{ }^{\circ} \mathrm{C}$ para condições de vento intenso $(0,86 \mathrm{~m} / \mathrm{s})$ e de $0,3{ }^{\circ} \mathrm{C}$ quando há ausência de vento. Neste trabalho utilizamos um erro de $0,58{ }^{\circ} \mathrm{C}$ para a TSM e de $30 \mathrm{~mm}$ para os dados de $\eta$, que é o erro nominal das medidas pontuais do TOPEX/Poseidon. Trata-se, portanto, de uma estimativa bastante conservadora dos erros.

Os valores de $T$ e $L$ de cada diagrama de dispersão foram calculados como as médias de $T$ e $L$ dos blocos $2 L \times 2 T$. Somente os blocos cujo desvio padrão foi de 1,5 vezes do desvio padrão do Hovmöller foram considerados no cálculo. Estabelecemos este critério para que apenas os sinais de amplitude relativamente grande fossem contabilizados nas estimativas de $T$ e $L$. Assim, obtivemos o número de onda $k=2 \pi / L$ e a frequência $\omega=2 \pi / T$ do sinal propagante de cada Hovmöller. Como forma de comparação com as previsões teóricas para efeito de classificação das ondas, representamos estes parâmetros no diagrama de dispersão das ondas equatoriais, descrito na seção a seguir. 


\subsubsection{Diagramas de dispersão}

Para movimentos próximo ao Equador, podemos utilizar a aproximação do plano beta equatorial. Nesta aproximação, o parâmetro de Coriolis $f$ é definido como o produto entre uma constante $(\beta)$ e a distância a partir do Equador $y: f=\beta y$. A aproximação é válida em latiudes menores que $30^{\circ} \mathrm{e}$, mesmo nas latitudes limites, o erro é de apenas 14\% (GILL, 1982). Nesta aproximação, $\cos \varphi \approx 1 \mathrm{e}$, portanto, $\beta$ é dado por $\beta=2 \omega / r=$ $2,28 \cdot 10^{-11} \mathrm{~m}^{-1} \mathrm{~s}^{-1}$, onde $\omega=7,27 \cdot 10^{-5} \mathrm{~s}^{-1}$ é a velocidade angular de rotação da Terra e $r=6,371 \cdot 10^{6} \mathrm{~m}$ é o raio médio da Terra. Considerando o modelo linear de águas rasas para um oceano invíscido de 1,5 camadas no plano $\beta$ equatorial, a relação de dispersão das ondas equatoriais, segundo Cane e Sarachik (1976); Gill (1982), Philander (1990), é dada por:

$$
\frac{\omega^{2}}{c^{2}}-k^{2}-\frac{\beta k}{\omega}=(2 n+1) \frac{\beta}{c}
$$

onde $\omega$ é a frequência, $k$ é o número de onda zonal, $\beta$ é $2,28 \cdot 10^{-11} \mathrm{~m}^{-1} \mathrm{~s}^{-1}$, $c$ é a velocidade de fase das ondas de gravidade e $n$ é o modo meridional. Modos meridionais são estruturas de oscilação estacionária confinadas meridionalmente pelo guia de ondas equatorial. No modelo considerado, $c=\sqrt{g^{\prime} H 1}$, onde $g^{\prime}$ é a gravidade reduzida e $H 1$ é a espessura da camada superior, isto é, a profundidade da picnoclina. Os valores destes parâmetros foram obtidos da seção longitudinal de média climatológica da densidade potencial referenciada na superfície (Sigma-0) do World Ocean Atlas 2009 (WOA09) em 2,5 $5^{\circ} \mathrm{N}$ (Figura 9]. Dessa forma, definimos $H 1=70 \mathrm{~m} \mathrm{e} g^{\prime}=\left(\left(\rho_{2}-\rho_{1}\right) / \rho_{1}\right) g=0,03 \mathrm{~m} \mathrm{~s}^{-2}$, onde $\rho_{1}$ é a densidade da camada superior, $\rho_{2}$ é a densidade da camada inferior e $g$ é a aceleração da gravidade.

A equação 1 representa a relação de dispersão dos modos oscilatórios aprisionados no Equador. Esta equação possui 4 soluções que descrevem conjuntos infinitos e discretos que relacionam $\omega$ e $k$, denominados ondas de gravidade, ondas de Rossby, onda de Rossby-gravidade e onda de Kelvin. As soluções da relação de dispersão 1 para $n=-1,0,1,2$ e 3 podem ser visualizadas no diagrama de dispersão da Figura 10 , no qual estão omitidas as frequências negativas. 


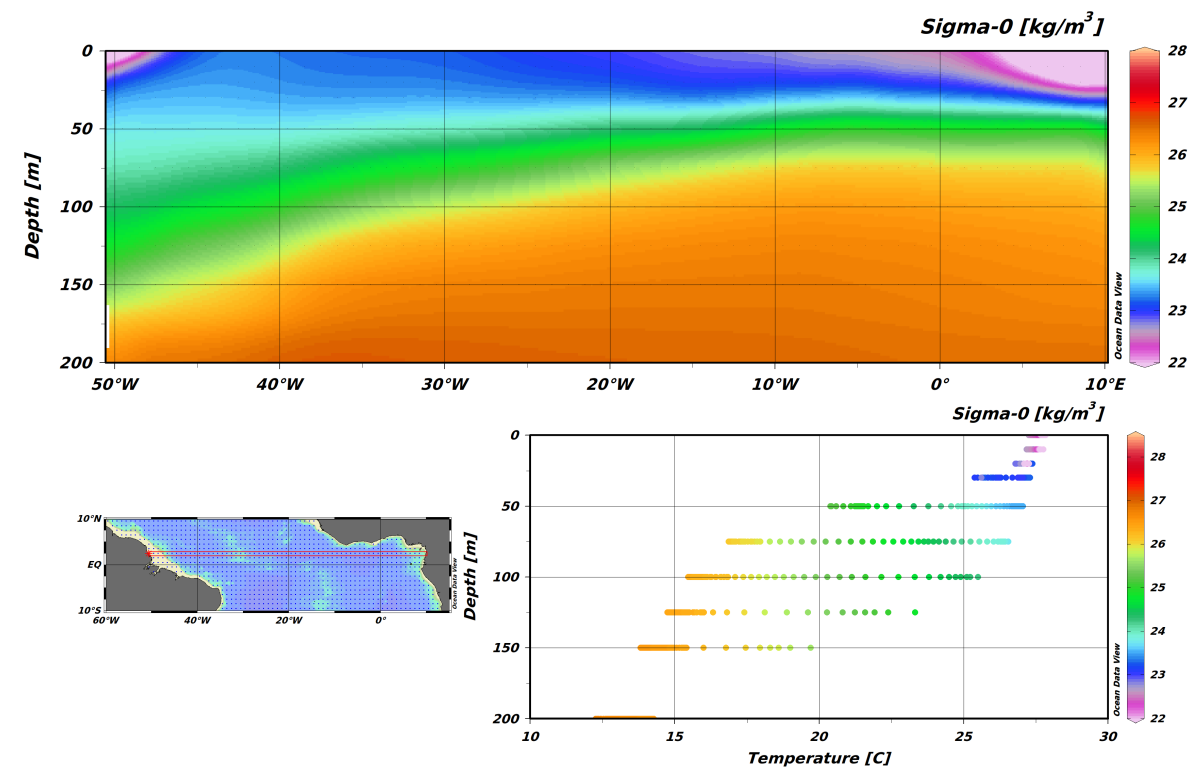

Figura 9: Seção longitudinal em $2,5^{\circ} \mathrm{N}$ de densidade potencial referida na superfície do WOA09.

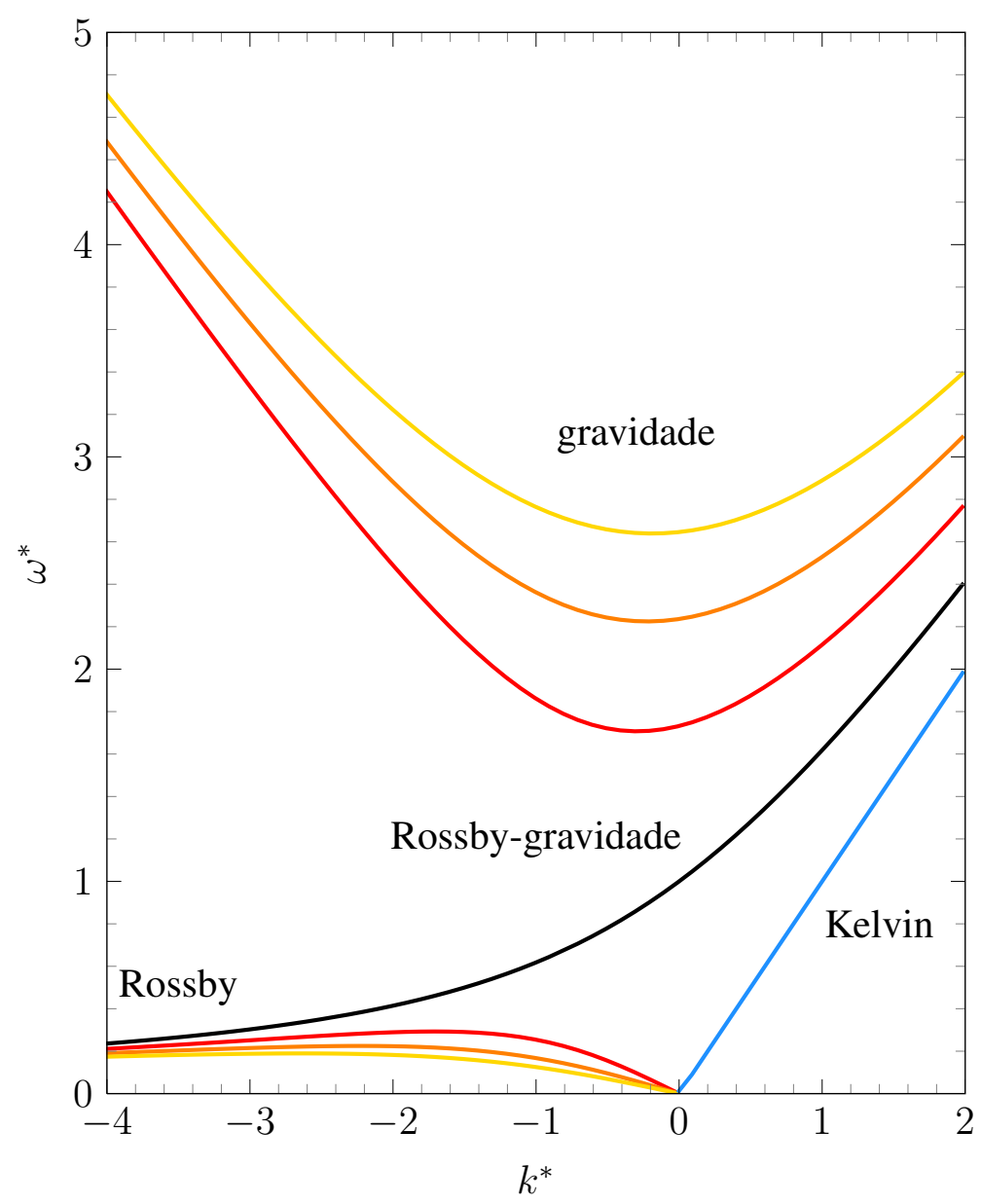

Figura 10: Relação de dispersão das ondas equatoriais para $n=-1$ (linha azul), $n=0$ (linha preta), $n=1$ (linha vermelha), $n=2$ (linha laranja) e $n=3$ (linha amarela). A unidade da frequência $\omega^{*}$ é $\sqrt{\beta c}$ e a unidade do número de onda zonal $k^{*}$ é o inverso do raio de deformação de Rossby $(\sqrt{c / \beta})$. [De Philander (1990); Cane e Sarachik (1976)] 
A onda de Kelvin é a solução para $n=-1$, de acordo com a equação 2 . A solução para $n=0$, representada pela equação 3 , é denominada onda de Rossbygravidade, ou OIT.

$$
\begin{gathered}
\omega=k c . \\
\frac{\omega}{c}-k-\frac{\beta}{\omega}=0
\end{gathered}
$$

Para as ondas de gravidade e de Rossby, existem $n$ soluções possíveis, para $n \geq 1$. Os modos ímpares $(n=1,3,5 \ldots)$ são simétricos em relação ao Equador e os modos pares $(n=2,4,6 \ldots)$ são antissimétricos. A Figura 10 , mostra que estas soluções são relativamente bem distintas e, por isso, a equação 1 pode ser escrita em suas formas aproximadas para representar as relações de dispersão destes conjuntos de onda separadamente. Para as ondas de gravidade, o termo $-\beta k / \omega$ é desprezível e a equação 1 pode ser aproximada para a denominada relação de dispersão das ondas de Poincaré (ou ondas de gravidade) confinadas no Equador:

$$
\omega^{2}=(2 n+1) \beta c+k^{2} c^{2}
$$

Nos ramos inferiores do diagrama de dispersão da Figura 10 , o termo $\omega^{2} / c^{2}$ é pequeno, e a equação 1 pode ser aproximada para a relação de dispersão das ondas de Rossby (ou ondas planetárias) aprisionadas no Equador:

$$
\omega=-\frac{\beta k}{k^{2}+(2 n+1) \lambda^{-2}}
$$

onde $\lambda^{2}$ é o quadrado do raio de deformação equatorial, igual a $c / \beta$.

Devido à forte intensidade das correntes predominantemente zonais na região tropical, a frequência das ondas zonalmente propagantes pode ser alterada via efeito Doppler. Philander (1979) mostrou que as ondas de Rossby e o ramo de Rossby das ondas de Rossby-gravidade são fortemente influenciadas pela SE, pois a velocidade de 
fase é comparável à máxima intensidade da corrente. Segundo Philander (1990), a relação de dispersão das ondas de Rossby influenciadas por um fluxo zonal é dada pela fórmula a seguir:

$$
\omega=\frac{U k^{3}-\beta k+k U_{y y}}{k^{2}+(2 n+1) \lambda^{-2}}
$$

onde $U=U(y)$ é o fluxo zonal na superfície em função da latitude e o subscrito yy indica segunda derivada em $y$.

O perfil meridional de $U$ utilizado para calcular a frequência das ondas de Rossby modificada pelo efeito Doppler pode ser visto na Figura 11. Este perfil médio baseia-se em dados de velocidade de superfície do Surface Velocity Program (SVP), mostrados na Figura 12, que combina dados de velocidade geostrófica superficial obtidas a partir da anomalia de altura medida por satélites altimétricos com dados de velocidade in situ de derivadores Lagrangianos. Este perfil é semelhante ao perfil de corrente zonal de Philander (1978), porém os valores das correntes neste caso são menores.
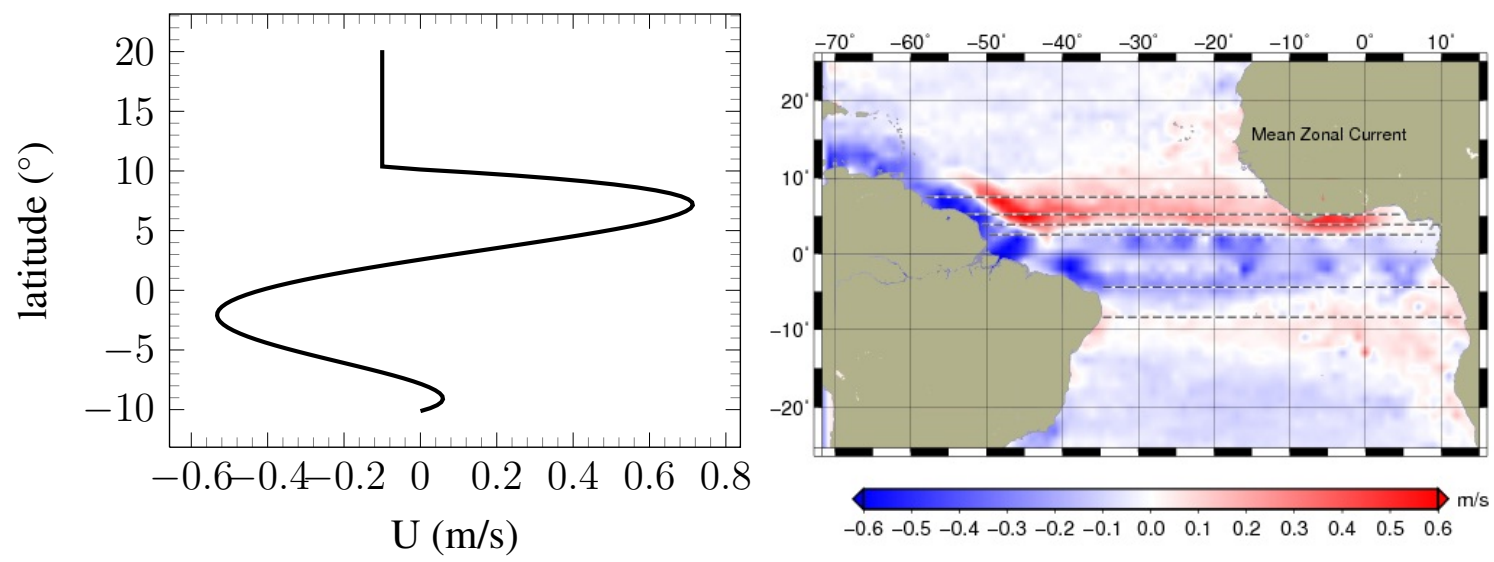

Figura 11: Perfil meridional da corrente zonal Figura 12: Média da componente zonal da veconsiderado no cálculo da frequência das ondas locidade geostrófica do SVP, em m/s. de Rossby modificada pelo efeito Doppler. 


\subsubsection{Regressão e correlação}

Para quantificar a influência da TSM sobre os parâmetros atmosféricos, utilizamos o método de regressão de um ponto, semelhantemente aos trabalhos de Hashizume et al. (2001), Caltabiano et al. (2005), Wu e Bowman (2007a), Neste método, assumimos que todos os pontos da região de estudo de cada campo atmosférico estão linearmente relacionados a um índice de atividade das ondas calculado num ponto de referência. Assim como no trabalho de Wu e Bowman (2007a), este índice foi definido como a anomalia de TSM filtrada no ponto de máxima de variância de TSM. O método ajusta uma relação linear entre um dos campos atmosféricos $F_{f}(x, y, t)$ e a anomalia de TSM filtrada no ponto de referência $T_{f 0}(t)=T_{f}\left(x_{0}, y_{0}, t\right)$. Assumimos que a média das anomalias filtradas de TSM é nula, de forma que a regressão pode ser dada por:

$$
F_{f}=b T_{f 0}
$$

onde o coeficiente de regressão linear $b$ é calculado por mínimos quadrados:

$$
b(x, y)=\frac{\sum_{i=1}^{N} F_{f}\left(x, y, t_{n}\right) T_{f 0}\left(t_{n}\right)}{\sum_{i=1}^{N} T_{f 0}^{2}\left(t_{n}\right)} .
$$

O coeficiente de regressão linear $b$ quantifica a alteração da variável atmosférica em relação à TSM assumindo que toda a variabilidade dessa deve-se à TSM. Assim, para definir quão linearmente a variável atmosférica se relaciona com a TSM e quantificar quanto da variabilidade atmosférica deve-se a esta, calculamos o coeficiente de correlação $(r)$ da regressão:

$$
r=\frac{S_{f t}(x, y)}{\sqrt{S_{t t}(x, y) S_{f f}(x, y)}}
$$

onde

$$
S_{f t}(x, y)=\sum_{n=1}^{N}\left(\left(F_{f}\left(x, y, t_{n}\right)-\overline{F_{f}\left(x, y, t_{n}\right)}\right) T_{f 0}\left(t_{n}\right)\right)
$$




$$
\begin{gathered}
S_{t t}(x, y)=\sum_{n=1}^{N} T_{f_{0}}^{2}\left(t_{n}\right) \\
S_{f f}(x, y)=\sum_{n=1}^{N}\left(F_{f}\left(x, y, t_{n}\right)-\overline{F_{f}\left(x, y, t_{n}\right)}\right)^{2}
\end{gathered}
$$

A regressão de um mapa em relação a um ponto de variabilidade conhecida implica em selecionar a variabilidade temporal de todo o mapa correlacionada ao fenômeno de interesse. O método é útil pois possibilita quantificar a relação entre a TSM na região de ocorrência das ondas e as variáveis atmosféricas em regiões remotas, como na ZCIT. Fica implícita nesta metodologia a ideia que as anomalias de TSM na banda espectral das OITs e ORCs oceânicas são as forçantes dos sinais atmosféricos. A sobreposição dos mapas de regressão obtidos permite visualizar os processos físicos que relacionam as variáveis atmosféricas na banda das OITs e ORCs às anomalias de TSM no ponto de referência. Assim, a fim de discorrer a respeito dos mecanismos de interação ar-mar sobre estas anomalias, calculamos a correlação com lag (atraso) espacial, na direção zonal, de acordo com a fórmula a seguir:

$$
c(x)=\frac{1}{n \sigma_{b T} \sigma_{b F}} \cdot \sum_{i=1}^{n}\left(b_{T i}-\overline{b_{T}}\right) \cdot\left(b_{F i+x}-\overline{b_{F}}\right),
$$

onde $c(x)$ é a correlação com $x$ unidades zonais de defasagem, $n$ é o atraso máximo (1000 km para as OITs e $1500 \mathrm{~km}$ para as ORCs), $b_{T}$ e $b_{F}$ são os coeficientes de regressão da TSM e das variáveis $V, P$ e $\vec{\nabla} \cdot \vec{\tau}$ em relação à TSM, respectivamente, $\sigma_{b T}$ e $\sigma_{b F}$ são os desvios padrão dos respectivos coeficientes de regressão e $\overline{b_{T}}$ e $\overline{b_{F}}$ são as médias dos mesmos coeficientes. 


\section{Resultados e discussão}

\subsection{Determinação da posição e intensidade da ZCIT}

As Figuras 13 e 14 mostram os mapas de vapor d'água integrado na atmosfera $(V)$ e da componente de larga escala do divergente da tensão de cisalhamento do vento $(\vec{\nabla} \cdot \vec{\tau})$ para o ano de 2004. As linhas tracejadas limitam a região onde os valores de $V$ são máximos e definem a região da ZCIT para cada mês do ano. Durante os meses de janeiro a abril, a ZCIT localiza-se mais ao sul, entre $6^{\circ} \mathrm{S}$ e $6^{\circ} \mathrm{N}$. Posições mais ao norte, entre 0 e $17^{\circ} \mathrm{N}$, são observadas nos meses de junho a outubro. Também é possível observar posicionamentos intermediários, quando a ZCIT transita entre as latitudes extremas. Isto ocorre em maio, quando a ZCIT migra do sul para o norte, e em novembro e dezembro quando esta transita para sul. Estes resultados estão de acordo com Xavier et al. (2000), que observaram posições ao norte entre junho e dezembro e ao sul entre janeiro e maio. A migração da ZCIT também pode ser observada na Tabela 1] que mostra os valores médios das latitudes extremas da ZCIT para cada mês do ano.

A grande quantidade de vapor d'água característica da ZCIT está associada aos movimentos verticais ascendentes induzidos pela convergência do vento em baixos níveis. Dessa forma, esperamos que as regiões de máximo $V$ coincidam com as regiões onde o $\vec{\nabla} \cdot \vec{\tau}$ seja negativo e mínimo. Nos mapas de $\vec{\nabla} \cdot \vec{\tau}$ para o ano de 2004 , as linhas tracejadas nas Figura 13 e 14 correspondem à ZCIT definida pelos dados de $V$. A zona onde o $\vec{\nabla} \cdot \vec{\tau}$ é mínimo fica a menos de $2^{\circ}$ dos máximos de $V$. Levando em conta o desvio padrão dos limites da ZCIT na Tabela 1, verificamos que as regiões de máximas convergência do vento e geração de vapor d'água são bastante coincidentes. Entretanto, nos meses de maio, junho e julho, a máxima convergência encontra-se ao sul dos máximos de $V$, apesar de haver valores negativos de $\vec{\nabla} \cdot \vec{\tau}$ na ZCIT. Nestes meses, em especial, mesmo a componente de larga escala do divergente do vento apresentou alta variabilidade.

A Tabela 1 mostra as latitudes ocupadas pela ZCIT para cada mês do ano e os valores médios mensais de vapor d'água integrado e convergência da tensão de cisalhamento do vento $(\vec{\nabla} \cdot \vec{\tau}<0)$. De acordo com a Tabela, durante o período de estudo, a ZCIT 
pode ser observada entre $6^{\circ} \mathrm{S}$ e $17^{\circ} \mathrm{N}$. Dessa forma, definimos como a área de estudo deste trabalho a região do oceano Atlântico compreendida entre $10^{\circ} \mathrm{S}$ e $20^{\circ} \mathrm{N}$. Nesta região, a intensidade da ZCIT pode ser caracterizada por valores da componente de larga escala da convergência da tensão de cisalhamento do vento de cerca de $0,5 \cdot 10^{-7} \mathrm{~kg} \mathrm{~m}^{-2} \mathrm{~s}^{-2}$ e por valores típicos de vapor d'água integrado na atmosfera próximos a $50 \mathrm{~mm}$.

Os resultados mostram que a presença da ZCIT é favorecida no hemisfério Norte. Segundo Hastenrath (1984), é a distribuição das anomalias de TSM que modula a posição da ZCIT. Portanto, o campo de TSM deve apresentar uma heterogeneidade inter-hemisférica. A assimetria da localização da ZCIT em relação ao Equador foi estudada por Philander et al. (1996), De acordo com Philander et al. (1996), o motivo pelo qual as águas quentes se localizam ao norte do Equador e não ao sul está associado a dois fatores. O primeiro deles envolve processos de instabilidades e feedbacks que podem tornar uma perturbação inicialmente simétrica, assimétrica. No entanto, ambos os hemisférios poderiam ser favorecidos. O segundo fator está associado à geometria dos continentes e é este que favorece o hemisfério Norte com as anomalias quentes de TSM e, consequentemente, com a ZCIT. No caso do Atlântico, o bojo formado pelo continente africano na região equatorial torna os ventos assimétricos. Esta assimetria é responsável pela distribuição de TSM, com águas quentes no hemisfério Norte e frias no Sul. Nobre e Shukla (1996) também sugeriram que a componente meridional do vento fora do Equador é a responsável pela formação do gradiente meridional das anomalias de TSM que desloca a ZCIT. 

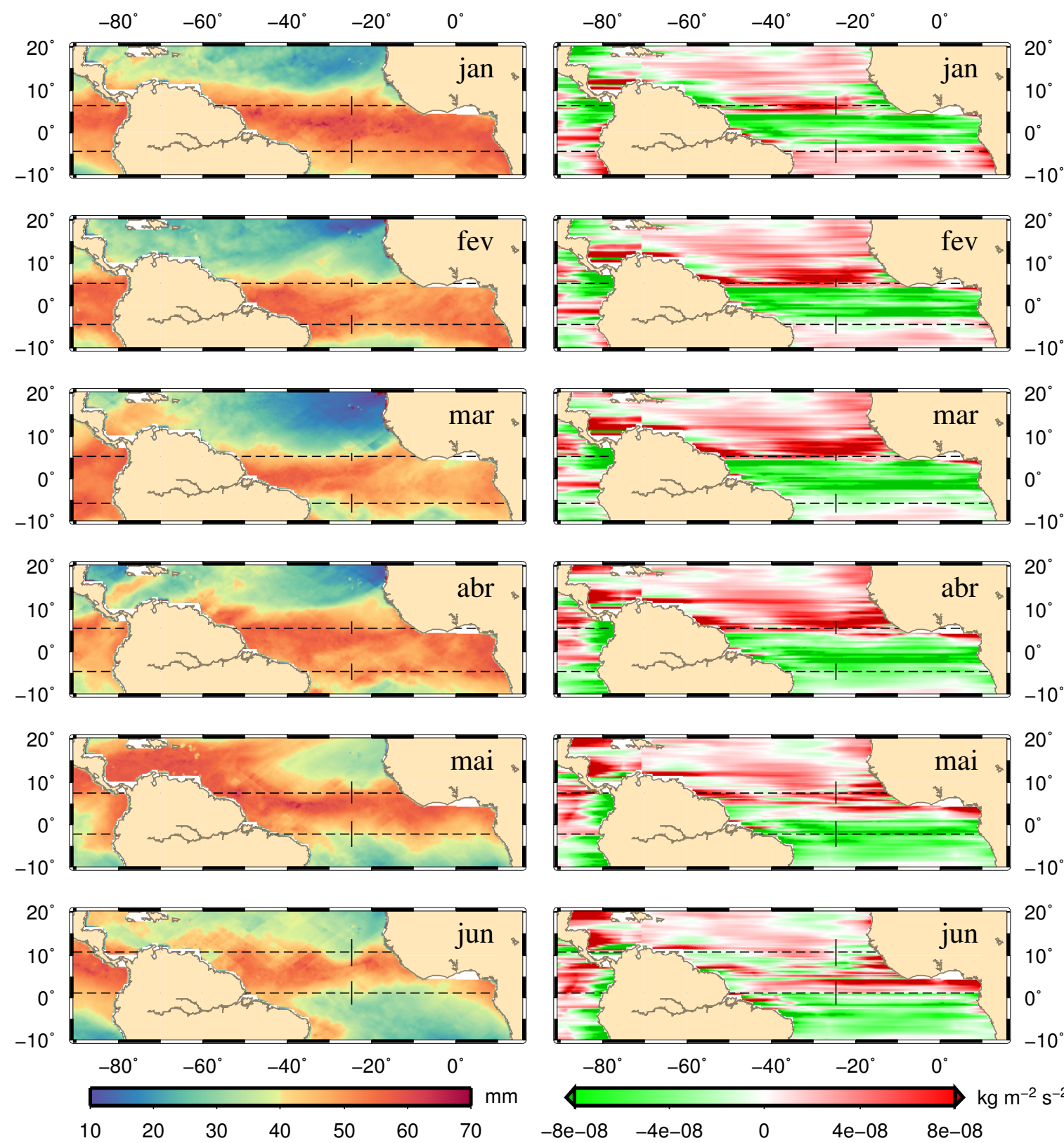

Figura 13: Vapor d'água integrado na atmosfera ( $V$, à esquerda), em mm, e divergente da tensão de cisalhamento do vento $\left(\vec{\nabla} \cdot \vec{\tau}\right.$, à direita), em $\mathrm{kg} \mathrm{m}^{-2} \mathrm{~s}^{-2}$, em 10 de janeiro, 14 de fevereiro, 13 de março, 17 de abril, 22 de maio e 26 de junho de 2004. As linhas horizontais tracejadas e as linhas verticais pretas representam as médias e os desvios padrão mensais dos limites da ZCIT, respectivamente, definidos pelos máximos de $V$. 


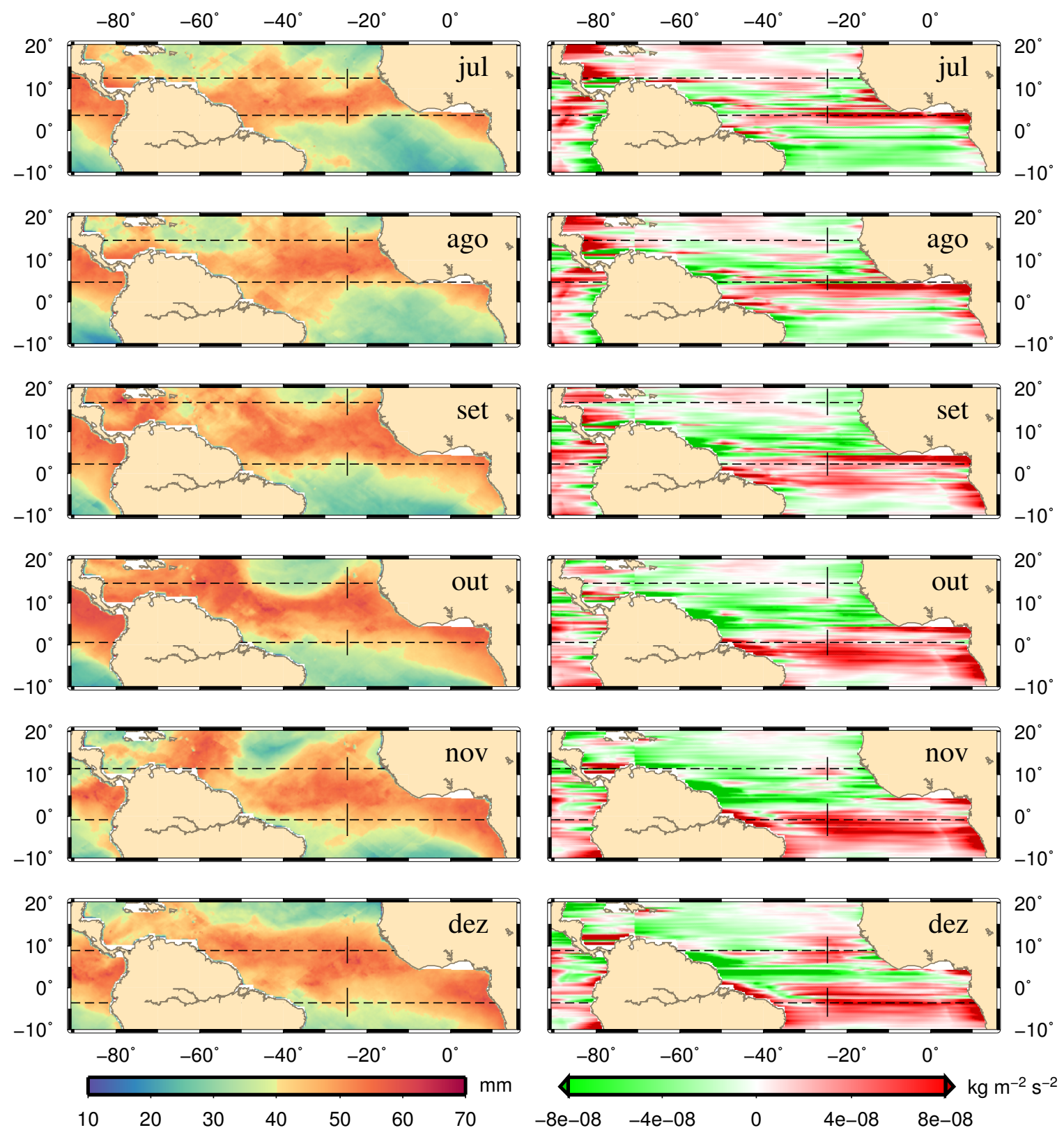

Figura 14: Similar à Figura 13 em 10 de julho, 7 de agosto, 11 de setembro, 9 de outubro, 13 de novembro e 18 de dezembro de 2004. 
Tabela 1: Médias e desvios padrão mensais das latitudes máximas e mínimas da ZCIT de 1998 a 2010 com base nos dados de $V$ e valores médios mensais de $V(\bar{V})$ e $\vec{\nabla} \cdot \vec{\tau}<0(\vec{\nabla} \cdot \vec{\tau}<0)$ na região da ZCIT.

\begin{tabular}{ccccc}
\hline & máxima & mínima & $\begin{array}{c}\overline{\vec{\nabla} \cdot \vec{\tau}<0} \\
\left(10^{-7} \cdot \mathrm{kg} \mathrm{m}^{-2} \mathrm{~s}^{-2}\right)\end{array}$ & $\bar{V}(\mathrm{~mm})$ \\
\hline janeiro & $(6 \pm 2)^{\circ} \mathrm{N}$ & $(5 \pm 3)^{\circ} \mathrm{S}$ & $-0,51$ & 49,59 \\
feveiro & $(5 \pm 1)^{\circ} \mathrm{N}$ & $(5 \pm 2)^{\circ} \mathrm{S}$ & $-0,52$ & 50,55 \\
março & $(5 \pm 1)^{\circ} \mathrm{N}$ & $(6 \pm 2)^{\circ} \mathrm{S}$ & $-0,48$ & 51,43 \\
abril & $(6 \pm 2)^{\circ} \mathrm{N}$ & $(5 \pm 2)^{\circ} \mathrm{S}$ & $-0,49$ & 53,70 \\
maio & $(8 \pm 3)^{\circ} \mathrm{N}$ & $(2 \pm 3)^{\circ} \mathrm{S}$ & $-0,46$ & 52,96 \\
junho & $(11 \pm 3)^{\circ} \mathrm{N}$ & $(1 \pm 3)^{\circ} \mathrm{N}$ & $-0,38$ & 50,32 \\
julho & $(12 \pm 2)^{\circ} \mathrm{N}$ & $(4 \pm 2)^{\circ} \mathrm{N}$ & $-0,42$ & 49,66 \\
agosto & $(15 \pm 3)^{\circ} \mathrm{N}$ & $(5 \pm 2)^{\circ} \mathrm{N}$ & $-0,46$ & 50,10 \\
setembro & $(17 \pm 3)^{\circ} \mathrm{N}$ & $(2 \pm 3)^{\circ} \mathrm{N}$ & $-0,46$ & 48,39 \\
outubro & $(15 \pm 4)^{\circ} \mathrm{N}$ & $(0 \pm 3)^{\circ}$ & $-0,50$ & 48,96 \\
novembro & $(11 \pm 3)^{\circ} \mathrm{N}$ & $(1 \pm 4)^{\circ} \mathrm{S}$ & $-0,53$ & 49,75 \\
dezembro & $(9 \pm 3)^{\circ} \mathrm{N}$ & $(4 \pm 4)^{\circ} \mathrm{S}$ & $-0,53$ & 48,56 \\
\hline
\end{tabular}




\subsection{Caracterização das OITs e ORCs no tempo e no espaço}

A Figura 15 mostra a distribuição da temperatura da superfície do mar (a-f) e da anomalia da altura (g-l) de $10^{\circ} \mathrm{S}$ a $20^{\circ} \mathrm{N}$ no oceano Atlântico entre maio e outubro de 2004. Durante este período, é possível observar o desenvolvimento de um padrão meandrante nos dados de TSM entre $5^{\circ} \mathrm{S}$ e $5^{\circ} \mathrm{N}$ que correpondem às OITs. Estas ondas começam a se desenvolver em maio (Figura 15 (a)), concomitante ao estabelecimento da língua fria na região, e se tornam bastante robustas entre junho e agosto (Figura 15 (bd)), o que também foi observado por Liu et al. (2000); Caltabiano et al. (2005); Wu e Bowman (2007a). De maio e agosto, é possível observar que a anomalia da altura da superfície do mar apresenta valores negativos na região de ocorrência das OITs (Figura 15 $(g-j))$, com a formação de um padrão de dipolo bem definido em junho e julho (Figura 15 (h-i)). A anomalia da altura da superfície do mar é resultado dos processos de expansão térmica e contração halina. Uma vez que as anomalias de salinidade tem papel secundário no Pacífico equatorial (SATO et al., 2000), os valores de negativos de $\eta$ devem estar relacionados às TSM, devido ao surgimento da língua fria, via processo de contração térmica. A partir de setembro e outubro, o padrão ondulatório na TSM se torna pouco perceptível (Figura 15 (e-f)), o padrão de dipolo nos dados de $\eta$ desaparece e os valores entre $5^{\circ} \mathrm{S}$ e $5^{\circ} \mathrm{N}$ passam a ser positivos (Figura $15(\mathrm{k}-1)$ ), o que pode ser explicado pelo aumento da TSM na região (Figura $15(\mathrm{k}-1)$ ).

O desenvolvimento das ondas de maio a outubro foi observado em todos os anos do período de estudo e, de uma forma geral, as maiores amplitudes ocorrem de junho a agosto. Entretanto, foi observada variabilidade interanual, mas que não é o objetivo de estudo deste trabalho. Uma breve discussão a respeito da variabilidade das anomalias de TSM associadas às OITs nesta escala encontra-se no apêndice B.

As mesmas distribuições espaciais e temporais da TSM podem ser vistas nos dados filtrados, como mostram os diagramas Hovmöller das ORCs e OITs (Figura 16. Nestas Figuras estão representados os anos de 2003 a 2005 apenas para facilitar a visualização dos sinais propagantes. Os diagramas Hovmöller para o período completo de estudo encontram-se no apêndice C. Nas latitudes $1^{\circ} \mathrm{S}, 0$ e $2^{\circ} \mathrm{N}$ as maiores amplitudes 


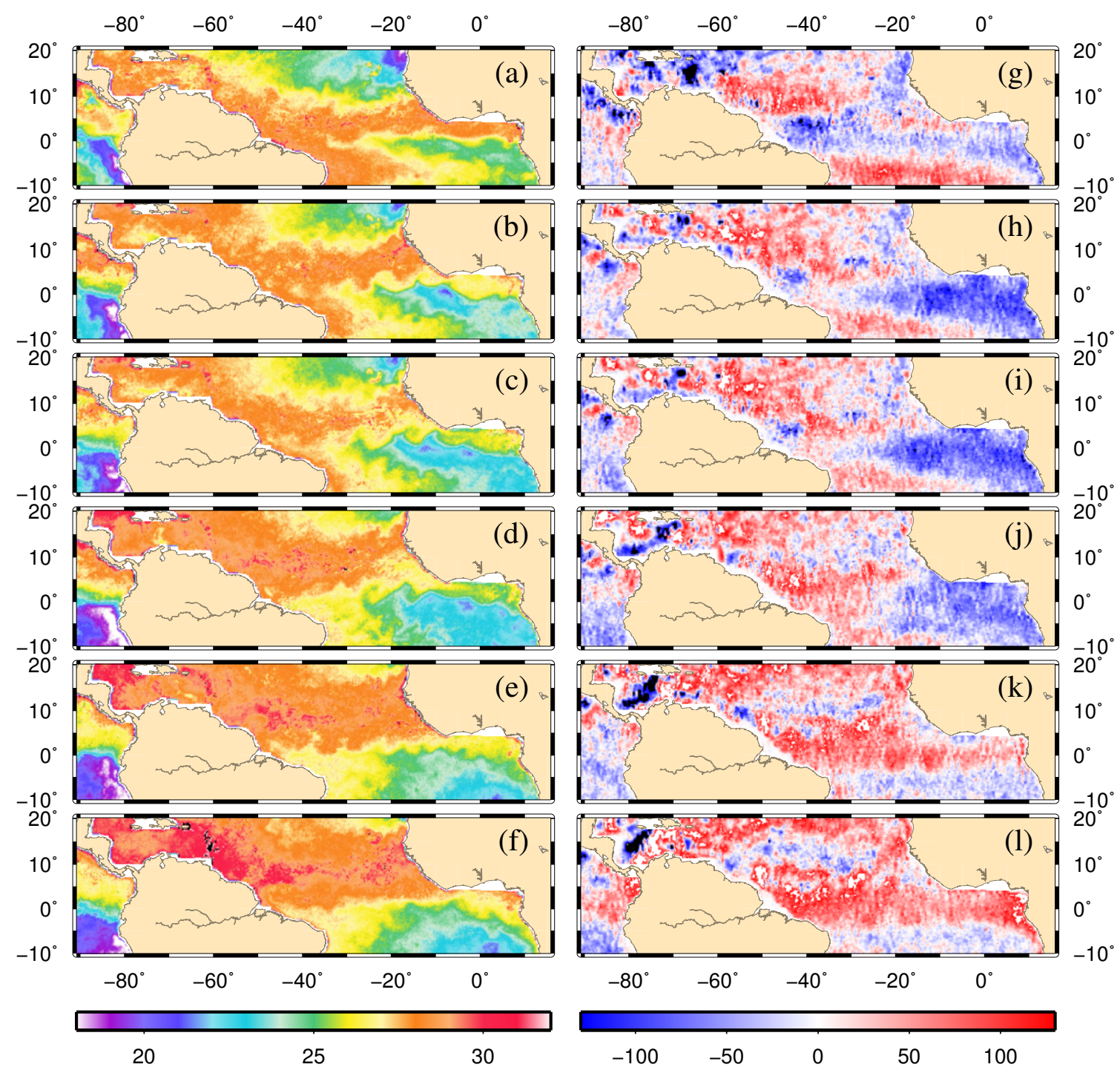

Figura 15: Temperatura da superfície do $\operatorname{mar}(\mathrm{a}, \mathrm{b}, \mathrm{c}, \mathrm{d}, \mathrm{e}, \mathrm{f})$, em ${ }^{\circ} \mathrm{C}$, e anomalia da altura da superfície do mar (g, h, i, j , k, l), em mm, em 22 de maio, 26 de junho, 10 de julho, 7 de agosto, 11 de setembro e 9 de outubro de 2004, respectivamente. 
entre maio e outubro são observadas na porção central da bacia do Atlântico. O favorecimento do hemisfério Norte deve estar associado à assimetria da localização da língua fria. Se a ressurgência equatorial promove o desenvolvimento das ondas por instabilidades baroclínicas (YU et al., 1995), estas terão as maiores amplitudes onde a intrusão for mais intensa.

Uma vez que o desenvolvimento das OITs está associado à língua fria, quando as ondas estão mais pronunciadas nos dados de TSM, a ZCIT ocupa posições mais ao norte, que é a região onde a TSM é mais elevada. Para os meses de maio a outubro, período em que se observa o desenvolvimento das ondas na TSM, a ZCIT ocupa as latitudes $(2 \pm 3)^{\circ} \mathrm{S}$ a $(15 \pm 4)^{\circ} \mathrm{N}$ (Tabela 1). Para os meses de junho a agosto, período de maior amplitude das ondas nos dados de TSM, a ZCIT encontra-se entre $(1 \pm 3)^{\circ} \mathrm{N} \mathrm{e}(15 \pm 3)^{\circ} \mathrm{N}$.

Os diagramas zonal-temporal para os dados de $V$ revelam que as maiores amplitudes ocorrem no hemisfério Norte, acima de $5^{\circ} \mathrm{N}$ onde há grande quantidade de vapor d'água associada à ZCIT (Figura 17). Além disso, os diagramas mostram que a velocidade de propagação dos padrões obtidos é relativamente alta em relação às outras variáveis em estudo. Cabe notar, mais nitidamente nas ORCs (diagramas superiores na Figura 17), que os sinais propagantes com as maiores amplitudes ocorrem por volta de agosto e setembro e continuam até dezembro. Os diagramas das ORCs e OITs nos dados de $P$ (Figura 18) revelam maiores amplitudes de maio a outubro entre $1^{\circ} \mathrm{S}$ e $10^{\circ} \mathrm{N}$ e no caso dos diagramas de $\vec{\nabla} \cdot \vec{\tau}$ (Figura 19 entre $5^{\circ} \mathrm{N}$ e $10^{\circ} \mathrm{N}$. Estes padrões atmosféricos em maiores latitudes pode ser uma resposta remota da atmosfera às anomalias de TSM na ZCIT. Isto será avaliado nas seções 5.4 e 5.5 .

Em todas as latitudes, observamos que os diagramas Hovmöller das ORCs e das OITs nos dados de TSM são muitos semelhantes. Além da intermitência em baixas latitudes associada à ressurgência, a partir de $10^{\circ} \mathrm{N}$, os padrões mais desenvolvidos ocorrem na porção leste da bacia e perdem a periodicidade associada à língua fria. Os diagramas Hovmöller de $\eta$ (Figura 20) também revelam uma semelhança entre as ondas, mas cujas distribuições espaciais e temporais diferem das observadas na TSM. Maiores amplitudes de $\eta$ são encontradas de $5^{\circ} \mathrm{N}$ a $20^{\circ} \mathrm{N}$ na porção oeste da bacia oceânica. Exceto por alguns 
padrões em $2^{\circ} \mathrm{N}$, os dados de $\eta$ não parecem se relacionar à intrusão da língua fria na região próxima ao Equador.

Os dados filtrados para OITs representados nos diagramas zonais-temporais $(x, t)$ para cada latitude $y$ foram reconvertidos em mapas $(x, y)$ para cada instante de tempo $t$. A Figura 21 mostra os mapas contendo a assinatura das OITs nos dados de TSM e $\eta$ em 2004 nos meses em que as amplitudes na TSM são máximas. As maiores amplitudes de TSM ocorrem nas proximidades do Equador, entre $5^{\circ} \mathrm{N}$ e $5^{\circ} \mathrm{S}$ onde foram observados os meandros nos dados de temperatura originais obtidos por satélites (Figura 15). Cabe notar nesta Figura que não há coincidência das máximas amplitudes de TSM com as de $\eta$, como visto nos diagramas Hovmöller. A banda das OITs nos dados de $\eta$ possuem maiores amplitudes na região noroeste da área de estudo, fora da região de ocorrência das ondas na TSM, e são mais acentuadas nos últimos meses de cada ano analisado. Embora as ondas tenham sido isoladas da mesma forma, os dois conjuntos de dados, possivelmente estão mostrando fenômenos distintos. Dessa forma, uma caracterização teórica com base na localização no diagrama de dispersão do par comprimento de onda e período dos sinais nos permitirá identificar dinamicamente os padrões oscilatórios obtidos e verificar se são fenômenos distintos ou não. 

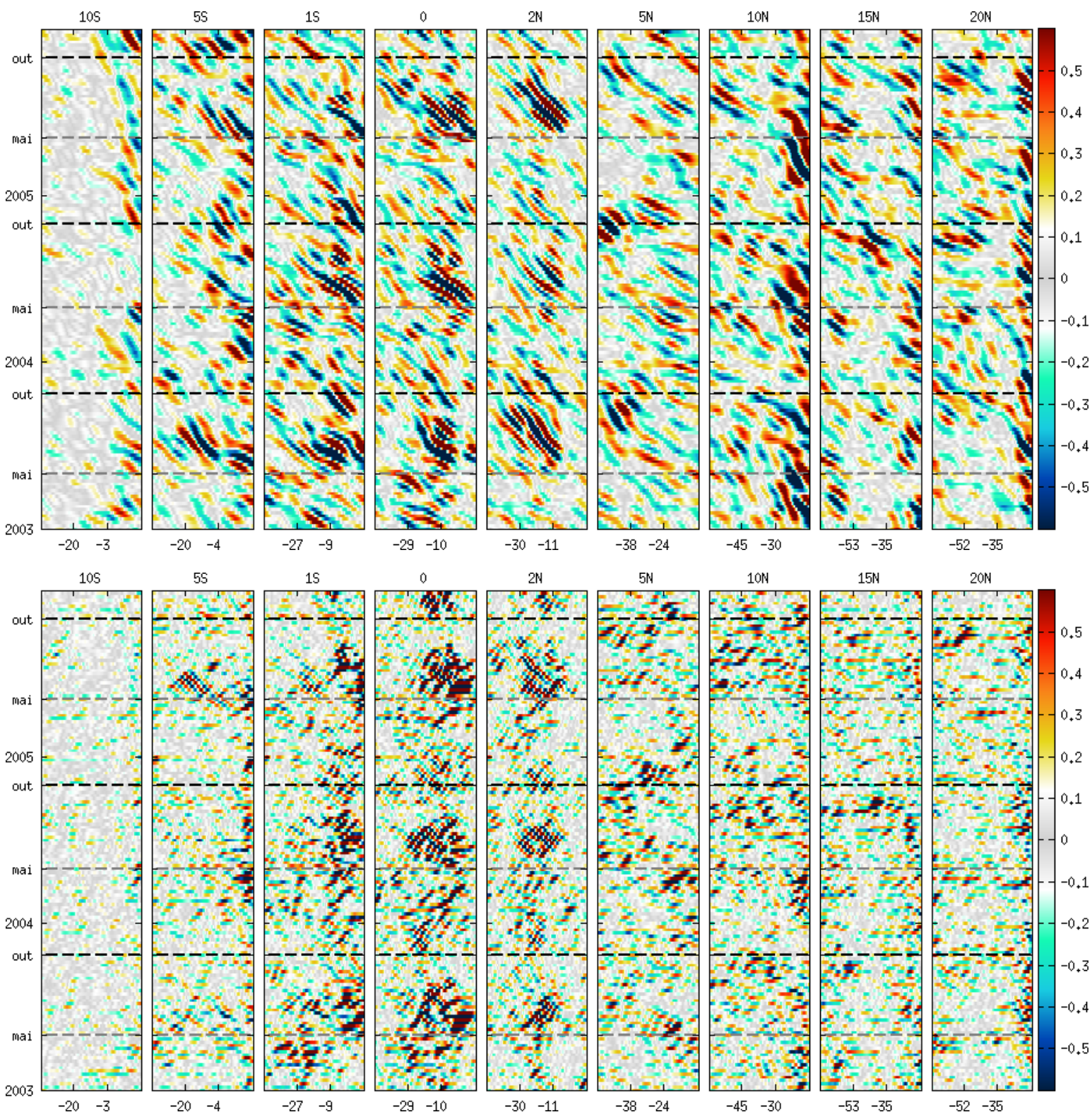

Figura 16: Diagramas Hövmöller das ORCs (superior) e OITs (inferior) nos dados de TSM de 2003 a 2005. As linhas tracejadas cinzas representam o mês de maio e as pretas o mês de outubro. 

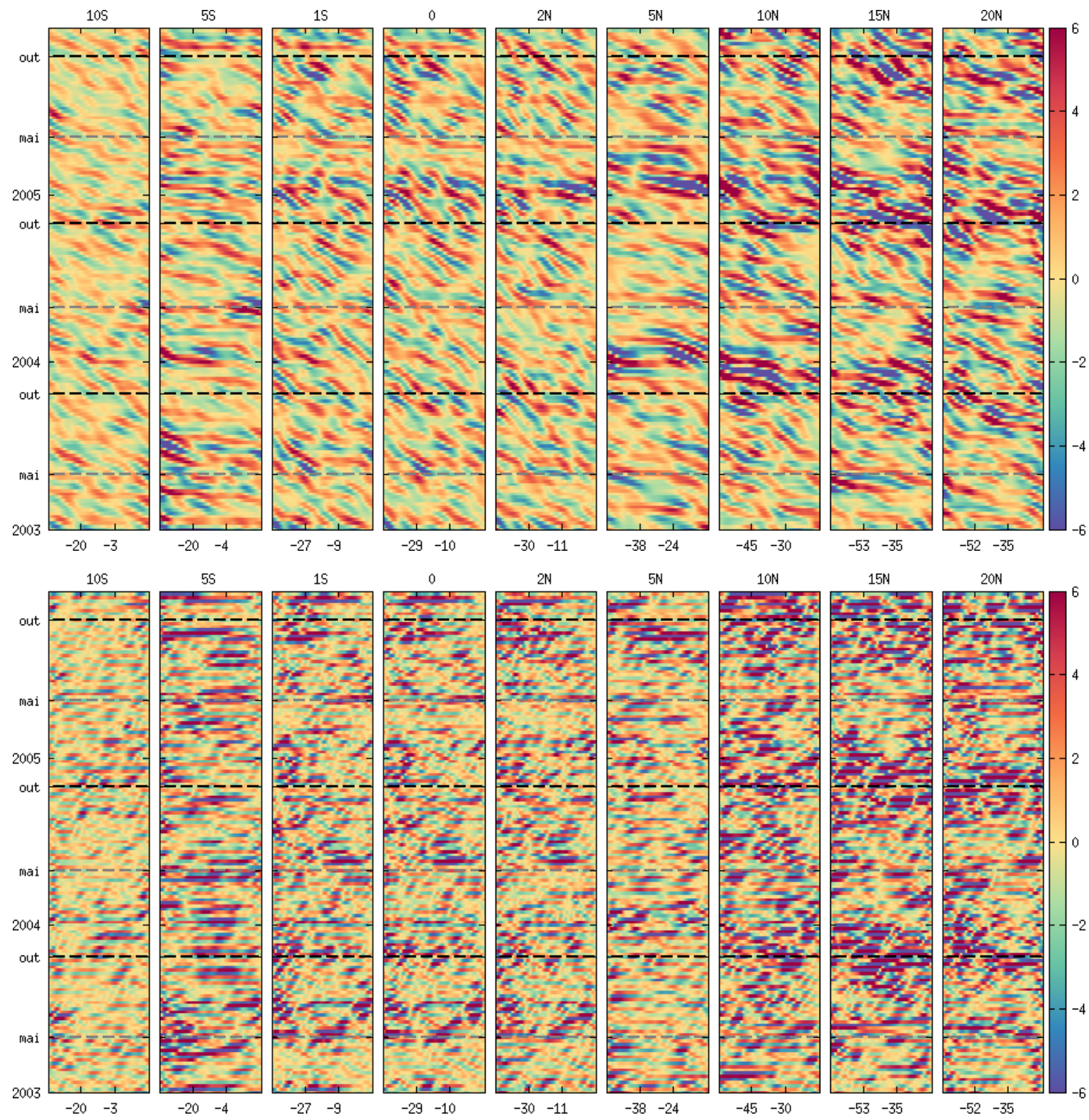

Figura 17: Semelhante à Figura 16 nos dados de $V$. 

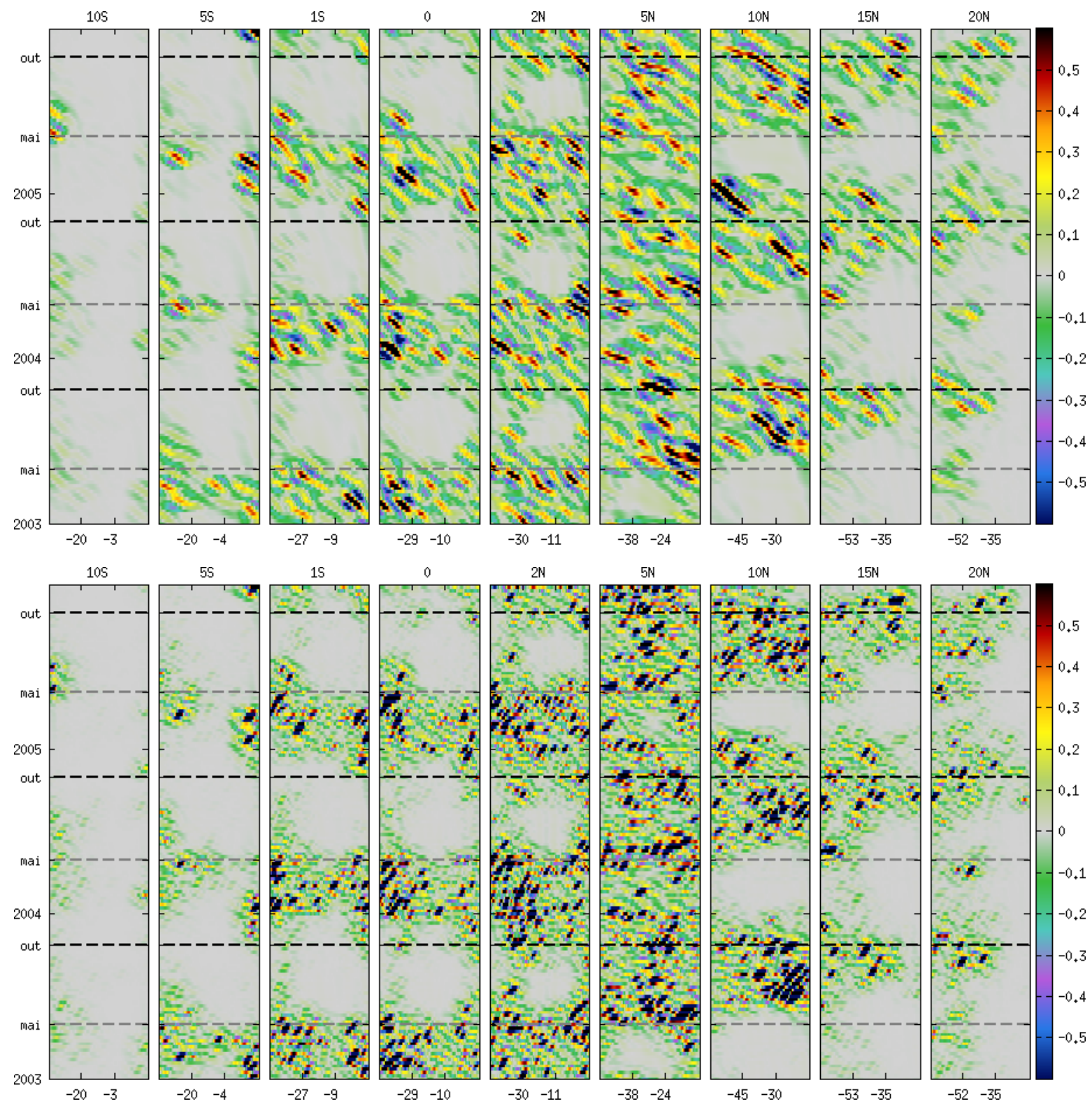

Figura 18: Semelhante à Figura 16 nos dados de $P$. 

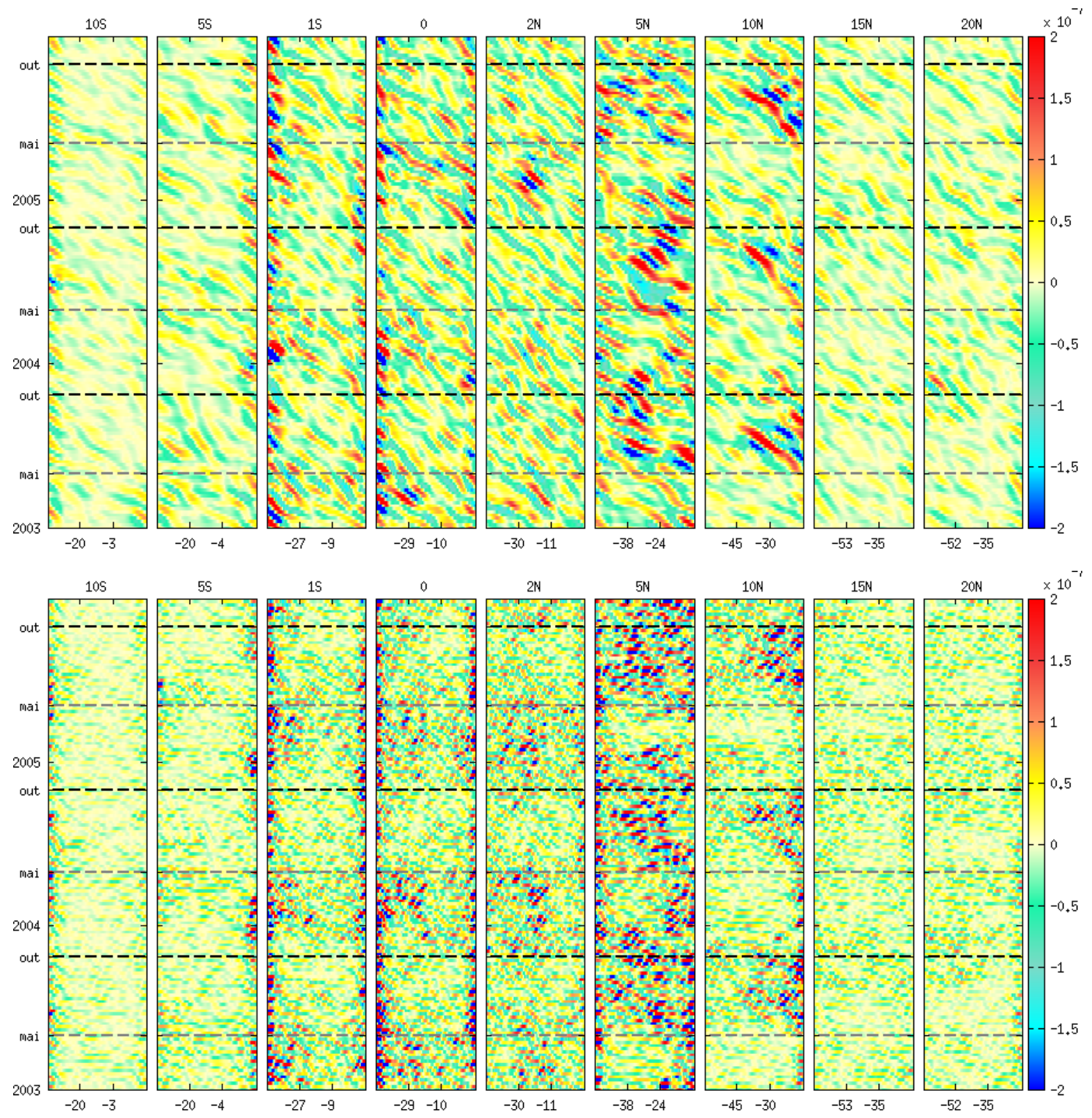

Figura 19: Semelhante à Figura 16 nos dados de $\vec{\nabla} \cdot \vec{\tau}$. 

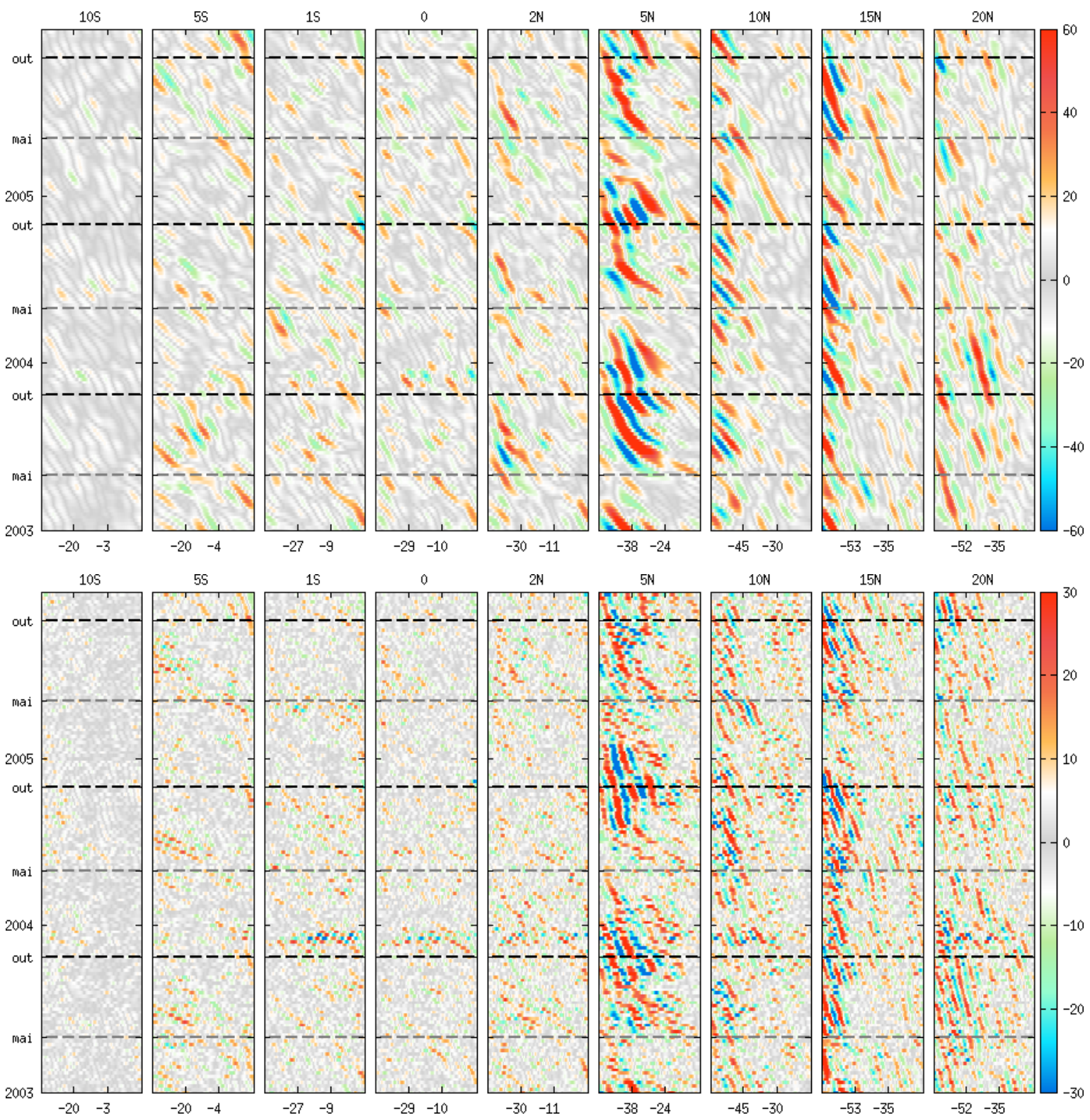

Figura 20: Semelhante à Figura 16 nos dados de $\eta$. 


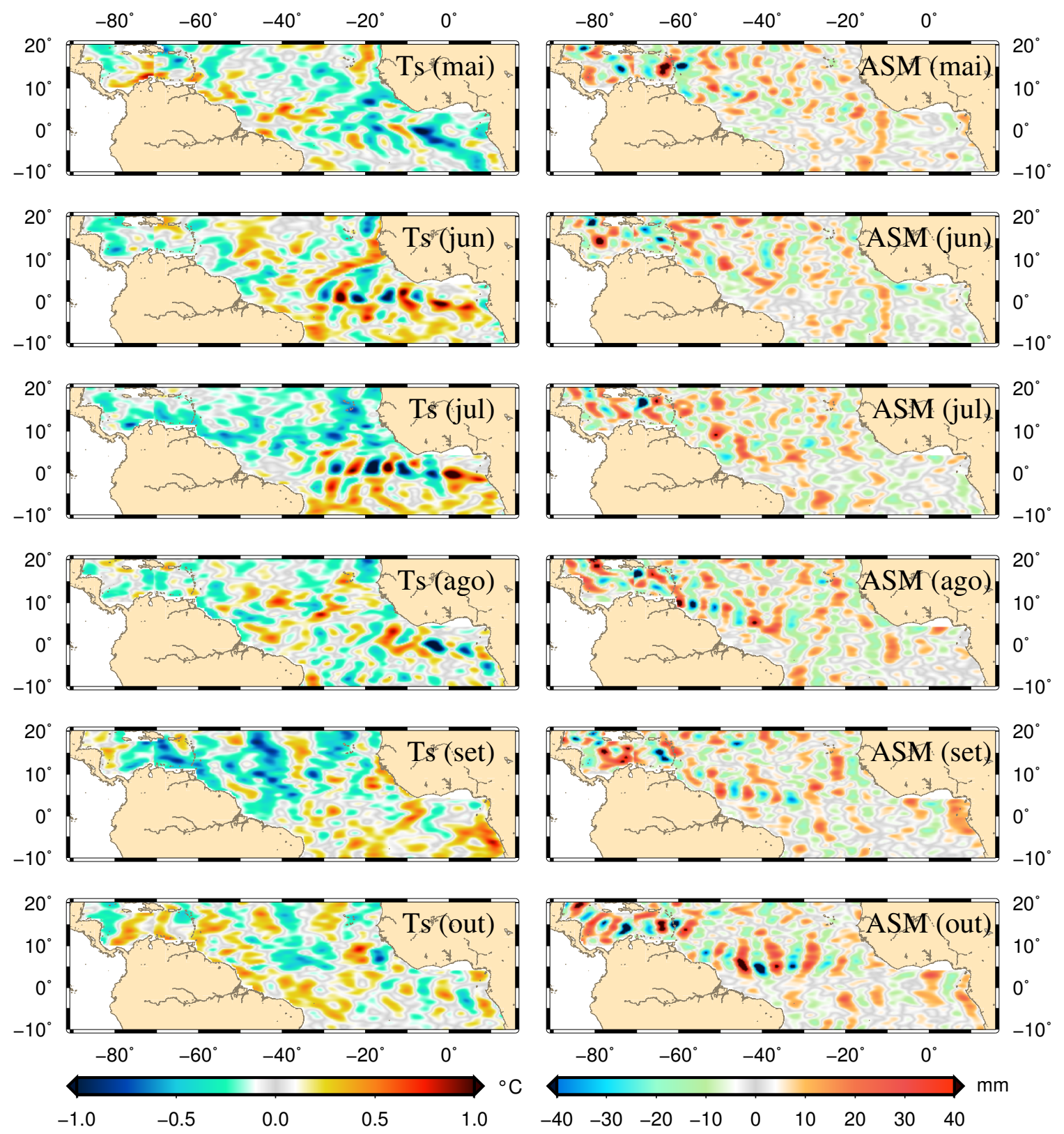

Figura 21: OITs nos dados de TSM (esquerda) e $\eta$ (direita) em maio, junho, julho, agosto, setembro e outubro de 2004. 


\subsection{Caracterização das OITs e ORCs com base na teoria}

A identificação teórica de feições oscilatórias é feita a partir da frequência $\omega$ e do número de onda $k$. Cada classe de onda possui um conjunto infinito de pares de $\omega \mathrm{e}$ $k$ que a identifica. Para as ondas equatoriais, estes conjuntos são as soluções da equação 1. Ondas de Rossby-gravidade e ondas de Rossby são descritas pelas relações 3 e 5 . respectivamente.

A metodologia ora adotada, baseada na transformada de Radon dos diagramas Hovmöller fornece o período e o comprimento de onda médios das feições propagantes com as amplitudes mais significativas. Para cada latitude, a identificação teórica das ondas foi feita representando-se o número de onda e a frequência derivados da transformada de Radon no diagrama de dispersão, como mostram as Figuras 22, 23 e 24 . A linha preta representa a relação de dispersão para as ondas de Rossby-gravidade (equação 3) e as linhas cinzas progressivamente menos espessas representam as soluções para ondas de Rossby (equação 5) para $n=1, n=2$ e $n=3$. A relação de dispersão para as ondas de Rossby modificadas pela presença de um fluxo zonal (equação 6) está representada pelas linhas tracejadas nos mesmos valores do modo meridional $n$. Condizentemente aos padrões inclinados nos diagramas zonais-temporais, a identificação dinâmica das oscilações no diagrama de dispersão com valores negativos de $\omega$ revela que OITs e ORCs nos dados de TSM e $\eta$ propagam fase para oeste. As OITs em todas as latitudes das Figuras 22, 23 e 24 (quadrados e círculos vermelhos) possuem $|k|>1 \mathrm{e}$, portanto, velocidade de grupo para leste. As ORCs (quadrados e círculos azuis) estão mais próximas ao limite entre ondas longas e curtas e podem ter velocidade de grupo para leste ou oeste dependendo da latitude.

As OITs nos dados de TSM (círculos vermelhos na Figura 23) comportam-se dinamicamente com o que a teoria prevê para ondas de Rossby-gravidade entre $0^{\circ}$ e $6^{\circ} \mathrm{N}$. Ao sul do Equador, a presença de um fluxo médio zonal para oeste modifica a relação de dispersão das ondas de Rossby. Por isso, as oscilações da TSM denominadas OITs podem ser identificadas tanto como ondas de Rossby-gravidade como ondas de Rossby modificadas pelo efeito Doppler (Figura 22). Se o efeito Doppler não for levado em 
consideração, nas latitudes próximas até $6^{\circ}$ do Equador, as OITs nos dados de TSM estão muito próximas da curva de relação de dispersão de ondas de Rossby-gravidade. Em latitudes maiores que $6^{\circ}$, considerando o erro na determinação de $\omega$ e $k$, as oscilações podem ser identificadas tanto como ondas de Rossby-gravidade como ondas de Rossby (Figuras 23 e 24).

Em toda a área de estudo, as ondas na banda das OITs nos dados de $\eta$ (quadrado vermelho nas Figuras 22, 23 e 24) comportam-se dinamicamente como ondas de Rossby. O filtro utilizado foi para isolar a banda das OITs. Mas, como a banda é larga, o resultado da análise dinâmica permite a identificação dos padrões como ORCs, com os módulos dos números de onda $k^{*}$ maiores que 1 . Considerando a modificação da relação pelo efeito Doppler, entre $10^{\circ} \mathrm{S}$ e $3^{\circ} \mathrm{N}$, não é possível identificar as oscilações como sendo do primeiro, segundo ou terceiro modo meridional (Figuras 22 e 23). O máximo que se pode afirmar é que, em média, os dados estão mais próximos do segundo modo. A norte de $3^{\circ} \mathrm{N}$, as oscilações são mais facilmente identificadas como do segundo ou terceiro modo meridional sem sofrer influência do fluxo básico Figuras 23 e 24.

Segundo a teoria de ondas equatoriais, as ORCs nos dados de TSM e $\eta$ são ondas de Rossby. Apesar de estarem próximas ao limite entre ondas longas e curtas $\left(k^{*}=-1\right)$, as ORCs na TSM são identificadas como ondas de Rossby longas do primeiro modo meridional entre $3^{\circ} \mathrm{S}$ e $3^{\circ} \mathrm{N}$ (círculos azuis nas Figuras 22 e 23). Nas outras latitudes são caracterizadas como do segundo modo. As ondas nos dados de $\eta$ são classificadas como do segundo modo meridional entre $6^{\circ} \mathrm{S}$ e $4^{\circ} \mathrm{N}$ e também estão mais próximas do limite teórico para ondas de Rossby longas (quadrados azuis nas Figuras 22 e 23). Em latitudes maiores, são caracterizadas como ORCs do terceiro modo meridional.

Nas Figuras 22, 23 e 24, a ocorrência ou não de efeito Doppler nas ondas de Rossby, tanto nos dados de TSM quando nos de $\eta$, é inconclusiva. Apesar do perfil meridional de corrente zonal adotado no cálculo da frequência das ondas equatoriais modificadas pelo efeito Doppler considerar que as correntes são barotrópicas, os erros na determinação de $\omega$ e $k$ pela transformada de Radon torna irrelevante os possíveis erros associados a esta simplificação. 
Dessa forma, de acordo com a teoria de ondas equatoriais, os sinais nos dados de TSM e $\eta$ com período de 49 dias e comprimento de onda de $1500 \mathrm{~km}$, denominados ORCs, são realmente ondas de Rossby. As OITs definidas com período de 21 dias e comprimento de onda $1000 \mathrm{~km}$ somente podem ser identificadas como ondas de Rossbygravidade nos dados de TSM. Os dados de $\eta$ não permitem a visualização de padrões propagantes cuja dinâmica respeita a solução teórica de ondas de Rossby-gravidade. Apesar da aproximação do plano $\beta$ equatorial poder ser aplicada até $30^{\circ}$ de latitude (GILL, 1982), os dados de TSM mostram que o modelo teórico de ondas de Rossby-gravidade pode ser adotado, na prática, em latitudes até cerca de $6^{\circ}$ do Equador.

Acreditamos que a não observação de OITs em dados de $\eta$ deva-se à baixa resolução temporal dos dados altimétricos. Como mostrado na seção 4, a resolução de 7 dias é suficiente para observar fenômenos de 21 dias. Entretanto, os dados com esta resolução produzidos pelo AVISO são resultados da interpolação de medidas a cada $\sim 10$ dias pelos satélites da série TOPEX/Jason-1/2 e 35 dias pelos satélites da série ERS-1/2/Envisat. A frequência de Nyquist para esta taxa é de $1 / 20 \mathrm{dia}^{-1}$. Esta é a maior frequência possível dos fenômenos que podem ser obtidos com uma resolução de 10 dias. A proximidade da escala das OITs à frequência de Nyquist mostra que as OITs estão no limite do fenômeno de menor período que se pode observar nos dados de $\eta$. Portanto, a não identificação das OITs neste conjunto de dados pode ser atribuída à resolução insuficiente dos dados em amostrar oscilações nesta banda de frequência. 

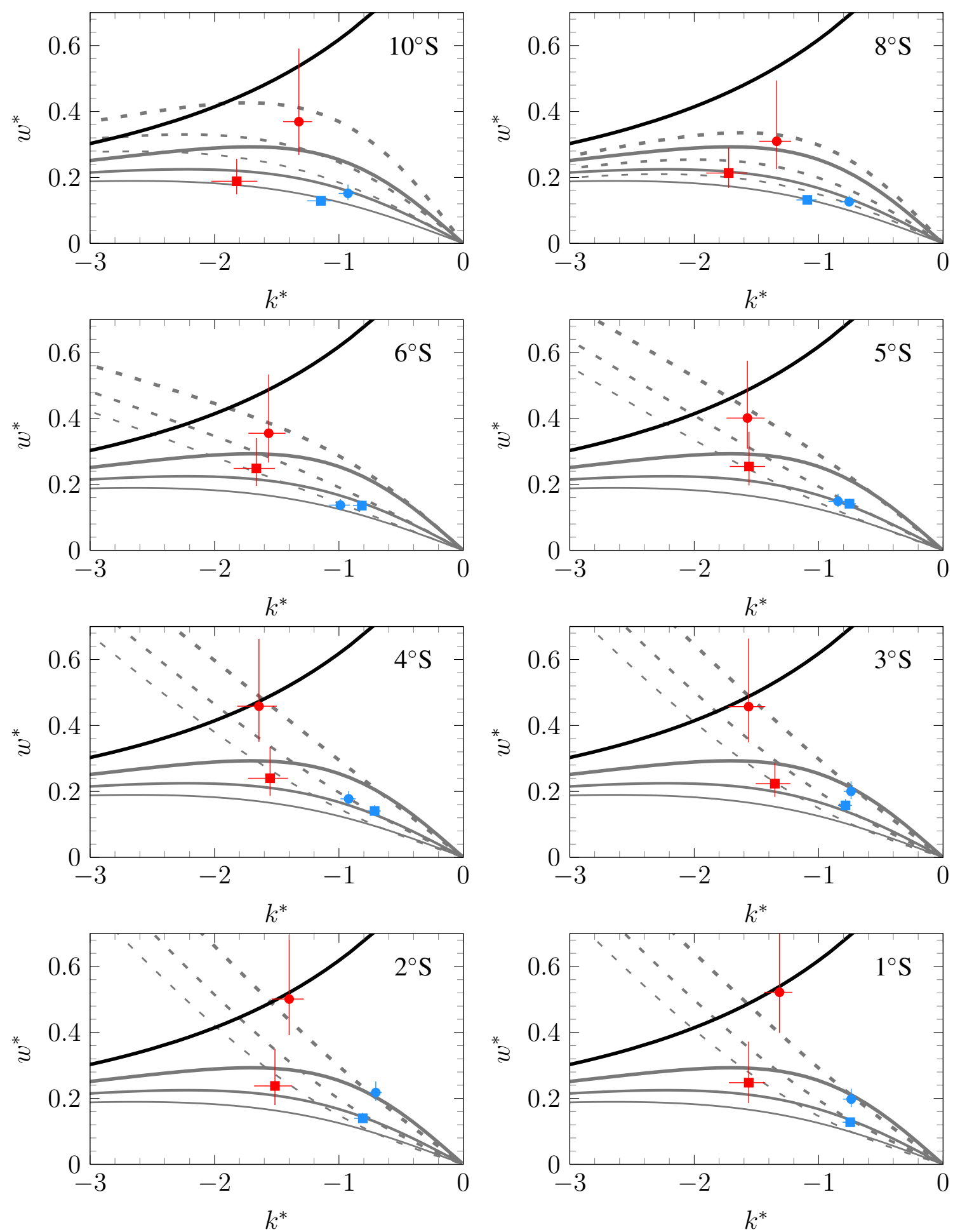

Figura 22: Relação de dispersão das OITs (linha preta) e ORCs do primeiro, segundo e terceiro modos meridionais (linhas cinzas progressivamente menos espessas) nas latitudes $10^{\circ} \mathrm{S}, 8^{\circ} \mathrm{S}, 6^{\circ} \mathrm{S}$, $5^{\circ} \mathrm{S}, 4^{\circ} \mathrm{S}, 3^{\circ} \mathrm{S}, 2^{\circ} \mathrm{S}$ e $1^{\circ} \mathrm{S}$. As soluções com efeito Doppler para os três modos estão representadas pelas linhas cinzas tracejadas em suas respectivas espessuras. O círculo vermelho (azul) representa as OITs (ORCs) na TSM e o quadrado vermelho (azul) representa as OITs (ORCs) de $\eta$. A cruz representa o erro associado a cada medida de $k$ e $\omega$ com intervalo de confiança de $95 \%$. 

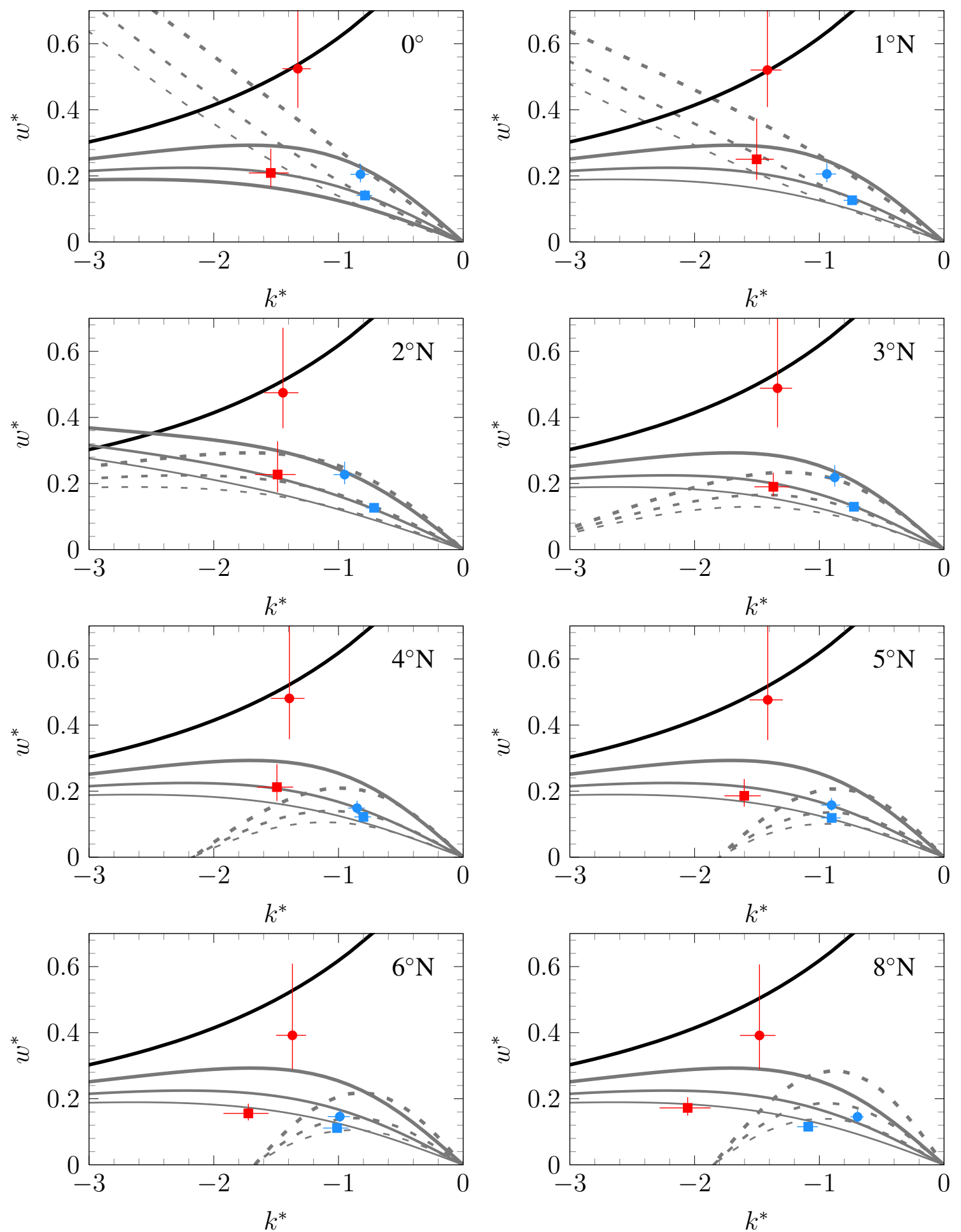

Figura 23: Similar à Figura $22 \mathrm{em} 0^{\circ} \mathrm{N}, 1^{\circ} \mathrm{N}, 2^{\circ} \mathrm{N}, 3^{\circ} \mathrm{N}, 4^{\circ} \mathrm{N}, 5^{\circ} \mathrm{N}, 6^{\circ} \mathrm{N}$ e $8^{\circ} \mathrm{N}$. O círculo vermelho (azul) representa as OITs (ORCs) na TSM e o quadrado vermelho (azul) as OITs (ORCs) em $\eta$. 

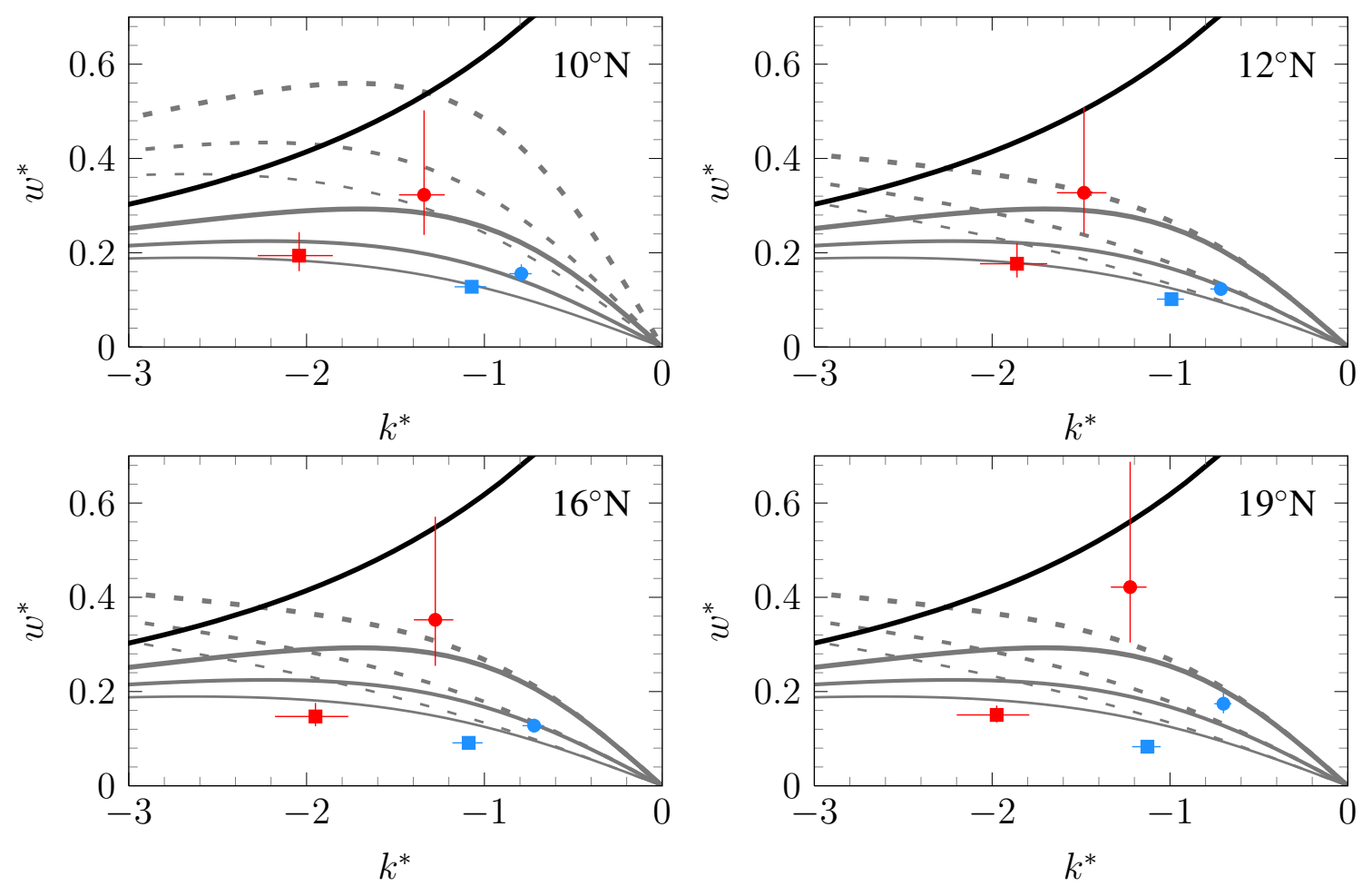

Figura 24: Similar à Figura $22 \mathrm{em} 10^{\circ} \mathrm{N}, 12^{\circ} \mathrm{N}, 16^{\circ} \mathrm{N}$ e $19^{\circ} \mathrm{N}$. O círculo vermelho (azul) representa as OITs (ORCs) na TSM e o quadrado vermelho (azul) as OITs (ORCs) em $\eta$.

Mesmo identificadas dinamicamente como ondas de Rossby, as ORCs nos dados de TSM próximo ao Equador possuem as amplitudes máximas de maio a outubro, como mostram os diagramas Hovmöller da Figura 16. Estas ondas de Rossby são diferentes das representadas nos dados de $\eta$, que não apresentam máximas amplitudes associadas à intrusão da língua fria. Aparentemente, a intrusão da língua fria modula as máximas amplitudes das ORCs apenas na TSM e não nos dados de $\eta$. Entre $3^{\circ} \mathrm{S}$ e $3^{\circ} \mathrm{N}$, as $\mathrm{ORCs}$ na TSM são do primeiro modo meridional e em $\eta$ do segundo (Figuras 22 e 23.

As instabilidades oriundas do cisalhamento das correntes e da ressurgência equatorial geram oscilações em diferentes frequências e números de onda, entre eles os referentes às OITs e ORCs. As oscilações observadas dependem do conjunto de dados analisado. E para um mesmo conjunto, diferentes tipos de ondas podem ocorrer simultaneamente. Por isso, a determinação do comprimento de onda das OITs em imagens de TSM obtidos por satélite deve levar em conta que as feições observadas são uma combinação de diversas oscilações com números de onda e frequência diferentes (LYMAN et al., 2007). 
A existência de diversos tipos de oscilações com características de ondas de Rossby e de Rossby-gravidade, que são genericamente denominadas de OITs, foi verificada por diversos autores (BUNGE et al., 2007; LYMAN et al., 2007; SCHUCKMANN et al., 2008; SHINODA et al., 2009; FARRAR, 2011). O mecanismo de geração destas ondas por processos de instabilidades é bastante controverso e atualmente não é conhecido em detalhes (SCHUCKMANN et al., 2008).

Polito e Sato (2003) sugeriram que a passagem de ondas de Rossby ou de Kelvin pode eventualmente deslocar as correntes subsuperficiais para um nível onde haja grande cisalhamento e gerar ondas de Rossby com perídos de 50 dias e comprimentos de ondas de $1500 \mathrm{~km}$. As correntes meridionais geradas pelas ondas de Rossby atuam como um catalisador na produção das ondas de alta frequência. As instabilidades que geram estas ondas podem ser as mesmas que geram as OITs.

Mais recentemente, Schuckmann et al. (2008) analisaram dados de corrente e resultados de um modelo de circulação geral no Atlântico tropical e verificaram que a produção de energia cinética associada às OITs nos primeiros $50 \mathrm{~m}$ de coluna d'água deve-se a instabilidade barotrópicas e baroclínicas. De acordo com os autores, no hemisfério Sul a geração de energia cinética ocorre por instabilidades baroclínicas associadas ao cisalhamento vertical do ramo central da CSE. Próximo ao Equador a principal fonte de energia para as ondas vem da instabilidade barotrópica pelo cisalhamento meridional entre a SE e a CSEn. Já no hemisfério Norte, tanto a instabilidade baroclínica causada pelo cisalhamento vertical da CSEn quanto a barotrópica gerada pelo cisalhamento horizontal entre esta mesma corrente e a CCNE promovem a geração de OITs. No hemisfério Norte, a instabilidade barotrópica é modulada sazonalmente pelo fluxo da CCNE, que é mais intenso durante o verão boreal. O menor gradiente de TSM no hemisfério Sul contribui para uma menor instabilidade baroclínica em relação ao hemisfério Norte.

Utilizando análise espectral, Lyman et al. (2007) identificaram 2 picos de energia centrados em 17 e 33 dias no Pacífico equatorial. Os sinais de 17 dias na temperatura de subsuperfície em $2^{\circ} \mathrm{S}$ e $2^{\circ} \mathrm{N}$ e na velocidade meridional em superfície a $0^{\circ}$ foram identificados como ondas de Rossby-gravidade e, como mostrado anteriormente, podem ser 
comparados com os sinais de 21 dias isolados no presente trabalho. Os sinais com 33 dias foram observados em dados de $\eta$ e de temperatura de subsuperfície em $5^{\circ} \mathrm{N}$ como ondas de Rossby dos primeiros modos baroclínico e meridional.

Os resultados de Lyman et al. (2007) são corroborados pelos resultados apresentados neste trabalho em vários aspectos. Os dados de temperatura são capazes de revelar a presença de OITs e ORCs e os dados de $\eta$ demonstram apenas ORCs. A variabilidade de 17 dias condiz com o previsto pela teoria de ondas de Rossby-gravidade geradas por instabilidades aprisionadas na superfície. Estas ondas na temperatura de subsuperfície, em torno de $100 \mathrm{~m}$ de profundidade, a $2^{\circ}$ de latitude estão associadas à velocidade meridional no Equador que é máxima na superfície. A dissipação vertical de energia permite que a estrutura das ondas se extenda até a termoclina. Lyman et al. (2007) observaram que a velocidade superficial no Equador não está associada às ondas de Rossby na temperatura subsuperficial em $5^{\circ} \mathrm{N}$. A atribuição das anomalias de temperatura à velocidade meridional nas OITs e a ausência de uma associação entre elas nas ORCs também corrobora a hipótese de que OITs e ORCs são geradas por fenômenos distintos. Apesar da instabilidade baroclínica não poder ser descartada, as ondas de Rossby nesta latitude são causadas por instabilidades barotrópicas associadas ao cisalhamento entre a CSE e a CCNE (LYMAN et al., 2005; LYMAN et al., 2007).

Shinoda et al. (2009) utilizaram dados altimétricos provenientes do satélite TOPEX com resolução de 10 dias e dados de TSM do TMI e verificaram picos espectrais na banda de 33 dias e $1500 \mathrm{~km}$ referentes à teoria de ondas de Rossby equatoriais do primeiro modo meridional. As variabilidades nos dados de TSM e $\eta$ são máximas a $2^{\circ} \mathrm{Ne} 5^{\circ} \mathrm{N}$, respectivamente. Os autores também observaram anomalias de velocidade superficial paralelas aos contornos das anomalias de $\eta$ em $5^{\circ} \mathrm{N}$, ambas localizadas sobre os máximos gradientes de TSM, o que demonstra o predomínio do balanço geostrófico que causa advecção meridional da frente de TSM. Mesmo que, inicialmente, instabilidades barotrópicas do cisalhamento entre a CCNE e CSE gerem perturbações de velocidade que advectem as anomalias de TSM, é possível que a variação da frente de TSM influencie a evolução das ondas devido ao campo de velocidade geostrófica (SHINODA et al., 2009). 
Lyman et al. (2007) mostraram que a geração de OITs na temperatura no Pacífico a $\pm 2^{\circ}$ do Equador independe de $\eta$, o que justifica a ausência destas ondas em dados de $\eta$. Mas, recentemente, Shinoda (2010), Shinoda (2012) identificaram picos espectrais com períodos de 17 dias e de 10-16 dias correspondentes à relação de dispersão de ondas de Rossby-gravidade em dados de $\eta$. Shinoda (2010) obtiveram as maiores variabilidades associadas ao período de 17 dias no Pacífico leste restritas a $4^{\circ}$ de latitude em ambos hemisférios. Shinoda (2012) observou as maiores variabilidades na banda de 10-16 dias centradas em $3^{\circ} \mathrm{S}$ para o primeiro modo baroclínico e em $2^{\circ} \mathrm{S}$ e $2^{\circ} \mathrm{N}$ para o segundo modo. As estruturas são antissimétricas em relação ao Equador, similar às ondas observadas na TSM, porém dominam no Pacífico oeste, ondas as anomalias de TSM são menos representativas. Entretanto, nestes trabalhos foram utilizados os resultados diários produzidos de forma temporária e experimental pelo AVISO. A resolução temporal dos dados altimétricos é de cerca de 10 dias e uma combinação de diversos satélites permite reduzir a distância temporal para 7 dias. Portanto, especulamos que o alcance de uma resolução diária introduz feições artificiais que podem originar os padrões identificados como ondas de Rossby-gravidade pelos autores. As conclusões obtidas por eles torna-se assim duvidosa.

Lyman et al. (2005) derivam um sistema de equações de autovalores e autovetores para a relação de dispersão das ondas de Rossby-gravidade influenciadas por correntes zonais correspondentes às observadas no Pacífico equatorial. O problema é desenvolvido para um modelo continuamente estratificado, mas os autores não apresentam uma solução matemática explícita para a solução. O problema é resolvido numericamente. Farrar (2011) utilizam a relação de dispersão de Lyman et al. (2005) na identificação dos padrões obtidos em dados de $\eta$. A curva da relação de dispersão fica muito mais próxima às ondas de Rossby que às de Rossby-gravidade, próximo ao limite entre ondas longas e curtas para o primeiro modo meridional. Por isso, alguns padrões de $\eta$ obtidos no presente trabalho, se fosse considerada a curva obtida por Farrar (2011), poderiam eventualmente ser identificados como ondas de Rossby-gravidade. Entretanto, para que isto fosse corroborado, seria necessário o desenvolvimento do problema para o modelo 
de 1,5 camadas levando em conta a distribuição das correntes superficiais do Atlântico equatorial, o que fugiria dos objetivos deste trabalho. Como a solução de Lyman et al. (2005) não se aplica a estas condições, não é possível simplesmente transladar a relação de dispersão derivada pelos autores para o presente caso. Portanto, admitimos que todos os padrões propagantes obtidos pelos dados de $\eta$ são dinamicamente identificados como ondas de Rossby. 


\subsection{Mapas de regressão}

Os pontos de máxima variância de TSM para ORCs e OITs foram utilizados como referência para as regressões entre as variáveis em estudo e a TSM. A Figura 25 mostra o mapa de variância da TSM de dezembro de 1998 a novembro de 2010 associada às ondas e os pontos de referência. As máximas variâncias de TSM relacionadas às ORCs e OITs foram de $0,31{ }^{\circ} \mathrm{C}^{2}$ em $0,875^{\circ} \mathrm{N} 10,125^{\circ} \mathrm{W}$ e $0,22{ }^{\circ} \mathrm{C}^{2}$ em $0,875^{\circ} \mathrm{N} 15,875^{\circ} \mathrm{W}$, respectivamente. Para ambas, as máximas variâncias localizam-se na porção leste da bacia. A região de ocorrência das ORCs e OITs foi definida como as latitudes nas quais a variância é até 2 vezes menor que o valor no ponto de referência. No caso das ORCs, a região de domínio das ondas está compreendida entre $2,625^{\circ} \mathrm{N}$ e $2,375^{\circ} \mathrm{S}$ e nas OITs entre $2,125^{\circ} \mathrm{N}$ e $2,125^{\circ} \mathrm{S}$. Esta é exatamente a área onde as ondulações são observadas na Figura 1 e, portanto, a região onde há maiores amplitudes de TSM. Os presentes resultados corroboram os valores de máxima variância encontrados por Wu e Bowman (2007a) entre $15^{\circ} \mathrm{W}$ e $20^{\circ} \mathrm{W}$ logo acima do Equador. Entretanto, no trabalho de Wu e Bowman (2007a), as máximas variâncias estão restritas ao hemisfério Norte, entre $1^{\circ} \mathrm{N}$ e $5^{\circ} \mathrm{N}$, e pouca atividade foi observada no hemisfério Sul.

A Figura 25 mostra também os mapas de variância de $V, P, \vec{\nabla} \cdot \vec{\tau}$ (DIV) e $\eta$ (ASM). As variâncias dos campos atmosféricos na banda das ORCs são inferiores em comparação com a banda das OITs, cuja influência é marcante e limitada ao hemisfério Norte e, em menor grau, ao litoral nordestino. O vapor integrado mostra maior variabilidade acima de $10^{\circ}$ N. Já os mapas de $P$ e $\vec{\nabla} \cdot \vec{\tau}$ apresentam maiores variâncias entre o Equador e $10^{\circ} \mathrm{N}$ e acompanham a posição da ZCIT. As variâncias médias de $V$ e $\vec{\nabla} \cdot \vec{\tau}$ são 1,6 vezes maior na escala das OITs e chega a ser o dobro no campo de $P$, como pode ser visto na Tabela 2 .

Os campos oceânicos revelam maior variabilidade na banda das ORCs. A variância média de TSM é 1,4 vezes superior à das OITs e 3 vezes maior nos dados de $\eta$ (paineis superiores e inferiores da Figura 25). Os mapas de variância de TSM para ORCs e OITs são bem similares. Essa semelhança também ocorre nos mapas de $\eta$. Para $\eta$, os maiores valores localizam-se na porção oeste da bacia, acima do Equador. Na TSM, 
Tabela 2: Variâncias máximas $\left(\sigma_{\max }^{2}\right)$ e médias $\left(\sigma_{\text {med }}^{2}\right)$ das variáveis em estudo para ORCs e OITs.

\begin{tabular}{ccccccc}
\hline & & $\mathrm{TSM}\left({ }^{\circ} \mathrm{C}^{2}\right)$ & $V\left(\mathrm{~mm}^{2}\right)$ & $P\left(\mathrm{~mm}^{2} \mathrm{~h}^{-2}\right)$ & $\vec{\nabla} \cdot \vec{\tau}\left(\mathrm{kg} \mathrm{m}^{-2} \mathrm{~s}^{-2}\right)$ & $\eta\left(\mathrm{mm}^{2}\right)$ \\
\hline$\sigma_{\text {max }}^{2}$ & ORCs & 0,31 & 125,61 & 0,07 & $0,12 \cdot 10^{-12}$ & $2,79 \cdot 10^{3}$ \\
& OITs & 0,27 & 230,18 & 0,19 & $0,31 \cdot 10^{-12}$ & $0,52 \cdot 10^{3}$ \\
\hline \multirow{2}{*}{$\sigma_{\text {med }}^{2}$} & ORCs & 0,07 & 8,24 & 0,02 & $0,48 \cdot 10^{-14}$ & $0,35 \cdot 10^{3}$ \\
& OITs & 0,05 & 13,29 & 0,04 & $0,78 \cdot 10^{-14}$ & $0,11 \cdot 10^{3}$ \\
\hline
\end{tabular}

apesar dos altos valores próximo à costa africana, as maiores variâncias localizam-se na região equatorial. A região de maior variabilidade de $\eta$ para ORCs e OITs são bastante coincidentes, pois ambas representam ondas de Rossby. Polito e Sato (2003); Lyman et al. (2007); Shinoda et al. (2009) obtiveram as maiores variabilidades de $\eta$ no Pacífico para ondas de Rossby em $5^{\circ} \mathrm{N}$, de acordo com o obtido no presente trabalho.

O método de regressão das séries temporais filtradas em cada ponto calculado em relação à série filtrada no ponto de referência possibilitou mapear a estrutura das OITs e ORCs nos campos de TSM, $V, P, \vec{\nabla} \cdot \vec{\tau}$ e $\eta$, como mostrado na Figura 26. Os paineis da Figura 26 quantificam a alteração de cada variável nos pontos $(x, y)$ para cada $1{ }^{\circ} \mathrm{C}$ de mudança na TSM no ponto de referência, indicado pela cruz branca, causada pela passagem das OITs e ORCs. A menção à estas regressões calculadas em relação ao ponto de referência serão denominadas regressão de 1 ponto e os mapas derivados desta metodologia serão referidos como mapas de regressão de TSM, $V, P, \vec{\nabla} \cdot \vec{\tau}$ e $\eta$, dependendo da variável a ser relacionada à TSM.

A estrutura espacial das OITs e ORCs na TSM domina entre $5^{\circ} \mathrm{S}$ e $5^{\circ} \mathrm{N}$ (paineis superiores na Figura 26). Os maiores valores de regressão de TSM ocorrem entre e o Equador e $3^{\circ} \mathrm{N}$ e atingem $0,5^{\circ} \mathrm{C}^{\circ} \mathrm{C}^{-1}$. A distribuição das anomalias mostra-se inclinada no sentido sudoeste-nordeste no hemisfério Norte. Esta inclinação pode ser resultado da advecção do sinal pelas correntes superficiais para oeste, mais intensas com a diminuição da latitude entre $5^{\circ} \mathrm{N}$ e $0^{\circ}$, conforme mostram as Figuras 11 e 12 , Outra possibilidade é o efeito $\beta$ que causa aumento da velocidade de fase próximo ao Equador. Há uma distinção entre os hemisférios com o coeficiente de regressão apresentando valores absolutos maiores no Norte em relação ao Sul, tanto nas ORCs como nas OITs. Além disso 

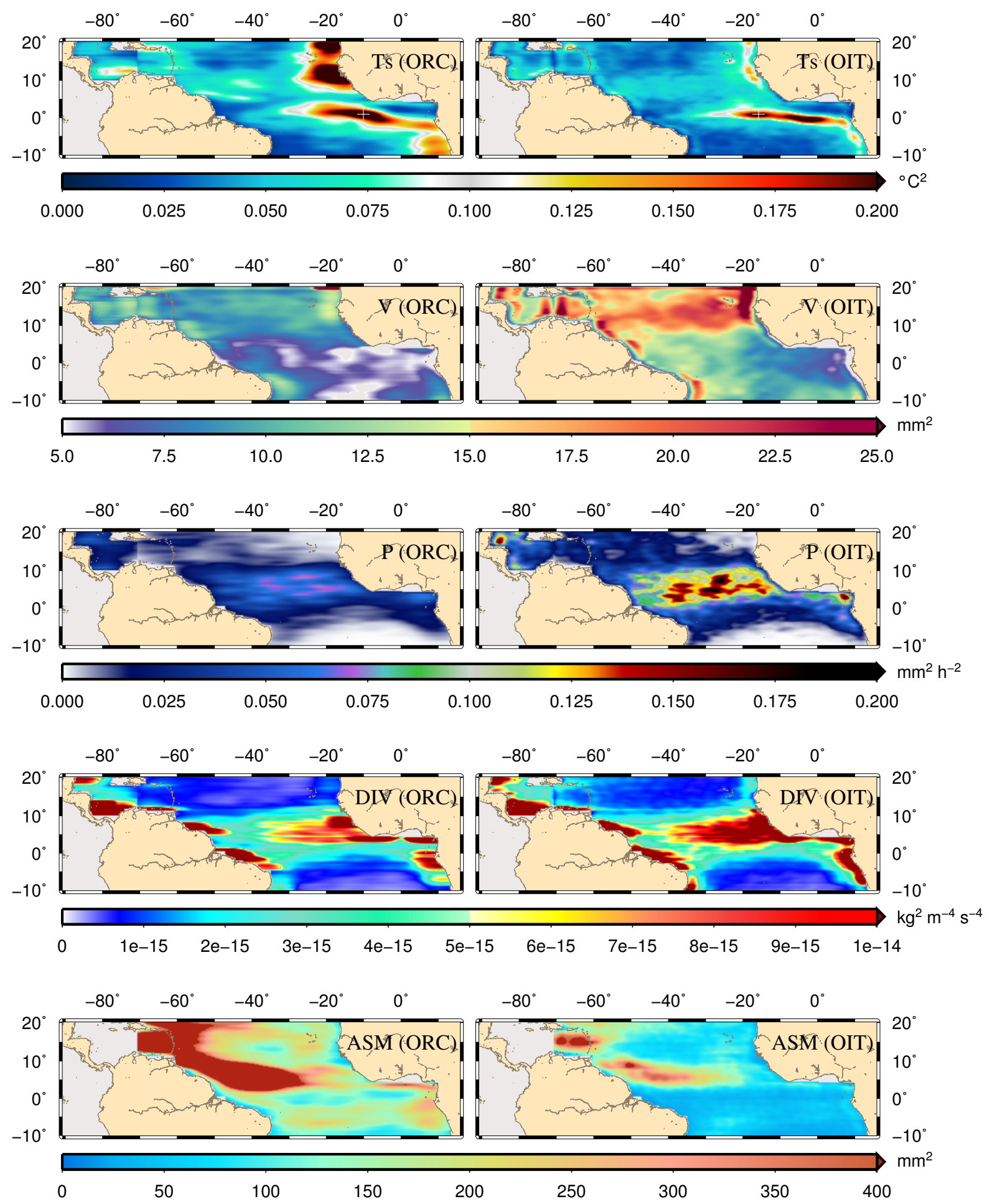

Figura 25: Variância de TSM $\left({ }^{\circ} \mathrm{C}^{2}\right), V\left(\mathrm{~mm}^{2}\right), P\left(\mathrm{~mm}^{2} \mathrm{~h}^{-2}\right), \vec{\nabla} \cdot \vec{\tau}\left(\mathrm{DIV} \mathrm{em} \mathrm{kg}^{2} \mathrm{~m}^{-4} \mathrm{~s}^{-4}\right)$ e $\eta$ $\left(\mathrm{ASM}\right.$ em $\mathrm{mm}^{2}$ ) para ORCs (esquerda) e OITs (direita). O símbolo + indica o ponto de referência (de máxima variância) de TSM, centrado em $0,875^{\circ} \mathrm{N} 10,125^{\circ} \mathrm{W}$ nas $\mathrm{ORCs} \mathrm{e} 0,875^{\circ} \mathrm{N} 15,875^{\circ} \mathrm{W}$ nas OITs. Os valores extremos de $\eta$ no Golfo do México foram desconsiderados para efeito de ilsutração. 
a estrutura da TSM nas OITs é antissimétrica em relação ao Equador. Padrões com estas mesmas características foram observados também por Wu e Bowman (2007a) em dados de TSM obtidos por satélites.

De acordo com Yu et al. (1995), a assimetria das anomalias de TSM deve-se às assimetrias meridionais da frente de TSM, deslocada para o hemisfério Norte, e dos dois ramos da CSE, sendo o ramo do hemisfério Norte mais intenso que o do Sul. De acordo com os autores, a presença da CCNE não está associada à assimetria meridional. Lyman et al. (2007) verificaram que a estrutura assimétrica das OITs em relação ao Equador em dados de temperatura subsuperficial é similar ao que a teoria prevê para ondas de Rossbygravidade do primeiro modo meridional na presença de um fluxo médio, de acordo com modelo teórico deduzido por Lyman et al. (2005). Por outro lado, é possível que a assimetria entre os hemisférios deva-se à independência dos fenômenos de geração das OITs no Norte e no Sul. Como Schuckmann et al. (2008) verificaram, no hemisfério Sul as ondas são geradas por instabilidades baroclínicas e no Norte por baroclínicas e barotrópicas. Neste último caso, os autores defendem que a modulação sazonal das OITs no hemisfério Norte está relacionada à variação da intensidade da CCNE.

Ao sul do Equador a Figura 22 revela que as OITs na TSM podem ser identificadas também como ORCs influenciadas pelo fluxo básico. Portanto, se as feições observadas forem ondas dinamicamente diferentes, formadas por processos distintos, a distribuição das anomalias em um hemisfério é independente do outro. Neste caso, as anomalias podem ser simétricas ou não. É necessária uma simulação numérica considerando a intrusão de uma língua fria deslocada para Norte e o padrão de correntes durante a época da ressurgência equatorial para avaliar quais os fenômenos que dominam e determinam o estabelecimento das distribuições de temperatura observadas.

Os mapas de regressão de $\eta$ para ORCs (paineis inferiores da Figura 26) revelam amplitudes muito maiores que nas OITs. A alteração de $\eta$ pela TSM no ponto de referência chega a $15 \mathrm{~mm}^{\circ} \mathrm{C}^{-1}$ nas ORCs e atinge pouco mais de $2 \mathrm{~mm}{ }^{\circ} \mathrm{C}^{-1}$ nas OITs. Portanto, a energia na banda das ORCs é dominante nos dados de $\eta$ em relação aos sinais com frequência e comprimento de onda característicos das OITs. Por outro lado, a regressão do 
mapa é feita em relação ao ponto de referência determinado pela máxima variância de TSM, que ocorre próximo ao Equador. Como os dados de $\eta$ não contém sinais dinamicamente identificados como ondas de Rossby-gravidade, não esperávamos que houvesse relação entre estas ondas na TSM e as ondas de Rossby em $\eta$, a não ser que trocassem energia.

Farrar (2011) demonstrou que a variabilidade de $\eta$ fora do Equador, até $20^{\circ} \mathrm{N}$, deve-se às instabilidades do sistema de correntes no Pacífico equatorial. O autor sugeriu que ondas de Rossby barotrópicas são irradiadas por OITs na região equatorial e podem carregar energia e momentum para latitudes médias. Como os mapas de regressão quantificam a relação entre $\eta$ e a TSM no ponto de referência a $0,875^{\circ} \mathrm{N}$ na bandas das OITs e ORCs, a ocorrência de padrões oscilatórios em latitudes mais altas pode corroborar a produção destas ondas nos dados de $\eta$ pelas instabilidades equatoriais. Considerando que os dados de $\eta$ contém apenas o sinal das ondas de Rossby, a regressão relativamente baixa de $\eta$ em relação à TSM na banda OITs (painel inferior direito da Figura 26), demonstra que a produção de ORCs a partir de OITs no Equador não é um mecanismo dominante. Já na banda das ORCs, as máximas regressões de $\eta$ acima de $5^{\circ} \mathrm{N}$ na borda oeste (painel inferior esquerdo da Figura 26) revela que estas ondas estão associadas às instabilidades que dão origem às ondas de Rossby na TSM próximo ao Equador.

Os paineis centrais da Figura 26 mostram que os maiores valores dos coeficientes de regressão nos dados de $P$ localizam-se a norte da região de domínio das ondas, entre $5^{\circ} \mathrm{N}$ e $10^{\circ} \mathrm{N}$. Para o $\vec{\nabla} \cdot \vec{\tau}$, as maiores alterações associadas à TSM concentram-se próximo ao ponto de referência e também alcançam $10^{\circ} \mathrm{N}$. O mapa de regressão de $V$ para ORCs mostra que os máximos valores encontram-se próximo ao ponto de referência, o que revela que, em primeira ordem, a TSM altera estes campos localmente, na região de ocorrência das ondas na TSM. Nos mapas de $V$ para as OITs as maiores regressões dominam a $\sim 10^{\circ}$ de latitude norte e a sul, o que novamente sugere uma influência remota da TSM no vapor na banda das OITs. A alteração dos campos atmosféricos pela TSM na escala das OITs e ORCs e os possíveis mecanismos responsáveis serão discutidos com mais detalhes na seção 5.5. 
Para averiguar se a resposta remota no campo de $P$ às OITs e ORCs atingem a ZCIT, calculamos uma nova regressão restrita ao período de máximas amplitudes das ondas nos dados de TSM (maio a outubro), que também coincide com a época do ano em que a ZCIT encontra-se em suas posições mais ao norte. A alteração dos campos atmosféricos pelas anomalias de TSM no Equador são similares aos resultados encontrados na Figura 26. Os mapas de regressão para cada ano encontram-se no apêndice D. 

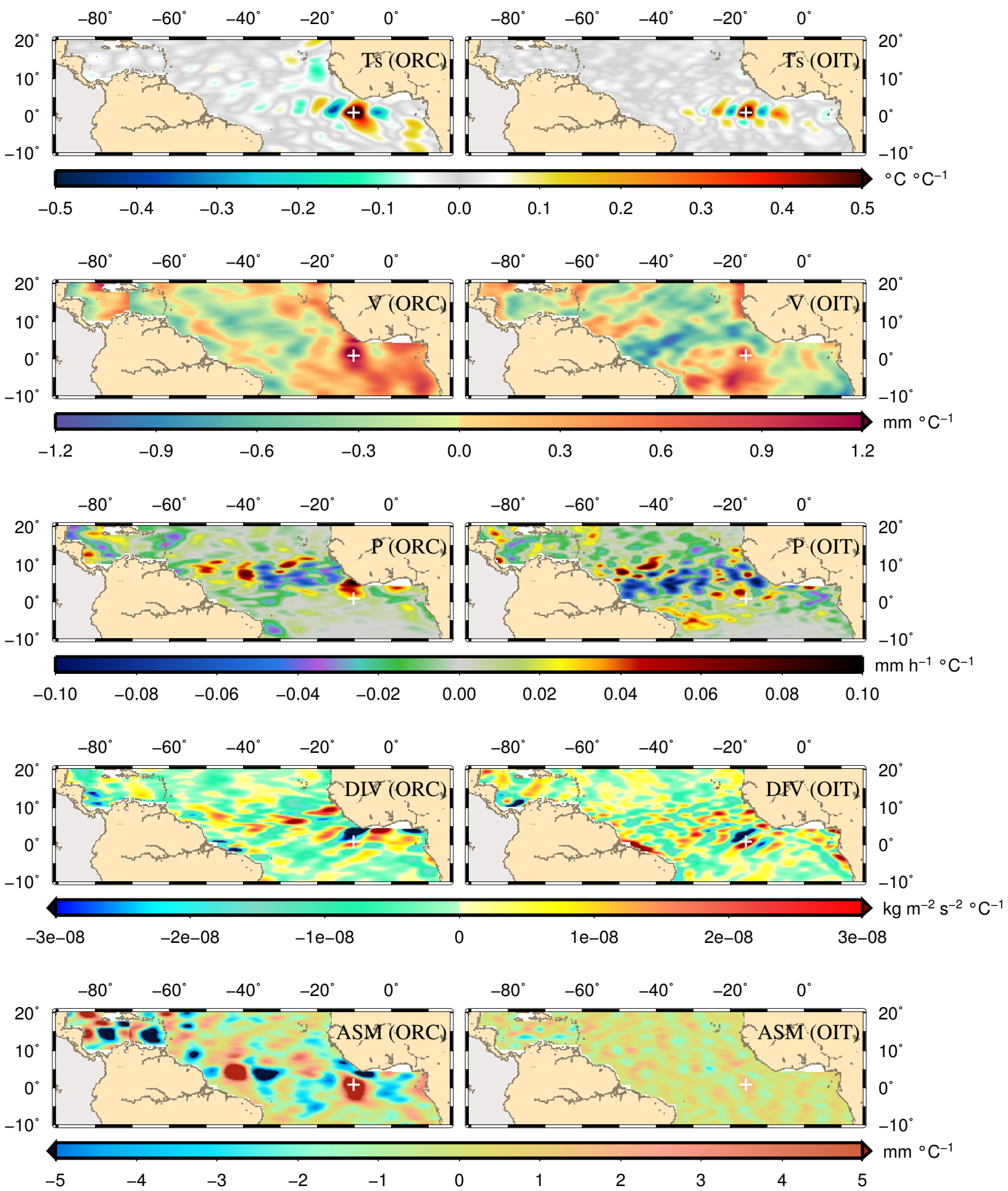

Figura 26: Mapas de regressão de TSM $\left({ }^{\circ} \mathrm{C}^{\circ} \mathrm{C}^{-1}\right), V\left(\mathrm{~mm}^{\circ} \mathrm{C}^{-1}\right), P\left(\mathrm{~mm} \mathrm{~h}^{-1}{ }^{\circ} \mathrm{C}^{-1}\right), \vec{\nabla} \cdot \vec{\tau}$ (DIV em $\mathrm{kg} \mathrm{m}^{-2} \mathrm{~s}^{-2}{ }^{\circ} \mathrm{C}^{-1}$ ) e $\eta$ (ASM em mm ${ }^{\circ} \mathrm{C}^{-1}$ ) para ORCs (esquerda) e OITs (direita). O símbolo + indica o ponto de referência (de máxima variância) de TSM, centrado em $0,875^{\circ} \mathrm{N} 10,125^{\circ} \mathrm{W}$ nas ORCs e $0,875^{\circ} \mathrm{N} 15,875^{\circ} \mathrm{W}$ nas OITs. 


\subsection{Correlações}

\subsubsection{Interação oceano-atmosfera sobre anomalias transientes de TSM}

O cálculo da regressão entre as variáveis em estudo e a TSM permite quantificar a influência desta sobre os campos atmosféricos. Para avaliar se a alteração é significativa, consideramos apenas os pontos de regressão nos quais a correlação entre a variável e a TSM no ponto de referência fosse estatisticamente significativa ao nível de 95\%. Assim, a sobreposição dos mapas de regressão possibilitou discutir os processos que possivelmente relacionam os sinais das ondas às variáveis oceânicas e atmosféricas.

O painel superior da Figura 27 mostra o mapa de correlação estatisticamente significativa na banda das OITs entre as séries temporais de $\vec{\nabla} \cdot \vec{\tau}(x, y)$ com a série temporal de TSM no ponto de referência indicado pela cruz preta. O cálculo da correlação de 1 ponto é análogo ao da regressão de 1 ponto e os mapas resultantes também serão referidos como mapas de correlação. O mapa de cores do painel inferior da Figura 27 representa a regressão de $\vec{\nabla} \cdot \vec{\tau}$ para as OITs. Os contornos sobrepostos neste painel representam o mapa de regressão de TSM para as mesmas ondas. A correlação significativa entre $\vec{\nabla} \cdot \vec{\tau}$ e TSM para as OITs domina próximo ao Equador, sobre as maiores amplitudes das ondas na TSM, entre as latitudes $2.875^{\circ} \mathrm{S}$ e $4.625^{\circ} \mathrm{N}$ e as longitudes $24.875^{\circ} \mathrm{W}$ e $6.125^{\circ} \mathrm{W}$. A extensão longitudinal desta influência é de $18,75^{\circ}$, mais de $1 / 3$ da extensão da bacia oceânica na latitude $0.875^{\circ} \mathrm{N}$. O coeficiente de correlação entre as séries filtradas na banda das OITs atinge valores superiores a $42 \%$. As maiores regressões de $\vec{\nabla} \cdot \vec{\tau}$ ocorrem na mesma região, onde a alteração do $\vec{\nabla} \cdot \vec{\tau}$ pela TSM atinge valores absolutos de $4 \cdot 10^{-8} \mathrm{~kg} \mathrm{~m}^{-2} \mathrm{~s}^{-2}{ }^{\circ} \mathrm{C}^{-1}$. A média dos valores de regressão para convergência e divergência ficam em torno de $2 \cdot 10^{-8} \mathrm{~kg} \mathrm{~m}^{-2} \mathrm{~s}^{-2}{ }^{\circ} \mathrm{C}^{-1}$. Isto significa que cada $1^{\circ} \mathrm{C}$ de anomalia de TSM causada pelas OITs o divergente da tensão de cisalhamento do vento altera em $2 \cdot 10^{-8} \mathrm{~kg} \mathrm{~m}^{-2} \mathrm{~s}^{-2}$. A Tabela 1 mostra que o valor típico da convergência da componente de larga escala da tensão de cisalhamento do vento na ZCIT é de $0,5 \cdot 10^{-7} \mathrm{~kg} \mathrm{~m}^{-2} \mathrm{~s}^{-2}$.

Portanto, podemos concluir que as OITs causam anomalias substanciais de $\vec{\nabla} \cdot \vec{\tau}$ próximo ao Equador, com $\sim 40 \%$ do valor obtido para a componente de larga escala na ZCIT.

Correlações significativas do $\vec{\nabla} \cdot \vec{\tau}$ também são observadas fora do Equador, 
porém com valores reduzidos, não ultrapassando $18 \%$. A alteração remota do $\vec{\nabla} \cdot \vec{\tau}$ pela TSM apresenta valores próximos a $7 \cdot 10^{-9} \mathrm{~kg} \mathrm{~m}^{-2} \mathrm{~s}^{-2}{ }^{\circ} \mathrm{C}^{-1}$, inferior à da região equatorial. Apesar da influência remota sobre o $\vec{\nabla} \cdot \vec{\tau}$ abranger toda a área de estudo, de $10^{\circ} \mathrm{S}$ a $20^{\circ} \mathrm{N}$, sua magnitude é menor e o mapa de regressão não apresenta um padrão de ondas tão bem definido quanto na região das maiores amplitudes de TSM.

A localização das anomalias de $\vec{\nabla} \cdot \vec{\tau}$ em relação às de TSM no painel inferior da Figura 27 revela que as máximas divergências do vento em baixos níveis ocorrem zonalmente defasadas em relação às máximas amplitudes de TSM, similar ao padrão da Figura 2 para a hipótese de Hayes et al. (1989) e Wallace et al. (1989), O padrão obtido na Figura 27 é resultado da aceleração do vento, predominantemente de leste, sobre as anomalias quentes de TSM e desaceleração sobre as anomalias frias, o que gera convergência (divergência) do vento a oeste das anomalias quentes (frias). Para corroborar a hipótese, calculamos a correlação entre as regressões de TSM e $\vec{\nabla} \cdot \vec{\tau}$ na latitude indicada pela linha roxa na Figura 27. A máxima correlação é de $94 \%, 51,4^{\circ}$ fora de fase, o que consideramos de acordo com a hipótese de Hayes et al. (1989) e Wallace et al. (1989). A diferença de fase entre as séries é totalmente dependente da relação entre as variáveis e a TSM no ponto de referência. $\mathrm{O}$ filtro utilizado não condiciona fase, apenas $L, T$ e $c_{p}$, o que reforça a hipótese de Hayes et al. (1989) e Wallace et al. (1989).

As anomalias de $\vec{\nabla} \cdot \vec{\tau}$ na região equatorial exibem um padrão inclinado na direção sudoeste-nordeste e não apresentam quebra de fase como as anomalias de TSM. A inclinação mais acentuada parece ser causada justamente pela assimetria inter-hemisférica de TSM. A defasagem de $180^{\circ}$ da distribuição de TSM inclina o padrão das anomalias de $\vec{\nabla} \cdot \vec{\tau}$ e permite que em ambos hemisférios ocorra divergência a oeste das anomalias frias e convergência a oeste das anomalias quentes, sem a formação de modos meridionais mais altos. A intensidade da alteração do $\vec{\nabla} \cdot \vec{\tau}$ pela TSM no hemisfério Norte é superior ao do hemisfério Sul, provavelmente, pelas menores anomalias de TSM neste hemisfério.

A convergência do vento em baixos níveis sobre o oceano promove movimento vertical ascendente da parcela de ar úmida. Assim, esperamos que a geração de vapor d'água ocorra sobre anomalias negativas de $\vec{\nabla} \cdot \vec{\tau}$. Como consequência, as maiores pre- 


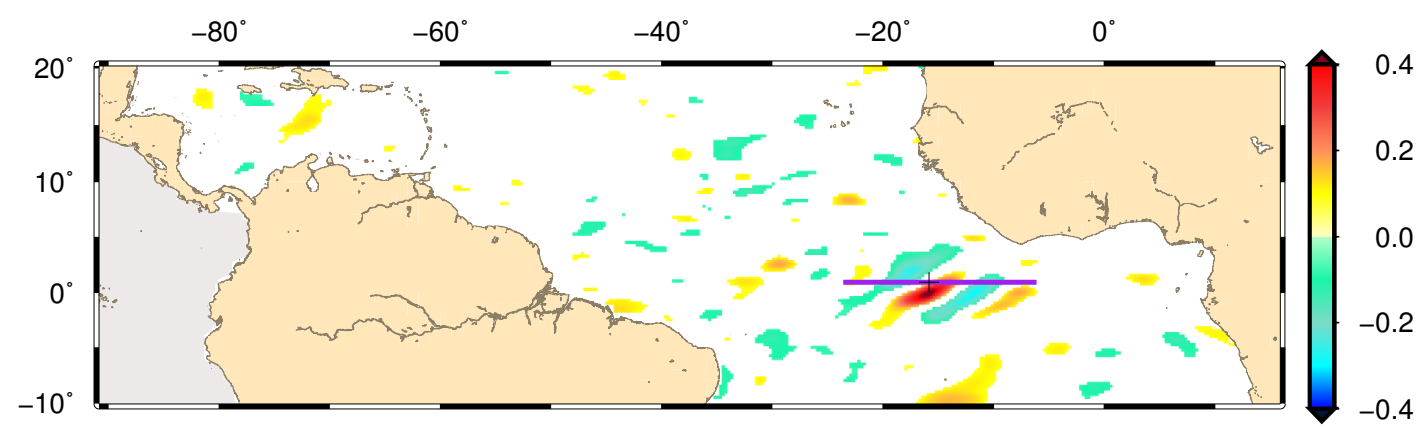

$\mathrm{kg} \mathrm{m}^{-2} \mathrm{~s}^{-2}{ }^{\circ} \mathrm{C}^{-1}$

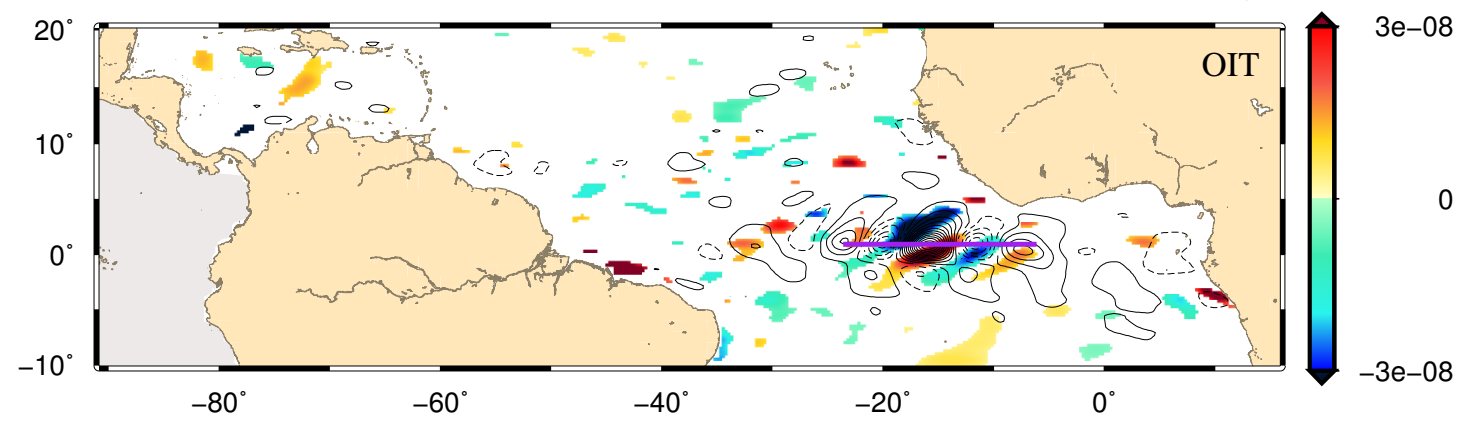

Figura 27: Superior: Correlação, com intervalo de confiança superior a 95\%, entre as séries temporais de $\vec{\nabla} \cdot \vec{\tau}$ e a série de TSM no ponto de referência indicado pelo símbolo + na banda das OITs. Inferior: Mapas de regressão de $\vec{\nabla} \cdot \vec{\tau}$ em relação à TSM no ponto $+\left(\mathrm{kg} \mathrm{m}^{-2} \mathrm{~s}^{-2}{ }^{\circ} \mathrm{C}^{-1}\right.$, escala de cores), onde a correlação é estatisticamente significativa, e de TSM em relação à TSM no ponto $+\left({ }^{\circ} \mathrm{C}^{\circ} \mathrm{C}^{-1}\right.$, contornos) na banda das OITs. Os contornos pretos contínuos (tracejados) representam regressão de TSM positiva (negativa) e estão plotados a cada $0,08{ }^{\circ} \mathrm{C}^{\circ} \mathrm{C}^{-1}$ entre $-1 \mathrm{e}$ $1{ }^{\circ} \mathrm{C}^{\circ} \mathrm{C}^{-1}$. A linha roxa é a seção latitudinal onde calculamos a correlação na Figura 28 .

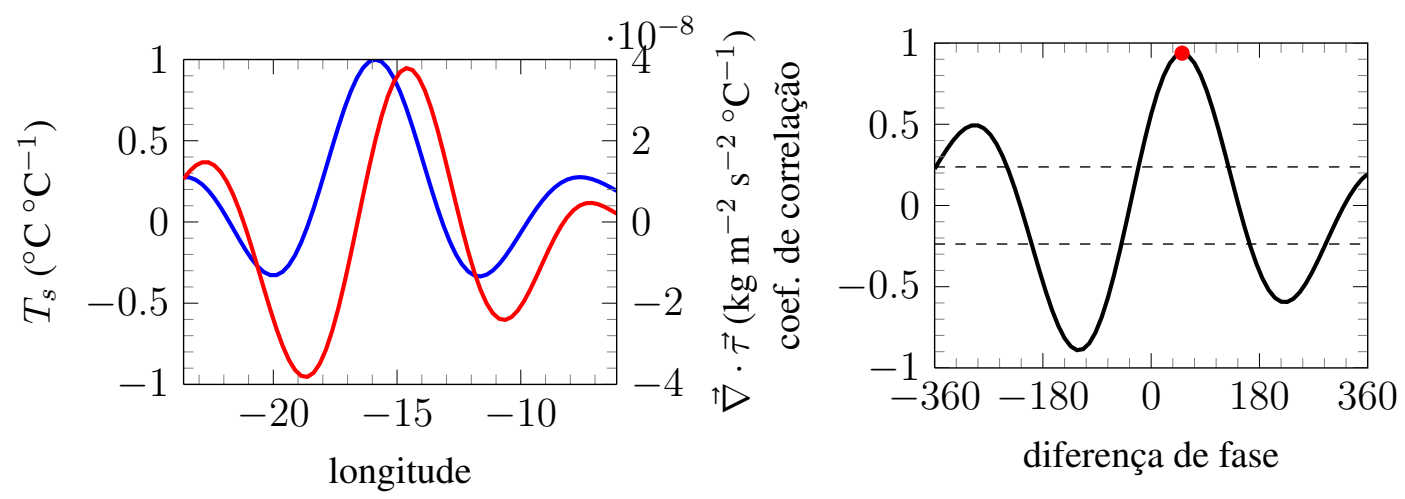

Figura 28: Esquerda: Regressões de $T_{s}\left({ }^{\circ} \mathrm{C}^{\circ} \mathrm{C}^{-1}\right)$ (linha azul) e $\vec{\nabla} \cdot \vec{\tau}\left(\mathrm{kg} \mathrm{m}^{-2} \mathrm{~s}^{-2}{ }^{\circ} \mathrm{C}^{-1}\right)$ (linha vermelha) para OITs na seção latitudinal a $0,875^{\circ} \mathrm{N}$ entre $23,625^{\circ} \mathrm{W}$ e $6,125^{\circ} \mathrm{W}$ representada pela linha roxa na Figura 27. Direita: Correlação com defasagem zonal entre as regressões de $T_{s}$ e $\vec{\nabla} \cdot \vec{\tau}$ na seção latitudinal. Diferença de fase positiva indica que $T_{s}$ lidera $\vec{\nabla} \cdot \vec{\tau}$. A máxima correlação está indicada pelo círculo vermelho. Correlações fora da região limitada pelas linhas tracejadas estão dentro do intervalo de $95 \%$ de confiança. 
cipitações são esperadas sobre regiões de convergência onde há vapor disponível para condensação. Portanto, é razoável supor que as anomalias positivas de $V$ e $P$ estejam a oeste das anomalias positivas de $\mathrm{TSM}, \sim 50^{\circ}$ fora de fase em relação a estas.

A Figura 29 mostra o mapa de correlação estatisticamente significativa de $V$ para as OITs (superior) e a sobreposição dos mapas de regressão de $V$ (escala de cores) e TSM (contornos) (inferior). Os mapas análogos de $P$ estão na Figura 30 . Correlações significativas entre $V$ e TSM, cujos valores absolutos chegam a 15\%, são observadas em torno do ponto de referência e a norte e a sul deste. Nas latitudes dominadas pelas ondas na TSM, as alterações significativas somente nas proximidades do ponto de referência, sugerem que TSM e $V$ estão em fase, isto é, que a geração de vapor d'água é favorecida sobre águas quentes. No ponto de referência, o aumento de $1{ }^{\circ} \mathrm{C}$ da TSM devido às OITs causa aumento de até $1 \mathrm{~mm}$ de $V$. Isto representa cerca de $2 \%$ dos valores médios de $V$ obtidos na ZCIT, de acordo com a Tabela 1 Apesar da região de influência significativa de $P$ ser relativamente pequena próxima ao ponto de referência, a alteração atinge 0,07 $\mathrm{mm} \mathrm{h}^{-1}$ para cada $1{ }^{\circ} \mathrm{C}$ de mudança na TSM e a correlação entre as variáveis é de $11 \%$. A fragmentação das regiões de influência das ondas nos dados de $P$ deve-se ao campo de precipitação ser bem menos homogêneo no tempo e no espaço que o de $V$.

A relação de fase entre os mapas de regressão de 1 ponto de $\vec{\nabla} \cdot \vec{\tau}$ e TSM sugere que a resposta do vento à TSM ocorre via mecanismo proposto por Hayes et al. (1989) e Wallace et al. (1989), Já a ausência de correlações significativas zonalmente defasadas em relação ao ponto de referência indica que o $V$ responde localmente à TSM segundo hipótese de Lindzen e Nigam (1987). A diferença nos processos que relacionam as variáveis atmosféricas às alterações de TSM pode ser explicada pela advecção horizontal e pela diferença entre os níveis verticais representados pelo $\vec{\nabla} \cdot \vec{\tau}$ e pelo $V$. O $\vec{\nabla} \cdot \vec{\tau}$ é uma medida inerente à superfície do mar, enquanto o $V$ é uma medida integrada verticalmente. Como observado por Small et al. (2003), o perfil de $V$ pode sofrer advecção horizontal dependendo do nível vertical. Dessa forma, se a convergência em baixos níveis gera vapor d'água próximo à superfície, ao ascender na atmosfera, esta anomalia de $V$ pode ser advectada pela existência de um possível fluxo zonal. Como a medida do satélite não 
permite uma visão 3D da variável, o que observa-se é o perfil vertical de $V$ projetado sobre um único nível. Dessa forma, se as anomalias positivas de $V$ estiverem sobre as anomalias negativas de $\vec{\nabla} \cdot \vec{\tau}$ e houver advecção, a fase esperada entre as anomalias não será respeitada. Portanto, como sugerido por Small et al. (2003), o mecanismo dominante que relaciona as anomalias de TSM, $\vec{\nabla} \cdot \vec{\tau}$ e $V$ não pode ser determinado se a advecção horizontal não for levada em conta.

As maiores influências da TSM sobre os campos de $V$ e $P$ ocorrem ao norte a ao sul da região de domínio das OITs na TSM, atingindo $9^{\circ}$ de latitude. Ao sul, as correlações chegam a $15 \%$ em ambos os campos e as variações de $V$ e $P$ induzidas remotamente pela TSM alcançam $1,1 \mathrm{~mm}^{\circ} \mathrm{C}^{-1} \mathrm{e} 0,05 \mathrm{~mm} \mathrm{~h}^{-1}{ }^{\circ} \mathrm{C}^{-1}$, respectivamente. As correlações entre as variáveis e a TSM atingem $-15 \%$ entre o Equador e $9^{\circ} \mathrm{N}$. Durante o período das ondas, esta região está contida na ZCIT, de acordo com a Tabela 11. Portanto a influência remota nos campos de $V$ e $P$ atinge a ZCIT, como verificado por Wu e Bowman (2007a), A alteração de $V$ pela TSM chega a $-1,1 \mathrm{~mm}{ }^{\circ} \mathrm{C}^{-1}$ e a de $P$ atinge $-0,11 \mathrm{~mm} \mathrm{~h}^{-1}{ }^{\circ} \mathrm{C}^{-1}$. Considerando que a ZCIT se caracteriza por valores de vapor d'água em torno $50 \mathrm{~mm}$, a alteração de $1{ }^{\circ} \mathrm{C}$ na TSM na região equatorial altera o $V$ na ZCIT em cerca de $2 \%$.

A consistência dos mapas de regressão de $V$ e $P$ para OITs corrobora a hipótese de influência remota. A Figura 31 mostra os mapas de regressão de $V$ (cores) e $P$ (contornos) onde a correlação entre as variáveis e a TSM no ponto de referência é estatisticamente significativa. A correlação ponto a ponto entre os mapas de regressão é de 95\%. Regressões positivas (negativas) de $P$ são observadas sobre regressões positivas (negativas) de $V$. A chuva é promovida somente onde há vapor d'água disponível para condensação. Como a variância da precipitação é maior na ZCIT (Figura 25), a influência das OITs na TSM é amplificada na região.

A nítida separação das anomalias positivas e negativas de $V$ e $P$ entre os hemisférios na Figura 31 pode ser atribuída à posição da ZCIT. A influência negativa na formação de vapor d'água e precipitação na ZCIT ocorre quando há aumento da TSM no ponto de referência. Durante a fase oposta, isto é, quando a TSM no ponto é anomalamente fria, há favorecimento de $V$ e $P$ na ZCIT e anomalias negativas ao sul. 

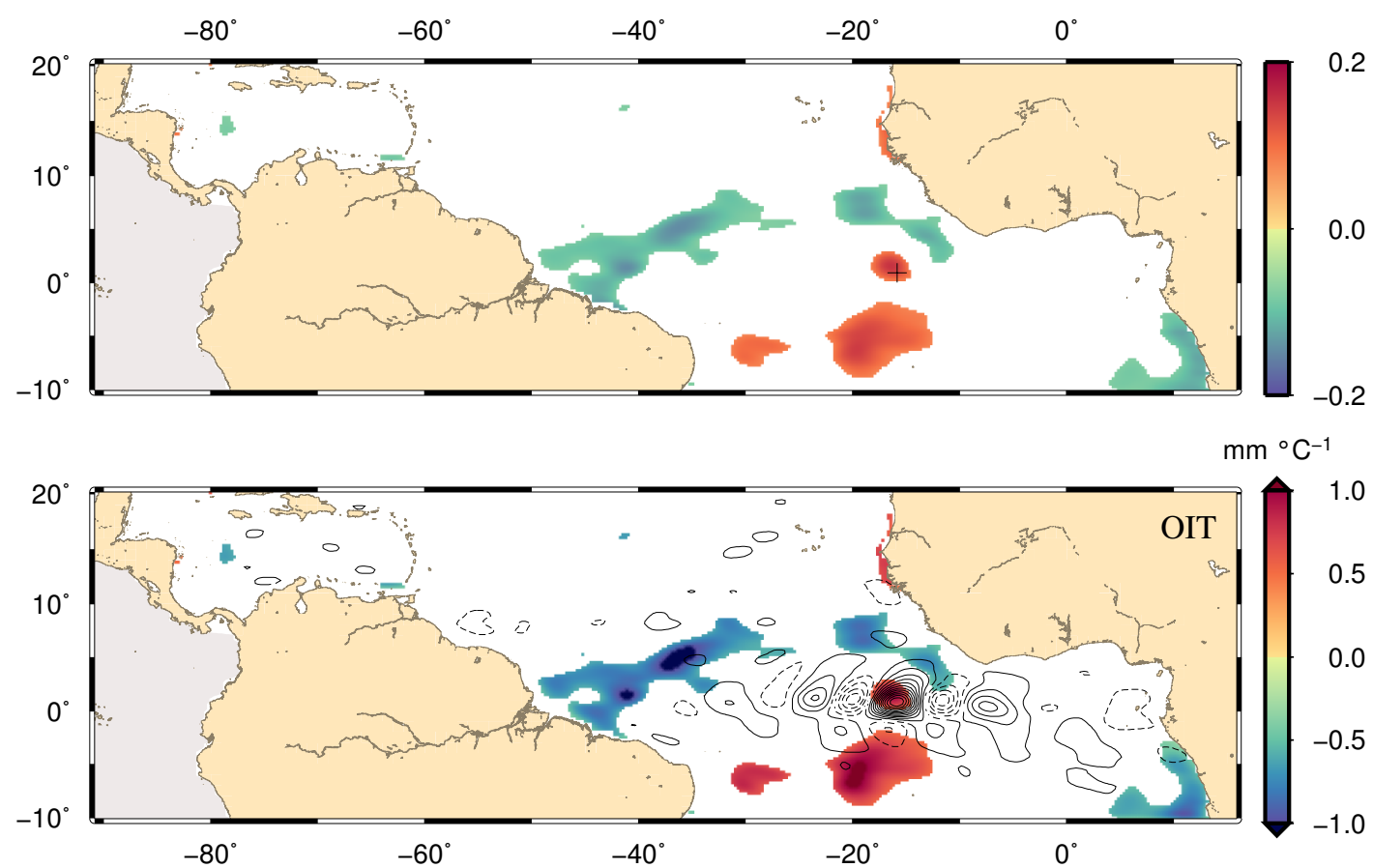

Figura 29: Similar à Figura 27 para os mapas de correlação (superior) e de regressão de $V$ $\left(\mathrm{mm}{ }^{\circ} \mathrm{C}^{-1}\right.$, inferior) em relação à TSM no ponto de referência para OITs.

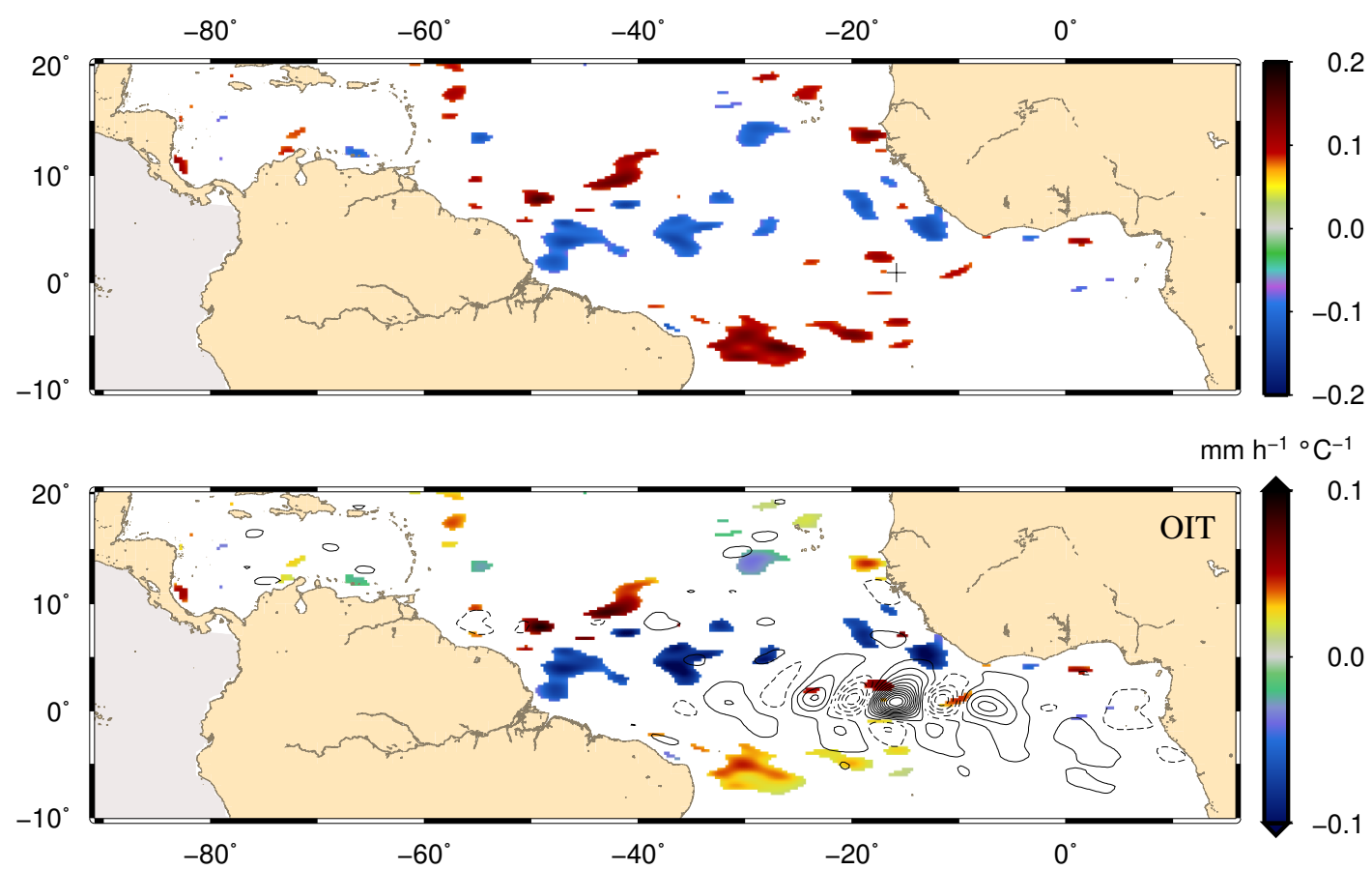

Figura 30: Similar à Figura 27 para os mapas de correlação (superior) e de regressão de $P(\mathrm{~mm}$ $\mathrm{h}^{-1}{ }^{\circ} \mathrm{C}^{-1}$, inferior) em relação à TSM no ponto de referência para OITs. 


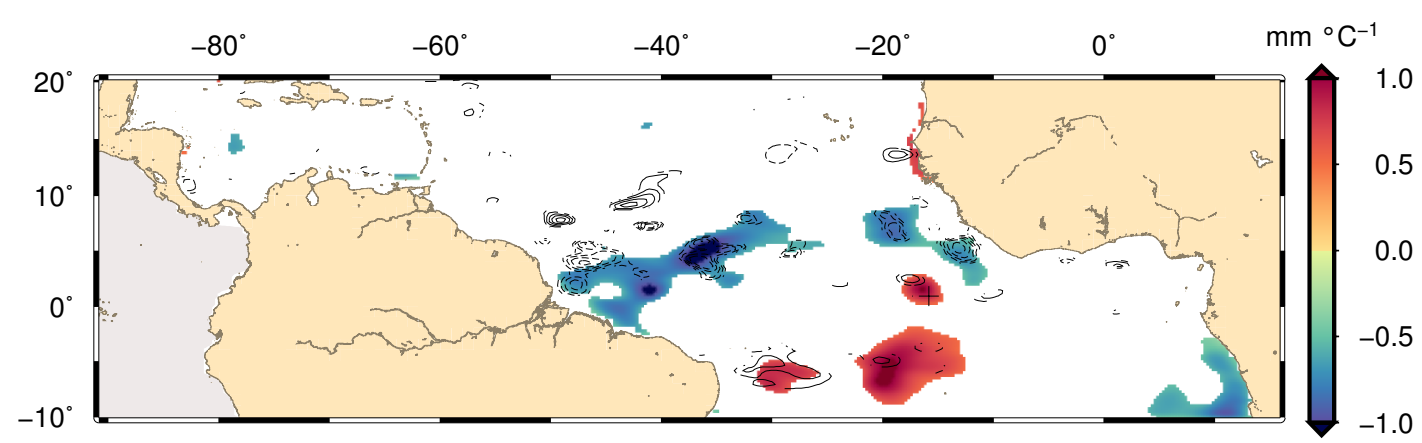

Figura 31: Mapas de regressão de $V\left(\mathrm{~mm}^{\circ} \mathrm{C}^{-1}\right.$, escala de cores) e de $P\left(\mathrm{~mm} \mathrm{~h}^{-1}{ }^{\circ} \mathrm{C}^{-1}\right.$, contornos) em relação à TSM no ponto de referência indicado pelo símbolo + na banda das OITs. Apenas as regiões onde a correlação entre as variáveis e a TSM é estatiscamente significativa estão representadas. Os contornos pretos contínuos (tracejados) representam regressões de $P$ positivas (negativas) e estão plotados a cada $0,01 \mathrm{~mm} \mathrm{~h}^{-1}{ }^{\circ} \mathrm{C}^{-1}$ entre $-0,1 \mathrm{e} 0,1 \mathrm{~mm} \mathrm{~h}^{-1}{ }^{\circ} \mathrm{C}^{-1}$.

Uma vez que as alterações do $\vec{\nabla} \cdot \vec{\tau}$ pela TSM ocorrem localmente e divergência em baixos níveis está associada a movimentos verticais e formação de vapor d'água e possivelmente precipitação, as anomalias de $V$ e $P$ deveriam ocorrer sobre as máximas anomalias de TSM, em resposta à alteração local do vento. Para que as alterações de $V$ e $P$ alcancem latitudes maiores que a da região dominada pelas anomalias de TSM, é necessário que algum mecanismo de transporte meridional advecte as anomalias para fora do local de geração. A componente meridional do vento na região de ocorrência das maiores anomalias de TSM é predominantemente de sul. Uma vez que o parâmetro de Coriolis é nulo no Equador, esta componente associada à ZCIT mais ao Norte é que induz a divergência equatorial e a consequente ressurgência de águas frias que propiciam a geração das ondas nos dados de TSM. As ondas por sua vez alteram o padrão de ventos localmente que induz anomalias de $V$ e $P$. Estas anomalias são advectadas para outras latitudes, alcançando até $10^{\circ}$ de distância do Equador. Portanto as anomalias mais distantes da área de geração são transportadas meridionalmente por cerca de 1000 km em 21 dias, o que corresponde a uma velocidade de $0,5 \mathrm{~m} \mathrm{~s}^{-1}$, o que é razoável face às velocidades meridionais do vento obtidas por satélites na região equatorial. A componente meridional do vento que desloca a ZCIT para o hemisfério Norte pode supostamente transportar as anomalias de $V$ e $P$ para a ZCIT. Já o transporte do sinal para sul requer que exista uma componente meridional negativa, o que não ocorre durante o período das ondas. Portanto, 
sugerimos que exista um possível padrão de teleconexão. Mas somente com modelagem numérica será possível avaliar se uma forçante oceânica na escala das ondas permite uma resposta atmosférica meridionalmente remota.

A sobreposição das regressões de TSM e $\vec{\nabla} \cdot \vec{\tau}$ para as ORCs mostra que a relação local entre as variáveis é semelhante às OITs (painel inferior da Figura 32). A correlação máxima de $74 \%$ entre as regressões na latitude indicada na Figura se dá a $129^{\circ}$ graus fora de fase com convergência do vento a oeste das anomalias quentes (Figura 33), o que pode sugerir dominância do mecanismo proposto por Hayes et al. (1989) e Wallace et al. (1989), O vento responde localmente às variações de TSM na região equatorial de forma a acelerar sobre águas quentes e desacelerar sobre águas frias causando centros de convergência e divergência sobre os máximos gradientes de TSM.

Na região de maiores amplitudes de TSM, os valores absolutos da correlação entre $\vec{\nabla} \cdot \vec{\tau}$ e a TSM no ponto de referência chegam a $39 \%$ (painel superior da Figura 32). As alterações de $\vec{\nabla} \cdot \vec{\tau}$ atingem $8,8 \cdot 10^{-8} \mathrm{~kg} \mathrm{~m}^{-2} \mathrm{~s}^{-2}{ }^{\circ} \mathrm{C}^{-1}$ nos locais de divergência e $1,3 \cdot 10^{-7} \mathrm{~kg} \mathrm{~m}^{-2} \mathrm{~s}^{-2}{ }^{\circ} \mathrm{C}^{-1}$ nas regiões de convergência (painel inferior da Figura 32 ,. Esta alteração do $\vec{\nabla} \cdot \vec{\tau}$ é comparável aos valores médios da componente de larga escala da convergência da tensão de cisalhamento na ZCIT. A alteração remota do campo de $\vec{\nabla} \cdot \vec{\tau}$ pela TSM nas ORCs é comparativamente mais significativa que nas OITs e também ocorrem em toda área de estudo. Ao norte da região de domínio das ondas, em $6^{\circ} \mathrm{N}$, as variações atingem $4,2 \cdot 10^{-8} \mathrm{~kg} \mathrm{~m}^{-2} \mathrm{~s}^{-2}{ }^{\circ} \mathrm{C}^{-1} \mathrm{e}-2,7 \cdot 10^{-8} \mathrm{~kg} \mathrm{~m}^{-2} \mathrm{~s}^{-2}{ }^{\circ} \mathrm{C}^{-1}$ e as correlações em relação ao ponto de referência alcançam $28 \%$. Entretanto, o mecanismo que altera os padrões de divergência em baixos níveis pelo campo de temperatura remoto é desconhecido.

Nas ORCs, as maiores alterações de $V$ estatisticamente significativas ocorrem sobre as maiores amplitudes de TSM, como pode ser obervado na Figura 34. As máximas correlações ocorrem próximo ao ponto de referência e alcançam 34\%. A variação de $V$ atinge $1,5 \mathrm{~mm}^{\circ} \mathrm{C}^{-1}$. Considerando os valores médios de $V$ na ZCIT da Tabela 1 , a passagem de ORCs promove alterações de $V$ com cerca de $3 \%$ dos valores da ZCIT. Correlações negativas que chegam a $-15 \%$ ocorrem na latitude próxima a do ponto de referên- 
cia, onde a influência alcança $-0,65 \mathrm{~mm}^{\circ} \mathrm{C}^{-1}$. Na região mais ao norte, em torno de $10^{\circ} \mathrm{N}$, as correlações negativas alcançam $-13 \%$ com variações de $-0,68 \mathrm{~mm}{ }^{\circ} \mathrm{C}^{-1}$. Nas ORCs, a influência remota do $V$ parece ser uma resposta da variação local de TSM associada à TSM no ponto de referência. Diferentemente das OITs, a influência deve-se à resposta remota da TSM no local. Nas OITs, exceto muito próximo ao ponto de referência, não se observa a sobreposição de anomalias de TSM e $V$ estatisticamente significativas.

A Figura 35 mostra que as maiores alterações da precipitação pela TSM na banda das ORCs ocorrem ao norte do ponto de referência, em torno de $10^{\circ} \mathrm{N}$. A correlação entre as variáveis chega a $19 \%$ e as variações atingem $\pm 0,08 \mathrm{~mm} \mathrm{~h}^{-1}{ }^{\circ} \mathrm{C}^{-1}$. Outra região que se destaca pelas grandes alterações de $V$ e $P$ nas Figuras 34 e 35 é a área próxima à porção oeste da África. Aparentemente, a localização mais a leste do ponto de referência para as regressões nas ORCs é a causa das maiores variações dos campos atmosféricos próximas ao continente africano. Na costa da Libéria, as variações de $V$ e $P$ atingem $1,3 \mathrm{~mm}{ }^{\circ} \mathrm{C}^{-1}$ e $0,1 \mathrm{~mm} \mathrm{~h}^{-1}{ }^{\circ} \mathrm{C}^{-1}$, respectivamente. Próximo a Serra Leoa ocorrem anomalias negativas de $P$ cuja alteração chega a $-0,05 \mathrm{~mm} \mathrm{~h}^{-1}{ }^{\circ} \mathrm{C}^{-1}$, mas que não são acompanhadas por alterações negativas no campo de $V$.

A coincidência espacial entre os mapas de reressão de $V$ e $P$ para as ORCs (Figura 36) é inferior em relação às OITs. A correlação entre os mapas de regressão nas regiões é de $68 \%$. Na ZCIT, entre o Equador e $15^{\circ} \mathrm{N}$ na Figura 36, a alteração do $V$ é predominantemente negativa quando há aumento da TSM no ponto de referência, como ocorre nas OITs. Entretanto, estas anomalias negativas de $V$ não são acompanhadas por alterações negativas de $P$. Além disso, o favorecimento da precipitação nestas latitudes ocorrem onde a geração de vapor d'água não é estatisticamente significativa. 


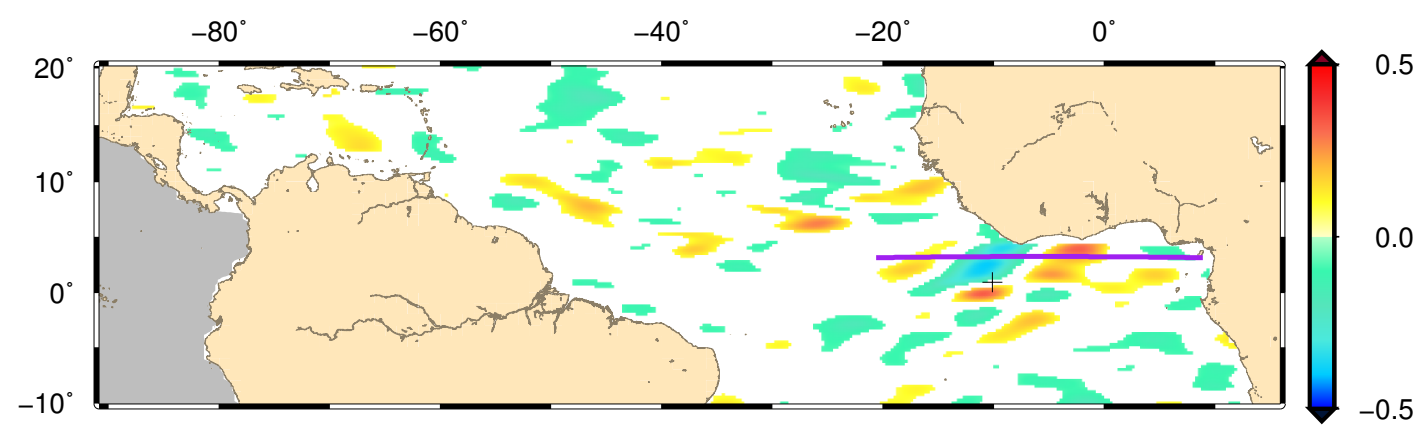

$\mathrm{kg} \mathrm{m}^{-2} \mathrm{~s}^{-2}{ }^{\circ} \mathrm{C}^{-1}$

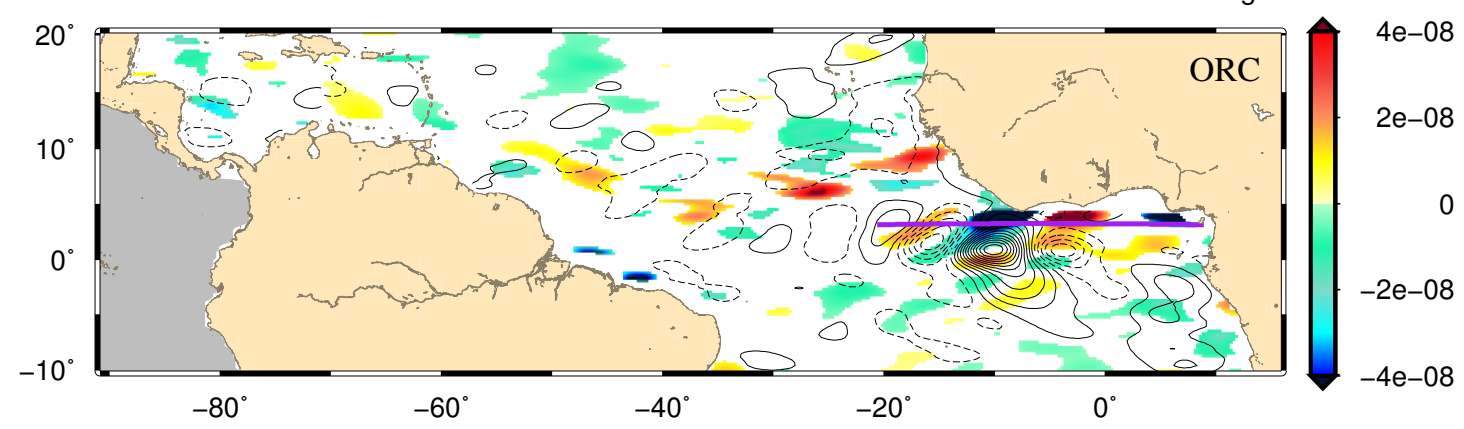

Figura 32: Superior: Correlação, com intervalo de confiança superior a 95\%, entre as séries temporais de $\vec{\nabla} \cdot \vec{\tau}$ e a série de TSM no ponto de referência indicado pelo símbolo + na banda das ORCs. Inferior: Mapas de regressão de $\vec{\nabla} \cdot \vec{\tau}$ em relação à TSM no ponto $+\left(\mathrm{kg} \mathrm{m}^{-2} \mathrm{~s}^{-2}{ }^{\circ} \mathrm{C}^{-1}\right.$, escala de cores), onde a correlação é estatisticamente significativa, e de TSM em relação à TSM no ponto $+\left({ }^{\circ} \mathrm{C}^{\circ} \mathrm{C}^{-1}\right.$, contornos) na banda das ORCs. Os contornos pretos contínuos (tracejados) representam regressão de TSM positiva (negativa) e estão plotados a cada $0,08{ }^{\circ} \mathrm{C}^{\circ} \mathrm{C}^{-1}$ entre $-1 \mathrm{e}$ $1{ }^{\circ} \mathrm{C}^{\circ} \mathrm{C}^{-1}$. A linha roxa é a seção latitudinal onde calculamos a correlação na Figura 33 .
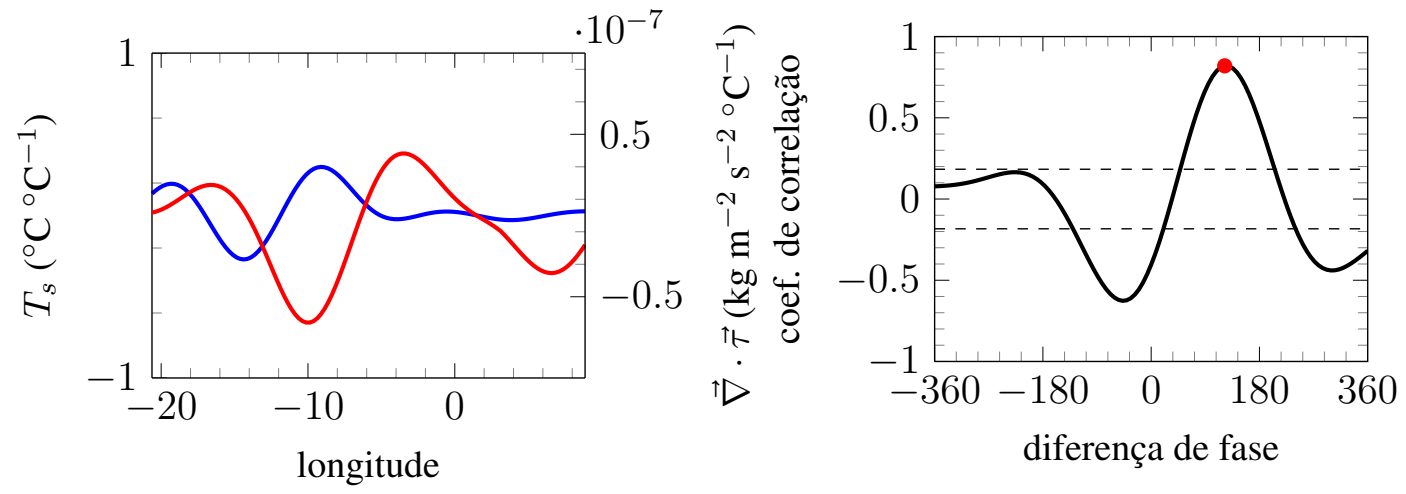

Figura 33: Esquerda: Regressões de $T_{s}\left({ }^{\circ} \mathrm{C}^{\circ} \mathrm{C}^{-1}\right)$ (linha azul) e $\vec{\nabla} \cdot \vec{\tau}\left(\mathrm{kg} \mathrm{m}^{-2} \mathrm{~s}^{-2}{ }^{\circ} \mathrm{C}^{-1}\right)$ (linha vermelha) para ORCs na seção latitudinal a $3,125^{\circ} \mathrm{N}$ entre $20,625^{\circ} \mathrm{W}$ e $8,875^{\circ} \mathrm{W}$ representada pela linha roxa na Figura 32 Direita: Correlação com defasagem zonal entre as regressões de $T_{s}$ e $\vec{\nabla} \cdot \vec{\tau}$ na seção latitudinal. Diferença de fase positiva indica que $T_{s}$ lidera $\vec{\nabla} \cdot \vec{\tau}$. A máxima correlação está indicada pelo círculo vermelho. Correlações fora da região limitada pelas linhas tracejadas estão dentro do intervalo de $95 \%$ de confiança. 


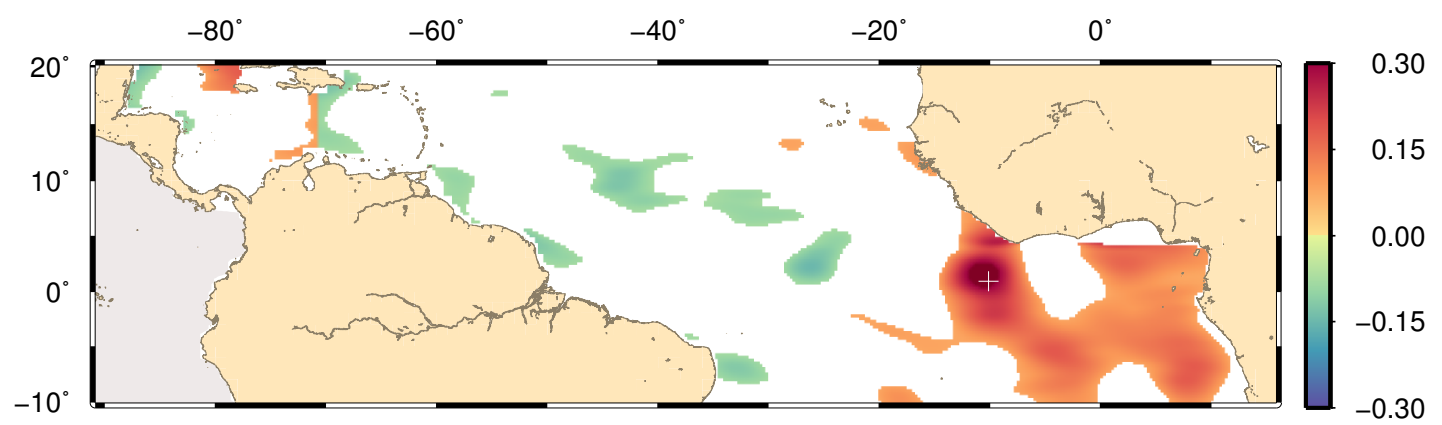

$\mathrm{mm}{ }^{\circ} \mathrm{C}^{-1}$

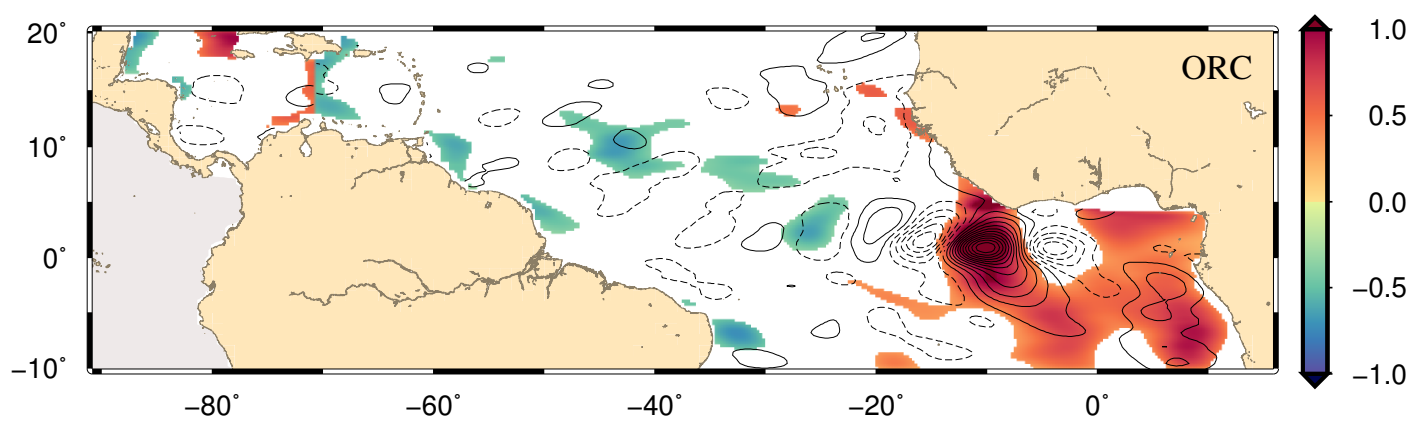

Figura 34: Similar à Figura 32 para os mapas de correlação (superior) e de regressão de $V$ $\left(\mathrm{mm}{ }^{\circ} \mathrm{C}^{-1}\right.$, inferior) em relação à TSM no ponto de referência para ORCs.
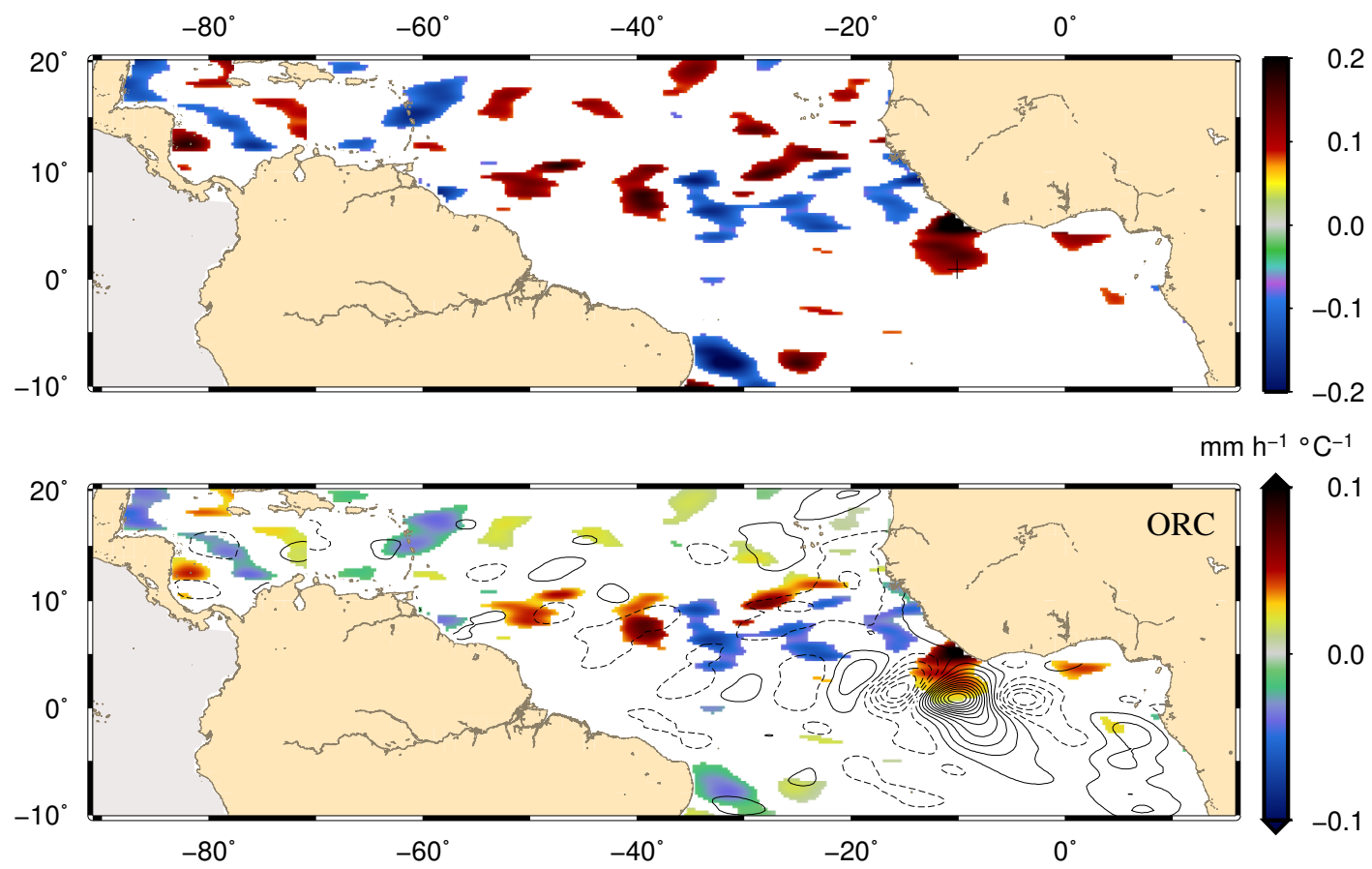

Figura 35: Similar à Figura 32 para os mapas de correlação (superior) e de regressão de $P(\mathrm{~mm}$ $\mathrm{h}^{-1}{ }^{\circ} \mathrm{C}^{-1}$, inferior) em relação à TSM no ponto de referência para ORCs. 


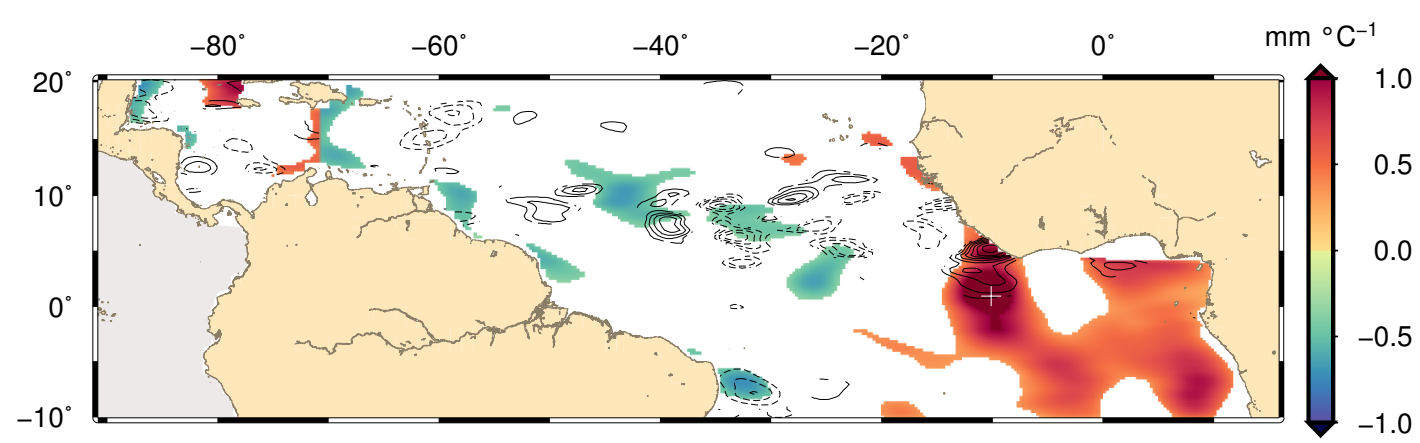

Figura 36: Mapas de regressão de $V\left(\mathrm{~mm}^{\circ} \mathrm{C}^{-1}\right.$, escala de cores) e de $P\left(\mathrm{~mm} \mathrm{~h}^{-1}{ }^{\circ} \mathrm{C}^{-1}\right.$, contornos) em relação à TSM no ponto de referência indicado pelo símbolo + na banda das ORCs. Apenas as regiões onde a correlação entre as variáveis e a TSM é estatiscamente significativa estão representadas. Os contornos pretos contínuos (tracejados) representam regressões de $P$ positivas (negativas) e estão plotados a cada $0,01 \mathrm{~mm} \mathrm{~h}^{-1}{ }^{\circ} \mathrm{C}^{-1}$ entre $-0,1 \mathrm{e} 0,1 \mathrm{~mm} \mathrm{~h}^{-1}{ }^{\circ} \mathrm{C}^{-1}$.

\subsubsection{Relação entre TSM e $\eta$}

Polito et al. (2001) sugeriram duas hipóteses relacionadas aos processos de interação entre as anomalias de $\eta$ e TSM. Na primeira hipótese, as anomalias de $\eta$ devem-se às anomalias de densidade dominadas por processo de expansão térmica associada às variações de TSM. Neste caso, as anomalias de $\eta$ e TSM estão em fase. Na segunda hipótese, o gradiente meridional de TSM devido à ressurgência é advectado pelas correntes geostróficas causadas pelas anomalias de $\eta$. Neste caso, as anomalias de $\eta$ e TSM estão $90^{\circ}$ fora de fase.

A sobreposição dos mapas de regressão de TSM e $\eta$ permite testar as hipóteses. Entretanto, como $\eta$ não contém o sinal das OITs, a hipótese não pode ser avaliada para estas ondas. A diferença entre os mapas de regressão de $\eta$ para OITs e ORCs pode ser vista na Figura 26. Apesar de haver sinais de padrão ondulatório, os valores de regressão para OITs nos paineis inferiores da Figura 26 são cerca de 7 vezes menor aos das ORCs. Além disso, a correlação significativa entre $\eta$ e TSM nas OITs é restrita à região próxima ao ponto de referência (não mostrado).

A Figura 37 mostra os mapas de regressões de $\eta$ (cores) e TSM (contornos) para ORCs sobrepostos. No caso da regressão de $\eta$, apenas as regiões onde a correlação de 1 ponto está dentro do intervalo de confiança de $95 \%$ estão representadas. Sobre regressões 
positivas (negativas) de TSM ocorrem regressões positivas (negativas) de $\eta$. A correlação das regressões na seção latitudinal indicada pela linha roxa é máxima com lag 0 e alcança 92\%. Portanto, de acordo com a hipótese de Polito et al. (2001), nas ORCs as anomalias de $\eta$ são causadas pelas anomalias de TSM por processsos de expansão térmica.

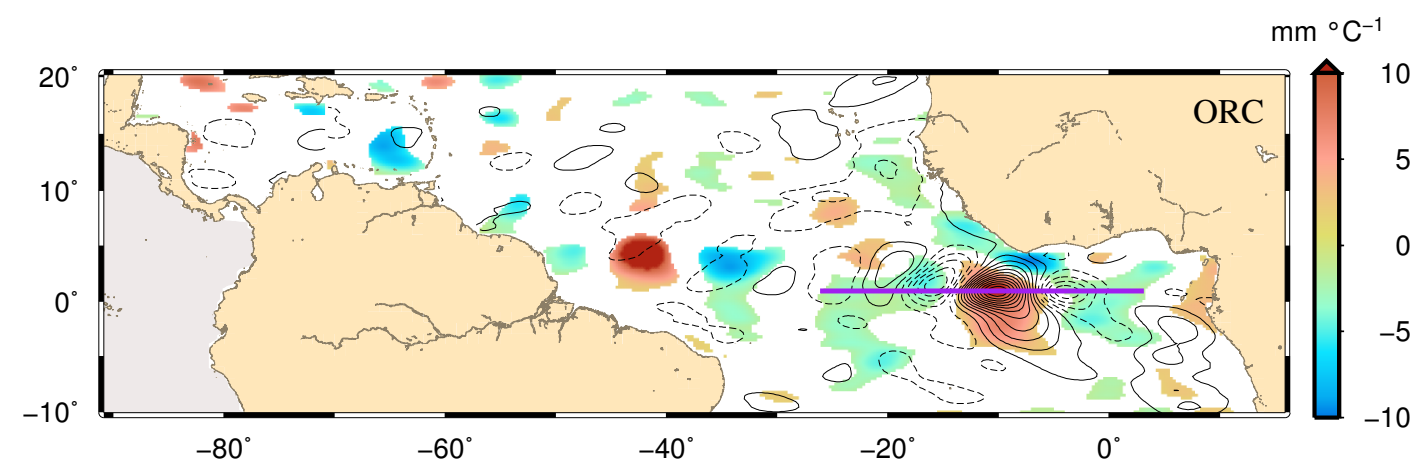

Figura 37: Mapas de regressão de $\eta\left(\mathrm{mm}{ }^{\circ} \mathrm{C}^{-1}\right.$, escala de cores $)$ e de $\operatorname{TSM}\left({ }^{\circ} \mathrm{C}^{\circ} \mathrm{C}^{-1}\right.$, contornos) em relação à TSM no ponto de referência localizado a $0,875^{\circ} \mathrm{N} 10,125^{\circ} \mathrm{W}$ na banda das ORCs. Apenas as regiões onde a correlação entre $\eta$ e TSM no ponto de referência é estatiscamente significativa estão representadas. Os contornos pretos contínuos (tracejados) representam regressões de TSM positivas (negativas) e estão plotados a cada $0,08{ }^{\circ} \mathrm{C}^{\circ} \mathrm{C}^{-1}$ entre -1 e $1{ }^{\circ} \mathrm{C}^{\circ} \mathrm{C}^{-1}$.
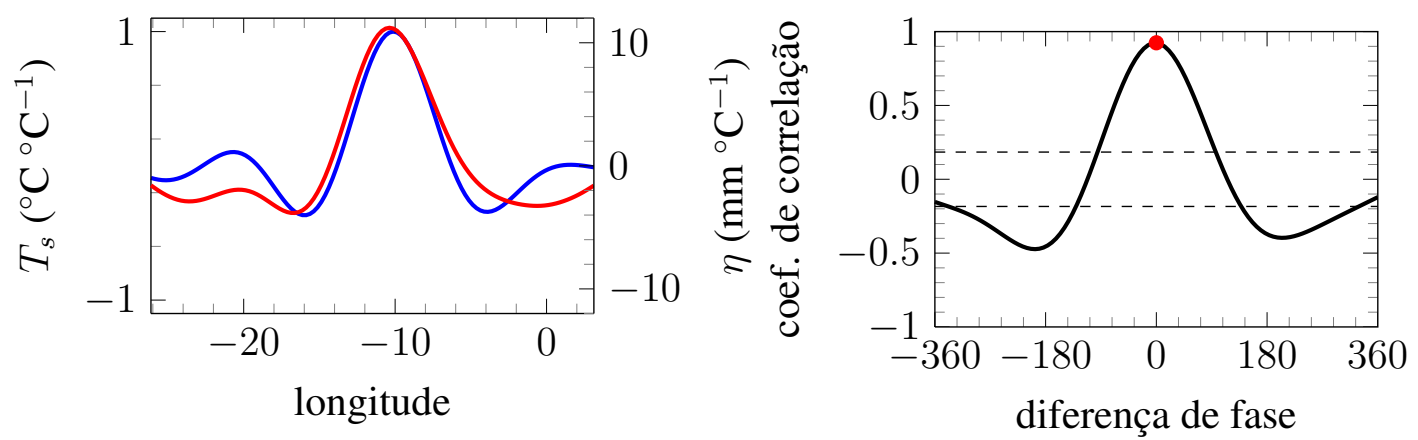

Figura 38: Esquerda: $T_{s}\left({ }^{\circ} \mathrm{C}^{\circ} \mathrm{C}^{-1}\right)$ (linha azul) e $\eta\left(\mathrm{mm}^{\circ} \mathrm{C}^{-1}\right)$ (linha vermelha) na seção latitudinal a $0,875^{\circ} \mathrm{N}$ entre $-23,625^{\circ} \mathrm{W}$ e $6,125^{\circ} \mathrm{W}$ representada pela linha roxa na Figura 37 . Direita: Correlação com defasagem zonal entre $T_{s}$ e $\eta$ na seção latitudinal. Diferença de fase positiva indica que $T_{s}$ causa $\eta$. A máxima correlação está indicada pelo círculo vermelho. Correlações fora da região limitada pelas linhas tracejadas estão dentro do intervalo de $95 \%$ de confiança. 


\subsection{Salinidade}

As Figuras 39 e 40 mostram as séries temporais de salinidade $(S)$ das boias PIRATA filtradas para ORCs e OITs, respectivamente. Em cada Figura, também estão representadas as ondas nos dados de $P$ na coordenada geográfica das boias. Para isolar os sinais nos dados de salinidade filtramos cada série com 2 filtros do tipo gaussiano, um com 49 dias e outro com 21 dias. O resultado da aplicação do filtro para ORCs é muito similar à série original. Assim, ao subtrair o sinal resultante dos dados originais restou apenas um ruído de alta frequência. Como o filtro para OITs contém apenas 3 pontos, a série resultante é idêntica à original. O que se observa nos sinais denominados de ORCs é na verdade a própria anomalia de salinidade suavizada e nos sinais denominados OITs o ruído de alta frequência desta anomalia. Os dados apresentaram grande carência de dados de fator de qualidade 1 e mesmo utilizando dados de fator de qualidade 2 dificilmente as séries possuíamos 2 anos de dados contínuos. 10 das 18 boias foram assim descartadas. A falta de conclusão a respeito da influência das ondas na salinidade superficial via anomalias de precipitação pode ser atribuída tanto à carência de séries temporais longas quanto à má qualidade dos dados.

É difícil identificar alguma associação entre as séries temporais de $P$ e $S$ nas Figuras 39 e 40 . As correlações obtidas entre as variáveis nas bandas das ORCs e OITs e os valores de $p$ de probabilidade se obter a mesma correlação a partir de séries aleatórias estão na Tabela 3 . Exceto nas boias localizadas nas latitudes $12^{\circ} \mathrm{N}$ e $6^{\circ} \mathrm{S}$, a correlação entre as séries está fora do intervalo de $95 \%$ de confiança. Em alguns casos, a chance de se obter a mesma correlação randomicamente chega a 78\%. Para as correlações estatiscamente significativas, os valores foram $-0,24$ e 0,19 para as duas boias da latitude $12^{\circ} \mathrm{N}$ na banda das ORCs. Como o aumento da precipitação acarreta no decréscimo da salinidade superficial, para que possamos atribuir a variabilidade de $S$ à de $P$, a correlação entre elas deve ser negativa. Apesar da correlação em $12^{\circ} \mathrm{N} 23^{\circ} \mathrm{W}$ ser negativa, a falta de correlações significativas nos outros pontos sugere que a relação procurada entre $P$ e $S$ não pode ser avaliada neste conjunto de dados.

Nas OITS, as boias localizadas nas latitudes $12^{\circ} \mathrm{N}, 6^{\circ} \mathrm{S}$ e $8^{\circ} \mathrm{S}$, as maiores ampli- 
Tabela 3: Coeficientes de correlação (c) entre $P$ e $S$ e valores de $p$ para ORCs e OITs nas latitudes das boias PIRATA. As correlações estatisticamente significativas estão representadas em negrito. O percentual de dias com ausência de dados em relação à duração da série temporal de cada boia estão indicados na última coluna.

\begin{tabular}{cccccc}
\hline latitude & $c_{\text {orc }}$ & $p_{\text {orc }}$ & $c_{\text {oit }}$ & $p_{\text {oit }}$ & $\%$ ausência \\
\hline $0^{\circ} 10^{\circ} \mathrm{W}$ & 0,03 & 0,78 & $-0,09$ & 0,34 & $4 \%$ \\
$6^{\circ} \mathrm{S} 10^{\circ} \mathrm{W}$ & $-0,10$ & 0,31 & $-\mathbf{0 , 3 4}$ & $\mathbf{4 \cdot 1 0}-\mathbf{6}$ & $17 \%$ \\
$8^{\circ} \mathrm{S} 30^{\circ} \mathrm{W}$ & $-0,03$ & 0,67 & 0,12 & 0,09 & $3 \%$ \\
$10^{\circ} \mathrm{N} 10^{\circ} \mathrm{W}$ & $-0,04$ & 0,65 & $-0,04$ & 0,70 & $9 \%$ \\
$12^{\circ} \mathrm{N} 23^{\circ} \mathrm{W}$ & $\mathbf{- 0 , 2 4}$ & $\mathbf{0 , 0 1}$ & $-0,05$ & 0,62 & $14 \%$ \\
$12^{\circ} \mathrm{N} 38^{\circ} \mathrm{W}$ & $\mathbf{0 , 1 9}$ & $\mathbf{0 , 0 1}$ & $-0,05$ & 0,51 & $7 \%$ \\
$15^{\circ} \mathrm{N} 38^{\circ} \mathrm{W}$ & $-0,10$ & 0,33 & $-0,03$ & 0,78 & $4 \%$ \\
$20^{\circ} \mathrm{N} 38^{\circ} \mathrm{W}$ & 0,03 & 0,78 & $-0,13$ & 0,20 & $5 \%$ \\
\hline
\end{tabular}

tudes de $S$ coincidem com as de $P$. Mas apenas a boia localizada em $6^{\circ} \mathrm{S} 10^{\circ} \mathrm{W}$ revelou correlação estatisticamente significativa e negativa, de -0,34. Entretanto, a ausência de resultados estatiscamente significativos nas outras boias torna duvidosa qualquer conclusão a respeito da influência das ondas na salinidade superficial causada por anomalias de precipitação. As boias cujas séries possuem o maior percentual de ausência de dado são as únicas que possuem correlação significativa e negativa (Tabela 3). As boias localizadas a $6^{\circ} \mathrm{S} 10^{\circ} \mathrm{W}$ e $12^{\circ} \mathrm{N} 23^{\circ} \mathrm{W}$ tiveram $17 \%$ e $14 \%$ dos pontos da série temporal de 2 anos interpolados. A correlação significativa é provavelmente resultado da interpolação e criação de sinais artificais. Portanto, a carência de dados de boa qualidade impediu a avaliação da hipótese científica deste trabalho.

As Figuras 41 e 42 mostram os perfis de salinidade e temperatura provenientes das boias PIRATA e de derivadores ARGO que foram coletados em pontos próximos às boias no mesmo dia. Do período em estudo de cada boia, só houve coincidência temporal nas medições feitas por ambos equipamentos nos pontos $0^{\circ} 10^{\circ} \mathrm{W}, 12^{\circ} \mathrm{N} 23^{\circ} \mathrm{W}, 6^{\circ} \mathrm{S} 10^{\circ} \mathrm{W}$ e $10^{\circ} \mathrm{S} 10^{\circ} \mathrm{W}$. Os perfis de salinidade e temperatura em $0^{\circ} 10^{\circ} \mathrm{W}$ e $12^{\circ} \mathrm{N} 23^{\circ} \mathrm{W}$ são razoavelmente coincidentes. Já em $0^{\circ} 10^{\circ} \mathrm{W}$ e $10^{\circ} \mathrm{S} 10^{\circ} \mathrm{W}$ a carência de dados de salinidade medidos pelas boias não permite a comparação entre os perfis. Entretanto, nos 4 pontos analisados, os perfis de salinidade diferem bastante do perfil climatológico mensal. As diferenças entre as médias verticais dos perfis do PIRATA e ARGO em relação ao do 
WOA09 ultrapassa 1 psu. Aparentemente, os dados de temperatura coletados pelo projeto PIRATA, pelo menos nestes 4 pontos, são mais consistentes aos perfis de temperatura dos derivadores ARGO que os dados de salinidade. Além disso, os perfis de temperatura mostram-se mais consistentes à climatologia que os de salinidade.

Lee et al. (2012) publicaram o primeiro trabalho de observação de OITs na salinidade superficial no Pacífico através de dados do satélite Aquarius, recentemente lançado. As anomalias de salinidade atingem valores de $\pm 0,5$ PSU e são máximas muito próximo ao Equador, onde as águas salinas do Pacífico Sul encontram águas menos salinas da ZCIT. O padrão ondulado nos dados de TSM também é observado nos dados de $S$ proveniente do satélite, onde os (as) cavados (cristas) frios (quentes) coincidem com salinidades altas (baixas).

A Figura 43 mostra a média vertical da salinidade entre $0 \mathrm{~m}$ e $5 \mathrm{~m}$ de profundidade de março de 2000 a dezembro de 2010 provenientes de 6090 perfis ARGO. A região a oeste de $30^{\circ} \mathrm{W}$ e a norte de $10^{\circ} \mathrm{S}$ não contém nenhuma medição na superfície durante o período considerado. É importante observar que este mapa médio está razoavelmente povoado de dados porque contém 11 anos de amostragens. A Figura 44 revela que diversas regiões foram amostradas durante um curto período. Próximo a $10^{\circ} \mathrm{N} 45^{\circ} \mathrm{W}$, por exemplo, há dados apenas de 2001 e 2002, a região a norte de $15^{\circ} \mathrm{N}$ foi amostrada de 2007 a 2010 e a sul de $5^{\circ} \mathrm{S}$ dominam medições em 2005 e 2006. A região com maior frequência de amostragem é entre $0^{\circ}$ e $10^{\circ} \mathrm{N}$. Portanto, a média calculada provém de medições longe de serem sinóticas, pode conter o viés de algum ano anômalo em regiões subamostradas e serve apenas para fornecer uma distribuição geral da salinidade superficial média. Levando isso em consideração, é possível obter uma razoável representação do padrão da salinidade superficial observada por Lee et al. (2012), com uma frente de salinidade próxima à $5^{\circ} \mathrm{N}$ com águas mais salinas a sul e menos salinas a norte, coincidente à frente de TSM observada por satélite. 

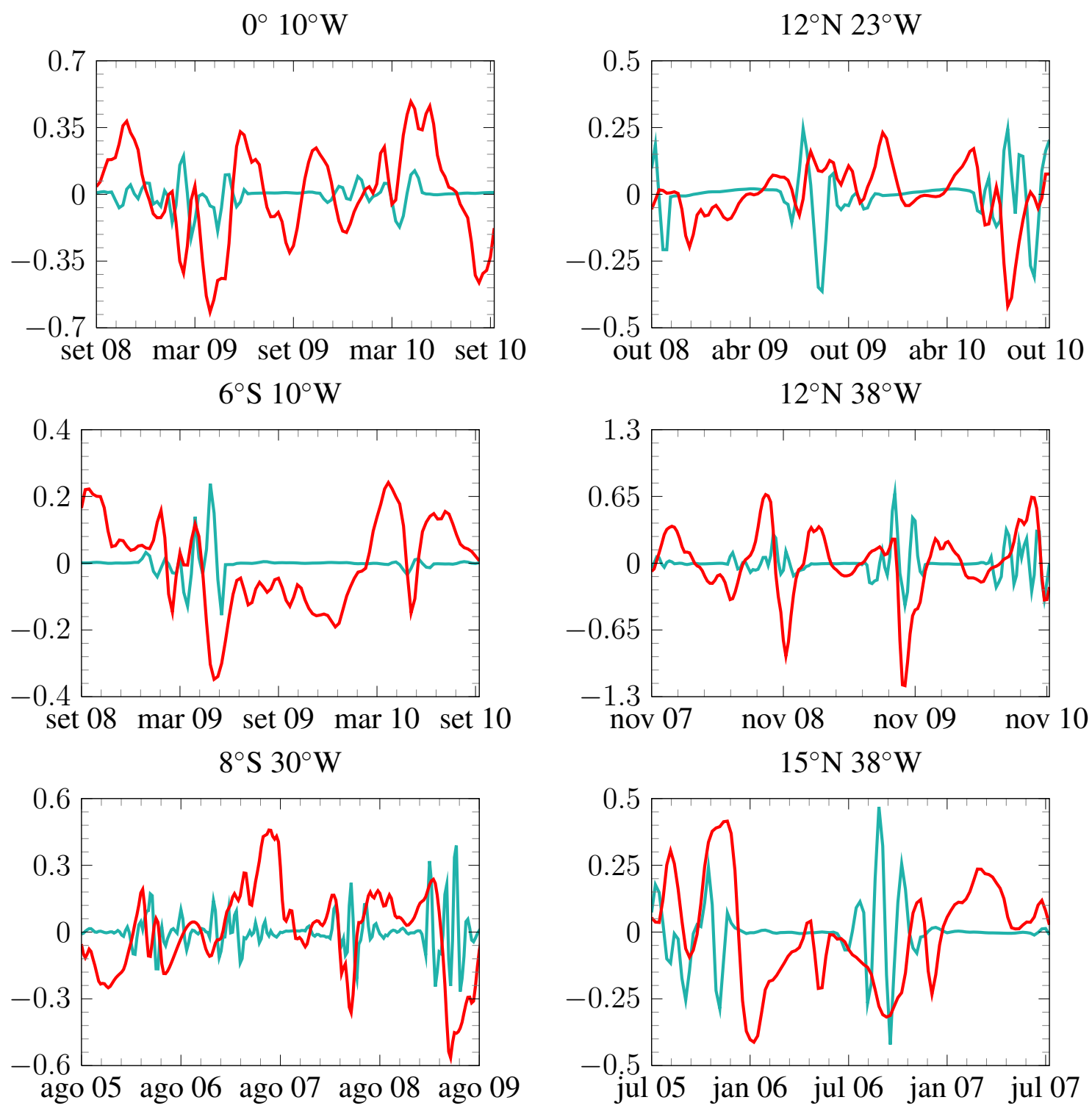

$10^{\circ} \mathrm{S} 10^{\circ} \mathrm{W}$
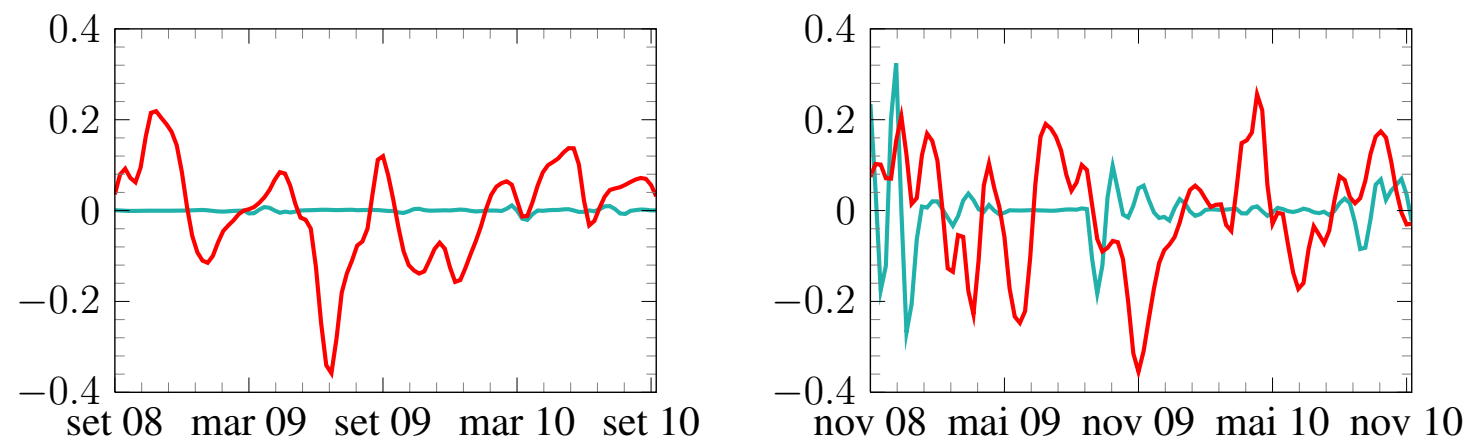

set 08 mar 09 set 09 mar 10 set 10

nov 08 mai 09 nov 09 mai 10 nov 10

$$
-P\left(\mathrm{~mm} \mathrm{~h}^{-1}\right)-S
$$

Figura 39: ORCs nos dados de $P$ (linha verde, em $\mathrm{mm} \mathrm{h}^{-1}$ ) e $S$ (linha vermelha) para cada boia PIRATA. 

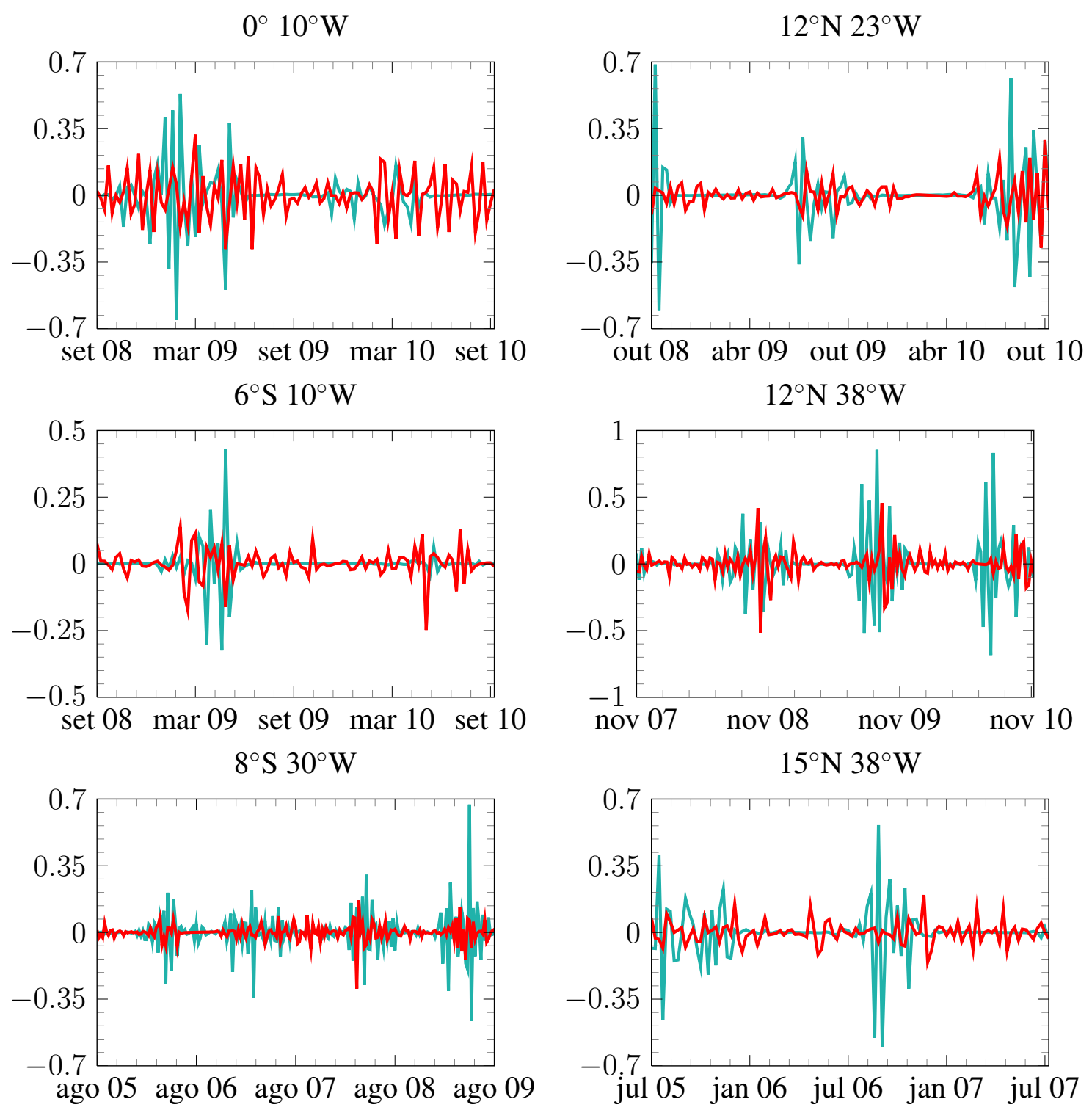

$10^{\circ} \mathrm{S} 10^{\circ} \mathrm{W}$
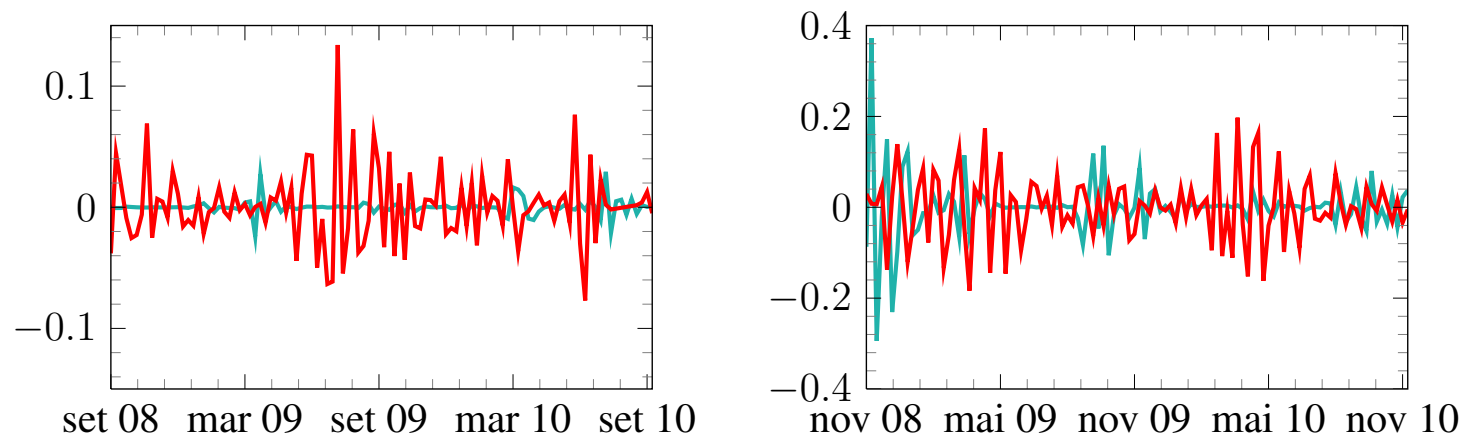

$$
-P\left(\mathrm{~mm} \mathrm{~h}^{-1}\right)-S
$$

Figura 40: Semelhante à Figura 39 para as OITs. 

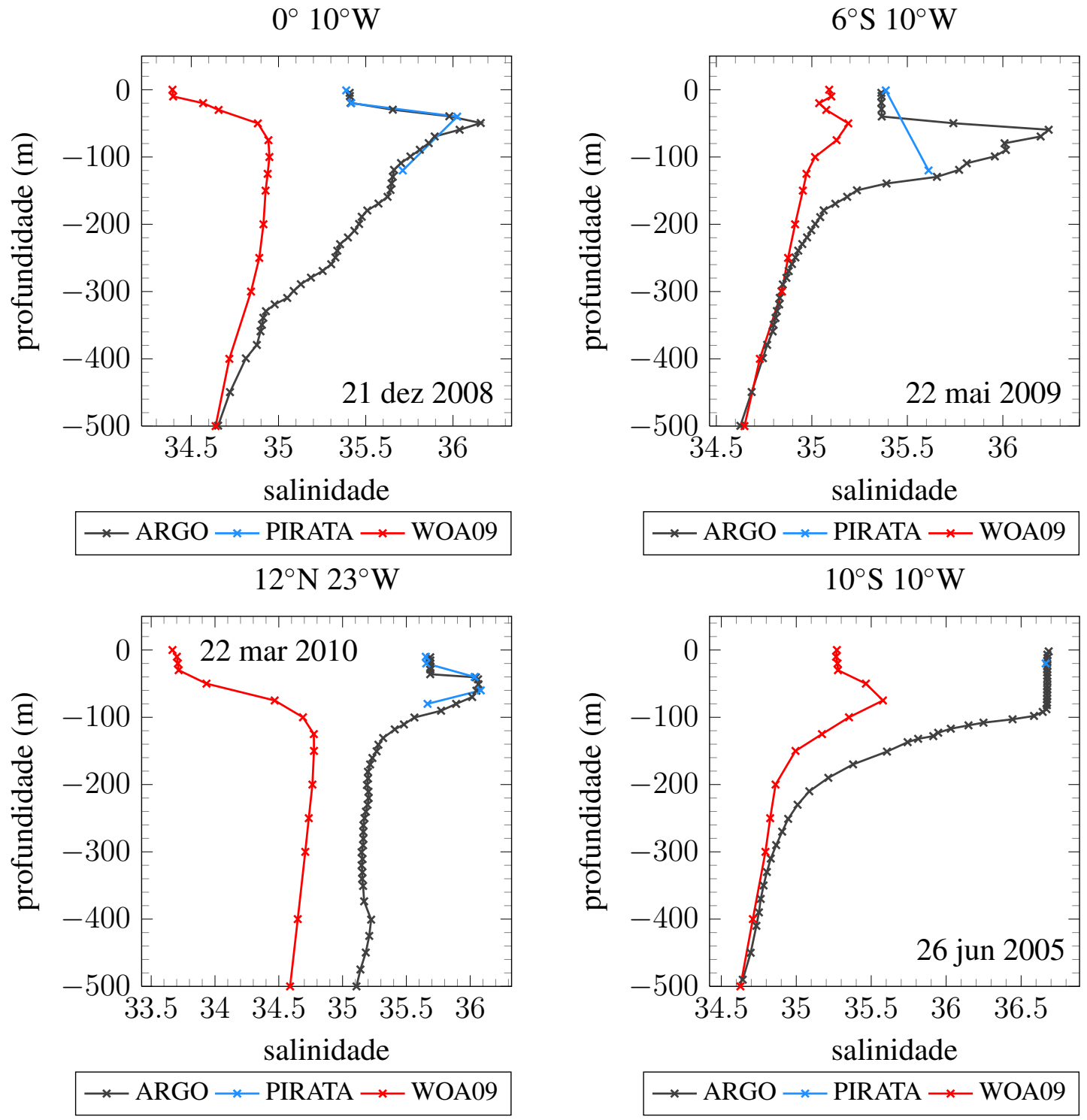

Figura 41: Perfis verticais de salinidade provenientes das boias PIRATA e dos derivadores ARGO coletados no mesmo dia e perfis climatológicos mensais do World Ocean Atlas 2009 (WOA09) na mesma localização. Os erros das medidas de salinidade do ARGO é de 0,02 nos pontos $0^{\circ} 10^{\circ} \mathrm{W}$ e $6^{\circ} \mathrm{S} 10^{\circ} \mathrm{W}, 0,05$ em $10^{\circ} \mathrm{S} 10^{\circ} \mathrm{W}$ e $1,00 \mathrm{em} 12^{\circ} \mathrm{N} 23^{\circ} \mathrm{W}$. 

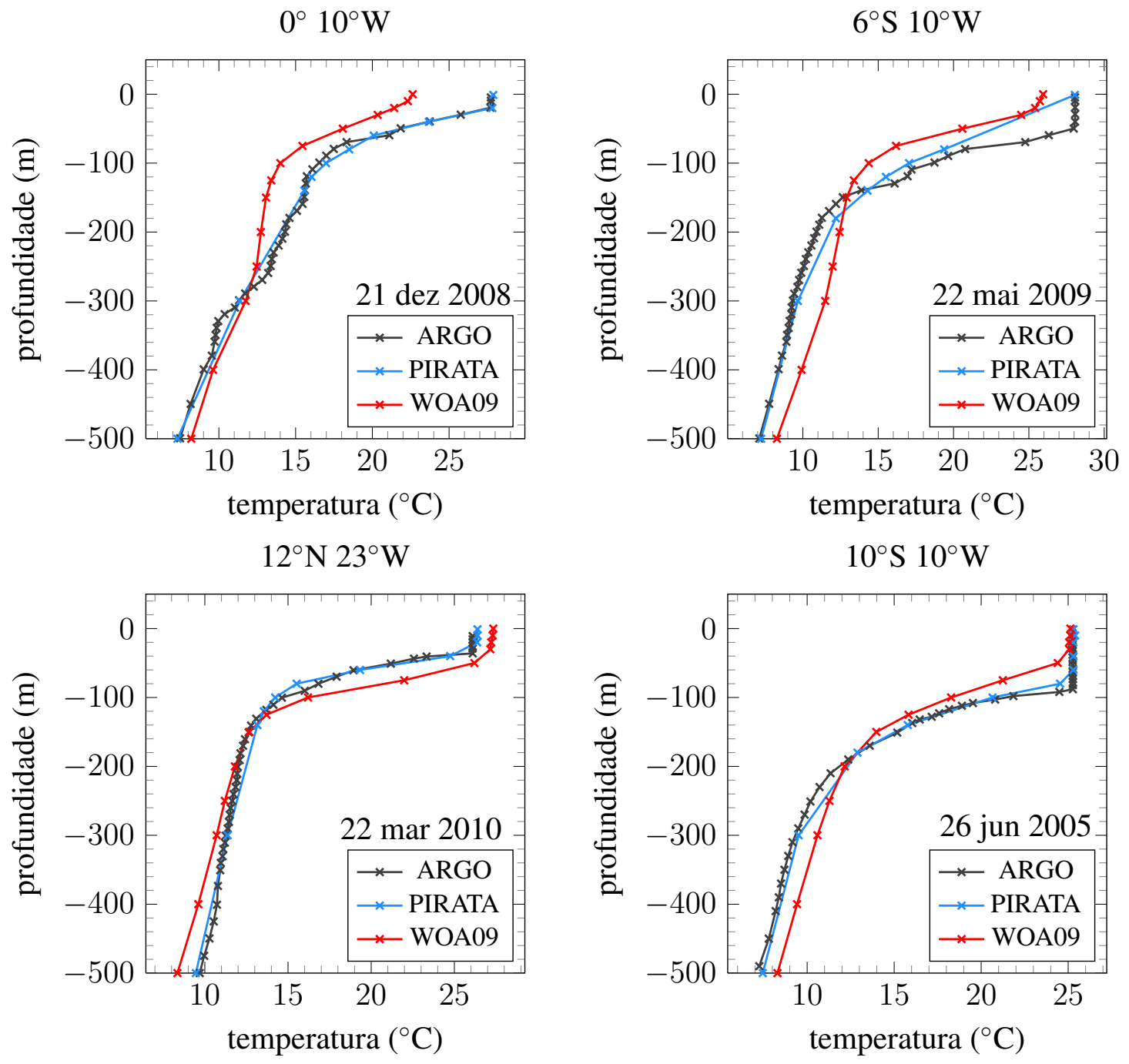

Figura 42: Semelhante à Figura 41 para os perfis de temperatura $\left({ }^{\circ} \mathrm{C}\right)$. Os erros das medidas de temperatura do ARGO é de $0,02{ }^{\circ} \mathrm{C}$ nos quatro pontos. 


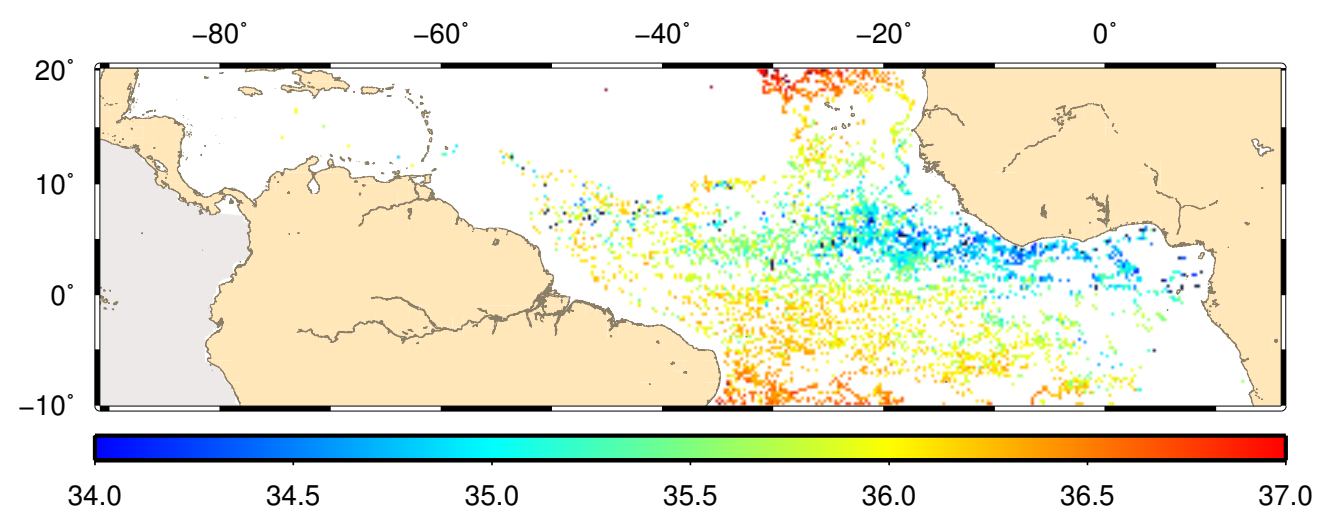

Figura 43: Média vertical da salinidade de $0 \mathrm{~m}$ a $5 \mathrm{~m}$ proveniente dos derivadores ARGO de março de 2000 a dezembro de 2010.

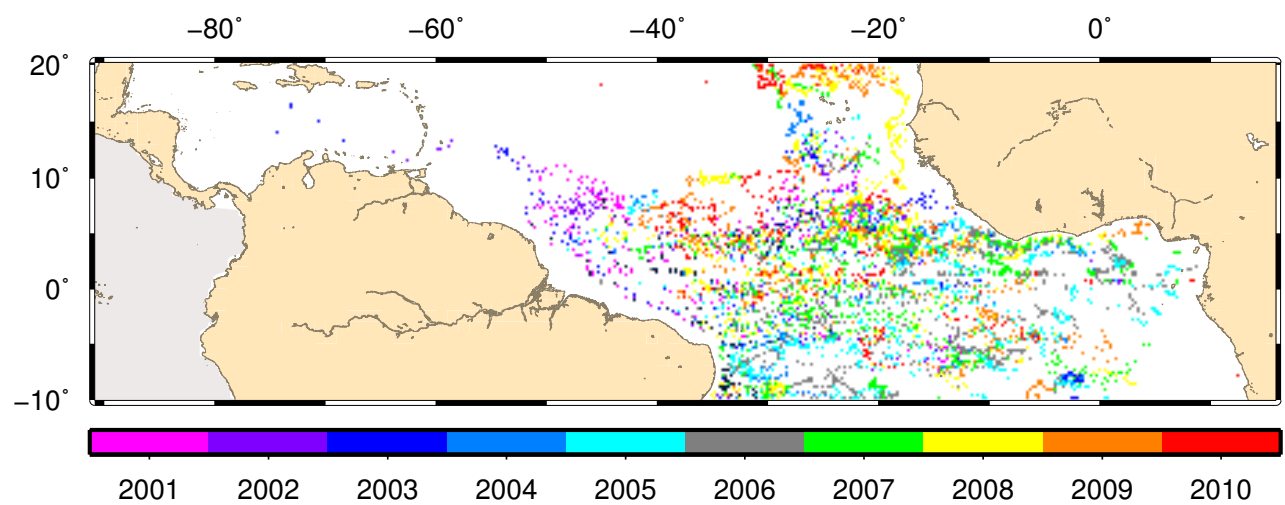

Figura 44: Posição dos perfis ARGO de março de 2000 a dezembro de 2010.

Devido à consistência da distribuição espacial dos dados de $S$ do ARGO aos obtidos por satélite, talvez fosse possível associar baixas temperaturas a altas salinidades e caracterizar a presença de OITs. Entretanto, mesmo com a interpolação dos dados a cada $0,25^{\circ}$ de latitude e longitude, as resoluções temporal e espacial dos derivadores não permitem a obtenção de séries temporais longas e contínuas em cada ponto. O ponto mais visitado na região de estudo foi medido repetidamente por 10 instantes de tempo e, na média, cada ponto amostrado teve 1,43 observações em instantes distintos. Dos 8464 perfis contidos na região de estudo, 6090 possuem dados entre $0 \mathrm{~m}$ e $5 \mathrm{~m}$ de profundidade e representam 4254 pontos amostrados.

A Figura 45 mostra os valores de salinidade e temperatura onde as correlações de TSM nas OITs são significativas ao nível de $95 \%$ e superiores a 10\%. As médias e desvios padrão destes valores calculados na região de domínio das ondas contida no hemisfério Norte onde a correlação é positiva e negativa estão na Figura 46. As baixas 
resoluções espacial e temporal dos dados dos derivadores ARGO não permite observar cavados (cristas) frios (quentes) e salinos (pouco salinas). Apesar de consistente à TSM obtida por satélite, com o valor médio de temperatura onde a correlação é negativa sendo inferior à temperatura média onde a correlação é positiva, o desvio padrão não permite diferenciar as duas regiões. O mesmo ocorre com a salinidade. O resultado é o mesmo ao considerar as regiões de correlações positivas de TSM na banda das ORCs (não mostrado).

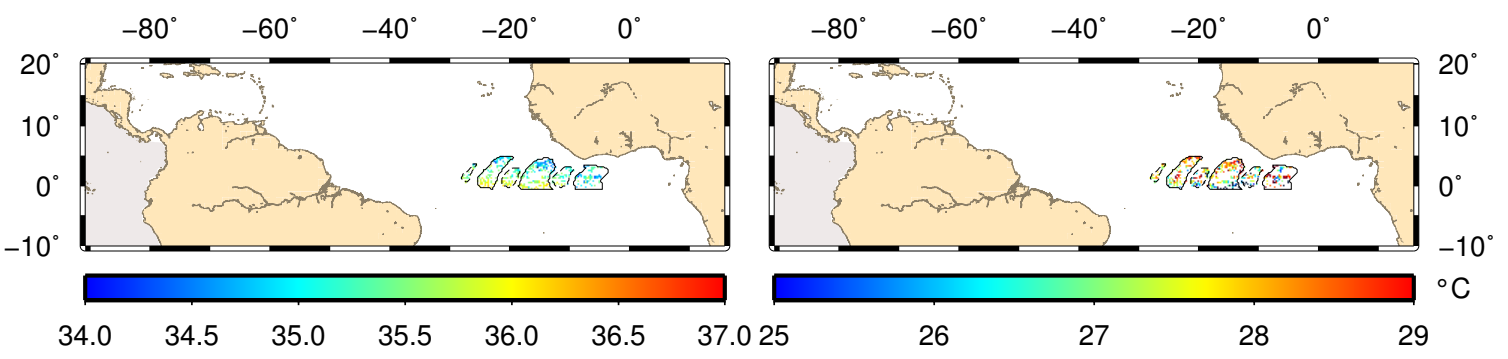

Figura 45: Médias da salinidade (esquerda) e temperatura (direita) superficiais dos derivadores ARGO de 2000 a 2010 (escalas de cores) onde a correlação significativa de TSM com a TSM no ponto de referência para OITs é positiva (linhas contínuas) e negativa (linhas tracejadas).
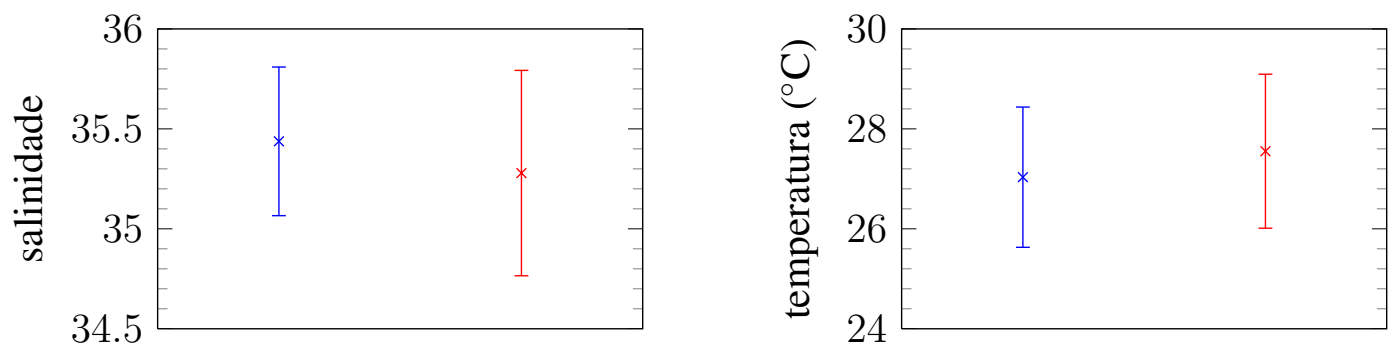

Figura 46: Média e desvio padrão da salinidade e temperatura superficiais obtidas dos derivadores ARGO na região onde a $T_{s}$ associada às OITs são negativas (azul) e positivas (vermelho).

A análise similar na região onde as alterações significativas da precipitação pelas anomalias de TSM também revela que a falta de dados inviabiliza atribuir as variações da salinidade superficial à $P$. Na Figura 47 estão representadas as médias superficiais de $S$ dos derivadores ARGO onde as correlações entre TSM e $P$ são positivas e negativas para OITs e ORCs. O alto desvio padrão de $S$ não permite caracterizar regiões de alta (baixa) salinidade devido a anomalias negativas (positivas) de chuva (Figura 48). As análises foram feitas apenas pro hemisfério Norte para que uma possível diferença de 
salinidade entre as regiões de correlações positivas e negativas pela distinção de $S$ das massas d'águas características dos locais não fosse atribuída erroneamente à precipitação.

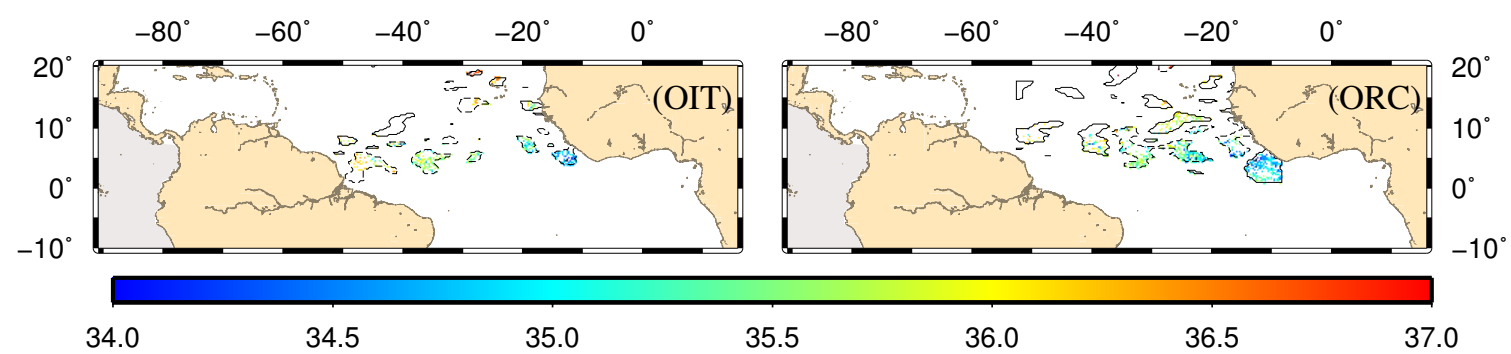

Figura 47: Média da salinidade superficial dos derivadores ARGO de 2000 a 2010 (escala de cor) onde a correlação significativa de $P$ com a TSM no ponto de referênia é positiva (linhas contínuas) e negativa (linhas tracejadas) para OITs (esquerda) e ORCs (direita).
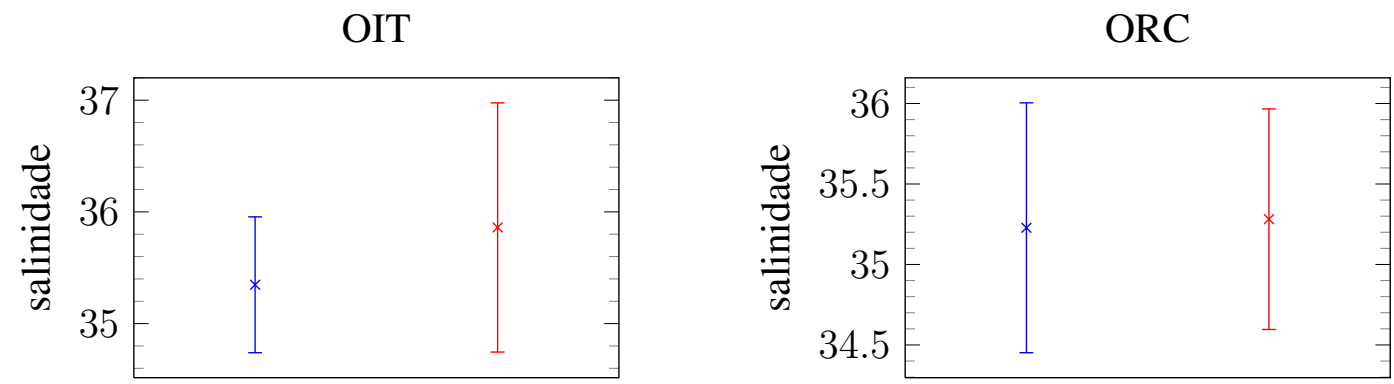

Figura 48: Média e desvio padrão da salinidade superficial obtida dos derivadores ARGO na região onde a correlação de $P$ associada às OITs (esquerda) e ORCs (direita) são negativas (azul) e positivas (vermelho).

É difícil tratar os dados Lagrangianos de forma Euleriana. Para que isso fosse possível, seria necessário uma quantidade maior de derivadores ARGO em operação. No cenário atual não foi possível obter uma série temporal de medidas diferentes que pudessem ser consideradas como de um mesmo ponto. Dessa forma, neste trabalho, os dados ARGO foram utilizados apenas como comparação dos perfis obtidos pelas boias PIRATA. Estas, por sua vez, apesar de serem medidas eulerianas, revelam carência de séries temporais longas com dados de alta qualidade. Portanto, a carência de evidências estatisticamente significativas a respeito da influência da precipitação sobre a salinidade da superfície do mar nas bandas espectrais que estudamos é atribuída à falta de dados e/ou a má qualidade dos dados disponíveis. 


\section{Conclusões}

\subsection{Sumário}

Na região tropical dos oceanos, a esfericidade da Terra no modelo linear de águas rasas quase-geostrófico para um oceano invíscido de 1,5 camadas é considerada. Duas das quatro soluções oscilatórias deste problema, as ondas de Rossby-gravidade e as ondas de Rossby, são de interesse neste trabalho. Embora dinamicamente diferentes, há similaridade entre frequências e números de onda e ambas apresentam propagação de fase para oeste. Estas semelhanças dificultam a identificação do padrão oscilatório meramente por comparação das medidas com valores da literatura, dadas as incertezas experimentais. Dessa forma, ainda que limitada pelas simplificações do modelo teórico adotado, a caracterização fundamentada na relação de dispersão das ondas equatoriais permitiu a identificação dos padrões ondulatórios obtidos por sensoriamento remoto.

As oscilações genericamente denominadas de ondas de instabilidade tropical são comumente observadas em dados de temperatura da superfície do mar obtidos por satélites na região equatorial dos oceanos (LEGECKIS, 1977). Na escala espaço-temporal destas ondas, observa-se domínio de certos processos oceânicos sobre os campos atmosféricos, cujas alterações alcançam a Zona de Convergência Intertropical (ZCIT) (WU e BOWMAN, 2007a). Entretanto, os trabalhos que tratam da influência atmosférica não discutem estas alterações levando em conta a separação dinâmica das ondas oceânicas.

Nós estudamos as alterações atmosféricas influenciadas pelas anomalias de temperatura da superfície do mar (TSM) causadas pela passagem de ondas observacionalmente semelhantes, porém dinamicamente distintas, as Ondas de Instabilidade Tropical (OITs) e as Ondas de Rossby Curtas (ORCs). Uma vez identificadas dinamicamente as oscilações da TSM, quantificamos as alterações dos campos de vapor d'água integrado verticalmente $(V)$, precipitação $(P)$ e divergente da tensão de cisalhamento do vento $(\vec{\nabla} \cdot \vec{\tau})$ nas bandas espectrais das OITs e ORCs na região da ZCIT. A salinidade da superfície do mar $(S)$ na escala das ondas também foi estudada a fim de responder à hipótese principal de que as anomalias de precipitação na ZCIT com períodos de 20 a 50 dias e dimensão 
zonal de 1000 a $1500 \mathrm{~km}$, causadas remotamente pelas OITs e/ou ORCs podem causar anomalias de salinidade da superfície do mar. Neste contexto, os principais resultados foram:

- Selecionamos oscilações com propagação de fase para oeste e identificamos como ORCs os sinais com período de $\sim 49$ dias e comprimento de onda de $\sim 1500 \mathrm{~km}$, e como OITs as ondas com $\sim 21$ dias e $\sim 1000 \mathrm{~km}$.

- A identificação dinâmica das OITs na temperatura da superfície do mar como ondas de Rossby-gravidade, de acordo com o modelo anteriormente descrito, é restrita entre $6^{\circ} \mathrm{S}$ e $6^{\circ} \mathrm{N}$. Em latitudes mais altas, as ondas são caracterizadas dinamicamente como ondas de Rossby curtas.

- O sinal oscilatório da altura da superfície do mar $(\eta)$ é dinamicamente identificado como onda de Rossby em todas as latitudes estudadas, de $10^{\circ} \mathrm{S}$ e $20^{\circ} \mathrm{N}$.

- As oscilações na banda das ORCs são caracterizadas como ondas de Rossby nos dados de temperatura e de anomalia da altura da superfície do mar pela teoria de ondas equatoriais em toda a área de estudo.

- As OITs e ORCs observadas na temperatura da superfície do mar se desenvolvem no oceano Atlântico equatorial de maio a outubro, com as maiores amplitudes de junho a agosto entre $5^{\circ} \mathrm{N}$ e $5^{\circ} \mathrm{S}$

- O período de ocorrência das ondas na TSM coincide com o de migração da ZCIT para norte, que ocupa posições de $(2 \pm 3)^{\circ} \mathrm{S}$ a $(8 \pm 3)^{\circ} \mathrm{N}$, em maio, a $(0 \pm 3)^{\circ} \mathrm{e}$ $(15 \pm 4)^{\circ} \mathrm{N}$, em outubro.

- Na ZCIT, a intensidade da componente de larga escala da convergência da tensão de cisalhamento do vento em baixos níveis é, em média, de $\sim 0,5 \cdot 10^{-7} \mathrm{~kg} \mathrm{~m}^{-2} \mathrm{~s}^{-2} \mathrm{e}$ promove quantidades de vapor d'água verticalmente integrado na atmosfera de, em média, $\sim 50 \mathrm{~mm}$.

- Quantificamos, via análise de regressão, anomalias de vapor d'água integrado verticalmente, precipitação e divergente da tensão de cisalhamento do vento na banda 
das ondas associadas às anomalias de temperatura da superfície do mar nas bandas de OITs e ORCs.

- As maiores alterações do $\vec{\nabla} \cdot \vec{\tau}$ associadas às OITs chegam a $4 \cdot 10^{-8} \mathrm{~kg} \mathrm{~m}^{-2} \mathrm{~s}^{-2}{ }^{\circ} \mathrm{C}^{-1}$ e $1,3 \cdot 10^{-7} \mathrm{~kg} \mathrm{~m}^{-2} \mathrm{~s}^{-2}{ }^{\circ} \mathrm{C}^{-1}$ para anomalias associadas a ORCs, que dominam próximo ao Equador e alcançam $10^{\circ} \mathrm{N}$.

- Na banda espectral das OITs, a influência da TSM sobre os campos de $V$ e $P$ atinge $9^{\circ}$ de latitude, na ZCIT, e alcançam $1,1 \mathrm{~mm}^{\circ} \mathrm{C}^{-1}$ e $0,11 \mathrm{~mm} \mathrm{~h}^{-1} \circ \mathrm{C}^{-1}$, respectivamente.

- Nas latitudes ocupadas pela ZCIT também ocorrem alterações de $P$ na banda das ORCs, que chegam a $0,08 \mathrm{~mm} \mathrm{~h}^{-1}{ }^{\circ} \mathrm{C}^{-1}$. Porém não são acompanhadas por mudanças de $V$ significativas, que são máximas próximo ao Equador e alcançam $1,5 \mathrm{~mm}^{\circ} \mathrm{C}^{-1}$.

- A modificação de $V$ pela TSM associada às ondas é de 2-3\% dos valores médios encontrados na ZCIT e as alterações de $\vec{\nabla} \cdot \vec{\tau}$ são comparáveis aos valores típicos da componente de larga escala do divergente da tensão de cisalhamento do vento.

- A relação de fase obtida dos mapas de regressão de divergente da tensão de cisalhamento do vento e de temperatura da superfície do mar na banda espectral das OITs e ORCs sugere a dominância do mecanismo de mistura vertical proposto por Hayes et al. (1989) e Wallace et al. (1989), com aceleração dos ventos sobre águas quentes e desaceleração sobre águas frias. Entretanto, os mapas de regressão de vapor d'água integrado verticalmente e precipitação não corroboram esta hipótese.

- O mecanismo dominante na modificação dos campos de vapor d'água integrado, precipitação e divergente da tensão de cisalhamento do vento deve ser determinado com base na diferença de fase entre as anomalias considerarando a advecção horizontal do gradiente de pressão pelo fluxo médio, conforme proposto por Small et al. (2003). 
- Não encontramos correlação estatisticamente significativa entre anomalias de salinidade superficial e de precipitação nas bandas das OITs e ORCs.

\subsection{Considerações finais e sugestões de trabalhos futuros}

A identificação com base na teoria revelou que é possível diferenciar observacionalmente ondas de Rossby-gravidade ou OITs de ORCs, corroborando os resultados de Lyman et al. (2007), Não observamos oscilações nos dados de $\eta$ caracterizadas dinamicamente como ondas de Rossby-gravidade. Apenas a TSM permite a observação destas ondas. Sugerimos que a baixa resolução temporal dos dados originais (i.e.: nível 2) de $\eta$ não permite a detecção de ondas de Rossby-gravidade. OITs e ORCs coexistem nos dados de TSM e o sinal de cada uma pode ser isolado utilizando filtros digitais. Os resultados obtidos nas Figuras 22 a 24 mostram que os dados de sensoriamento remoto permitem a obtenção de oscilações cuja dinâmica valida o previsto pelo modelo linear adotado.

As instabilidades oriundas do sistema de correntes e da ressurgência equatorial promovem o surgimento de ondas com diferentes frequências, números de onda e modos meridionais, como mostram os diagramas de dispersão das Figuras 22 a 24, corroborando os resultados de Lyman et al. (2007); Han et al. (2008) e Schuckmann et al. (2008). As oscilações observadas dependem do conjunto de dados analisado. Observamos que o desenvolvimento das OITs e ORCs na TSM são muito mais dependentes da intrusão da língua fria que as ondas nos dados de $\eta$. Isso mostra a importância da instabilidade baroclínica na geração destas ondas nos dados de TSM, como sugerido por Yu et al. (1995) e Schuckmann et al. (2008), Entretanto, o processo de instabilidade dominante na produção de cada onda com diferentes modos meridionais deve ser determinado a partir de modelos numéricos que testem diferentes configurações das distribuições horizontal e vertical das correntes e da intrusão sazonal da língua fria.

Os sinais das OITs nos dados de TSM no painel superior direito da Figura 26 revelam oposição de fase inter-hemisférica de $\sim 180^{\circ}$, de acordo com os resultados encontrados por Wu e Bowman (2007a). Esta assimetria não pode ser explicada pela teoria de 
ondas equatoriais de Philander (1990), Cane e Sarachik (1976) pois as ondas de Rossbygravidade são a solução da relação de dispersão para o modo meridional zero $(n=0)$. Se o mecanismo gerador dominante difere entre os hemisférios (SCHUCKMANN et al., 2008), a gênese das ondas nos hemisférios Norte e Sul é independente e, portanto, qualquer diferença de fase poderia ser obtida. Por outro lado, a defasagem zonal pode ser resultado da advecção relativa do sinal entre os hemisférios pelas correntes zonais, como proposto por Lyman et al. (2007), Dada a sugestão de Lyman et al. (2007), para se explicar a oposição de fase, é necessária a derivação de uma solução para ondas de Rossby-gravidade com efeito Doppler a partir do modelo de águas rasas de 1,5 camadas para o Atlântico tropical que leve em conta a existência de um fluxo básico realístico.

Diversos autores atribuem a formação dos meandros nos dados de TSM ilustrados na Figura 1 à advecção da frente de temperatura pelas correntes geostróficas geradas por anomalias de $\eta$ associada às ondas (FLAMENT et al., 1996; POLITO et al., 2001; SHINODA et al., 2009; LEE et al., 2012). Neste caso, as anomalias de TSM e $\eta$ estão zonalmente defasadas em $90^{\circ}$. Esta relação de fase não foi testada na banda das OITs pois os dados de $\eta$ não revelam ondas dinamicamente iguais. Já na banda das ORCs, as anomalias das variáveis estão em fase. Isto revela que a expansão térmica é o processo que relaciona as anomalias de $\eta$ às de TSM nas ORCs, de acordo com Polito et al. (2001). Embora já fosse sabido que a expansão térmica é o mecanismo dominante nas ondas de Rossby em outras latitudes (POLITO e SATO, 2003), a observação deste processo na região equatorial é inédita e supostamente independente da produção das anomalias na banda das OITs.

A variabilidade atmosférica associada às anomalias de TSM em duas bandas do espectro zonal-temporal características de ondas dinamicamente distintas é um resultado ainda não quantificado na literatura. Este foi obtido a partir do cálculo das regressões dos campos atmosféricos em relação à TSM em um ponto, denominado ponto de referência. Os mapas de regressão quantificam a alteração das variáveis atmosféricas em toda a área de estudo devido à alteração em $1{ }^{\circ} \mathrm{C}$ na TSM no ponto de referência, localizado a $0,875^{\circ} \mathrm{N}$ no Atlântico leste. Dessa forma, verificamos que as anomalias de TSM na região 
equatorial são capazes de produzir mudanças atmosféricas em regiões remotas, como na ZCIT.

A resposta remota da atmosfera à passagem das ondas equatoriais na banda das OITs pode ser verificada no vapor d'água integrado verticalmente e na precipitação nas Figuras 29 e 30 . Na banda das ORCs, a influência remota é mais significativa nos dados de $P$ (Figura 35). As influências remotas da TSM sobre $V$ e $P$ nas OITs atingem a ZCIT e corroboram os resultados de Wu e Bowman (2007a), As ondas oceânicas alteram as variáveis atmosféricas a $\sim 1000 \mathrm{~km}$ de distância da sua região de domínio. Além disso, a consistência da distribuição espacial dos padrões de $V$ e $P$ na Figura 31 mostra que chuva só ocorre onde há vapor d'água disponível para a condensação. A concordância de fase das anomalias de vapor d'água e precipitação nas OITs ocorre em 95\% dos locais onde a alteração destas variáveis pela TSM é significativa, o que também é um resultado inédito.

A alteração local da atmosfera às anomalias de TSM ocorre no divergente da tensão de cisalhamento do vento, como mostram os mapas de regressão das Figuras 27 e 32. Da relação de fase entre os mapas de regressão de TSM e $\vec{\nabla} \cdot \vec{\tau}$ concluímos que o mecanismo de mistura vertical proposto por Hayes et al. (1989) e Wallace et al. (1989) é o dominante na alteração do campo de $\vec{\nabla} \cdot \vec{\tau}$ devido às anomalias de TSM na bandas das OITs e ORCs. Os centros de divergência e convergência do vento em baixos níveis ocorrem a oeste das anomalias frias e quentes, respectivamente. Contudo, a não consistência de anomalias de $V$ e $P$ sobre as regiões de máxima convergência mostra que a advecção horizontal do gradiente de pressão pelo fluxo médio deve ser levada em conta, conforme sugerido por Small et al. (2003) e Wu et al. (2008), Apesar disso, observamos que embora as ondas sejam dinamicamente diferentes, com escalas espaciais e temporais ligeiramente distintas, a influência das OITs e ORCs sobre o campo de divergência do vento é similar e, portanto, a advecção horizontal influencia igualmente as duas escalas.

Embora a formação de sinais ondulatórios nos dados de $V$ de Wu e Bowman (2007a) não tenha sido corroborado, observamos outro resultado ainda não relatado na literatura. Há uma nítida formação de dipolo nos mapas de regressão de $V$ e, em menor grau, de $P$ nas OITs, com os pólos centrados em $\sim 5^{\circ} \mathrm{Ne} \sim 5^{\circ} \mathrm{S}$ (Figuras $29 \mathrm{e} 30$ ). Quando 
o hemisfério Norte é provido de vapor d'água e precipitação devido ao aumento da TSM no ponto de referência, o hemisfério Sul é desprovido. A situação oposta ocorre quando há diminuição da TSM no ponto de referência. Os resultados indicam que o transporte das anomalias para norte é causado pela componente meridional do vento responsável por deslocar a ZCIT para norte durante o período das ondas (NOBRE e SHUKLA, 1996).

A hipótese de alteração da salinidade superficial pelas anomalias de precipitação na ZCIT associada à passagem das ondas na região equatorial não pode ser verificada. A falta de dados de salinidade de alta qualidade do projeto PIRATA impediu a investigação da hipótese. Das 18 boias disponíveis, 10 foram descartadas por não conterem séries relativamente contínuas por 2 anos. Das 8 boias restantes, apenas 2 revelaram correlação estatiscamente significativa entre $S$ e $P$. Entretanto, as séries temporais destas boias foram as que apresentaram maior percentual de ausência de dados (de 14\% e 17\% em relação ao comprimento total da série), o que corrobora que é necessária maior quantidade de dados e de alta qualidade. A natureza Lagrangiana dos dados dos derivadores ARGO, utilizados como alternativa, e a carência de uma maior quantidade destes equipamentos impediu a obtenção de mapas sinóticos e a verificação do sinal das ondas nos dados de salinidade. Lee et al. (2012) detectaram sinais na escala das ondas em dados de salinidade superficial medida por satélites. Portanto, propomos que estudos posteriores utilizando este conjunto de dados possam reavaliar a hipótese principal do trabalho.

A partir de maio, a componente meridional do vento, assimétrica em relação ao Equador, promove a ressurgência equatorial e o deslocamento das águas quentes e da ZCIT para o hemisfério Norte (HASTENRATH, 1984). A intrusão de água fria aliada aos cisalhamentos horizontais e verticais do complexo sistema de correntes equatoriais propiciam o surgimento de ondas como as OITs e ORCs, que podem ser observadas em dados de TSM (PHILANDER, 1978; YU et al., 1995). Na escala destas ondas, os mecanismos de interação oceano-atmosfera atuam de forma que a atmosfera responda aos fluxos de calor sensível e latente do oceano (CHELTON e XIE, 2010; SMALL et al., 2008). Estas alterações não ficam restritas à região das ondas e podem alcançar a ZCIT (WU e BOWMAN, 2007a). Sugerimos que as anomalias de precipitação geradas causam 
anomalias da salinidade superficial, mas esta hipótese não pode ser investigada.

A principal contribuição deste trabalho é a confirmação das hipóteses de que o modelo linear de águas rasas quase-geostrófico para um oceano invíscido de 1,5 camadas sob a aproximação do plano $\beta$ equatorial é capaz de descrever a dinâmica de OITs e ORCs observadas por dados de satélites, que estas ondas coexistem e são distinguíveis na temperatura da superfície do mar e que produzem alterações no campo de vento por mecanismos similares. Até o presente momento, desconhecemos outro estudo que alie a separação e a identificação teórica dos padrões propagantes obtidos por satélites às análises dos processos de interação oceano-atmosfera.

As conclusões sobre a formação das ondas e sobre os mecanismos de influência atmosférica baseadas em dados de sensoriamento remoto podem ser refutadas a partir de modelos numéricos. Sugerimos como trabalhos futuros a utilização de modelos que incluam, isoladamente, a intrusão da língua fria sazonal deslocada para o hemisfério Norte, o sistema de correntes equatoriais em superfície e em subsuperfície em função da latitude, com condições para ocorrência de instabilidades barotrópicas e baroclínicas para que se possa avaliar quais mecanismos determinam: (i) a diferença de fase observada nos dados de TSM entre os hemisférios; (ii) a assimetria inter- hemisférica das amplitudes; (iii) a produção de ondas de Rossby-gravidade e ondas de Rossby nos dados de TSM. Para a determinação dos processos dominantes na modificação das variáveis atmosféricas, deve ser levado em conta a existência de um fluxo médio realístico. A solução da relação de dispersão com efeito Doppler para ondas de Rossy-gravidade também é uma sugestão para trabalhos futuros, uma vez que poderia revelar se algum dos sinais aqui identificados como ondas de Rossby são ondas de Rossby-gravidade influenciadas pelas correntes.

A utilização dos dados de salinidade provenientes de satélite é uma alternativa à utilização de dados in-situ, como mostra o trabalho de Lee et al. (2012), As características sinóticas e a grande resolução temporal destes dados podem permitir que a alteração da salinidade devido às anomalias de precipitação seja avaliada. Sugerimos também o estudo da variabilidade interanual das anomalias de TSM a fim de investigar se as amplitudes das OITs e ORCs são moduladas pelo fenômeno ENOS. 


\section{Referências}

BENADA, J. R. PO. DAAC merged GDR (TOPEX/Poseidon) generation B user's handbook, version 2.0. Rep. JPL PO. DAAC, v. 68, p. D002, 1997.

BUNGE, L.; PROVOST, C.; KARTAVTSEFF, A. Variability in horizontal current velocities in the central and eastern equatorial atlantic in 2002. J. Geophys. Res., v. 112, n. C2, p. C02014, 2007.

CALTABIANO, A. C. V.; ROBINSON, I. S.; PEZZI, L. P. Multi-year satellite observations of instability waves in the Tropical Atlantic ocean. Ocean Science Discussions, v. 2, p. 1-35, 2005.

CANE, M. A.; SARACHIK, E. S. Forced baroclinic ocean motions: 1. linear equatorial unbounded case. J. Mar. Res., v. 34, p. 629-665, 1976.

CHELTON, D. B.; ESBENSEN, S. K.; SCHLAX, M. G.; THUM, N.; FREILICH, M. H.; WENTZ, F. J.; GENTEMANN, C. L.; MCPHADEN, M. J.; SCHOPF, P. S. Observations of coupling between surface wind stress and sea surface temperature in the eastern tropical Pacific. J. Climate, v. 14, p. 1479-1498, 2001.

CHELTON, D. B.; XIE, S.-P. Coupled ocean-atmosphere interaction at oceanic mesoscales. Oceanography, v. 23, n. 4, p. 51-69, 2010.

CONTRERAS, R. F. Long-term observations of Tropical Instability Waves. $J$. Phys. Ocean., v. 32, p. 2715-2722, 2002.

CORNILLON, P.; PARK, K.-A. Warm core ring velocities inferred from NSCAT. Geophys. Res. Let., v. 28, n. 4, p. 575-578, 2001.

COX, M. D. Generation and propagation of 30-day waves in a numerical model of the Pacific. J. Phys. Ocean., v. 10, p. 1168-1186, 1980.

CRONIN, M. F.; XIE, S.-P.; HASHIZUME, H. Barometric pressure variations associated with eastern Pacific Tropical Instability Waves. J. Climate, v. 16, p. 30503057, 2003.

CUSHMAN-ROISIN, B.; BECKERS, J.-M. Introduction to Geophysical Fluid 
Dynamics: Physical and numerical aspects. Hanover, New Hampshire: Academic Press, 2006.

DESER, C.; BATES, J. J.; WAHL, S. The influences of sea surface temperature gradients on stratiform cloudiness along the Equatorial Front in the Pacific ocean. $J$. Climate, v. 6, p. 1172-1180, 1993.

DÜING, W.; HISARD, P.; KATZ, E.; MEINCKE, J.; MILLER, L.; MOROSHKIN, K. V.; PHILANDER, G.; RIBNIKOV, A. A.; VOIGT, K.; WEISBERG, R. Meanders and long waves in the equatorial Atlantic. Nature, v. 257, p. 280-284, 1975.

EBUCHI, N.; GRABER, H.; CARUSO, M. Evaluation of wind vectors observed by QuikSCAT/SeaWinds using ocean buoy data. J. Atmos. and Oceanic Techn., v. 19, p. 2049-2062, 2002.

FARRAR, J. T. Barotropic Rossby waves radiating from tropical instability waves in the Pacific Ocean. J. Phys. Ocean., v. 41, p. 1160-1181, 2011.

FLAMENT, P. J.; KENNAN, S. C.; KNOX, R. A.; NIILER, P. P.; BERNSTEIN, R. L. The three-dimensional structure of an upper ocean vortex in the tropical Pacific ocean. Nature, v. 383, p. 610-613, 1996.

GILL, A. E. Atmosphere-Ocean Dynamics. San Diego, California: Academic Press, 1982. 662 p. (International Geophysics Series, v. 30).

GRODSKY, S. A.; CARTON, J. A.; PROVOST, C.; SERVAIN, J.; LORENZZETTI, J. A.; MCPHADEN, M. J. Tropical instability waves at $0^{\circ} \mathrm{N}, 23^{\circ} \mathrm{W}$ in the Atlantic: a case study using Pilot Research Moored Array in the Tropical Atlantic (PIRATA) mooring data. J. Geophys. Res., v. 110, n. C08010, 2005.

GÓES, M.; WAINER, I. Equatorial currents transport changes for extreme warm and cold events in the Atlantic Ocean. Geophys. Res. Let., v. 30, n. 5, p. 8006, 2003.

HAN, W.; WEBSTER, P. J.; LIN, J.-L.; LIU, W. T.; FU, R.; YUAN, D.; HU, A. Dynamics of intraseasonal sea level and thermocline variability in the equatorial Atlantic during 2002-03. J. Phys. Oceanography, v. 38, p. 945-967, 2008. 
HASHIZUME, H.; XIE, S.-P.; LIU, W. T.; TAKEUCHI, K. Local and remote atmospheric response to tropical instability waves: a global view from the space. $J$. Geophys. Res., v. 106, n. D10, p. 10173-10185, 2001.

HASTENRATH, S. Interannual variability and annual cycle: Mechanisms of circulation and climate in the tropical Atlantic. Mon. Wea. Rev., v. 112, p. 1097-1107, 1984.

HASTENRATH, S.; GREISCHAR, L. Circulation mechanisms related to Northeast Brazil rainfall anomalies. J. Geophys. Res., v. 98, n. D3, p. 5093-5102, 1993.

HAYES, S. P.; MCPHADEN, M. J.; WALLACE, J. M. The influence of seasurface temperature on surface wind in the eastern equatorial Pacific: Weekly to monthly variability. J. Climate, v. 2, p. 1500-1506, 1989.

KELLY, B. G.; MEYERS, S. D.; O’BRIEN, J. J. On a generating mechanism for Yanai waves and the 25-day oscillation. J. Geophys. Res., v. 100, n. C6, p. 10589-10612, 1995.

LEE, T.; LAGERLOEF, G.; GIERACH, M. M.; KAO, H.-Y.; YUEH, S.; DOHAN, K. Aquarius reveals salinity structure of tropical instability waves. Geophys. Res. Let., v. 39, n. 12, p. L12610, 2012.

LEGECKIS, R. Long waves in the Eastern Equatorial Pacific ocean: A view from a geostationary satellite. Science, v. 197, p. 1179-1181, 1977.

LINDZEN, R. S.; NIGAM, S. On the role of sea surface temperature gradients in forcing low-level winds and convergence in the tropics. J. Atmosph. Science., v. 44, n. 17 , p. $2418-2436,1987$.

LIU, W. T.; XIE, X.; POLITO, P. S.; XIE, S.-P.; HASHIZUME, H. Atmospheric manifestation of tropical instability wave observed by QuikSCAT and Tropical Rain Measuring Mission. Geophys. Res. Lett., v. 27, n. 16, p. 2545-2548, 2000.

LIU, W. T.; ZHANG, A.; BISHOP, J. K. B. Evaporation and solar irradiance as regulators of sea surface temperature in annual and interannual changes. J. Geophys. Res., v. 99, n. C6, p. 12623-12637, 1994. 
LYMAN, J. M.; CHELTON, D. B.; DESZOEKE, R. A.; SAMELSON, R. M. Tropical instability waves as a resonance between equatorial rossby waves. J. Phys. Ocean., v. 35, n. 2, p. 232-254, 2005.

LYMAN, J. M.; JOHNSON, G. C.; KESSLER, W. S. Distinct 17- and 33-day Tropical Instability Waves in subsurface observations. J. Phys. Ocean., v. 37, p. 855$872,2007$.

MANTUA, N. J.; HARE, S. R.; ZHANG, Y.; WALLACE, J. M.; FRANCIS, R. C. A Pacific Interdecadal Climate Oscillation with impacts on salmon production. Bull. Am. Meteo. Soc., v. 78, n. 6, p. 1069-1079, 1997.

MASINA, S.; PHILANDER, S. G. H.; BUSH, A. B. G. An analysis of tropical instability waves in a numerical model of the Pacific Ocean 2. Generation and energetics of the waves. J. Geophys. Res., v. 104, n. C12, p. 29637-29661, 1999.

MATSUNO, T. Quasi-geostrophic motions in the equatorial area. J. Meteor. Soc. Japan, v. 44, n. 1, p. 25-43, 1966.

MITCHELL, T. P.; WALLACE, J. M. The annual cycle in equatorial convection and sea surface temperature. J. Climate, v. 5, p. 1140-1156, 1992.

MOLINARI, R. L. Observations of eastward currents in the tropical South Atlantic ocean: 1978-1980. J. Geophys. Res., v. 87, p. 9707-9714, 1982.

NOBRE, P.; SHUKLA, J. Variations of sea surface temperature, wind stress and rainfall over the Tropical Atlantic and South America. J. Climate, v. 9, n. 16, p. 2464 2479, 1996.

O’BRIEN, J. J. Equatorial oceanography. Rev. Geophysics and Space Phys., v. $17,1979$.

OKUMURA, Y.; XIE, S.-P.; NUMAGUTI, A.; TANIMOTO, Y. Tropical Atlantic air-sea interaction and its influence on the NAO. Geophys. Res. Lett., v. 28, p. 1507-1510, 2001.

PARK, K.-A.; CORNILLON, P. C. Stability-induced modification of sea surface winds over Gulf Stream rings. Geophys. Res. Let., v. 29, n. 24, p. 2211, 2002. 
PEREZ, R. C.; LUMPKIN, R.; JOHNS, W. E.; FOLTZ, G. R.; HORMANN, V. Interannual variations of Atlantic tropical instability waves. J. Geophys. Res., v. 117, n. C3, p. C03011, 2012.

PEZZI, L. P.; RICHARDS, K. J. Effects of lateral mixing on the mean state and eddy activity of an equatorial ocean. J. Geophys. Res., v. 108, n. C12, p. 3371, 2003.

PEZZI, L. P.; SOUZA, R. B.; DOURADO, M. S.; GARCIA, C. A. E.; MATA, M. M.; SILVA-DIAS, M. A. F. Ocean-atmosphere in situ observations at the BrazilMalvinas Confluence region. Geophys. Res. Let., v. 32, p. L22603, 2005.

PEZZI, L. P.; VIALARD, J.; RICHARDS, K. J.; MENKES, C.; ANDERSON, D. Influence of ocean-atmosphere coupling on the properties of Tropical Instability Waves. Geophys. Res. Let., v. 31, p. L16306, 2004.

PHILANDER, S. G. H. Instabilities of zonal equatorial currents, 2. J. Geophys. Res., v. 83, n. C7, p. 3679-3682, 1978.

PHILANDER, S. G. H. Equatorial waves in the presence of the Equatorial Undercurrent. J. Phys. Ocean., v. 9, n. 2, p. 254-262, 1979.

PHILANDER, S. G. H. El Niño, La Niña, and the Southern Oscillation. San Diego, California: Academic Press, 1990. 293 p. (International Geophysics Series, v. 46).

PHILANDER, S. G. H.; GU, D.; HALPERN, D.; LAMBERT, G.; LAU, N.-C.; LIU, T.; PACANOWSKI, R. C. Why the ITCZ is mostly north of the Equator. J. Climate, v. 9, p. 2958-2972, 1996.

POLITO, P. S.; CORNILLON, P. Long baroclinic Rossby waves detected by TOPEX/Poseidon. J. Geophys. Res., v. 102, n. C2, p. 3215-3235, 1997.

POLITO, P. S.; LIU, W. T. Global characterization of Rossby waves at several spectral bands. J. Geophys. Res., v. 108, n. C1, 2003.

POLITO, P. S.; RYAN, J. P.; LIU, W. T.; CHAVEZ, F. P. Oceanic and atmospheric anomalies of tropical instability waves. Geophys. Res. Lett., v. 28, n. 11, p. 2233-2236, 2001. 
POLITO, P. S.; SATO, O. T. Patterns of sea surface height and heat storage associated to intraseasonal Rossby waves in the tropics. J. Geophys. Res., v. 108, n. C12, p. $3373,2003$.

QIAO, L.; WEISBERG, R. H. Tropical Instability Wave kinematics: Observations from the Tropical Instability Wave experiment. J. Geophys. Res., v. 100, n. C5, p. 8677-8693, 1995.

ROBINSON, I. S. Measuring the oceans from space: the principles and methods of satellite oceanography. Berlin: Springer, 2004.

SATO, O. T.; POLITO, P. S.; LIU, W. T. Importance of salinity measurements in the heat storage estimation from TOPEX/Poseidon. Geophys. Res. Lett., v. 27, n. 4, p. $549-551,2000$.

SCHUCKMANN, K. V.; BRANDT, P.; EDEN, C. Generation of tropical instability waves in the atlantic ocean. J. Geophys. Res., v. 113, n. C8, p. C08034, 2008.

SEO, H.; JOCHUM, M.; MURTUGUDDE, R.; MILLER, A. J.; ROADS, J. Feedback of Tropical-Instability-Wave-induced atmospheric variability onto the ocean. J. Climate, v. 20, p. 5842-5855, 2007.

SHINODA, T. Observed dispersion relation of Yanai waves and 17-day tropical instability waves in the Pacific Ocean. SOLA, J-STAGE, v. 6, p. 17-20, 2010.

SHINODA, T. Observation of first and second baroclinic mode Yanai waves in the ocean. Q. J. R. Meteorol. Soc., v. 138, n. 665, p. 1018-1024, 2012.

SHINODA, T.; KILADIS, G. N.; ROUNDY, P. E. Statistical representation of equatorial waves and tropical instability waves in the Pacific Ocean. Atmosph. Res., v. 94 , p. $37-44,2009$.

SIEDLER, G.; ZANBENBERG, N.; ONKEN, R.; MORLIÈRE, A. Seasonal changes in the tropical Atlantic circulation: Observation and simulation of the Guinea Dome. J. Geophys. Res., v. 97, p. 703-715, 1992.

SMALL, R. J.; DESZOEKE, S. P.; XIE, S.-P.; O’NEILL, L.; SEO, H.; SONG, 
Q.; CORNILLON, P.; SPALL, M.; MINOBE, S. Air-sea interaction over ocean fronts and eddies. Dynamics of Atmospheres and Oceans, v. 45, p. 274-319, 2008.

SMALL, R. J.; XIE, S.-P.; WANG, Y. Numerical simulation of atmospheric response to Pacific Tropical Instability Waves. J. Climate, v. 16, p. 3723-3741, 2003.

STRAMMA, L.; SCHOTT, F. The mean flow field of the tropical Atlantic Ocean. Deep-Sea Res. II, v. 46, p. 279-303, 1999.

TALLEY, L. D.; PICKARD, G. L.; EMERY, W. J.; SWIFT, J. H. Descriptive Physical Oceanography: An introductory. 6. ed. Amsterdam: Elsevier, 2011. 555 p.

WACONGNE, S. On the difference in strength between Atlantic and Pacific undercurrents. J. Phys. Ocean., v. 20, p. 792-800, 1990.

WACONGNE, S.; PITON, B. The near-surface circulation int the northeastern corner of the South Atlantic Ocean. Deep-Sea Res., v. 39, n. 7/8, p. 1273-1298, 1992.

WALLACE, J. M.; MITCHELL, T. P.; DESER, C. The influence of sea-surface temperature on surface wind in the eastern equatorial Pacific: Seasonal and interannual variability. J. Climate, v. 2, p. 1492-1499, 1989.

WEISBERG, R. H.; WEINGARTNER, T. J. Instability waves in the Equatorial Atlantic Ocean. J. Phys. Ocean., v. 18, p. 1641-1657, 1988.

WU, Q.; BOWMAN, K. P. Multiyear satellite observations of the atmospheric response to Atlantic tropical instability waves. J. Geophys. Res., v. 112, n. D19, p. D19104, 2007a.

WU, Q.; BOWMAN, K. P. Interannual variations of tropical instability waves observed by the Tropical Rainfall Measuring Mission. Geophys. Res. Let., American Geophysical Union, v. 34, n. 9, p. L09701, 2007 b.

WU, Q.; MAHAJAN, S.; BOWMAN, K. P.; CHANG, P. Atmospheric response to atlantic tropical instability waves in Community Atmosphere Model version 3. $J$. Geophys. Res., v. 113, n. D15, p. D15125, 2008.

XAVIER, T. M. B. S.; XAVIER, A. F. S.; DIAS, P. L. S.; DIAS, M. A. F. S. A 
Zona de Convergência Intertropical - ZCIT e suas relações com a chuva no Ceará (19641998). R. Bras. Meteorologia, v. 15, n. 1, p. 27-43, 2000.

XIE, S.-P. Satellite observations of cool ocean-atmosphere interaction. Bull. Am. Meteor. Soc., v. 85, n. 2, p. 195-208, 2004.

XIE, S.-P.; ISHIWATARI, M.; HASHIZUME, H.; TAKEUCHI, K. Coupled ocean-atmospheric waves on the equatorial front. Geophys. Res. Lett., v. 25, p. 38633866, 1998.

YU, Z.; MCCREARY, J. P.; PROEHL, J. A. Meridional asymetry and energetics of tropical instability waves. J. Phys. Ocean., v. 25, p. 2997-3007, 1995.

ZHANG, H.-M.; BATES, J. J.; ; REYNOLDS, R. W. Assessment of composite global sampling: Sea surface wind speed. Geophys. Res. Lett., v. 33, p. L17714, 2006. 


\section{APÊNDICE A}

\section{Ajuste linear senoidal de mínimos quadrados}

O ajuste de mínimos quadrados descrito a seguir foi aplicado para isolar os sinais anuais, as médias e as tendências nas variáveis em estudo: temperatura da superfície do mar, vapor d'água integrado verticalmente, precipitação, divergente da tensão de cisalhamento do vento, anomalia da altura da superfície do mar e salinidade.

$x_{i}$ : tempo, a cada 7 dias de 1998 a 2010

$T=365,25:$ período

$\omega x_{i}=\frac{2 \pi}{T} x_{i}$, onde $\omega$ é a frequência

$\widehat{y_{i}}$ : variável modelada, no caso $\eta, \mathrm{TSM}, V, P, \nabla \cdot \vec{\tau}$ e $S$

$\widehat{y_{i}}=b_{0}+b_{1} x_{i}+b_{2} \operatorname{sen}\left(\omega x_{i}\right)+b_{3} \cos \left(\omega x_{i}\right)$

$b_{0}:$ coeficiente linear, que representa os valores médios

$b_{1}$ :coeficiente angular, que representa a tendência

O melhor $b_{0}, b_{1}, b_{2}$ e $b_{3}$ é aquele que minimiza a média de $\left|\epsilon_{i}\right|$ ou de

$$
\epsilon_{i}^{2} \cdot \overline{\epsilon_{i}^{2}}=\frac{1}{N} \sum_{i=1}^{N} \epsilon_{i}^{2} .
$$

Como $N$ é constante, basta minimizar

$$
S_{e}=\sum_{i=1}^{N} \epsilon_{i}^{2} .
$$

Para minimizar $S_{e}$ em Relação a $b_{0}, b_{1}, b_{2}$ e $b_{3}$ utiliza-se as seguintes fórmulas:

$$
\begin{gathered}
y_{i}=\widehat{y}_{i}+\epsilon_{i} \quad \widehat{y_{i}}=b_{0}+b_{1} x_{i}+b_{2} \operatorname{sen}\left(\omega x_{i}\right)+b_{3} \cos \left(\omega x_{i}\right) \\
\epsilon=y_{i}-b_{0}-b_{1} x_{i}-b_{2} \operatorname{sen}\left(\omega x_{i}\right)-b_{3} \cos \left(\omega x_{i}\right) \\
S_{e}=\sum_{i=1}^{N} \epsilon_{i}^{2}
\end{gathered}
$$


Assim, obtem-se:

$$
S_{e}=\sum_{i=1}^{N}\left(y_{i}-b_{0}-b_{1} x_{i}-b_{2} \operatorname{sen}\left(\omega x_{i}\right)+b_{3} \cos \left(\omega x_{i}\right)\right)^{2}
$$

Estima-se $\widehat{b_{0}}, \widehat{b_{1}}, \widehat{b_{2}}$ e $\widehat{b_{3}}$ de modo que $\frac{\partial S_{e}}{\partial b_{0}}=0, \frac{\partial S_{e}}{\partial b_{1}}=0, \frac{\partial S_{e}}{\partial b_{2}}=0$ e $\frac{\partial S_{e}}{\partial b_{3}}=0$

$$
\begin{aligned}
& \frac{\partial S_{e}}{\partial b_{0}}=0 \Rightarrow-2\left(\sum_{i=1}^{N} y_{i}-N b_{0}-b_{1} \sum_{i=1}^{N} x_{i}-b_{2} \sum_{i=1}^{N} \operatorname{sen}\left(\omega x_{i}\right)-b_{3} \sum_{i=1}^{N} \cos \left(\omega x_{i}\right)\right)=0 \\
& b_{0} N+b_{1} \sum_{i=1}^{N} x_{i}+b_{2} \sum_{i=1}^{N} \operatorname{sen}\left(\omega x_{i}\right)+b_{3} \sum_{i=1}^{N} \cos \left(\omega x_{i}\right)=\sum_{i=1}^{N} y_{i} \\
& \frac{\partial S_{e}}{\partial b_{1}}=0 \Rightarrow-2\left(\sum_{i=1}^{N} x_{i} y_{i}-b 0 \sum_{i=1}^{N} x_{i}-b_{1} \sum_{i=1}^{N} x_{i}^{2}-b_{2} \sum_{i=1}^{N} x_{i} \operatorname{sen}\left(\omega x_{i}\right)-b_{3} \sum_{i=1}^{N} x_{i} \cos \left(\omega x_{i}\right)\right)=0 \\
& b_{0} \sum_{i=1}^{N} x_{i}+b_{1} \sum_{i=1}^{N} x_{i}^{2}+b_{2} \sum_{i=1}^{N} x_{i} \operatorname{sen}\left(\omega x_{i}\right)+b_{3} \sum_{i=1}^{N} x_{i} \cos \left(\omega x_{i}\right)=\sum_{i=1}^{N} x_{i} y_{i} \\
& \frac{\partial S_{e}}{\partial b_{2}}=0 \Rightarrow-2\left(\sum_{i=1}^{N} y_{i} \operatorname{sen}\left(\omega x_{i}\right)-b_{0} \sum_{i=1}^{N} \operatorname{sen}\left(\omega x_{i}\right)-b_{1} \sum_{i=1}^{N} x_{i} \operatorname{sen}\left(\omega x_{i}\right)-b_{2} \sum_{i=1}^{N} \operatorname{sen}^{2}\left(\omega x_{i}\right)\right. \\
& \left.-b_{3} \sum_{i=1}^{N} \operatorname{sen}\left(\omega x_{i}\right) \cos \left(\omega x_{i}\right)\right)=0 \\
& b_{0} \sum_{i=1}^{N} \operatorname{sen}\left(\omega x_{i}\right)+b_{1} \sum_{i=1}^{N} x_{i} \operatorname{sen}\left(\omega x_{i}\right)+b_{2} \sum_{i=1}^{N} \operatorname{sen}^{2}\left(\omega x_{i}\right)+b_{3} \sum_{i=1}^{N} \operatorname{sen}\left(\omega x_{i}\right) \cos \left(\omega x_{i}\right)=\sum_{i=1}^{N} y_{i} \operatorname{sen}\left(\omega x_{i}\right) \\
& \frac{\partial S_{e}}{\partial b_{3}}=0 \Rightarrow-2\left(\sum_{i=1}^{N} y_{i} \cos \left(\omega x_{i}\right)-b_{0} \sum_{i=1}^{N} \cos \left(\omega x_{i}\right)-b_{1} \sum_{i=1}^{N} x_{i} \cos \left(\omega x_{i}\right)-b_{2} \sum_{i=1}^{N} \operatorname{sen}\left(\omega x_{i}\right) \cos \left(\omega x_{i}\right)\right. \\
& \left.-b_{3} \sum_{i=1}^{N} \cos ^{2}\left(\omega x_{i}\right)\right)=0
\end{aligned}
$$


$b_{0} \sum_{i=1}^{N} \cos \left(\omega x_{i}\right)+b_{1} \sum_{i=1}^{N} x_{i} \cos \left(\omega x_{i}\right)+b_{2} \sum_{i=1}^{N} \operatorname{sen}\left(\omega x_{i}\right) \cos \left(\omega x_{i}\right)+b_{3} \sum_{i=1}^{N} \cos ^{2}\left(\omega x_{i}\right)=\sum_{i=1}^{N} y_{i} \cos \left(\omega x_{i}\right)$

Defini-se as seguintes matrizes $X, Y$ e $B$ :

$$
X=\left(\begin{array}{cccc}
1 & x_{1} & \operatorname{sen}\left(\omega x_{i}\right) & \cos \left(\omega x_{i}\right) \\
\vdots & \vdots & \vdots & \vdots \\
1 & x_{N} & \operatorname{sen}\left(\omega x_{N}\right) & \cos \left(\omega x_{N}\right)
\end{array}\right) \quad Y=\left(\begin{array}{c}
y_{1} \\
\vdots \\
y_{N}
\end{array}\right) \quad B=\left(\begin{array}{c}
b_{0} \\
b_{1} \\
b_{2} \\
b_{3}
\end{array}\right)
$$

Dessa forma, reescreve-se as equações anteriores:

$$
\begin{gathered}
b_{0} N+b_{1} \sum_{i=1}^{N} x_{i}+b_{2} \sum_{i=1}^{N} \operatorname{sen}\left(\omega x_{i}\right)+b_{3} \sum_{i=1}^{N} \cos \left(\omega x_{i}\right)=\sum_{i=1}^{N} y_{i} \\
b_{0} \sum_{i=1}^{N} x_{i}+b_{1} \sum_{i=1}^{N} x_{i}^{2}+b_{2} \sum_{i=1}^{N} x_{i} \operatorname{sen}\left(\omega x_{i}\right)+b_{3} \sum_{i=1}^{N} x_{i} \cos \left(\omega x_{i}\right)=\sum_{i=1}^{N} x_{i} y_{i} \\
b_{0} \sum_{i=1}^{N} \operatorname{sen}\left(\omega x_{i}\right)+b_{1} \sum_{i=1}^{N} x_{i} \operatorname{sen}\left(\omega x_{i}\right)+b_{2} \sum_{i=1}^{N} \operatorname{sen}^{2}\left(\omega x_{i}\right)+b_{3} \sum_{i=1}^{N} \operatorname{sen}\left(\omega x_{i}\right) \cos \left(\omega x_{i}\right)=\sum_{i=1}^{N} y_{i} \operatorname{sen}\left(\omega x_{i}\right) \\
b_{0} \sum_{i=1}^{N} \cos \left(\omega x_{i}\right)+b_{1} \sum_{i=1}^{N} x_{i} \cos \left(\omega x_{i}\right)+b_{2} \sum_{i=1}^{N} \operatorname{sen}\left(\omega x_{i}\right) \cos \left(\omega x_{i}\right)+b_{3} \sum_{i=1}^{N} \cos ^{2}\left(\omega x_{i}\right)=\sum_{i=1}^{N} y_{i} \cos \left(\omega x_{i}\right)
\end{gathered}
$$

na forma matricial nota-se que

$$
X^{\prime} X=\left(\begin{array}{ccc}
1 & \cdots & 1 \\
x_{1} & \cdots & x_{N} \\
\operatorname{sen}\left(\omega x_{i}\right) & \cdots & \operatorname{sen}\left(\omega x_{N}\right) \\
\cos \left(\omega x_{i}\right) & \cdots & \cos \left(\omega x_{N}\right)
\end{array}\right)\left(\begin{array}{cccc}
1 & x_{1} & \operatorname{sen}\left(\omega x_{N}\right) & \cos \left(\omega x_{N}\right) \\
\vdots & \vdots & \vdots & \vdots \\
1 & x_{N} & \operatorname{sen}\left(\omega x_{N}\right) & \cos \left(\omega x_{N}\right)
\end{array}\right)
$$




$$
\begin{aligned}
& =\left(\begin{array}{cccc}
N & \sum_{i=1}^{N} x_{i} & \sum_{i=1}^{N} \operatorname{sen}\left(\omega x_{i}\right) & \sum_{i=1}^{N} \cos \left(\omega x_{i}\right) \\
\sum_{i=1}^{N} x_{i} & \sum_{i=1}^{N} x_{i}^{2} & \sum_{i=1}^{N} x_{i} \operatorname{sen}\left(\omega x_{i}\right) & \sum_{i=1}^{N} x_{i} \cos \left(\omega x_{i}\right) \\
\sum_{i=1}^{N} \operatorname{sen}\left(\omega x_{i}\right) & \sum_{i=1}^{N} x_{i} \operatorname{sen}\left(\omega x_{i}\right) & \sum_{i=1}^{N} \operatorname{sen}^{2}\left(\omega x_{i}\right) & \sum_{i=1}^{N} \operatorname{sen}\left(\omega x_{i}\right) \cos \left(\omega x_{i}\right) \\
\sum_{i=1}^{N} \cos \left(\omega x_{i}\right) & \sum_{i=1}^{N} x_{i} \cos \left(\omega x_{i}\right) & \sum_{i=1}^{N} \operatorname{sen}\left(\omega x_{i}\right) \cos \left(\omega x_{i}\right) & \sum_{i=1}^{N} \cos ^{2}\left(\omega x_{i}\right)
\end{array}\right) \\
& X^{\prime} Y=\left(\begin{array}{ll}
\sum_{i=1}^{N} & y_{i} \\
\sum_{i=1}^{N} & x_{i} y_{i} \\
\sum_{i=1}^{N} & y_{i} \operatorname{sen}\left(\omega x_{i}\right) \\
\sum_{i=1}^{N} & y_{i} \cos \left(\omega x_{i}\right)
\end{array}\right) \\
& b_{0} N+b_{1} \sum_{i=1}^{N} x_{i}+b_{2} \sum_{i=1}^{N} \operatorname{sen}\left(\omega x_{i}\right)+b_{3} \sum_{i=1}^{N} \cos \left(\omega x_{i}\right)=\sum_{i=1}^{N} y_{i} \\
& b_{0} \sum_{i=1}^{N} x_{i}+b_{1} \sum_{i=1}^{N} x_{i}^{2}+b_{2} \sum_{i=1}^{N} x_{i} \operatorname{sen}\left(\omega x_{i}\right)+b_{3} \sum_{i=1}^{N} x_{i} \cos \left(\omega x_{i}\right)=\sum_{i=1}^{N} x_{i} y_{i} \\
& b_{0} \sum_{i=1}^{N} \operatorname{sen}\left(\omega x_{i}\right)+b_{1} \sum_{i=1}^{N} x_{i} \operatorname{sen}\left(\omega x_{i}\right)+b_{2} \sum_{i=1}^{N} \operatorname{sen}^{2}\left(\omega x_{i}\right)+b_{3} \sum_{i=1}^{N} \operatorname{sen}\left(\omega x_{i}\right) \cos \left(\omega x_{i}\right)=\sum_{i=1}^{N} y_{i} \operatorname{sen}\left(\omega x_{i}\right) \\
& b_{0} \sum_{i=1}^{N} \cos \left(\omega x_{i}\right)+b_{1} \sum_{i=1}^{N} x_{i} \cos \left(\omega x_{i}\right)+b_{2} \sum_{i=1}^{N} \operatorname{sen}\left(\omega x_{i}\right) \cos \left(\omega x_{i}\right)+b_{3} \sum_{i=1}^{N} \cos ^{2}\left(\omega x_{i}\right)=\sum_{i=1}^{N} y_{i} \cos \left(\omega x_{i}\right)
\end{aligned}
$$

Como o produto das matrizes é $\left(X^{\prime} X\right) B=\left(X^{\prime} Y\right)$

a solução para $B$ é: $B=\left(X^{\prime} X\right)^{-1}\left(X^{\prime} Y\right)$

A solução de $B=\left(X^{\prime} X\right)^{-1}\left(X^{\prime} Y\right)$ é a matriz de coeficientes $B$. Quando inseridos em $\widehat{y_{i}}=b_{0}+b_{1} x_{i}+b_{2} \operatorname{sen}\left(\omega x_{i}\right)+b_{3} \cos \left(\omega x_{i}\right)$ resultam na senóide ajustada. Esta senóide passa por $(\bar{x}, \bar{y})$ e minimiza $\epsilon$. 


\section{APÊNDICE B}

\section{Variabilidade interanual das OITs nos dados de TSM}

A Figura 49 mostra as anomalias de TSM relativas às OITs para o mês de maiores amplitudes em cada ano. Há variação interanual da amplitude das maiores anomalias, da localização e da época destas e do número de anomalias positivas e negativas. Os anos 2001 a 2005 e 2007 apresentaram as maiores amplitudes. Segundo Schuckmann et al. (2008), apesar da geração das OITs ser modulada pela variabilidade das correntes, a intensidade do fenômeno parece ser não determinística.

O cisalhamento das correntes superficiais gera instabilidades barotrópicas que contribuem para o densevolvimento de OITs (PHILANDER, 1978; WEISBERG e WEINGARTNER, 1988). Os resultados de modelo mostram que em anos que a TSM é tipicamente baixa, há intensificação das correntes superficiais e consequente aumento do cisalhamento entre a SE e a CSE, associado a um aumento no entranhamento de água fria na superfície (GÓES e WAINER, 2003). O oposto ocorre em anos caracterizados por TSM mais frias. A atuação destes mecanismos promove a variabilidade observada em dados de TSM, como mostra a Figura 49 

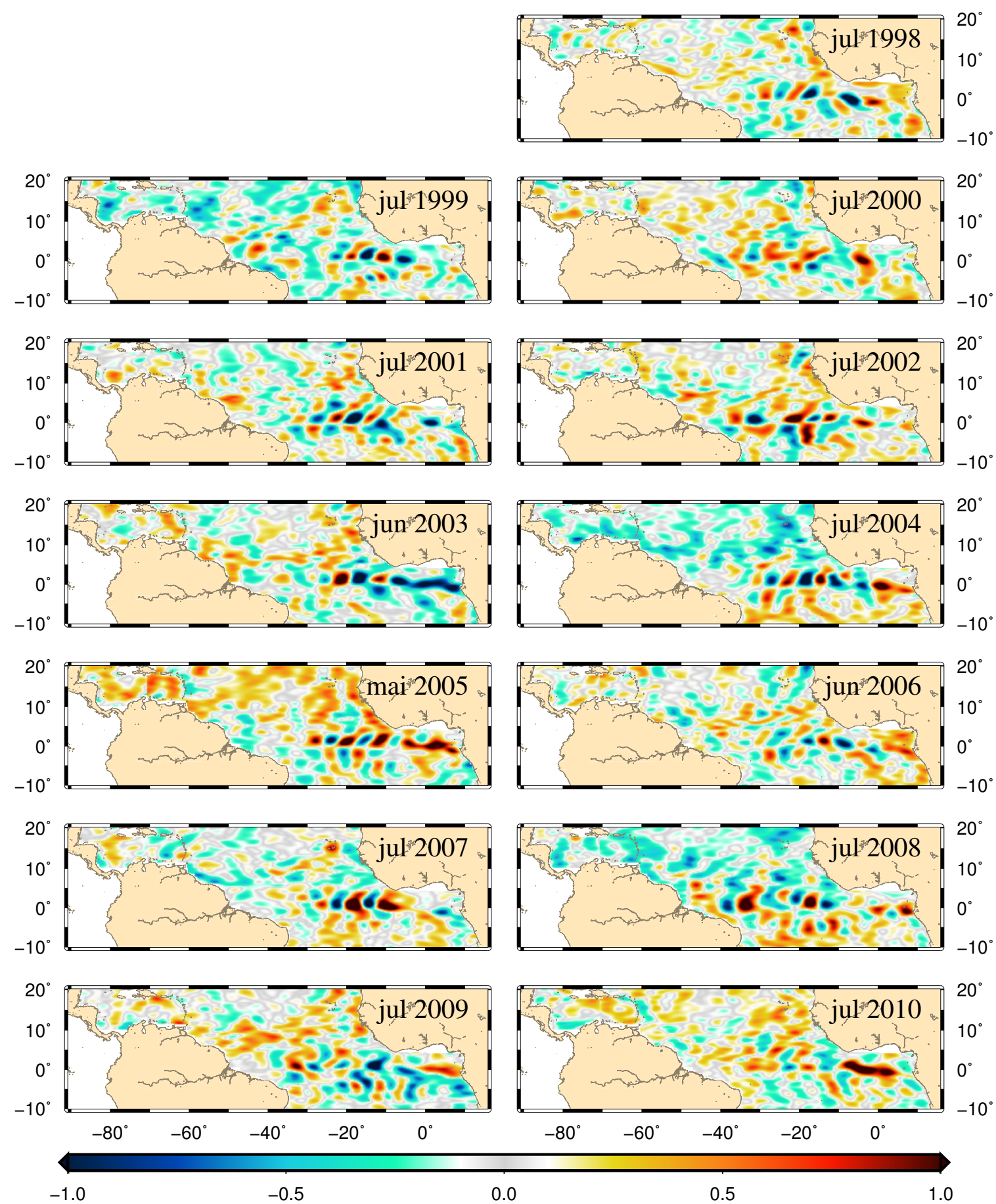

Figura 49: OITs nos dados de TSM no meses em que as amplitudes são máximas em cada ano. 


\section{APÊNDICE C}

\section{Diagramas Hovmöller}

As Figuras 50 a 54 mostram os diagramas Hovmöller nas bandas do espectro associadas às OITs e ORCs nos dados de TSM, $V, P, \vec{\nabla} \cdot \vec{\tau}$ e $\eta$ de 1998 a 2010.
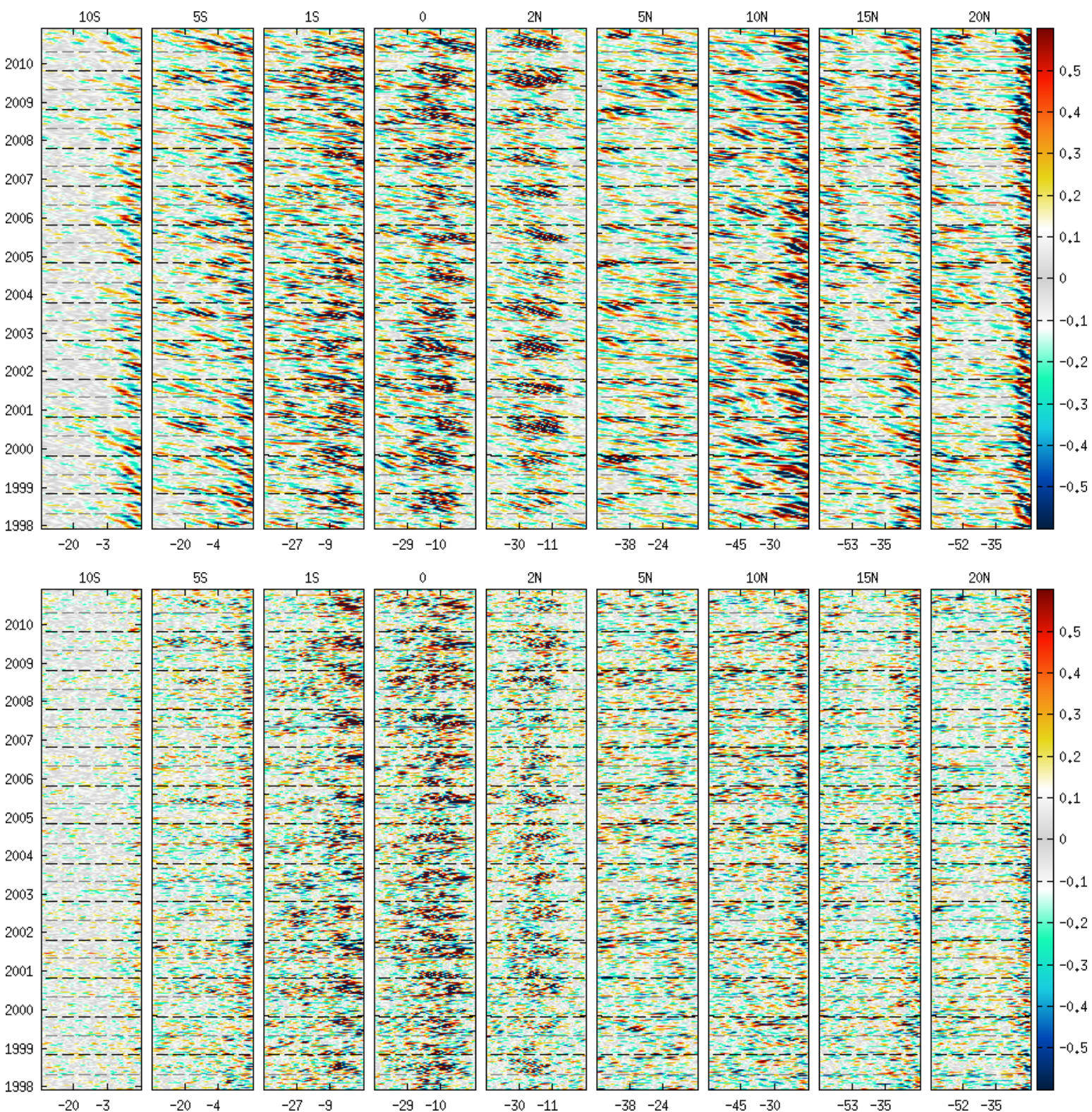

Figura 50: Diagramas Hövmöller das ORCs (superior) e OITs (inferior) nos dados de TSM. As linhas tracejadas cinzas representam o mês de maio e as pretas o mês de outubro. 

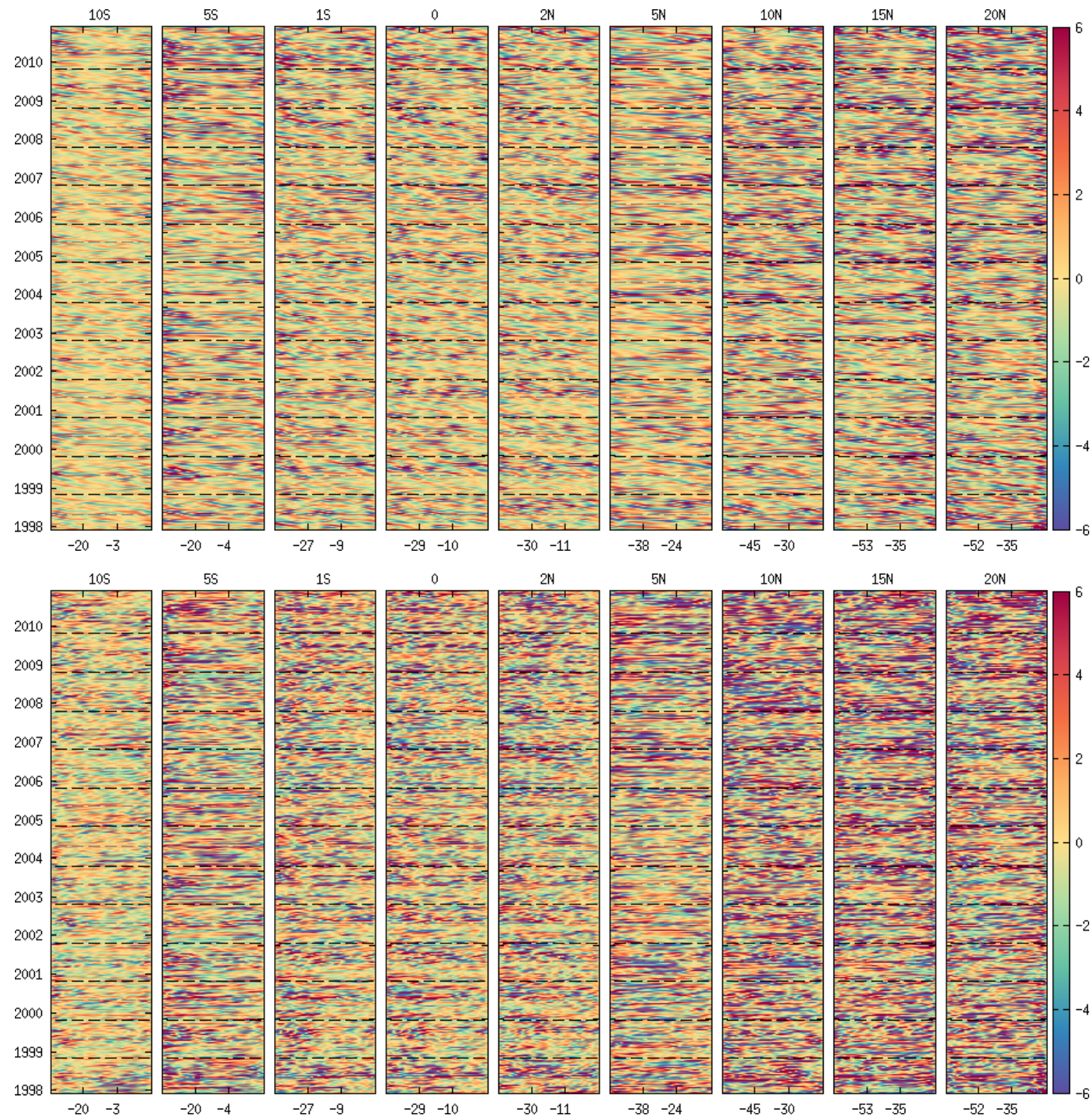

Figura 51: Semelhante à Figura 50 nos dados de $V$. 

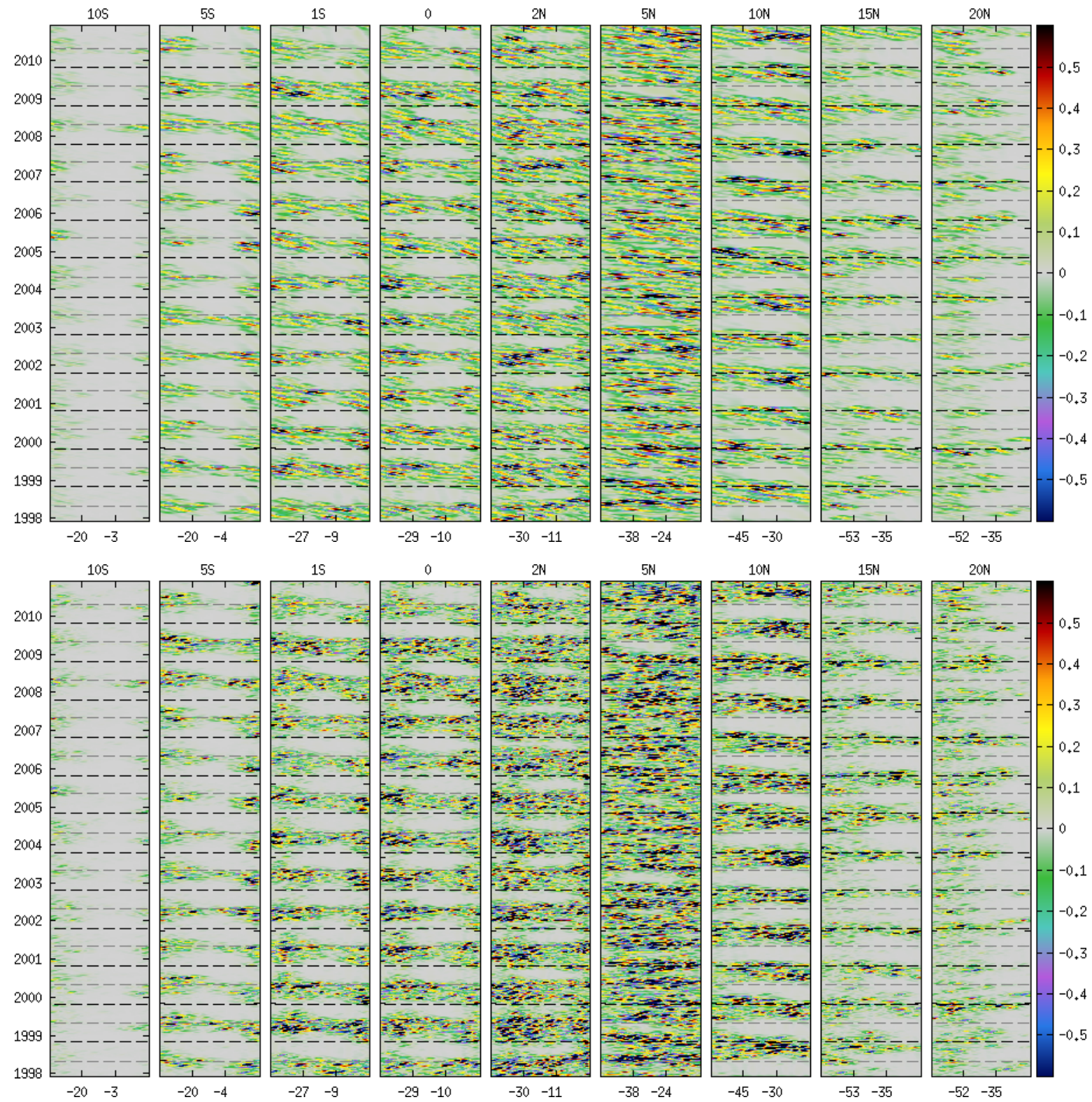

Figura 52: Semelhante à Figura 50 nos dados de $P$. 

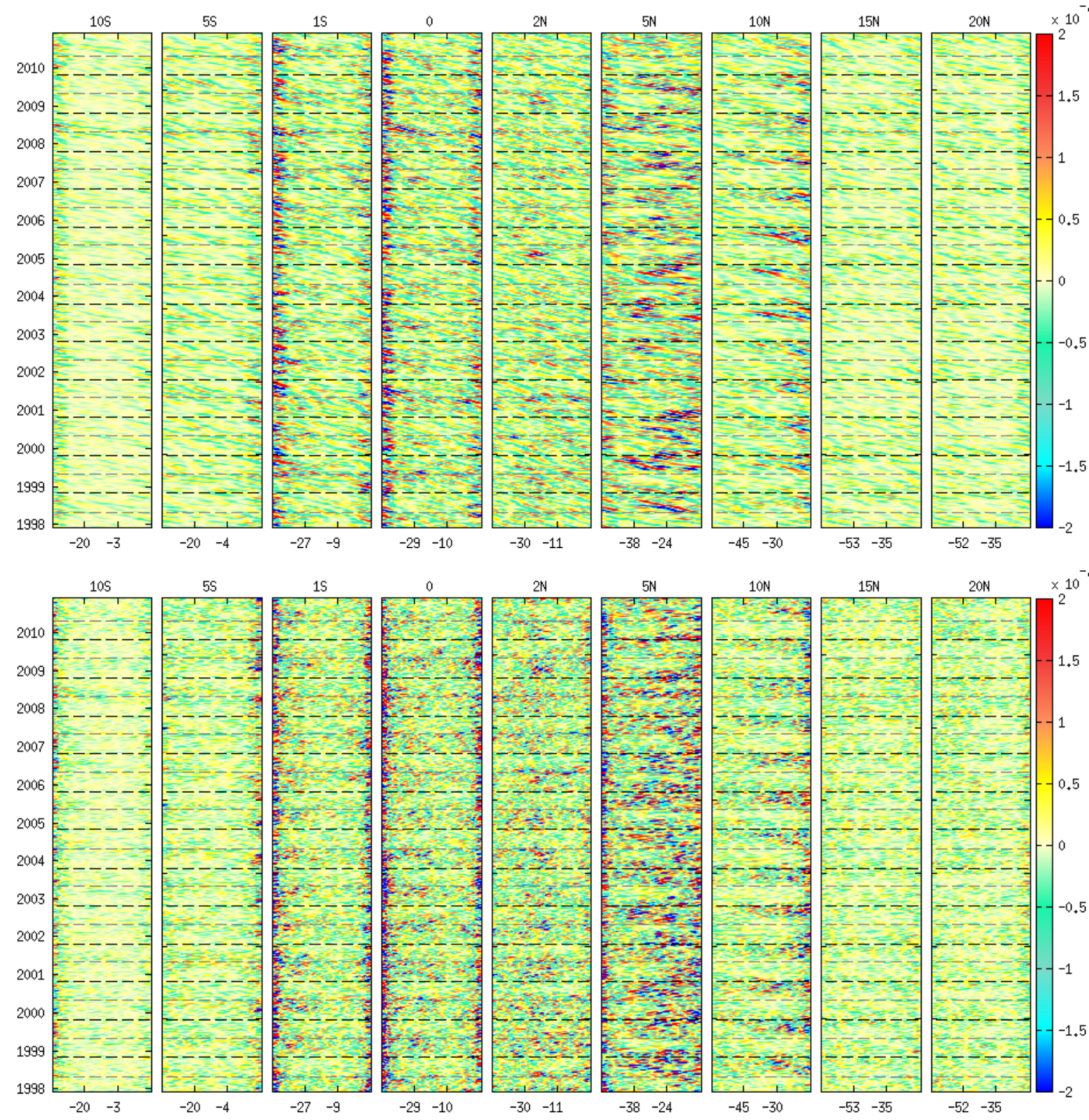

Figura 53: Semelhante à Figura 50 nos dados de $\vec{\nabla} \cdot \vec{\tau}$. 

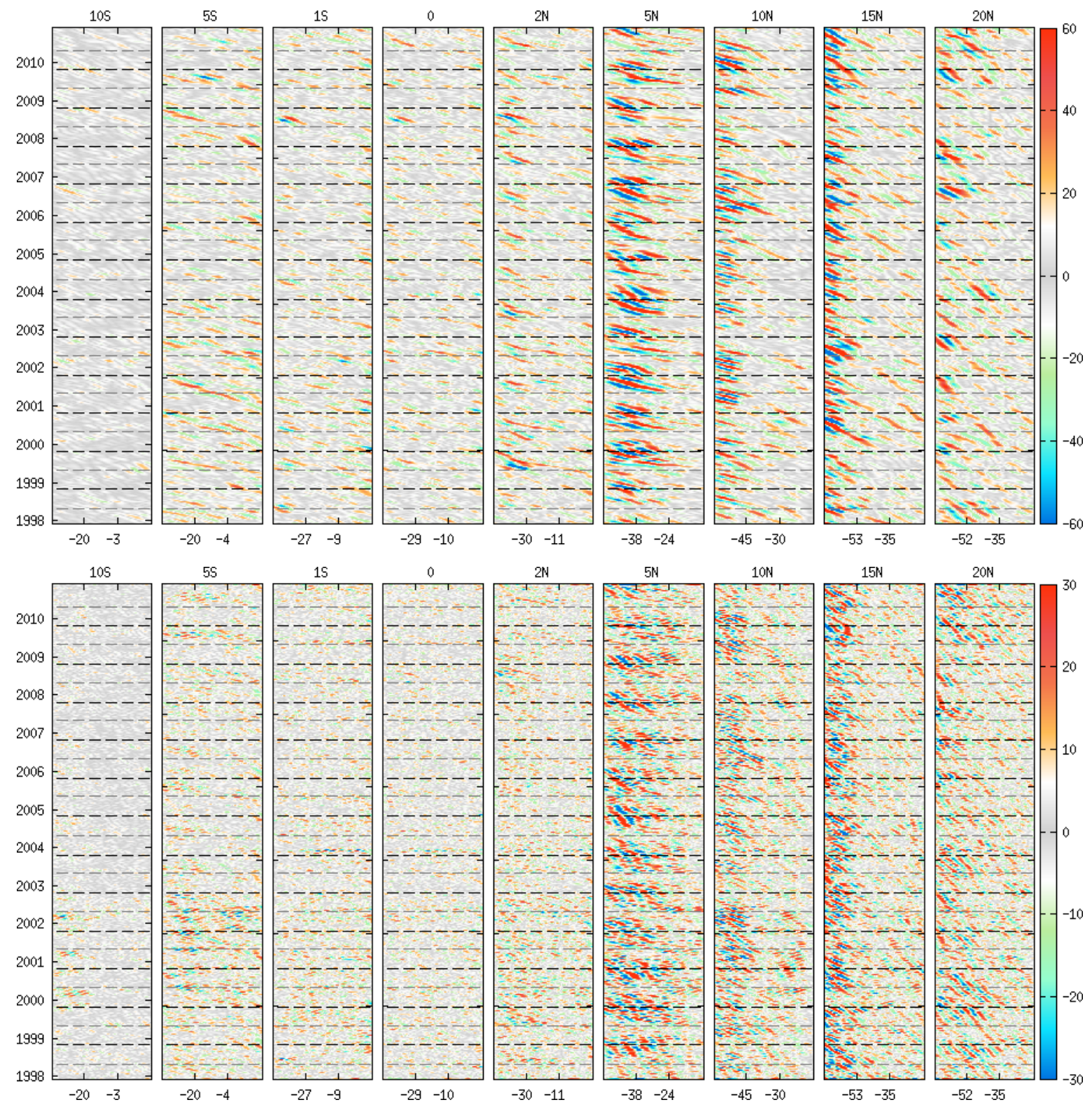

Figura 54: Semelhante à Figura 50 nos dados de $\eta$. 


\section{APÊNDICE D}

\section{Mapas de regressão anuais das variáveis atmosféricas}

As Figuras 55 a 60 mostram os mapas de regressão das variáveis atmosféricas em relação à TSM no ponto de referência para cada ano na banda das OITs e ORCs. As regressões foram calculadas de maio a outubro, período das máximas amplitudes nos dados de TSM e de migração da ZCIT para o norte. Podemos observar os mesmos padrões de modificações remotas apresentados na Figura 26. 


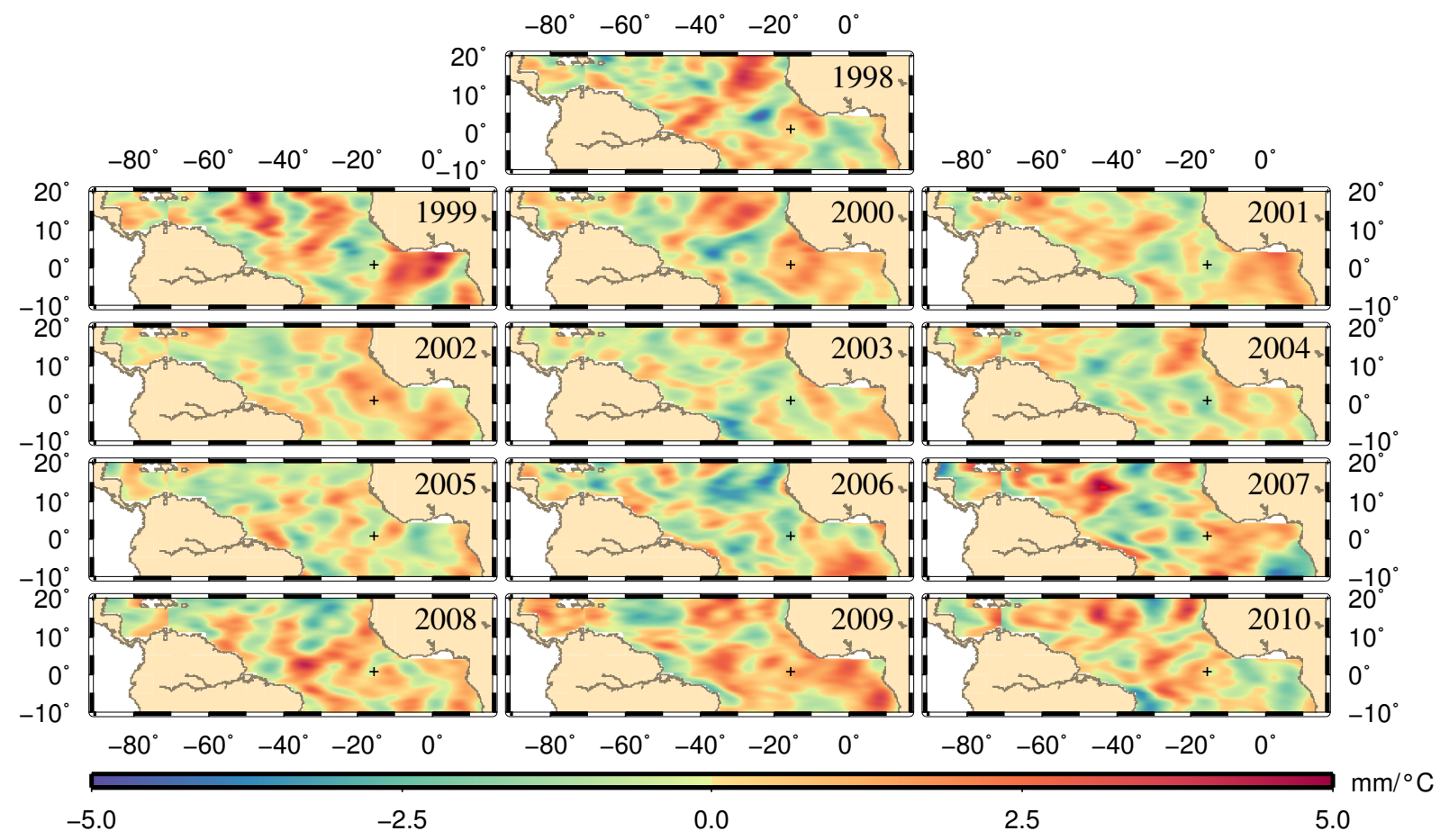

Figura 55: Mapas de regressão de $V\left(\mathrm{~mm}^{\circ} \mathrm{C}^{-1}\right)$ para ORCs de maio a outubro. O símbolo + indica o ponto de referência (de máxima variância) de TSM, centrado em $0,875^{\circ} \mathrm{N} 10,125^{\circ} \mathrm{W}$.

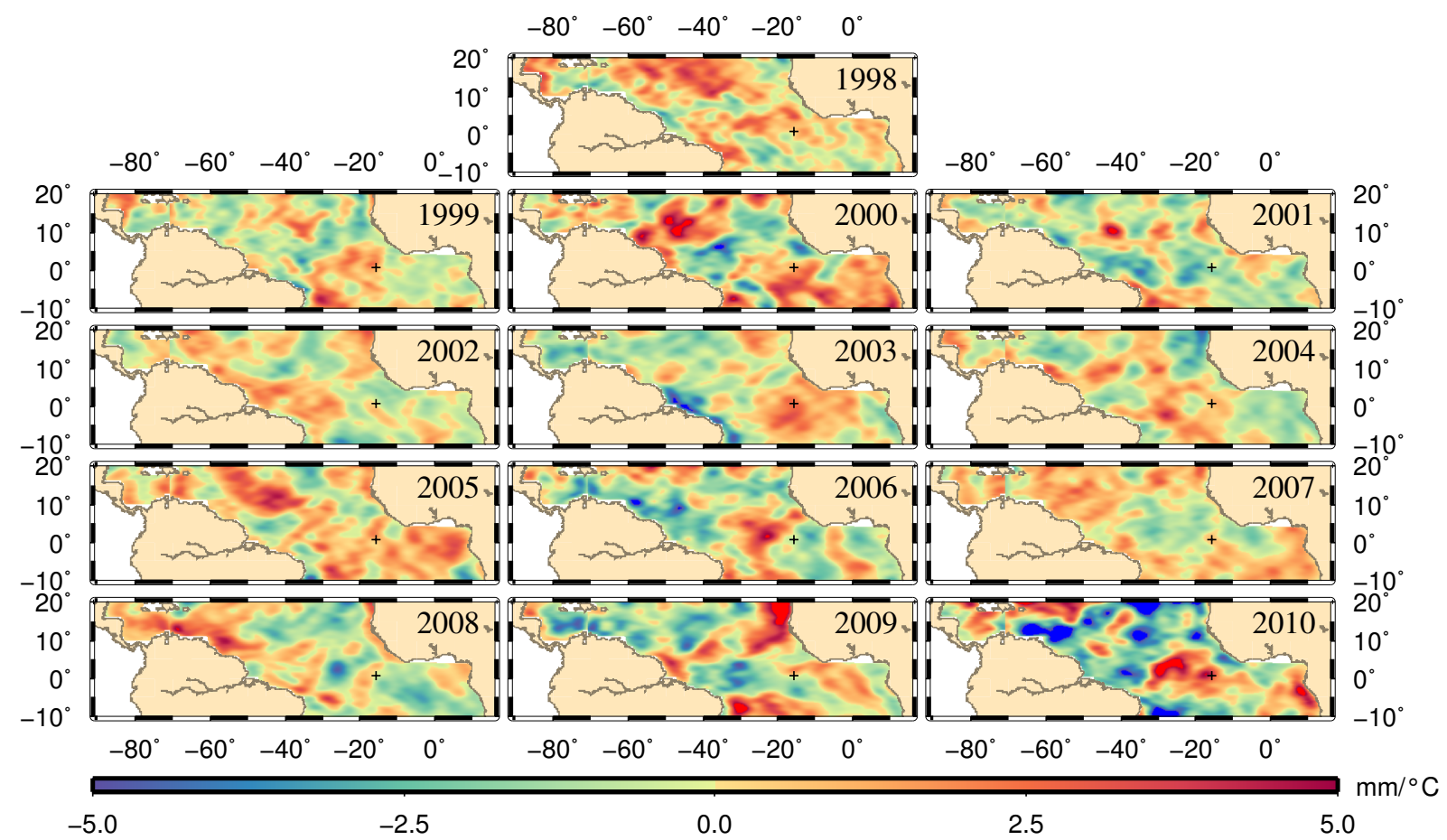

Figura 56: Semelhante à Figura 55 para as OITs. O símbolo + indica o ponto de referência (de máxima variância) de $\mathrm{TSM}$, centrado em $0,875^{\circ} \mathrm{N} 15.875^{\circ} \mathrm{W}$. 


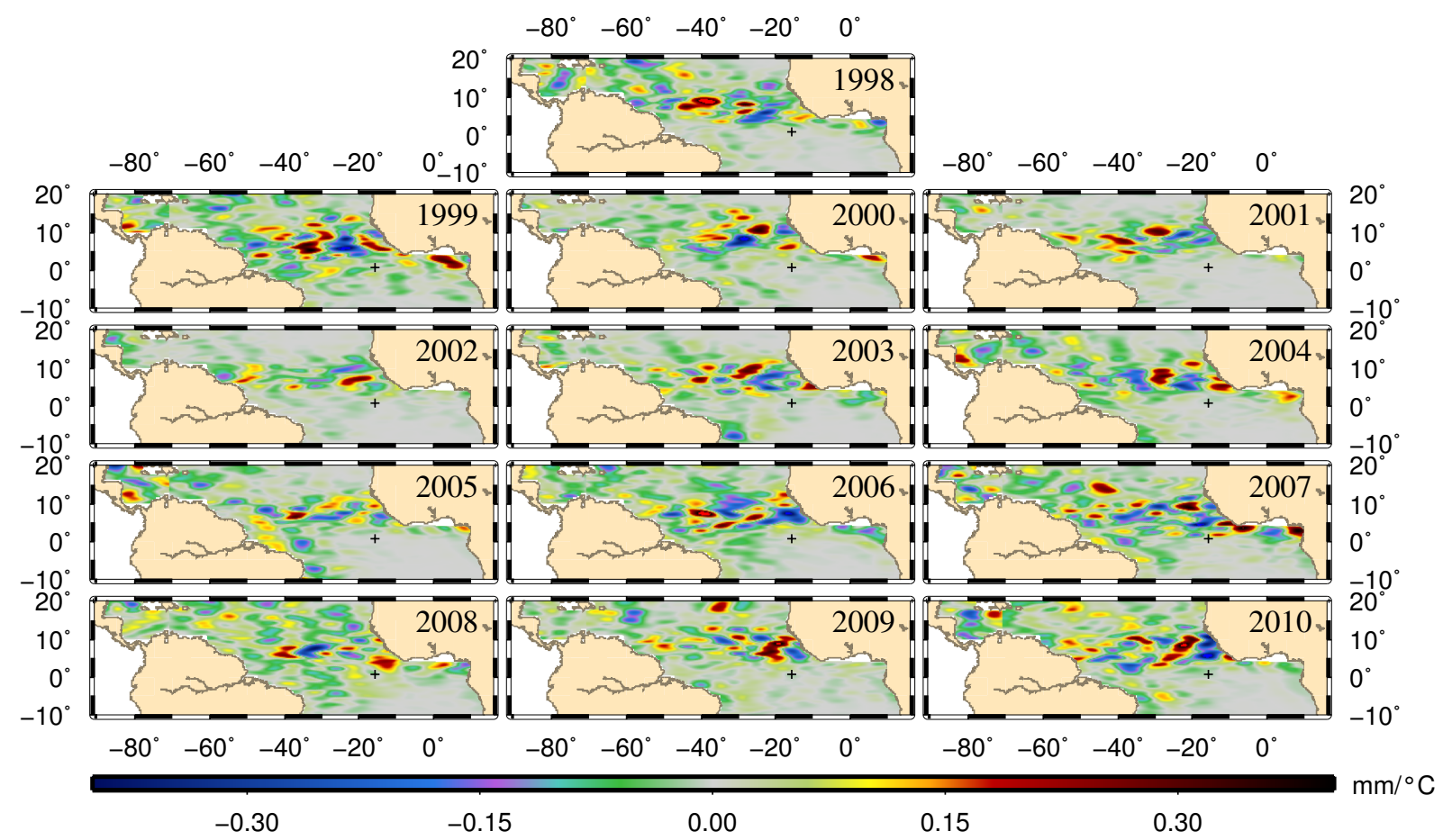

Figura 57: Mapas de regressão de $V\left(\mathrm{~mm} \mathrm{~h}^{-1}{ }^{\circ} \mathrm{C}^{-1}\right)$ para ORCs de maio a outubro. O símbolo + indica o ponto de referência (de máxima variância) de TSM, centrado em $0,875^{\circ} \mathrm{N} 10,125^{\circ} \mathrm{W}$.

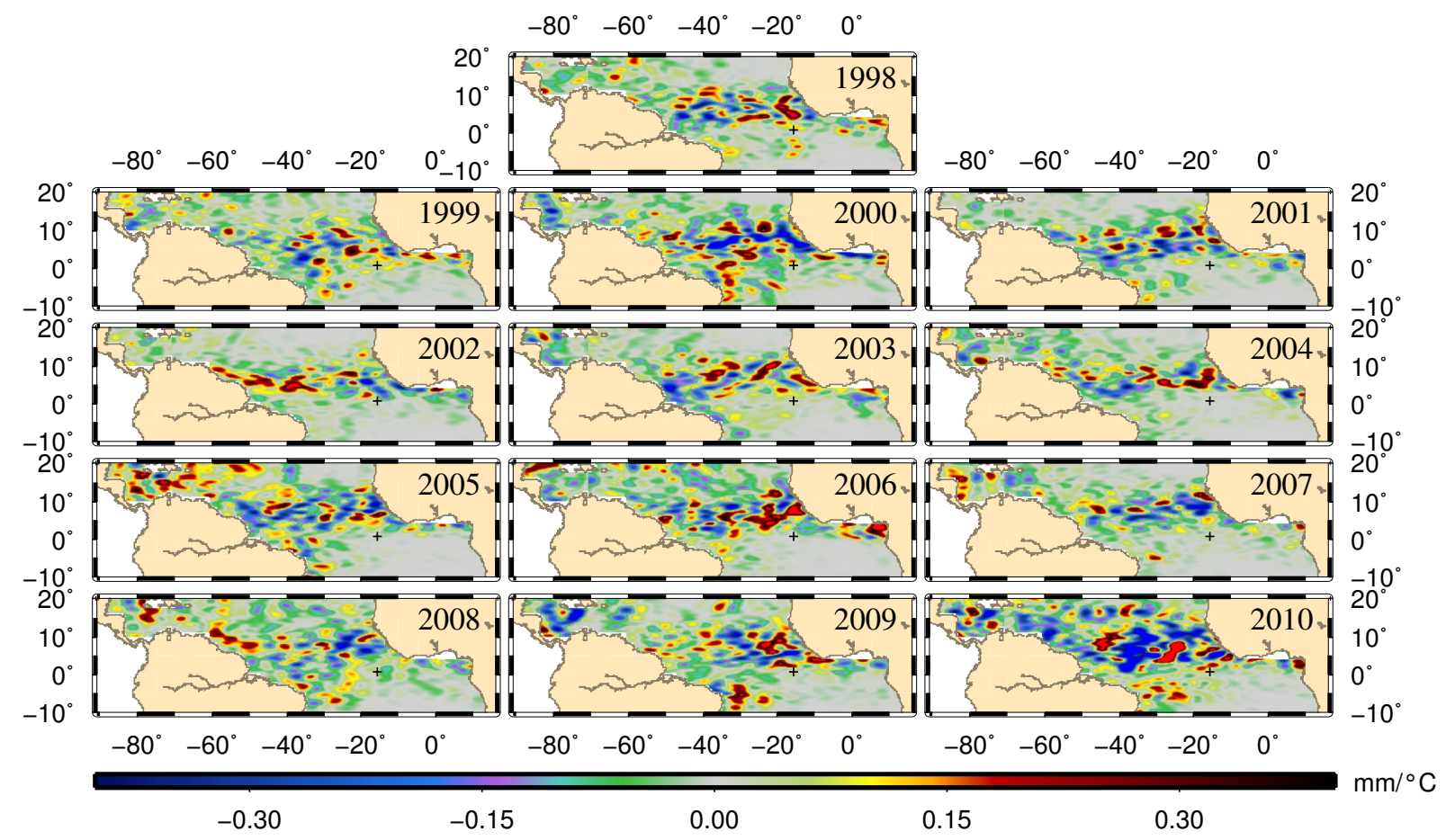

Figura 58: Semelhante à Figura 57 para as OITs. O símbolo + indica o ponto de referência (de máxima variância) de $\mathrm{TSM}$, centrado em $0,875^{\circ} \mathrm{N} 15.875^{\circ} \mathrm{W}$. 


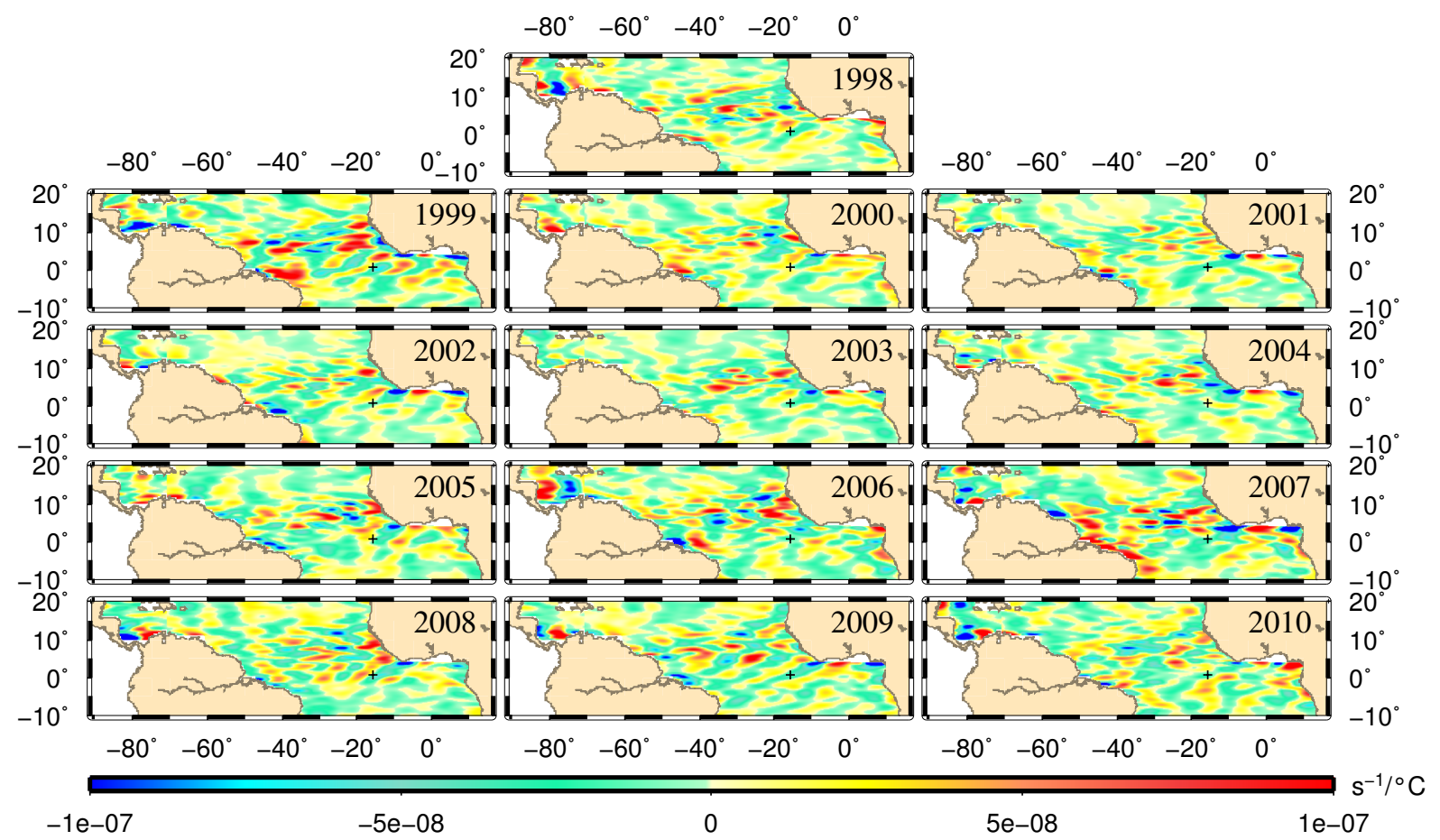

Figura 59: Mapas de regressão de $\vec{\nabla} \cdot \vec{V}\left(\mathrm{~kg} \mathrm{~m}^{-2} \mathrm{~s}^{-2}{ }^{\circ} \mathrm{C}^{-1}\right)$ para ORCs de maio a outubro. O símbolo + indica o ponto de referência (de máxima variância) de TSM, centrado em $0,875^{\circ} \mathrm{N}$ $10,125^{\circ} \mathrm{W}$.

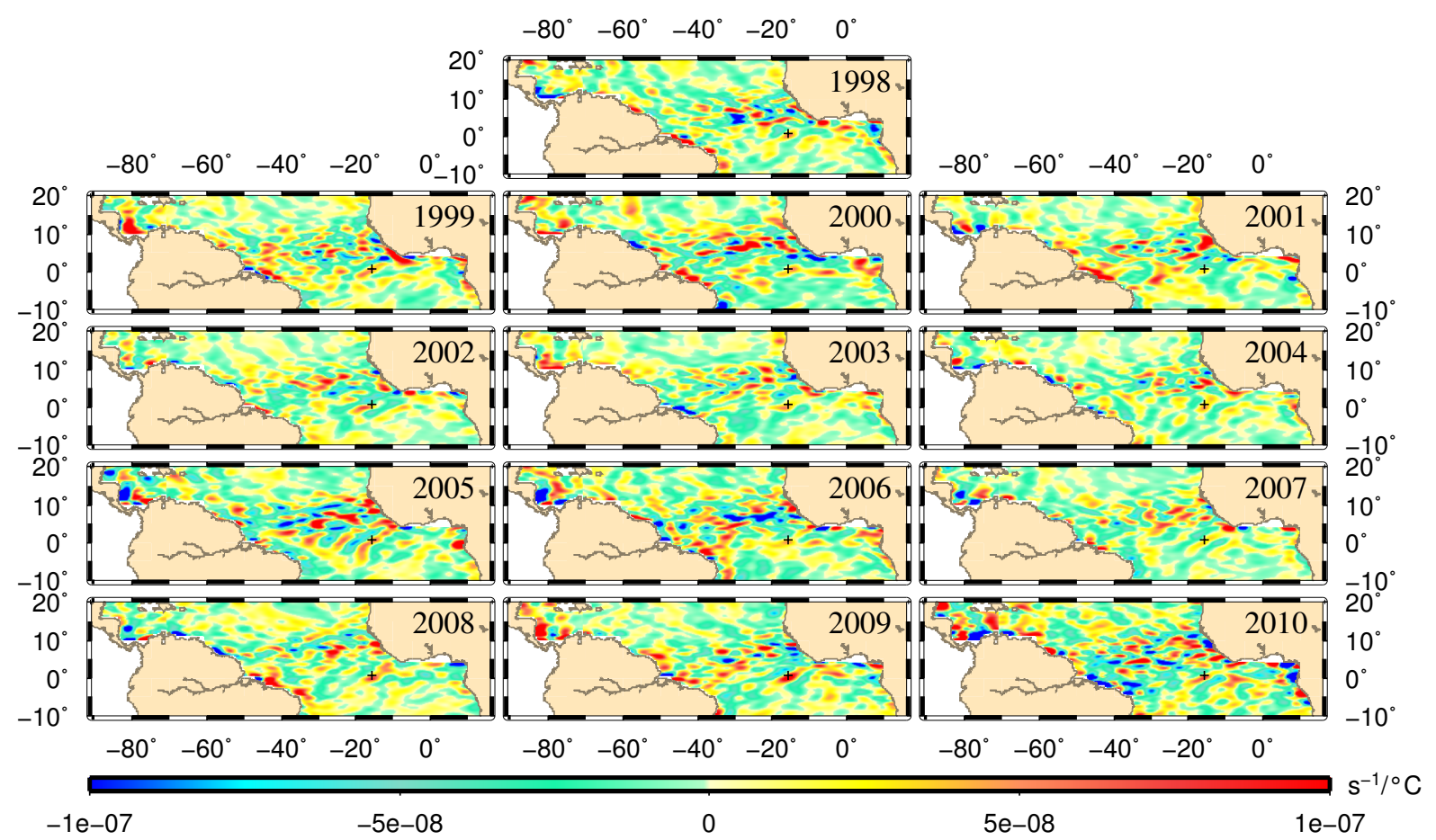

Figura 60: Semelhante à Figura 59 para as OITs. O símbolo + indica o ponto de referência (de máxima variância) de $\mathrm{TSM}$, centrado em $0,875^{\circ} \mathrm{N} 15.875^{\circ} \mathrm{W}$. 